UNIVERSIDADE DE SÃO PAULO

FACULDADE DE FILOSOFIA, CIÊNCIAS E LETRAS DE RIBEIRÃO PRETO DEPARTAMENTO DE PSICOLOGIA PROGRAMA DE PÓS-GRADUAÇÃO EM PSICOLOGIA

\title{
O Teste de Fotos de Profissões (BBT-Br) em adolescentes: Evidências psicométricas.
}

\author{
Rafael Paz Landim Barrenha
}

Dissertação apresentada ao Programa de PósGraduação em Psicologia da Faculdade de Filosofia, Ciências e Letras de Ribeirão Preto da Universidade de São Paulo como parte dos requisitos para obtenção do grau de Mestre em Ciências, Área: Psicologia.

\section{Ribeirão Preto}


RAFAEL PAZ LANDIM BARRENHA

\section{O Teste de Fotos de Profissões (BBT-Br) em adolescentes: Evidências psicométricas.}

Orientadora: Profa. Dra. Sonia Regina Pasian

Dissertação apresentada ao Programa de PósGraduação em Psicologia da Faculdade de Filosofia, Ciências e Letras de Ribeirão Preto da Universidade de São Paulo como parte dos requisitos para obtenção do grau de Mestre em Ciências, Área: Psicologia.

\section{Ribeirão Preto}


AUTORIZO A REPRODUÇÃO TOTAL OU PARCIAL DESTE TRABALHO, POR QUALQUER MEIO CONVENCIONAL OU ELETRÔNICO, PARA FINS DE ESTUDO E PESQUISA, DESDE QUE CITADA A FONTE.

\section{FICHA CATALOGRÁFICA}

Barrenha, Rafael Paz Landim

O Teste de Fotos de Profissões (BBT-Br) em adolescentes:

Evidências Psicométricas. Ribeirão Preto, 2011.

192 p. : il. ; $30 \mathrm{~cm}$

Dissertação de Mestrado, apresentada à Faculdade de Filosofia, Ciências e Letras de Ribeirão Preto/USP. Área de concentração: Psicologia.

Orientador: Pasian, Sonia Regina.

1. Orientação Profissional. 2. Avaliação Psicológica. 3. BBTBr. 4. Adolescentes. 5. Normas. 6. Validade. 


\section{FOLHA DE APROVAÇÃO}

Nome: Barrenha, Rafael Paz Landim

Título: O Teste de Fotos de Profissões (BBT-Br) em adolescentes: Evidências psicométricas.

Dissertação apresentada à Faculdade de Filosofia, Ciências e Letras de Ribeirão Preto da Universidade de São Paulo como parte dos requisitos para obtenção do grau de Mestre em Ciências, Área: Psicologia

Aprovado em _____ 2011

\section{Banca Examinadora}

Prof. Dr.

Instituição: Assinatura:

Prof. Dr.

Instituição: Assinatura:

Prof. Dr. Instituição: Assinatura: 


\section{Dedicatória}

Dedico este trabalho a meus pais, Afonso e Eunice, que sempre se dedicaram inteiramente aos seus filhos. Não tenho como expressar em palavras todo o amor e gratidão que tenho para com vocês. Amo muito vocês, obrigado por tudo. 


\section{AGRADECIMENTOS}

A Deus, por tudo.

Aos meus pais, Afonso e Eunice, e a meu irmão Afonso Henrique, por todo o amor, apoio, confiança, ensinamentos e dedicação que me criaram como pessoa e profissional.

À Profa. Dra. Sonia Regina Pasian, minha orientadora, por quem tenho tanto carinho e admiração. Seu apoio, cuidado, confiança, supervisão e paciência constantes foram os alicerces fundamentais para o desenvolvimento não só deste trabalho, mas de minha formação profissional.

À Dra. Erika Tiemi Kato Okino, minha “co"-orientadora. Sua presença, amizade e ajuda durante todo o processo foram essenciais para a realização desta Dissertação.

Aos Professores Drs. Maiana Nunes e Ricardo Primi, pelas contribuições e sugestões no Exame de Qualificação.

À Profa. Lucy de Melo-Silva, pela disponibilidade e contribuições durante a defesa dessa Dissertação, e por ter ajudado a despertar em mim o gosto pelo BBT-Br e pela Orientação Profissional.

À Profa. Dra. Thaís Zerbini, pela disponibilidade e colaboração essencial para o enriquecimento e desenvolvimento metodológico deste trabalho.

À Vanessa, minha amada companheira, por todo o amor, apoio, carinho e paciência nos momentos mais "críticos". Sua ajuda foi das mais importantes para a realização e conclusão desta etapa.

Ao pessoal do Centro de Pesquisas em Psicodiagnóstico, em especial às amigas Camila Corlatti, Mariana Noce, Maria Luisa Jardim-Maran, Renata Raspantini, Roberta Cury e Suelen Fernandes, pelo companheirismo, acolhimento, colaboração e aprendizado proporcionado. 
Ao Prof. Dr. José Lino de Oliveira Bueno e todo o pessoal do Lablino, em especial aos amigos João Borin, Vivian Calderan e Alexandre Fachini, por me acolherem em minha Iniciação Científica, incentivando e despertando meu interesse para a pesquisa.

À Ana Lucia, Lúcia e Paulo, do Espaço Psi, pela oportunidade, amizade e ensinamentos nestes três anos de trabalho.

Aos demais colaboradores, Iara, Uanda, Juliana, Alessandro, Malu e Nichollas, pela amizade, companheirismo e trabalho conjunto na livraria.

À psicóloga Thaís Sucissi Blodorn, pelo acompanhamento, cuidado e toda a ajuda prestada nestes últimos cinco anos.

Aos amigos de Jales, que sempre me incentivaram, dando forças para continuar em frente. "Desistam de me fazer desistir!".

A todos os amigos da $41^{\mathrm{a}}$ turma de Psicologia, pois valeu muito a pena, "estando destinado à eternidade”, conviver e aprender com vocês.

Aos “comparsas” de República: Amarildo, Daniboy, Frodo, Lucão e Mineiro. Cada um, a seu modo, colaborou não só com essa Dissertação, mas para o enriquecimento de minha vida inteira. Que a distância não diminua nossa amizade e a lembrança dos momentos vividos. " $N a$ alvorada venceremos!”

A todos os docentes e funcionários da Pós-Graduação do Programa de Psicologia da Faculdade de Ciências e Letras de Ribeirão Preto, pelo constante acompanhamento e ajuda na realização deste trabalho.

A todos os amigos, familiares, professores que me ajudaram/ensinaram de alguma forma. Infelizmente esse espaço é pequeno para citar e agradecer a todos que fizeram, fazem e continuarão fazendo parte da minha vida, desenvolvimento e realizações profissionais. Obrigado! 


\section{RESUMO}

Barrenha, R. P. L. (2011). O Teste de Fotos de Profissões em adolescentes: Evidências psicométricas. 192 p. Dissertação de Mestrado, Departamento de Psicologia, Faculdade de Filosofia, Ciências e Letras de Ribeirão Preto, Universidade de São Paulo.

O Teste de Fotos de Profissões (BBT-Br) constitui-se como método projetivo de avaliação psicológica de inclinações motivacionais e interesses. De origem suíça, este instrumento foi adaptado ao Brasil e estudado nas últimas três décadas, buscando seu aperfeiçoamento no contexto brasileiro. Em consonância com esta meta, o presente trabalho objetivou elaborar novos referenciais normativos para as duas versões (feminina e masculina) do instrumento, examinando-se possível efeito da origem e série escolar sobre a produção de adolescentes do Ensino Médio brasileiro, potenciais solicitantes de Orientação Vocacional/Profissional, onde este instrumento tem apresentado positivos e relevantes resultados. Além disso, este estudo buscou identificar evidências empíricas de validade fatorial e precisão para a forma masculina e a feminina do BBT-Br. Foram examinados 1582 protocolos do BBT-Br (em suas duas versões), sendo 862 estudantes do sexo feminino e 720 do sexo masculino, com idades entre 14 e 19 anos, da $1^{\mathrm{a}}, 2^{\mathrm{a}}$ e $3^{\mathrm{a}}$ séries do ensino médio de escolas públicas e particulares de cidade do interior paulista. Estes casos foram retirados de Banco de Dados colecionado no Centro de Pesquisas em Psicodiagnóstico da Faculdade de Filosofia, Ciências e Letras de Ribeirão Preto. Os resultados foram elaborados em função da versão do BBT-Br (feminina ou masculina), descrevendo-os de modo a compor novos padrões normativos para este método projetivo, focalizando índices de produtividade e estruturas de inclinação motivacional (positivas e negativas) dos adolescentes, realizando-se comparações inferenciais (ANOVA One way) em função do sexo, da procedência escolar (particular ou pública) e da série escolar. A precisão das duas versões do BBT-Br foi estimada por sua consistência interna (Alfa de Cronbach) e foram realizadas análises fatoriais exploratórias (por meio da Principal Axis Factoring - PAF, com rotação Varimax) dos resultados, determinando-se extrações de quatro, cinco, seis, sete e oito fatores para testar o melhor modelo ao conjunto dos dados. Uma vez selecionada a extração mais representativa, foi verificada a consistência interna dos fatores encontrados. Os resultados apontaram diferenças significativas no modo dos adolescentes selecionarem fotos representativas de interesses e rejeições de atividades profissionais, indicando especificidades no modo de responder ao BBT-Br em função do sexo, origem e série escolar. A precisão variou entre 0,57 e 0,82 , indicando bons índices de fidedignidade para as duas formas do BBT-Br. Os resultados das PAFs realizadas apontaram para a extração de seis fatores como mais representativa dos dados do BBT-Br, formas feminina e masculina, com precisão variando entre 0,72 e 0,90, indicando bons índices de fidedignidade para esta extração fatorial. As atuais evidências empíricas, de modo geral, indicaram adequados índices psicométricos para este instrumento projetivo, agregando valor científico e qualificando o uso do BBT-Br no contexto sócio-cultural brasileiro, reforçando suas possibilidades informativas sobre inclinações motivacionais e interesses em estudantes do ensino médio.

Palavras-Chave: Orientação Profissional, Avaliação psicológica, Adolescentes, BBT-Br, Validade, Precisão, Normas. 


\begin{abstract}
Barrenha, R. P. L. (2011). The Berufsbilder-Test BBT-Br among teenagers: Psychometric evidences. 192 p. Thesis (Master's Degree) - University of São Paulo at Ribeirão Preto, Faculty of Philosophy, Sciences and Letters from Ribeirão Preto, University of São Paulo.
\end{abstract}

The Berufsbilder Test, BBT-Br, is a projective method of psychological assessment for motivational inclinations and interests. This Swiss instrument was adapted for use in Brazil and has been studied for the last three decades, in the pursuit of its improvement for the Brazilian background. In line with this goal, the present work sought to formulate new normative references for both instrument versions (female and male), evaluating the possible effect of school grade and origin on the teenagers' production. The sample was composed by Brazilian high school teenagers, potential applicants for Vocational / Professional Guidance, where this instrument has presented positive relevant results. Furthermore, this study aimed to identify empirical evidences of factorial validity and accuracy for both male and female BBT$\mathrm{Br}$ forms. Were examined 1582 protocols from both versions of BBT-Br, from which 862 were female students and 720 were male students, ages from 14 to 19 years old, from $1^{\text {st }}, 2^{\text {nd }}$ and $3^{\text {rd }}$ grades. They studied in both public and private schools from the interior of the state of São Paulo (Brazil). These cases were from a databank collected in the Research Center in Psychodiagnostic from the Faculty of Philosophy, Sciences and Letters from Ribeirão Preto. The results were prepared according to the BBT-Br versions, describing them in the way to compose new normative standards for this projective method, focusing productivity indexes and motivational inclination structure (positive and negative) from the teenagers, performing inferential comparisons (One way ANOVA) on gender, academic origination (public or private) and school grade. The accuracy of both BBT-Br versions was estimated by its inner consistency (Cronbach's Alfa) and exploratory factorial analysis (Principal Axis Factoring PAF, with Varimax rotation) from the results were performed, determining extractions of four, five, six, seven and eight factors to test the best model to the data series. Once the most representative extraction was selected, the inner consistency of the found factors was verified. The results pointed to significant differences in the way teenagers select representative pictures of interests and rejections of professional activities, indicating specificities in the way of answering to the BBT-Br on gender, origin and school grade. The accuracy varied from 0,57 to 0,82 , indicating good reliability indexes for both BBT-Br forms. The PAFs results pointed to a six factors extraction as the most representative of the data with accuracy from 0,72 to 0,90 , indicating good reliability indexes for this factorial extraction. Current empirical evidences, altogether, indicated appropriate psychometric indexes to this projective instrument, adding scientific value and qualifying the use of BBT-Br in Brazilian sociocultural context, reinforcing its informative possibilities about motivation inclinations and interests in high school students.

Keywords: Vocational guidance, Psychological assessment, Teenagers, BBT-Br, Validity, Reliability, Norms. 


\section{LISTA DE QUADROS}

Quadro 1 - Quadro comparativo da interpretação dos fatores identificados pela PAF com extração de seis fatores dos resultados do BBT-Br feminino $(n=862)$ e masculino $(n=720)$. 


\section{LISTA DE TABELAS}

Tabela 1 - Caracterização da amostra atual (n=1582) em função da versão do BBT-Br, série e origem escolar. 62

Tabela 2 - Estatística descritiva (mediana, média e desvio padrão) e inferencial (ANOVA) da produtividade do BBT-Br $(n=1582)$ em função do sexo. 76

Tabela 3 - Estatística descritiva (mediana, média e desvio padrão) e comparações entre médias (ANOVA) das escolhas positivas dos radicais de inclinação primários e secundários do BBT-Br, em função do sexo (versão do BBT-Br). 77

Tabela 4 - Estatística descritiva (mediana, média e desvio padrão) e comparações entre médias (ANOVA) das escolhas negativas dos radicais de inclinação primários e secundários do BBT-Br, em função do sexo (versão do BBT-Br). 79

Tabela 5 - Estatística descritiva (mediana, média e desvio padrão) e inferencial dos índices de produtividade da Amostra Feminino (n=862) em função da origem escolar. 81

Tabela 6 - Estatística descritiva (mediana, média e desvio padrão) e inferencial da estrutura de inclinação motivacional positiva (primária e secundária) do BBT-Br da Amostra Feminina (n=862), em função da origem escolar. 82

Tabela 7 - Estatística descritiva (mediana, média e desvio padrão) e inferencial da estrutura de inclinação motivacional negativa (primária e secundária) do BBT-Br da Amostra Feminina (n=862), em função da origem escolar. 83

Tabela 8 - Estatística descritiva (mediana, média e desvio padrão) e inferencial (ANOVA) dos índices de produtividade da Amostra Feminina do BBT-Br $(n=720)$ em função da origem escolar. 84 
Tabela 9 - Estatística descritiva (mediana, média e desvio padrão) e inferencial da estrutura de inclinação motivacional positiva (primária e secundária) do BBT-Br da Amostra Masculina ( $n=720)$, em função da origem escolar. 85

Tabela 10 - Estatística descritiva (mediana, média e desvio padrão) e inferencial da estrutura de inclinação motivacional negativa (primária e secundária) do BBT-Br da Amostra Masculina ( $n=720)$, em função da origem escolar. 86

Tabela 11 - Estatística descritiva (mediana, média e desvio padrão) e inferencial (ANOVA) da produtividade do BBT-Br Feminino (n=862) em função da série escolar. As diferenças significativas foram destacadas para melhor visualização. 88

Tabela 12 - Estatística descritiva (mediana, média e desvio padrão) e inferencial das estruturas de inclinação motivacional positiva (primária e secundária) do BBT-Br da Amostra Feminina ( $n=862$ ), em função da série escolar.

Tabela 13 - Estatística descritiva (mediana, média e desvio padrão) e inferencial das estruturas de inclinação motivacional negativa (primária e secundária) do BBT-Br da Amostra Feminina ( $n=862$ ), em função da série escolar. 91

Tabela 14 - Estatística descritiva (valores mínimo e máximo, média e desvio padrão) e inferencial (ANOVA) dos índices de produtividade do BBT-Br Masculino (n=720) para os estudantes da $1^{a}$ série (262), $2^{a}$ série $(n=181)$ e $3^{a}$ série $(n=277)$ do ensino médio. 92

Tabela 15 - Estatística descritiva (mediana, média e desvio padrão) e inferencial (ANOVA) das estruturas de inclinação motivacional positiva (primária e secundária) do BBT-Br da Amostra Masculina (n=720), em função da série escolar. 93

Tabela 16 - Estatística descritiva (mediana, média e desvio padrão) e inferencial (ANOVA one way) das estruturas de inclinação motivacional negativa (primária e secundária) do BBT-Br da Amostra Masculina (n=720), em função da série escolar. .95 
Tabela 17 - Resultados encontrados pela extração de quatro fatores, método Principal Axis Factoring com rotação Varimax, para a amostra feminina $(n=862)$. 98

Tabela 18 - Resultados encontrados pela extração de cinco fatores, método Principal Axis Factoring com rotação Varimax, para a amostra feminina $(n=862)$. 99

Tabela 20 - Resultados encontrados pela extração de sete fatores, método Principal Axis Factoring com rotação Varimax, para a amostra feminina $(n=862)$. 101

Tabela 21 - Resultados encontrados pela extração de oito fatores, método Principal Axis Factoring com rotação Varimax, para a amostra feminina $(n=862)$. 102

Tabela 22 - Itens (fotos) que não atingiram carga fatorial mínima $(0,30)$ nas PAFs (rotação Varimax) de quatro, cinco, seis, sete e oito fatores, da forma feminina do BBT-Br $(n=862)$.

Tabela 23 - Itens (fotos) da forma feminina do BBT-Br (n=862) que compõem o Fator 1 da PAF (rotação Varimax) de seis fatores, com respectivos radicais de inclinação de Achtnich.

Tabela 24 - Itens (fotos) da forma feminina do BBT-Br (n=862) que compõem o Fator 2 da PAF (rotação Varimax) de seis fatores, com respectivos radicais de inclinação de Achtnich.

Tabela 25 - Itens (fotos) da forma feminina do BBT-Br (n=862) que compõem o Fator 3 da PAF (rotação Varimax) de seis fatores, com respectivos radicais de inclinação de Achtnich.

Tabela 26 - Itens (fotos) da forma feminina do BBT-Br (n=862) que compõem o Fator 4 da PAF (rotação Varimax) de seis fatores, com respectivos radicais de inclinação de Achtnich. 
Tabela 27 - Itens (fotos) da forma feminina do BBT-Br $(n=862)$ que compõem o Fator 5 da PAF (rotação Varimax) de seis fatores, com respectivos radicais de inclinação de Achtnich.

Tabela 28 - Itens (fotos) da forma feminina do BBT-Br $(n=862)$ que compõem o Fator 6 da PAF (rotação Varimax) de seis fatores, com respectivos radicais de inclinação de Achtnich. 112

Tabela 29 - Resultados encontrados pela extração de quatro fatores, método Principal Axis Factoring com rotação Varimax, para a amostra masculina $(n=720)$. 114

Tabela 30 - Resultados encontrados pela extração de cinco fatores, método Principal Axis Factoring com rotação Varimax, para a amostra masculina $(n=720)$. 115

Tabela 31 - Resultados encontrados pela extração de seis fatores, método Principal Axis Factoring com rotação Varimax, para a amostra masculina $(n=720)$. 116

Tabela 32 - Resultados encontrados pela extração de sete fatores, método Principal Axis Factoring com rotação Varimax, para a amostra masculina $(n=720)$.

Tabela 33 - Resultados encontrados pela extração de oito fatores, método Principal Axis Factoring com rotação Varimax, para a amostra masculina $(n=720)$. 118

Tabela 34 - Itens (fotos) que não atingiram carga fatorial mínima $(0,30)$ nas PAFs (rotação Varimax) de quatro, cinco, seis, sete e oito fatores, da forma Masculina do BBT-Br $(n=720)$.

Tabela 35 - Itens (fotos) da forma masculina do BBT-Br $(n=720)$ que compõem o Fator 1 da PAF (rotação Varimax) de seis fatores, com respectivos radicais de inclinação de Achtnich. 
Tabela 36 - Itens (fotos) da forma masculina do BBT-Br (n=720) que compõem o Fator 2 da PAF (rotação Varimax) de seis fatores, com respectivos radicais de inclinação de Achtnich.

Tabela 37 - Itens (fotos) da forma masculina do BBT-Br $(n=720)$ que compõem o Fator 3 da PAF (rotação Varimax) de seis fatores, com respectivos radicais de inclinação de Achtnich. 125

Tabela 38 - Itens (fotos) da forma masculina do BBT-Br $(n=720)$ que compõem o Fator 4 da PAF (rotação Varimax) de seis fatores, com respectivos radicais de inclinação de Achtnich.

Tabela 39 - Itens (fotos) da forma masculina do BBT-Br $(n=720)$ que compõem o Fator 5 da PAF (rotação Varimax) de seis fatores, com respectivos radicais de inclinação de Achtnich. 128

Tabela 40 - Itens (fotos) da forma masculina do BBT-Br $(n=720)$ que compõem o Fator 6 da PAF (rotação Varimax) de seis fatores, com respectivos radicais de inclinação de Achtnich.

Tabela 41 - Precisão (coeficientes Alfa de Cronbach) das versões originais (feminina $e$ masculina) do BBT-Br (com oito radicais de inclinação motivacional). 132

Tabela 42 - Precisão (coeficientes Alfa de Cronbach) das versões feminina e masculina do BBT-Br a partir das PAF com solução de seis fatores. 


\section{LISTA DE ANEXOS E APÊNDICES}

ANEXO A - Autorização do Comitê de Ética em Pesquisa

APÊNDICE A - Homogeneidade da Produtividade por série escolar feminina $(n=862)$

APÊNDICE B - Homogeneidade dos Radicais Primários Positivos por série escolar feminina $(\mathrm{n}=862)$

APÊNDICE C - Homogeneidade dos Radicais Secundários Positivos por série escolar feminina $(n=862)$

APÊNDICE D - Homogeneidade dos Radicais Primários Negativos por série escolar feminina $(n=862)$

APÊNDICE E - Homogeneidade dos Radicais Secundários Negativos por série escolar feminina $(\mathrm{n}=862)$

APÊNDICE F - Homogeneidade da Produtividade por série escolar masculina ( $n=720)$

APÊNDICE G - Homogeneidade dos Radicais Primários Positivos por série escolar masculina $(n=720)$

APÊNDICE H - Homogeneidade dos Radicais Secundários Positivos por série escolar masculina $(\mathrm{n}=720)$

APÊNDICE I - Homogeneidade dos Radicais Primários Negativos por série escolar masculina $(\mathrm{n}=720)$

APÊNDICE J - Homogeneidade dos Radicais Secundários Negativos por série escolar masculina $(n=720)$ 


\section{SUMÁRIO}

1. APRESENTAÇÃ

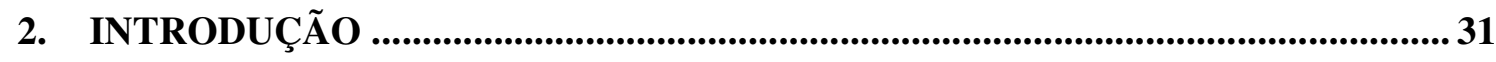

2.1. AvaliaÇÃo Psicológica e OrientaÇÃo Profissional: OS MÉtodos PROJETIVOS. .. 31

2.2. VALIDADE DE INSTRUMENTOS DE AVALIAÇÃo PSICOLÓGICA ..................................... 39

2.3. O TESTE DE Fotos DE Profissões (BBT-BR) .................................................. 46

2.4. BBT-BR EM ASSOCIAÇÕES A OUTROS MÉTODOS DE AVALIAÇÃO PSICOLÓGICA ............... 51

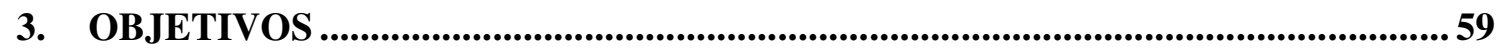

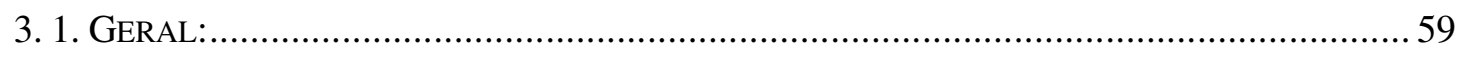

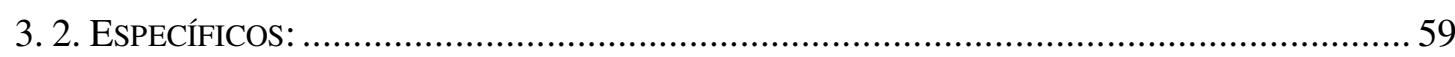

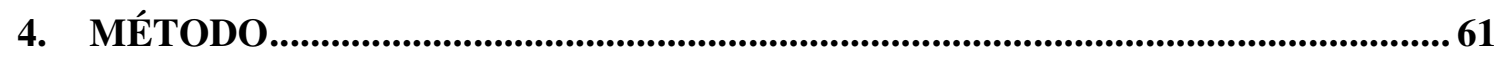

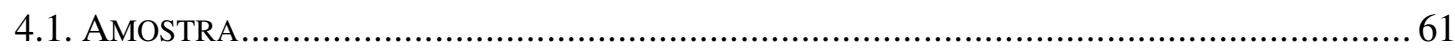

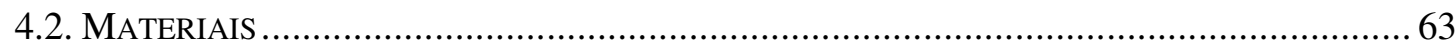

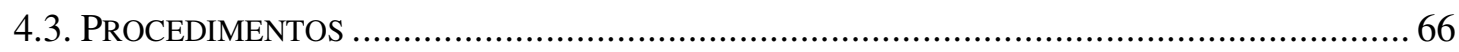

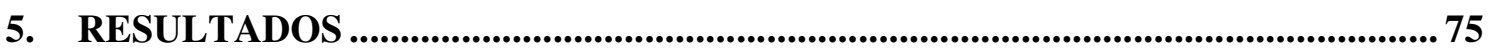

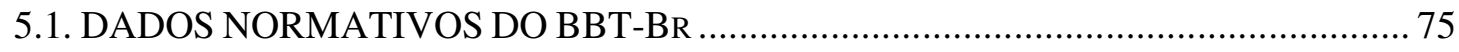

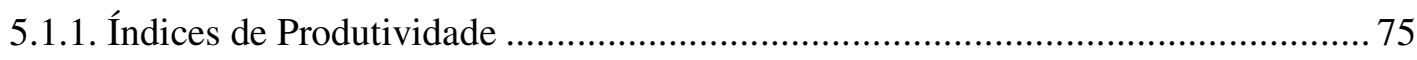

5.1.2. Estruturas de inclinação motivacional........................................................ 76

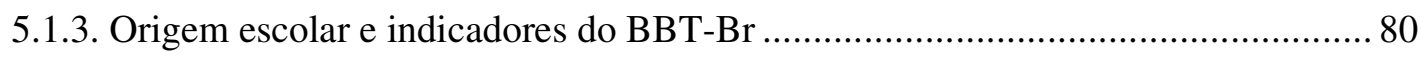

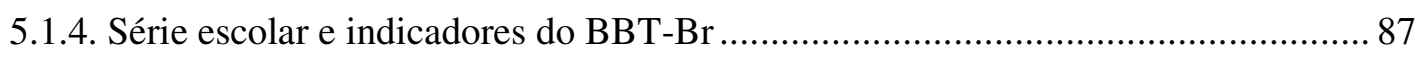


5.2.1. Validade fatorial do BBT-Br Feminino

5.2.2. Validade fatorial do BBT-Br Masculino.

5.2.3. Análise Fatorial Exploratória (PAF) com extração de seis fatores: Comparação de achados na versão Feminina e Masculina do BBT-Br.

5.3. PRECISÃO DO BBT-BR

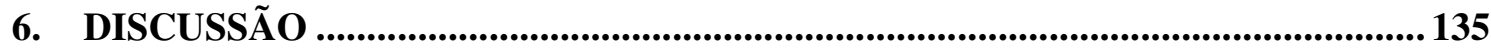

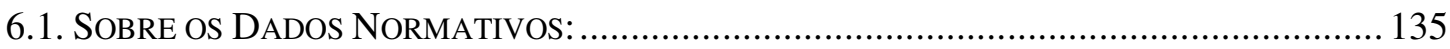

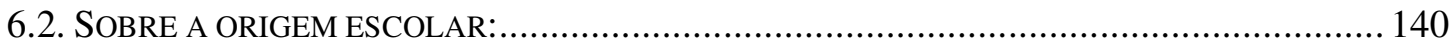

6.2.1. Origem escolar na versão feminina do BBT-Br.......................................... 140

6.2.2. Origem escolar na versão masculina do BBT-Br.......................................... 142

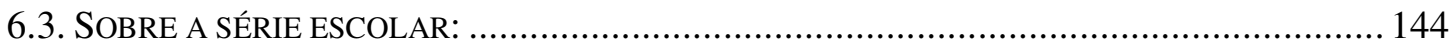

6.3.1. Série escolar na versão feminina do BBT-Br ..................................................... 144

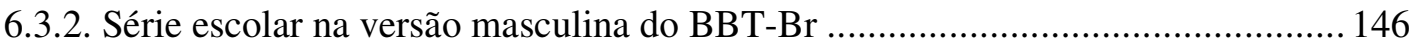

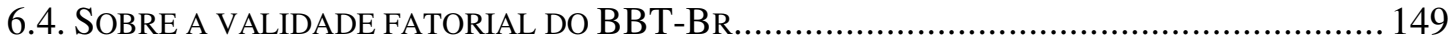

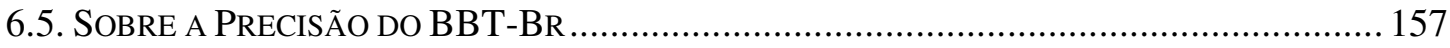

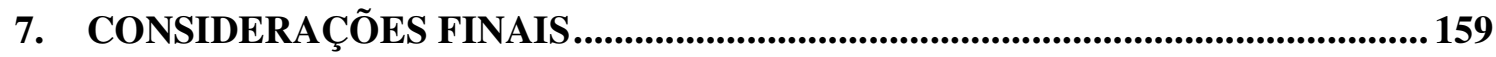

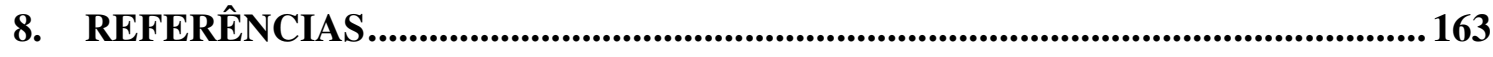

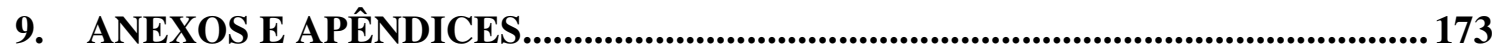




\section{APRESENTAÇÃO}

A Avaliação Psicológica mostra-se como um dos campos profissionais onde a presença de psicólogos bem treinados é imprescindível. A formação e a qualificação do psicólogo para atuar neste contexto mostra-se de extrema importância (Alchieri, Noronha \& Primi, 2003; Villemor-Amaral \& Pasqualini-Casado, 2006; Urbina, 2007). Neste sentido, os instrumentos e técnicas disponíveis para o uso em avaliação psicológica devem ser igualmente qualificados. Atualmente, a preocupação com a qualidade dos instrumentos de avaliação psicológica disponíveis para os psicólogos brasileiros ganha espaço e destaque entre as diversas áreas de pesquisa em Psicologia. Com o desenvolvimento de novas metodologias e a conscientização da necessidade de contínua pesquisa e aprimoramento dos instrumentos de avaliação psicológica, em especial a busca constante por novas evidências de validade e precisão, a Avaliação Psicológica tende a apresentar desenvolvimento cada vez maior. Esse desenvolvimento é essencial para a atuação prática cotidiana dos psicólogos, pois busca garantir que seus instrumentos de trabalho possuam cada vez maiores níveis de qualidade, com possibilidade de maior amplitude em seus campos de utilização.

A avaliação psicológica têm se mostrado bastante importante em diferentes contextos profissionais, podendo-se destacar a área da Orientação Vocacional/Profissional (Pasian, Okino \& Melo-Silva, 2007). As intervenções nessa área visam, principalmente, a auxiliar os orientandos a realizarem escolhas mais conscientes, sadias, que promovam maior satisfação em suas carreiras. Neste sentido, a compreensão de aspectos individuais, interesses, influências familiares e do grupo social, maturidade, motivações, auto-conhecimento, dentre outros aspectos, é de extrema importância neste processo, que geralmente tem duração delimitada e focal. Considerando esta necessidade de maior entendimento sobre os orientandos em um curto intervalo de tempo, os instrumentos de avaliação psicológica podem ser ótimas ferramentas a serem utilizadas para favorecer este processo de intervenção. Cabe, portanto, a realização de pesquisas buscando aprimorar as técnicas já existentes e com boa aceitação e utilização nestes processos de Orientação Vocacional/Profissional, uma vez que 
esse aprimoramento tende a refinar e acrescentar novas e valiosas informações acerca dos possíveis usos dos instrumentos.

A realização da presente pesquisa encontra-se neste contexto de atualização e de aprimoramento de instrumentos de avaliação psicológica com uso privilegiado em processos de Orientação Vocacional/Profissional e Reorientação de Carreira. Especificamente, os objetivos desse estudo visaram apresentar novos referenciais normativos e prosseguir com a investigação de evidências de validade do Teste de Fotos de Profissões, o BBT-Br. Esta técnica é atualmente o único método projetivo de avaliação psicológica, voltado para uso prioritário em processos de Orientação Vocacional/Profissional, aprovado pelo Conselho Federal de Psicologia (Conselho Federal de Psicologia, 2011) para uso no contexto brasileiro, apresentando boas evidências psicométricas para sua utilização em processos de Orientação Vocacional/Profissional (Pasian, Okino e Melo-Silva, 2007; Noce, 2008; Okino, 2009; Shimada, 2011).

Em relação ao meu interesse pessoal na realização deste estudo, posso dizer que o interesse pelos instrumentos de avaliação psicológica sempre estiverem presentes em minha graduação. Cursando as disciplinas de Técnicas de Exame Psicológico, Técnicas de Investigação da Personalidade, Orientação Profissional e Técnicas Projetivas em Psicologia Clínica, pude conhecer melhor diversos instrumentos de avaliação e meu interesse aumentou, com maior destaque para os métodos projetivos de avaliação psicológica, que se mostraram fascinantes. Passei a acompanhar as atividades de pesquisa no Centro de Pesquisa em Psicodiagnóstico da FFCLRP - USP e fui realizando leituras bibliográficas neste campo do conhecimento. Encerrando a graduação, imediatamente fui contratado como psicólogo na Albuquerque Comércio de Livros Ltda, distribuidora autorizada das principais editoras responsáveis pela publicação dos testes psicológicos aprovados para uso no Brasil. Essa experiência como psicólogo responsável pela comercialização dos instrumentos de avaliação proporcionou um rico contato não só com o material disponível no mercado, mas também com outros psicólogos que trabalham com estes instrumentos, seja no campo do trânsito, na clínica, em orientação, enfim, nos mais variados contextos. De certa maneira, creio que estes contatos e influências acabaram por aumentar meu interesse em instrumentos de avaliação psicológica, levando-me a tentar realizar um estudo focado em características psicométricas de instrumento de avaliação psicológica, ou seja, relativo à construção e à validação das técnicas, buscando evidências empíricas de sustentação para a prática profissional dos psicólogos. Pensando no linguajar próprio do BBT-Br, considero que foram os interesses V, $\mathrm{G}$ e $\mathrm{S}$, combinados, que impulsionaram a necessidade de realizar o presente trabalho. 
É importante destacar ainda que, durante o processo de desenvolvimento desta Dissertação, foram realizadas alterações e acrescentados objetivos nas estratégias metodológicas inicialmente pensadas. Essas modificações e reformulação nos métodos propostos decorreram da insuficiência das análises preliminares em responder as perguntas formuladas para esta investigação. Ressalta-se aqui, a importante ajuda e consultoria dasprofessoras Thais Zerbini e Fabiana Queiroga (respectivamente do Departamento de Psicologia da FFCLRP - USP e do Instituto de Psicologia da Universidade de Brasília; comunicação pessoal, 13 de Maio de 2010), que contribuíram para o bom entendimento e melhoria dos métodos de análise de dados utilizados no presente trabalho

Feitas essas considerações de caráter de contextualização do estudo, pode-se afirmar que o objetivo do presente estudo é apresentar e descrever novos padrões normativos para o BBT-Br, em suas formas feminina e masculina, e prosseguir com os estudos de validade e precisão desse método projetivo de avaliação psicológica, por meio da análise fatorial exploratória, com números pré-definidos de fatores e da análise da consistência intera. Para tanto, recorreu-se à análise dos protocolos do BBT-Br existente em extenso Banco de Dados do Centro de Pesquisas em Psicodiagnóstico da Faculdade de Filosofia, Ciências e Letras de Ribeirão Preto, composto por dados de quatro amplos projetos de pesquisa realizados com o BBT-Br.

Sendo assim, o presente estudo foi estruturado apresentando, inicialmente, uma Introdução que: contextualiza o uso dos métodos projetivos em Avaliação Psicológica, com ênfase na Orientação Profissional; apresenta as antigas e atuais definições de validade para instrumentos de avaliação psicológica; apresenta a fundamentação teórica que embasa o Teste de Fotos de Profissões (BBT-Br); e descreve brevemente as principais pesquisas de validação envolvendo o BBT-Br. A seguir, são detalhados os Objetivos do presente estudo. Os Métodos adotados para se alcançar esses objetivos são detalhados em seqüência.

Posteriormente, são apresentados os Resultados alcançados no estudo, seguindo-se a lógica apresentada nos objetivos aqui delineados. Essa apresentação dos dados é feita sempre primeiro com a versão feminina do BBT-Br, seguida pelos resultados da versão masculina.

A Discussão retoma os Resultados, integrando-os com a literatura, e propondo hipóteses interpretativas para as evidências aqui encontradas. Por fim, as Considerações Finais encerram o trabalho, retomando os principais resultados e discorrendo acerca das possibilidades e limitações deste estudo, apresentando também propostas para novas pesquisas com o BBT-Br. 


\section{INTRODUÇÃ̃O}

\subsection{Avaliação Psicológica e Orientação Profissional: Os métodos projetivos.}

A amplitude do objeto de estudo e a diversidade de possibilidades técnicas da Psicologia produzem, como conseqüência, grande complexidade em suas perspectivas teóricas e aplicações práticas. Dentre estas alternativas, os processos de avaliação psicológica se constituem como recursos historicamente relevantes e que exigem contínuo aprimoramento técnico e científico, conforme apontado por Cunha (2000), Anastasi e Urbina (2000), Noronha e Alchieri (2005) e Urbina (2007). O objetivo da avaliação psicológica, de acordo com Tavares (2003), é promover a melhor compreensão possível de aspectos relevantes do funcionamento psíquico de um indivíduo ou grupo de indivíduos, utilizando-se de um conjunto de informações disponíveis no momento, a partir das evidências obtidas por técnicas reconhecidas e validadas empiricamente.

Dentro dos instrumentos e técnicas utilizados para avaliação psicológica, as ricas e diversificadas possibilidades interpretativas advindas dos métodos projetivos são reconhecidas na literatura científica há longa data. Para Villemor-Amaral e Pasqualini-Casado (2006) estas técnicas enfatizam aspectos qualitativos e psicológicos do indivíduo avaliado, reconhecendo-o como possuidor de motivações implícitas e complexidade singular.

Para além destas contribuições, estes métodos, no entanto, são alvo constante de críticas, como já comentaram Draime e Jacquemin (1989) há mais de duas décadas. De acordo com estes pesquisadores, os múltiplos questionamentos sobre instrumentos de exame psicológico, em especial os projetivos, estão relacionados ao longo período em que estes foram utilizados pelos psicólogos sem a preocupação com estudos de sua validade e/ou padronização ao contexto sócio-cultural brasileiro, sem mencionar a inadequação e o despreparo técnico em suas utilizações. Estes autores ressaltaram a importância dos estudos de padronização e de validação das técnicas psicológicas a serem aplicadas e a qualificação do profissional que fará uso das mesmas. Outros autores (Ottati, Noronha \& Salvatti, 2003; Noronha \& Alchieri, 2005; Alchieri, Noronha \& Primi, 2003; Hutz, 2009) também ressaltam a importância da qualificação profissional e a ausência de estudos psicométricos da grande maioria dos testes psicológicos comercializados no Brasil até 2003. 
Ao focalizar o debate sobre a cientificidade dos métodos projetivos de avaliação psicológica, Fensterseifer e Werlang (2008) citam, como principais críticas recebidas por este tipo de instrumento: dificuldades na determinação de suas propriedades psicométricas, influência do aplicador sobre as respostas do examinando e a fragilidade de grande parte dos trabalhos realizados na tentativa de validar esses métodos. Destas, a mais contundente referese aos baixos índices de validade e fidedignidade que os testes projetivos apresentam, em comparação com as chamadas técnicas objetivas. Apesar disso, as mesmas autoras discorrem sobre a reconhecida validade e utilidade clínica dos métodos projetivos de avaliação psicológica na prática cotidiana dos psicólogos. Ressaltam que os procedimentos de validação utilizados em testes psicométricos não se aplicam exatamente da mesma forma na investigação das técnicas projetivas.

Argumentos semelhantes também foram discutidos no trabalho de Villemor-Amaral e Pasqualini-Casado (2006), afirmando que os instrumentos de avaliação psicológica requerem padronização, atualizações periódicas e apresentação de características psicométricas. No entanto, o critério de cientificidade das técnicas projetivas não pode se basear apenas em seu rigor psicométrico, em detrimento de sua utilidade e validade clínica. Segundo estas pesquisadoras, os instrumentos mais objetivos, como escalas de auto-relato, são mais eficazes em acessar as necessidades explícitas dos respondentes, ou seja, aquelas características que as pessoas reconhecem em seu funcionamento rotineiro. Desta maneira, ao responder a uma escala ou a um questionário, o indivíduo apresenta respostas mais intencionais, onde o motivo ou necessidade que impele a esta resposta é claro para o respondente. Já as informações obtidas por medidas projetivas acessam o comportamento de tendências mais espontâneas, motivadas por necessidades implícitas, que o sujeito não acessa diretamente ou racionalmente, mas que são passíveis de se manifestar em outros contextos.

$\mathrm{Na}$ tentativa de oferecer recursos técnicos para sistematização das evidências de validade para instrumentos de avaliação psicológica, Tavares (2003) retoma e discute o conceito de validade clínica. Apresentou, neste trabalho, as possibilidades desta estratégia, contextualizando suas limitações, seus procedimentos e seus alcances para o contexto da avaliação psicológica. Segundo este pesquisador, o psicólogo busca apreender o significado da interação entre os dados obtidos e o sujeito analisado, com toda sua história pessoal e complexidade, demonstrando, desta forma, a capacidade do instrumento encontrar e sinalizar informações relevantes sobre o psiquismo do indivíduo avaliado, chamando-a de "validade clínica”. Este autor, portanto, ressalta a importância tanto de uma avaliação nomotética (comparação dos escores obtidos com grupos de indivíduos) quanto de uma avaliação 
idiográfica (onde a performance do sujeito é comparada com sua própria performance, em momentos diferentes ou situações semelhantes, focalizando sua unidade e complexidade peculiares) em quaisquer testes psicológicos, sejam técnicas projetivas, escalas, inventários, dentre outros. É neste sentido que a validade clínica ganha força, pois, ao utilizar diferentes procedimentos (entrevistas com familiares, observações longitudinais sobre o comportamento, dentre outros) pode-se incrementar um processo de avaliação psicológica, proporcionando informações relevantes e de caráter prognóstico sobre os indivíduos.

Ainda dentro das preocupações gerais relativas aos aspectos técnicos da avaliação psicológica, foco do presente projeto, faz-se importante incluir as reflexões e as sugestões apresentadas por Meyer e Kurtz (2006). Estes importantes pesquisadores da área de avaliação psicológica focalizaram em seu trabalho o questionamento sobre a classificação dos testes psicológicos em "objetivos" e "projetivos". Segundo este autor, há necessidade de superação técnica desta divisão classificatória dos instrumentos de avaliação psicológica, em especial aqueles voltados para investigação de características da personalidade. Isto porque o que é objetivo em instrumentos como escalas de auto-relato, é o fato de que psicólogo que administra o método não precisa interpretar seus resultados, uma vez que é o indivíduo que deve, ao responder os itens, identificar quais características se aplicam melhor a sua personalidade. Ao se nomear este procedimento de "objetivo", ignora-se os processos subjetivos que influenciam a resposta do indivíduo, incluindo-se ambigüidades inerentes aos itens do teste, dinâmica da personalidade do sujeito, limitações em sua auto-percepção e até mesmo projeções que venham a ocorrer. Por outro lado, como também aponta Güntert (2001), os testes projetivos também não seriam baseados unicamente no mecanismo da projeção (como postulado por Freud), onde alguns elementos inconscientes do self seriam projetados para o mundo externo. Meyer e Kurtz (2006) citam, como exemplo, o Método de Rorschach, onde as respostas também seriam influenciadas pelo modo como o indivíduo classifica estímulos ou resolve problemas e não apenas por suas projeções. Para além deste problema de conceituação correta do instrumento, esses autores apontam para a conotação positiva que o termo "objetivo" suscita, que muitas vezes não é completamente garantida pelos inventários aos quais se referem. Deste modo, parece acontecer que algum instrumento "objetivo" seja considerado "bom" apenas pelo termo "objetivo" em si, sugerindo adequação técnica, porém independentemente de suas reais características psicométricas. Para estes pesquisadores, portanto, seria necessário revisar a terminologia técnica para classificação dos instrumentos de avaliação da personalidade, tendo em vista o tipo de tarefas solicitadas e as alternativas disponíveis de resposta, o que ofereceria maior ou menor liberdade de expressão por parte do 
indivíduo. Neste sentido, sugerem, dentre outros, os termos "inventários de auto-relatos", "testes expressivos de personalidade", "tarefas comportamentais" e "métodos construtivos" ou "implícitos".

As considerações anteriores também foram objeto de reflexão e de argumentos elaborados por Ritzler (2006). Ele também discorre sobre a terminologia de "testes objetivos" e "testes projetivos", considerando essa classificação dicotômica como ultrapassada e imprecisa, uma vez que não apreende, em sua totalidade, a natureza dos métodos de avaliação de personalidade. Este autor sugere que os instrumentos sejam classificados em dois grandes grupos: métodos de autorrelato (para substituir o termo "testes objetivos") e métodos de autoexpressão (para designar os "métodos projetivos"), pensando nos processos implicados nas respostas a estes tipos de instrumentos de avaliação psicológica. Esta proposição de revisão terminológica dos testes psicológicos, na verdade, é dilemática na área e, até o momento, sem solução satisfatória, como argumentam Fensterseifer e Werlang (2008). Apesar disso, é preciso que os profissionais que usam os instrumentos de avaliação psicológica tenham consciência destes aspectos técnicos e os acompanhem em suas implicações teóricas e na prática profissional.

Pode-se depreender que, apesar das dificuldades técnicas próprias aos métodos de avaliação psicológica, historicamente há um esforço para sua superação e aprimoramento, o que permanece vigente até hoje (Urbina, 2007). Focalizando, especificamente, os métodos projetivos, existem limites e críticas referentes a suas qualidades psicométricas, porém suas evidências clínicas também são muito ricas, possibilitando acesso a informações de natureza mais complexa acerca dos indivíduos, como bem argumentado por Fensterseifer e Werlang (2008) e Villemor-Amaral e Pasqualini-Casado (2006). Outro ponto em comum destacado por estas autoras é relativo à necessidade de se persistir no estudo de procedimentos metodológicos que demonstrem e acrescentem evidências de validade às técnicas projetivas, uma vez que o rigor psicométrico agrega confiabilidade aos instrumentos. Essas autoras ainda argumentam sobre a necessidade de ser efetivado adequado treinamento técnico com profissionais e pesquisadores em Psicologia, estimulando-os a trabalhar com as condições de padronização das técnicas de avaliação psicológica (materiais, instruções, procedimentos de aplicação e de avaliação), bem como com suas qualidades psicométricas globais (dados normativos, validade, precisão), buscando sempre atualizações técnico-científicas nos materiais utilizados e nos profissionais que os utilizam. Esses argumentos também são considerados por Hutz (2009) como fatores implicados na própria ética da prática profissional 
do psicólogo, sobretudo no tocante à adequada qualidade da formação para embasar esta atuação em seus diferentes contextos de aplicação dos instrumentos de avaliação psicológica.

Essa busca de procedimentos metodológicos que demonstram e acrescentam evidências de validade aos métodos projetivos foi realçada também por Villemor-Amaral (2009). Essa autora considera que a validação de técnicas projetivas pode ser considerada como um desafio à parte, uma vez que seus princípios de análise e interpretação se apóiam mais em pressupostos teóricos do que em evidências oriundas de procedimentos psicométricos. Sendo assim, a autora aponta a impossibilidade de se pensar na validade de técnicas projetivas (ou Métodos de Autoexpressão) sem pensar na finalidade de uso do instrumento. Com base nestes argumentos, há que se pensar, conforme argumenta a pesquisadora, sobre o fato de que um teste ser válido e aprovado para o uso no contexto brasileiro não significa necessariamente que as interpretações aos dados sejam válidas, ou mesmo úteis, em diferentes contextos. Villemor-Amaral (2009) conclui dizendo que a complexidade da avaliação psicológica é mais abrangente que as soluções oferecidas pela psicometria, adentrando também na questão de como se dá a atuação profissional do psicólogo.

Um dos vários campos de aplicação dos métodos de avaliação psicológica, a área de Orientação Vocacional/Profissional (OPV), beneficia-se destes recursos técnicos, tanto no Brasil quanto em termos internacionais, como atestam as orientações da International Association for Educational and Vocacional Guidance (IAEVG) e as diretrizes brasileiras para a formação nesta área, segundo a Associação Brasileira de Orientação Profissional (ABOP). O processo de avaliação psicológica neste contexto desenvolve-se por diferentes estratégias técnicas, de natureza e princípios específicos, a depender do modelo teórico adotado (Leitão \& Ramos, 2004; Levenfus \& Soares, 2010). Pode-se afirmar que a avaliação psicológica no contexto de orientação escolar e educacional inicia-se durante a entrevista inicial, continuando por todo o processo de intervenção, independentemente do uso ou não de instrumentos de avaliação psicológica (Leitão \& Ramos, 2004).

Apesar de não existir consenso entre os orientadores profissionais acerca do uso de testes psicológicos no processo de OPV, Pasian, Okino e Melo-Silva (2007) afirmam que, existe uma concordância geral sobre a necessidade de um correto diagnóstico das vivências dos indivíduos que solicitam auxílio da Orientação Profissional/Vocacional, de modo a possibilitar uma intervenção adequada e assertiva sobre a problemática. Entretanto, como já visto anteriormente, para a realização de um correto diagnóstico, é necessário que os 
instrumentos de avaliação psicológica utilizados sejam adequadamente padronizados, apresentem boas qualidades psicométricas e atualizações normativas periódicas.

Noronha, Freitas e Otatti (2003) analisaram os manuais de oito instrumentos utilizados em processos de Orientação Profissional: QVI - Questionário Vocacional de Interesses (Oliveira, 1982), LIP - Levantamento de Interesses Profissionais (Del Nero, 1975), Kuder Inventário de Interesses (Kuder, 2000), Inventário de Interesses (Thurstone, Angelini \& Angelini, 2002), GEIST - Inventário Ilustrado de Interesses (Geist, sem data), Teste de Catálogo de Livros Bessa-Tramer (Bessa, 1998), TEV - Teste das Estruturas Vocacionais (Minicucci, 1983) e QUATI (Zacharias, 2000). Foram analisados os seguintes aspectos: autor, editor, ano de publicação, padronização, validade e precisão. Os resultados encontrados indicaram ausência de grande parte dessas informações nos manuais analisados, indicando a necessidade de novos estudos e pesquisas, em vista das novas exigências e preocupação com a qualidade dos instrumentos de avaliação psicológica.

Em outra pesquisa semelhante, com os mesmos instrumentos (à exceção do QUATI), Otatti, Noronha e Salviatti (2003) aplicaram o Questionário para Avaliar a Qualidade dos Testes, proposto por Prieto e Muniz, utilizado na Espanha, possibilitando a avaliação dos instrumentos quanto a qualidade do material, validade, precisão, normas, dentre outros aspectos. Novamente, os resultados apontaram a falta de informações pertinentes e necessárias para a boa qualidade e validade dos instrumentos de avaliação psicológica.

Sparta, Bardagi e Teixeira (2006) apresentaram as características de dois modelos teóricos para avaliação em Orientação Profissional, o Modelo de Avaliação Psicológica Centrado no Resultado e o Modelo de Avaliação Psicológica Centrada no Processo, citando os principais instrumentos utilizados no contexto brasileiro. Segundo estes autores, o modelo Centrado no Resultado tem, como principal preocupação, a definição de uma escolha profissional. Por meio do uso de instrumentos de avaliação psicológica, são avaliadas as características individuais (inteligência, aptidões, interesses e personalidade) do orientando, com o objetivo de traçar um perfil profissional que permita identificar ambientes e ocupações congruentes ao perfil encontrado. Esse modelo foi desenvolvido no auge da utilização e criação dos testes psicológicos (Pasquali, 2010), sendo bastante utilizado e desenvolvido internacionalmente até os dias atuais. A teoria de Holland (Holland, 1975), que considera seis dimensões da personalidade (o realista, o investigativo, o artístico, o social, o empreendedor e o convencional) que compõem não só os interesses profissionais, mas também os ambientes de trabalho, pode ser apontada como exemplo das modernas teorias de Avaliação Psicológica 
Centrada em Resultados. Os instrumentos de avaliação psicológica mais utilizados, neste contexto, tendem a ser baterias de aptidões e inventários de interesses (Urbina, 2007).

Em relação ao Modelo de Avaliação Psicológica Centrada no Processo, Sparta et al. (2006) apontam que a ênfase deste modelo está na aprendizagem do processo de escolha, preocupando-se com os processos internos e externos que levam o orientando a selecionar determinada profissão. Desta forma, este modelo de avaliação promove o autoconhecimento do orientando, sem foco direto na investigação de possibilidades relacionadas a esta ou aquela escolha profissional. Bohoslavsky (1977) e Super (Super, Savickas \& Super, 1996) são apontados como principais representantes deste modelo. Esses autores consideram a entrevista como instrumento principal dos processos de Orientação Profissional, sendo facultativo o uso de testes psicológicos. Quando utilizados, estes instrumentos devem auxiliar o orientador no processo diagnóstico, permitindo intervenções mais precisas e adequadas. Neste sentido, também são mais recorrentes escalas de autoconhecimento, técnicas projetivas, dentre outros.

Sparta et al. (2006) finalizam seu trabalho ressaltando a necessidade de novos estudos com os instrumentos de avaliação psicológica, visando a seu aperfeiçoamento, além de maior preparo e boa formação dos orientadores profissionais, posicionamento compartilhado por Pasian et al. (2007) e Hutz (2009). Sparta et al. (2006) enfatizam ainda a necessidade de uso da avaliação psicológica em processos de Orientação Vocacional/Profissional (OVP), independentemente do modelo e abordagem teórica adotados pelo orientador.

Com o intuito de fornecer maior arcabouço teórico aos profissionais que atuam em OVP, possibilitando intervenções psicológicas de maior qualidade, Nunes, Okino, Noce e Jardim-Maran (2008) fizeram uma revisão de três modelos teóricos bastante estudados na área de desenvolvimento de interesses profissionais (Teoria Sócio-cognitiva, Tipologia de Holland e Perspectiva Psicodinâmica). Também foram apresentados os testes psicológicos baseados nesses três modelos e utilizados no contexto brasileiro.

Segundo essas autoras, a Teoria Sócio-Cognitiva conceitua os interesses como padrões de gostos, aversões e indiferenças a atividades profissionais (Nunes et al., 2008). Esses padrões de interesses são influenciados pela auto-eficácia (capacidade individual de organizar e desenvolver certas ações) e as expectativas de resultados (crenças sobre as conseqüências dessas ações). Por esta teoria, as pessoas tendem a ter interesse em atividades onde se sentem eficazes, o que gera boas expectativas de resultados. Na época de publicação do trabalho, não havia instrumentos de avaliação psicológica, com base nesta concepção teórica, comercializados e aprovados pelo Conselho Federal de Psicologia para uso no Brasil. 
Na seqüência da apresentação dos modelos teóricos, as autoras descrevem a Teoria da Personalidade Vocacional de Holland (1997), que considera os interesses profissionais como uma forma de expressão da personalidade. As autoras descrevem o SDS (Primi, Mansão Muniz \& Nunes, 2010), padronizado e validado para a população brasileira, como o instrumento que ilustra esta aplicação teórica, tornando viável a investigação sistemática de seus princípios, embasando intervenções práticas.

Por fim, as autoras descrevem a Perspectiva Psicodinâmica dos Interesses como representada pelas teorias desenvolvidas por vários autores (Roe, 1957; Bordin, Nachmann \& Segall, 1963; Achtnich, 1991) que consideram as motivações, necessidades, impulsos e mecanismos inconscientes na elaboração e desenvolvimento dos interesses profissionais. Como exemplo de instrumento baseado na Perspectiva Psicodinâmica, as autoras descrevem o Teste de Fotos de Profissões (BBT) de Achtnich (1991) e suas padronizações brasileiras, o BBT-Br Masculino (Jacquemin, 2000) e o BBT-Br Feminino (Jacquemin, Okino, Noce, Assoni \& Pasian, 2006), alvo do presente estudo.

Outro aspecto teórico referente aos interesses profissionais é a questão da possível influência do gênero na configuração destes interesses. Vários autores (Bueno, Lemos \& Tomé, 2004; Levenfus \& Bandeira, 2007; Levenfus \& Bandeira, 2009; Nunes \& Noronha, 2009; Sartori, Noronha \& Nunes, 2009; Primi et al., 2010) vem identificando diferenças entre os interesses profissionais de homens e mulheres. De modo sintético, pode-se atribuir estas diferenças ao maior interesse feminino em atividades de contato interpessoal e ajuda, em contrapartida ao elevado interesse masculino em atividades mais práticas, que exigem maior raciocínio lógico. Levenfus e Bandeira (2010), inclusive, ao discorrerem sobre possíveis interpretações psicodinâmicas do Teste de Avaliação dos Interesses Profissionais (AIP), apontam para a hipótese da existência de profissões predominantemente femininas ou masculinas, ressaltando a importância de se comparar os interesses obtidos pelo avaliando com as médias normativas especificamente desenvolvidas por sexo.

Diante do exposto, pode-se depreender o esforço de atualização e aperfeiçoamento não só das técnicas de avaliação psicológica, mas também dos processos e teorias de Orientação Vocacional/Profissional, com a preocupação em oferecer melhores subsídios e técnicas para aprimorar as intervenções psicológicas nos processos de OVP. É neste contexto que se insere o presente trabalho, que objetiva investigar evidências empíricas de validade do BBT-Br e elaborar padrões de referência (normas) para adolescentes. Com esta diretriz, os próximos tópicos versarão, especificamente, sobre aspectos relacionados aos princípios técnicos de 
validação de instrumentos de exame psicológico e sobre o Teste de Fotos de Profissões BBT-Br, fundamentando a presente proposta investigativa.

\subsection{Validade de instrumentos de avaliação psicológica}

Dada a extrema importância dos indicadores de validade para qualquer instrumento de avaliação psicológica, uma maior explanação deste conceito faz-se necessária neste momento. Pasquali (2001) define a validade de um teste psicológico como a capacidade deste instrumento avaliar, de fato, o que supostamente anuncia medir. Essa definição de validade tornou-se a mais conhecida e difundida no contexto brasileiro, sendo, até hoje, possivelmente uma definição clássica bastante utilizada. Entretanto, a publicação dos Standards for Educacional and Psychological Testing (APA, 2000) disponibilizou relevantes diretrizes para a revisão conceitual de validade, o que foi incorporado também nas orientações técnicas do Sistema de Avaliação dos Testes Psicológicos (SATEPSI) do Conselho Federal de Psicologia (CFP, 2010) no Brasil. Optou-se, neste momento, por inicialmente apresentar a classificação mais clássica de validade, com apenas três tipos, para depois apresentar as definições atuais, buscando evidenciar a própria evolução e desenvolvimento deste importante conceito.

Na perspectiva mais clássica e a partir das considerações de Fachel e Camey (2000), realizadas no contexto brasileiro, existiriam três tipos de validade: validade de conteúdo, validade de critério e validade de construto (ou conceito). A validade de conteúdo refere-se ao exame sistemático do conteúdo do instrumento de avaliação psicológica, determinando se seus itens cobririam uma amostra representativa do comportamento a ser medido e se a escolha dos itens está apropriada e relevante. Pode ser subdividida em dois tipos: validade de conteúdo e validade aparente. Essa validade pode ser avaliada por meio da concordância do julgamento de juízes, peritos na área do traço medido, que avaliam a representatividade dos itens em relação aos conceitos e à relevância dos objetivos a medir (validade de conteúdo propriamente dita) ou por meio da avaliação da linguagem, da forma com que o conteúdo do instrumento está sendo apresentado (validade aparente).

A validade de critério, por sua vez, pode ser subdividida em validade concorrente e validade preditiva. Diz respeito ao quanto o instrumento de avaliação é capaz de predizer, temporalmente, uma determinada variável chamada de critério (Fachel \& Camey, 2000). O critério poderia ser obtido por resultados advindos de outros instrumentos já validados pela literatura e independentes do teste a ser avaliado, segundo Pasquali (2001). A diferença entre 
a validade concorrente e a preditiva refere-se ao momento em que esta avaliação independente da variável ocorre. No caso da validade concorrente, a aplicação do instrumento de avaliação a ser validado ocorre conjuntamente à aplicação do instrumento independente, verificando se o teste é capaz de predizer, no tempo presente, o critério estabelecido. Já para a avaliação da validade preditiva, inicialmente realiza-se uma aplicação do teste a ser validado, e, após determinado período de tempo, faz-se o diagnóstico do critério por outra técnica já consagrada. Em outras palavras, avalia-se a qualidade com a qual o instrumento medido pode predizer um critério futuro, segundo Fachel e Camey (2000).

Ainda tomando as considerações destas autoras, a validade de construto refere-se ao grau pelo qual um instrumento de avaliação mede o componente teórico ou traço para o qual ele foi designado, ou construído, para medir. No entanto, como o construto é uma variável latente não-observável, ele não pode ser diretamente mensurado. Desta maneira, a validade de construto "não é validade empírica no sentido da correlação do teste com um critério observável, mas sim é validade teórica, isto é, é a relação entre o teste e algum constructo teórico (variável latente) de interesse” (Fachel \& Camey, 2000, p. 164). Para se averiguar esta validade, as autoras citam os apontamentos de Anastasi (1988), que afirma que a validade relacionada ao construto requer a acumulação gradual de informação utilizando-se várias fontes, dividas em três tipos de validade: validade convergente, validade discriminante e validade fatorial. A validade convergente relaciona-se à medida da correlação existente entre o teste novo e um instrumento já considerado como válido pela comunidade científica da área (que avalie o mesmo construto teórico). Quanto maior a correlação entre eles, maior a possibilidade do novo instrumento alcançar estimativas sobre este construto em foco. Já a validade discriminante focaliza o quanto a medida em questão difere, significativamente, de construtos distintos, observados por outras técnicas avaliativas também já existentes e reconhecidas em seus propósitos. Por fim, a validade fatorial recorre a análises estatísticas multivariadas para identificar traços psicológicos (fatores latentes) nos itens de um instrumento de avaliação psicológica.

Muito utilizada na validação de escalas psicológicas, a análise fatorial afirma que um número menor de traços latentes é o bastante para explicar um número maior de itens, ou seja, ela explicita o que o instrumento em questão está medindo, isto é, os fatores, bem como clarifica quais itens compõem cada fator (Pasquali, 2009, 2010). Para tanto, este mesmo autor ressalta a importância do instrumento a ser validado ter sido construído com base em teoria psicológica consolidada e aceita, possibilitando que as análises fatoriais sejam utilizadas como um método para examinar hipóteses advindas desses pressupostos teóricos. 
$\mathrm{Na}$ tentativa de aglutinar os avanços científicos internacionais da área de avaliação psicológica e aplicá-los no contexto do aprimoramento dos instrumentos e procedimentos técnicos dos psicólogos no Brasil e proporcionar sua avaliação contínua, o Conselho Federal de Psicologia publicou a Resolução CFP 002/2003, que define e regulamenta o uso, elaboração e comercialização dos testes psicológicos. Nesta Resolução foram apresentados os requisitos mínimos para que os instrumentos de avaliação possam ser reconhecidos como testes psicológicos, subdividindo-os em técnicas que utilizam "questões de múltipla escolha e outros similares, tais como 'acerto e erro', 'inventários' e 'escalas'” (Resolução CFP 002/2003, p. 2) ou testes projetivos.

Para os métodos projetivos de avaliação psicológica, segundo a Resolução CFP 002/2003, os requisitos mínimos obrigatórios da técnica seriam: apresentação da fundamentação teórica, com especial ênfase na definição do construto a ser avaliado e possíveis utilizações deste instrumento; apresentação de evidências empíricas de validade e precisão das interpretações propostas; apresentação do sistema de correção e interpretação em relação à amostra de normatização, além de apresentação clara dos procedimentos de aplicação e correção. É importante observar que estes mesmos requisitos também são exigidos para testes de origem estrangeira, que deverão passar por amplo processo de adaptação para o contexto brasileiro, antes de ser autorizado para uso nesta realidade.

Especificamente, para os quesitos relativos às evidências empíricas de validade, a Resolução do Conselho Federal de Psicologia (CFP) 002/2003, em seu anexo 1, que contém os Critérios de Avaliação da Qualidade de Testes Psicológicos (Resolução CFP 002/2003) considerava, como quesitos de avaliação, os seguintes tipos de validade:

1) Validade baseada na análise de conteúdo ou domínio: avalia se o teste apresenta ampla e precisa definição do conteúdo dos itens e sua associação ao construto em foco no instrumento, podendo-se recorrer à consulta a especialistas da área como balizadores deste processo.

2) Validade de critério: avalia a justificativa da relação teste-critério, em especial a discussão de como o construto avaliado se relaciona com eventos comportamentais observáveis. Consideram as evidências de validade de critério concorrente e preditiva, assim definidas: a) validade convergente (evidências de associações significativas, de alta magnitude, deste instrumento com outro teste já aprovado para uso); b) validade discriminante (evidências de associações não significativas entre o teste avaliado e outro instrumento, voltado a construto diferente e não relacionado empírica ou teoricamente ao anterior); c) validade de construtos relacionados ("estudo da relação entre testes que avaliam construtos diferentes mas, teórica e empiricamente, relacionados" (Resolução CFP 002/2003, p. 19). 
3) Validade de construto, incluindo diversas estratégias técnicas, a saber: a) evidências de validade da estrutura interna (por meio de Análise Fatorial Exploratória, Consistência Interna, Análise Fatorial Confirmatória, DIF e outros); b) evidências baseadas no processo de resposta ("relações entre os processos mentais ligados ao construto em causa e as respostas aos itens do instrumento” - Resolução CFP 002/2003, p. 21), ou seja, avalia as propostas explicativas dos processos mentais envolvidos na resposta aos itens do teste (recorrendo a estratégias da Teoria de Resposta aos Itens - TRI).

Pode-se observar, portanto, que a regularização dos instrumentos de avaliação psicológica no Brasil, realizada a partir dos requisitos mínimos propostos pela Resolução CFP 002/2003, era focada na definição mais clássica de validade, abarcando conteúdo, critério e construto, coerentemente com o modo como este conceito era compreendido e difundido no contexto brasileiro e já apresentado anteriormente (Fachel e Camey, 2000). Desde então, com o desenvolvimento e aprimoramento dos instrumentos de avaliação psicológica, o próprio conceito de validade pôde ser aprimorado, possibilitando melhores garantias científicas da utilização dos testes.

A American Psychological Association - APA (2000) também apresenta definições e orientações gerais sobre os procedimentos técnicos implicados na avaliação psicológica, incluindo detalhamento técnico sobre os índices psicométricos que os sustentam. Na verdade, estas diretrizes da APA foram consideradas no processo de elaboração das Resoluções do CFP a respeito dos testes psicológicos, estando ali incorporadas. Especificamente a respeito do conceito de validade, central neste presente projeto, a APA aponta que, para a validade de um teste psicológico ser demonstrada, são necessárias evidências científicas que: a) confirmem que o instrumento realmente mede, ou mensura, determinado construto; b) comprovem a existência de representatividade de conteúdo para os itens do teste, em relação aos escores obtidos; c) demonstrem a capacidade do método em predizer aspectos relevantes do comportamento em foco. Além disso, é realçada a necessidade de que os utilizadores destas técnicas sejam co-responsáveis pela obtenção de novas evidências de validade, mantendo-as sempre atualizadas.

Um dos desenvolvimentos mais importantes do conceito remete à conscientização de que não é o teste em si que apresenta evidências de validade, mas sim as interpretações decorrentes da utilização da técnica que podem ser válidas ou não, se utilizadas para o propósito a qual foram pesquisadas. Sendo assim, pode-se pensar em validade como a intensidade na qual as interpretações obtidas dos dados empíricos do instrumento de avaliação encontram sustentação em base científica sólida (Urbina, 2007). Assim, a validade passa a ser 
um conceito associado às interpretações realizadas com os dados obtidos pela utilização de determinada técnica. Neste contexto, a definição tripartite (conteúdo, critério e construto) foi reformulada, com a sistematização de novo modelo conceitual para compreender a validade, baseada em evidências empíricas, onde a validade de construto acaba por abranger os demais conceitos de validade (Primi, Muniz \& Nunes, 2009). Os diferentes tipos de evidências de validade passam a ser classificados em cinco categorias (Primi et al. 2009; Ambiel et al., 2011), a saber:

a) Evidências de validade baseadas no conteúdo: Este tipo de evidência advém da representatividade e abrangência dos itens do instrumento para cobrir um domínio ou construto que se pretende avaliar. Pode ser investigada por meio de análise lógica ou empírica dos itens, verificando se os mesmos representam adequadamente a teoria proposta para explicação do construto e se as interpretações propostas aos escores do instrumento parecem adequadas. A análise de especialistas na teoria, julgando se os itens do instrumento se mostram consistentes com os propósitos do instrumento, também pode ser considerada como evidência de validade baseada no conteúdo.

b) Evidências de validade baseadas no processo de resposta: Este tipo de evidência advém do levantamento de dados sobre os processos mentais envolvidos no processo de resposta/comportamento induzidos pelos estímulos do instrumento. De modo geral, este tipo de evidência busca evidenciar, por meio de modelos explicativos, aspectos da teoria subjacente ao instrumento de avaliação, sendo identificado por comparações entre padrões de respostas dos participantes em determinados itens diante da previsão proposta pelo modelo. Quanto maior a coerência entre as respostas empíricas e o modelo proposto, maior a confiança/validade do construto estudado. Outra maneira de se investigar esta fonte de validade seria a realização de entrevistas com os participantes da amostra, buscando identificar os processos mentais envolvidos na resolução do teste, ou a realização de estudos empíricos comparando como observadores/juízes registram e interpretam os dados oriundos da avaliação realizada, verificando-se a coerência destas observações com o construto proposto.

c) Evidências de validade baseadas na estrutura interna: Essa fonte de evidências baseia-se nos dados sobre a estrutura de correlações entre os itens relacionados a um mesmo construto psicológico, ou a algum aspecto em particular desse construto. São esperadas altas correlações entre itens relacionados ao mesmo construto/aspecto do construto. Desta maneira, busca-se garantir a coesão das informações e interpretações obtidas a partir do instrumento psicológico. Usualmente, para verificação empírica destas evidências, são utilizados procedimentos de 
análise fatorial e análise da consistência interna dos resultados do instrumento em amostras representativas e suficientemente grandes para permitir este tipo de análises.

d) Evidências de validade baseadas nas relações com variáveis externas: Procura-se verificar a relação entre dados levantados pelo instrumento e por outras variáveis externas e relevantes para à validade do método. Destacam-se como fontes de informação as pesquisas com outros instrumentos de avaliação que medem construtos semelhantes/iguais (evidência de validade convergente) ou distintos (evidência de validade divergente) e as investigações que envolvem critérios comportamentais relacionados ao construto avaliado pelo método. As investigações de critério podem envolver a aplicação do instrumento e observação do critério imediatamente ou em um curto espaço de tempo (evidência de validade concorrente) ou a aplicação do instrumento e a avaliação do critério após determinado espaço de tempo (evidência de validade preditiva).

e) Evidências de validade baseadas nas conseqüências da avaliação: estudam as conseqüências sócio-ambientais do uso do instrumento, averiguando se, de fato, sua utilização está atingindo os objetivos para os quais o método foi desenvolvido. Primi et al. (2009) ressaltam que esse tipo de evidência não se relaciona propriamente às características técnicas de construção do instrumento, mas sim ao modo como o mesmo é utilizado pelos psicólogos nos diferentes contextos para o qual foi criado. Examina-se, portanto, se o uso do instrumento em questão traz benefícios não só para os avaliadores, mas também para os indivíduos submetidos a eles submetidos.

Essa classificação das cinco diferentes fontes de evidência de validade passou a ser incorporada na análise dos requisitos mínimos dos testes psicológicos, realizada pelo SATEPSI, desde 2009 (Anexo 1 da Resolução CFP 002/2003). De modo geral, a ficha atual de avaliação dos instrumentos de avaliação psicológica é composta por três seções bastante amplas, que se referem à descrição geral do teste, aos requisitos técnicos (construto, validade, fidedignidade, etc) e análise dos requisitos mínimos, que sumariza as informações anteriores (Nunes \& Primi, 2010). Observa-se, portanto a preocupação crescente, por parte do Conselho Federal, em promover a melhoria dos instrumentos utilizados em avaliação psicológica no Brasil.

Estes esforços de aprimoramento técnico-cientifícos dos instrumentos de avaliação psicológica, contudo, só fazem sentido na medida em que fundamentam possibilidades de informações mais adequadas sobre diferentes aspectos do comportamento humano, objetivo maior da utilização destas técnicas nos mais variados contextos. No Brasil, a partir dos estímulos do CFP, houve melhorias nesta área, como apontam Souza Filho, Belo e Gouveia 
(2006). Segundo estes autores, o desenvolvimento e o avanço na utilização de técnicas de avaliação psicológica confundem-se com o desenvolvimento da Psicologia como Ciência e profissão no Brasil, uma vez que a pesquisa com instrumentos de avaliação realiza-se, prioritariamente, em centros universitários. Com a propagação da Psicologia na formação universitária (a partir da década de 1930) e criação dos cursos de graduação em Psicologia (a partir da década de 1960), o interesse pelas técnicas de avaliação psicológica foi aumentando, até a criação dos primeiros laboratórios preocupados com instrumentos de avaliação psicológica. Estes autores enfatizam, no entanto, que o aumento dos cursos de graduação em Psicologia não se desenvolveu paralelamente aos investimentos de pesquisa científica na área, deixando muito a desejar em suas demonstrações de qualidade técnica. Por fim, sinalizam a recente preocupação, principalmente a partir de 2000, relativa ao aperfeiçoamento das técnicas de investigação psicológica, incluindo-se a criação do SATEPSI (Sistema de Avaliação dos Testes Psicológicos), instância do CFP que avalia e acompanha a qualidade e o desenvolvimento dos instrumentos de avaliação psicológica utilizados no contexto brasileiro. Estas iniciativas têm estimulado maior investigação científica nesta área e grande reflexão sobre os processos de formação profissional do psicólogo, favorecendo aprimoramentos técnico-científicos, certamente úteis a todos os envolvidos numa avaliação psicológica, assegurando-lhe o devido rigor.

Periodicamente, o SATEPSI divulga uma lista com os instrumentos de avaliação aprovadas para uso no contexto brasileiro. Consultando-se a última lista do SATEPSI (Conselho Federal de Psicologia, 2011), atualizada em Julho de 2011, encontram-se, seis métodos prioritariamente voltados para utilização em processos de Orientação Profissional/Vocacional: AIP - Avaliação dos Interesses Profissionais (Levenfus \& Bandeira, 2009), BBT-Br - Teste de Fotos de Profissões, formas Masculina e Feminina (Jacquemin, 2000; Jacquemin et al., 2006), EMEP - Escala de Maturidade para a Escolha Profissional (Neiva, 1999), EAP - Escala de Aconselhamento Profissional (Noronha, Sisto \& Santos, 2007), IAO - Inventário de Avaliação Ocupacional, (submetido à avaliação por Eugênia Matilde Peixoto Sofal), e SDS - Questionário de Busca Auto-dirigida (Primi, et al., 2010). Apesar de já atenderem aos requisitos psicométricos mínimos preconizados internacionalmente, a atualização destes instrumentos de avaliação psicológica, com a realização de novas pesquisas visando seu aprimoramento, deve ser realizada constantemente. É nessa direção que se volta o presente trabalho, focalizando o Teste de Fotos de Profissões BBT-Br. 


\subsection{O Teste de Fotos de Profissões (BBT-Br)}

O BBT-Br constitui-se num método projetivo de avaliação psicológica elaborado por Martin Achtnich na década de 1970, na Suíça (Achtnich, 1991). Sua base teórica, originada nos princípios da Teoria de Personalidade de Szondi (1975), admite a existência de variáveis que influenciam e compõem os interesses e as escolhas humanas, determinados pelas estruturas de inclinação motivacional e personalidade de cada indivíduo. Estas variáveis se combinariam de diferentes maneiras em cada pessoa, interferindo e orientando suas escolhas ocupacionais. Este instrumento apresenta amplas possibilidades de utilização nos processos de orientação profissional e recolocação de carreira, por ser capaz de investigar dados relevantes acerca da personalidade e dos interesses do orientando (Melo-Silva \& Jacquemin, 2001).

Com base nestes princípios e em sua vasta experiência clínica e empírica com Orientação Profissional, Achtnich (1991) desenvolveu o Teste de Fotos de Profissões, originalmente Berufsbilder Test, de onde advém sua sigla BBT. Seu autor elaborou princípios teóricos para classificar e avaliar interesses, expressos em estruturas de inclinação motivacional, pautadas por uma combinação de oito fatores (chamados dimensões ou radicais de inclinação). Segundo o autor, esses oito radicais de inclinação existiriam em proporções variáveis em cada indivíduo e seriam justamente as intensidades de prevalência de determinados fatores que influenciariam, internamente, o comportamento de escolha profissional para busca de satisfação de determinadas necessidades psíquicas.

A manifestação dessas necessidades ocorre na forma de interesses por atividades e por determinados ambientes dentro do mundo real, favorecendo seleção específica de contatos com determinados instrumentos e objetos, com objetivos delineados pelas motivações internas. Desta forma, para Achtnich (1991), uma atividade profissional pode ser descrita por cinco aspectos fundamentais: as atividades que permite exercer; os instrumentos utilizados em seu exercício; os objetos sobre os quais se trabalha; os locais onde a atividade é exercida e os objetivos que se pretende alcançar.

A estrutura motivacional (de preferências e de rejeições) seria composta por uma combinação específica dos oito radicais de inclinação motivacional propostos por Achtnich (1991). Estes radicais passam a ser, resumidamente, descritos, de modo a fundamentar seus significados gerais em termos de motivações e de interesses implícitos.

- Fator W: relativo a atividades relacionadas ao toque, à sensibilidade, à necessidade de estar em contato com outras pessoas de forma amável e afetuosa. O indivíduo sinaliza preferência 
por trabalhar com objetos suaves, o tato, a água, artigos de higiene e outros desta natureza. Seu ambiente de trabalho caracteriza-se por apresentar possibilidades de contato, relacionados principalmente a servir e a cuidar diretamente das pessoas. Achtnich (1991) relaciona o fator W à feminilidade.

- Fator K: relacionado às atividades que envolvem utilização de força física, agressividade, perseverança, objetividade, domínio sobre os outros. Utiliza prioritariamente objetos resistentes (metal, aço, ferro, entre outros), objetos a demolir, o próprio adversário dominado. Seu ambiente de trabalho apresenta estes elementos agressivos e rudes. Relacionado por Achtnich (1991) à masculinidade.

- Fator S: relativo a necessidade de atuar em atividades sociais. É subdividido em duas vertentes: $\underline{\text { Sh }}$ e $\underline{\mathrm{Se}}$. A vertente $\underline{\mathrm{Sh}}$ relaciona-se ao interesse em cuidar, ajudar o outro. Utiliza prioritariamente objetos relacionados ao salvamento ou à cura. Seu ambiente favorece ações de ajuda. Já a vertente $\underline{S e}$ é referente ao interesse em atividades que envolvam movimento, mudança, liderança. Relaciona-se à energia psíquica, ao dinamismo. Utiliza prioritariamente objetos que envolvam dificuldades, impondo desafios e decisões rápidas. Seu ambiente favorece a mudança e o inesperado.

- Fator Z: relacionado à necessidade de mostrar a si ou a sua obra, de ser valorizado e apreciar o que é esteticamente belo. Utiliza prioritariamente objetos relacionados a formas estéticas e embelezamento; objetos que possam ser exibidos e aprovados. Seu ambiente favorece a exposição de si ou de seu trabalho.

- Fator V: relativo à necessidade de objetividade, da razão, do senso de realidade, da precisão. Utiliza prioritariamente objetos relacionados a números, registros, regras, planejamento. Seu ambiente de trabalho envolve geralmente espaços fechados (escritórios, laboratório, por exemplo), onde existe boa organização dos elementos que o compõem, de forma lógica e prática.

- Fator G: relaciona-se a atividades que envolvem imaginação, intuição, criatividade, pesquisa. Utiliza prioritariamente objetos facilitadores do exercício da criatividade, inesperado, originalidade e espontaneidade. Seu ambiente de trabalho abarca geralmente locais fechados (laboratório, ateliê, escritórios, entre outros), mas que também envolva contato interpessoal para o desenvolvimento de raciocínio abstrato e busca de conhecimentos.

- Fator M: relativo a necessidade de trabalhar com matérias (substancias químicas, dinheiro, terra, limpeza), de modo constante e persistente, atividades rotineiras e busca pelo passado. Utiliza prioritariamente objetos relacionados à matéria bruta em si: terra, barro, argila, produtos de limpeza, dinheiro. Seu ambiente de trabalho envolve geralmente situações em que 
se necessita de limpeza, asseio, constância, meticulosidade; ou locais que envolvam o manuseio de substâncias, como a terra.

- Fator O: relativo a necessidade de atuar oralmente, dividido em duas vertentes: Or e $\underline{\text { On}}$. A

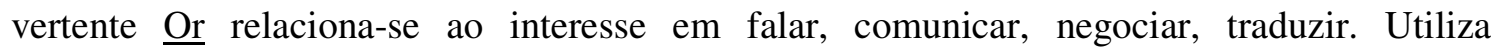
prioritariamente objetos que permitam amplo contato social, com possibilidades de comunicação oral. Atua em ambientes favorecedores do contato social. Já a vertente $\underline{\text { On }}$ representa o interesse em alimentar, nutrir, cozinhar. Utiliza prioritariamente objetos relacionados à nutrição (bebidas, comidas) quanto relacionados a descanso e bem-estar. Atua geralmente em locais de preparação de alimentos ou que favoreçam o contato com o outro por meio da alimentação.

O Teste de Fotos de Profissões (BBT) busca "clarificar tendências inconscientes que direcionam ou bloqueiam a escolha de certas áreas profissionais e favorecer a busca de informações sobre o mundo das profissões” (Noce, 2008, p. 115). É um instrumento eficiente para uso em processos de Orientação Profissional/Vocacional (Jacquemin \& Pasian, 1991).

Uma das primeiras tentativas de adaptar o BBT para outro país foi realizada por Foulon (1981), com um estudo de validade de conteúdo na Bélgica. Para tanto, as fotos do BBT foram apresentadas para 10 moças e 10 rapazes, estudantes do ensino médio, com idades entre 16 e 19 anos. Foi solicitado que cada um deles descrevesse as 96 fotos do instrumento. As 1920 descrições (20 para cada uma das 96 fotos) foram entregues a três juízes independentes, que deveriam interpretar e codificá-las de acordo com os oito radicais de inclinação de Achtnich (1991), confirmando se as fotos de fato representavam o radical a elas associado teoricamente. Os resultados confirmaram o radical de inclinação primário para 40 das 96 fotos do BBT para o contexto belga, confirmando a necessidade de adaptação do instrumento para contextos socioeconômicos diferentes do contexto original, na Suíça.

Também na Bélgica, Lievyns (1987) realizou estudo onde aplicou a versão masculina do BBT em 506 estudantes (289 moças e 217 rapazes), com idades entre 17 e 24 anos. Esses estudantes eram clientes do serviço de Orientação Profissional/Vocacional (OPV) e Reorientação Profissional da Université Catholique de Louvain, sendo a amostra dividida em quatro grupos (mulheres em OPV, mulheres em re-orientação, homens em OPV e homens em re-orientação). A autora buscou averiguar evidências de validade interna e consistência interna das fotos do BBT em seu contexto sócio-cultural. Para a avaliação da validade interna, esta autora considerou que deveria ocorrer uma correlação positiva significativa entre a foto e o radical de inclinação de Achtnich (1991), utilizando-se a correlação de Pearson, com índice de corte 0,20. Já para avaliar a consistência interna, foi realizado o teste de Kuder Richardson. 
Os resultados apontaram correlações de 0,26 a 0,87, na amostra masculina, e 0,16 a 0,76 , na amostra feminina. Em relação à consistência interna, os índices variaram de 0,69 até 0,89 para a amostra masculina, e 0,59 a 0,71 para a amostra feminina. Ambos os resultados foram considerados, pela autora, como bons índices de validade e fidedignidade do BBT no contexto sócio-cultural estudado.

Em Portugal, Leitão (1993) estudou evidências de validade preditiva e de conteúdo do BBT. Para tanto, aplicou este método projetivo de avaliação psicológica, individualmente, em 40 adolescentes (20 homens e 20 mulheres), com idades entre 14 e 15 anos. Os dados obtidos foram analisados por quatro juízes independentes, seguindo a tabela de profissões de Achtnich (1991). Os resultados apontaram alto índice de acordo entre os juízes (92,0\% nos dados femininos e 87,3\% nos dados masculinos) e a confirmação do radical de inclinação primário em 53 fotos da versão feminina e 52 fotos da versão masculina. Diante destes resultados, a autora apontou a necessidade de adaptação deste instrumento de avaliação psicológica aos contextos sócio-culturais onde seria utilizado, incluindo Portugal.

No Brasil, a implantação do BBT foi realizada por Jacquemin (1982), que iniciou as pesquisas de validação e adaptação do método para o contexto brasileiro. Em artigo sobre o histórico e pesquisas desenvolvidas com o BBT no Brasil, Pasian et al. (2007) descreveram sucintamente as pesquisas nacionais com este instrumento, publicadas até o momento, sugerindo novas áreas de investigação com este método projetivo. Dentre estas pesquisas, destacaremos as que envolveram questões de validação do instrumento e que são mais recentes, por se tratar do foco deste trabalho, apresentadas em sequência cronológica a seguir.

Jacquemin (1989) pesquisou a validade interna do BBT masculino realizando sua aplicação individual em 80 alunos, de ambos os sexos, da segunda e terceira séries do ensino médio de Ribeirão Preto (SP). Os resultados apontaram que as descrições das fotos realizadas pelos participantes confirmavam o radical de inclinação proposto em cerca de metade das fotos. Também analisando a validade interna do BBT, dessa vez da forma feminina, Jacquemin e Nunes (1990) aplicaram o instrumento em 40 alunas do ensino médio de Ribeirão Preto (SP). As descrições dadas pelas participantes também indicaram a necessidade de reformulação de algumas fotos deste método projetivo, visando manter o radical de inclinação proposto teoricamente por Achtnich (1991).

Confirmada a necessidade de reformulação das fotos, foram realizados novos estudos visando a adequação das fotos ao contexto brasileiro. Dessa maneira, foram reformuladas 42 fotos do BBT Masculino e 47 do BBT Feminino e aplicadas em estudantes brasileiros (Jacquemin, 1995; Jacquemin et al., 1998, Jacquemin, 2000; Jacquemin et al., 2000; 
Jacquemin et al., 2001; Jacquemin et al., 2003; Okino et al., 2003). Esses pesquisas deram origem aos manuais do BBT adaptados para o contexto brasileiro, agora renomeado como BBT-Br, Jacquemin (2000 - forma Masculina) e Jacquemin et al. (2006 - forma Feminina).

Sbarderlini (1997) investigou o BBT como instrumento de re-opção de curso universitário e a capacidade preditiva da técnica na adaptação à nova escolha profissional. Para tanto, a autora entrevistou 299 universitários que haviam solicitado re-opção de curso em uma universidade federal brasileira, aplicando o BBT individualmente em 19 desses participantes. A análise das estruturas de inclinação motivacional permitiu à autora investigar a concordância ou não do perfil motivacional dos participantes em relação ao curso em que se encontravam, elaborando diagnósticos favoráveis ou desfavoráveis a respeito da satisfação das necessidades profissionais no novo curso solicitado. Cerca de dois anos depois da primeira aplicação, os participantes do estudo foram procurados novamente e questionados sobre sua situação no curso universitário de reopção, constatando-se que $90 \%$ dos casos confirmaram o diagnóstico realizado por meio do BBT, fortalecendo o caráter preditivo desse método projetivo.

Em outro trabalho sobre a validade do BBT, Bernardes (2000) investigou, por meio de estudo longitudinal, a validade preditiva do instrumento como prognóstico de escolhas profissionais. Neste estudo, a autora aplicou, em um primeiro momento, o BBT em um grupo de dez adolescentes, com idades entre 16 e 20 anos, do terceiro ano do ensino médio. Após aproximadamente três anos, ocorreu a segunda aplicação do instrumento, juntamente com um questionário e realização de uma entrevista clínica, visando obter relatos de vida e de interesses ocupacionais. Os dados possibilitaram levantar informações bastante positivas acerca da eficiência do BBT como instrumento prognóstico.

Noce (2003) realizou trabalho visando agilizar os procedimentos de aplicação e interpretação do BBT-Br masculino, mantendo a validade e qualidade das informações adquiridas. Elaborou uma versão reduzida da técnica, totalizando 64 fotos e igualando o total de fotos (oito) para cada radical de inclinação de Achtnich (1991). Segundo essa autora, as 16 fotos representativas dos radicais de inclinação $\mathrm{S}, \mathrm{Z}, \mathrm{V}$ e $\mathrm{G}$ poderiam ser reduzidas a oito fotos cada, eliminando a necessidade de ponderação e diminuindo consideravelmente o tempo de utilização e interpretação do BBT-Br, uma vez que esse número discrepante de fotos nestes fatores acrescenta poucos elementos relevantes à interpretação. Para realizar a redução das fotos foram utilizados dois critérios de seleção: proporção de escolhas e rejeições na amostra de normatização do BBT-Br e análise por juízes independentes. Pela análise desses critérios, a autora selecionou as oito fotos mais representativas dos radicais de inclinação $\mathrm{S}, \mathrm{Z}, \mathrm{V}$ e $\mathrm{G}$, 
elaborando a versão reduzida da técnica, para a qual foram elaborados padrões normativos pela aplicação coletiva em 345 estudantes do ensino médio da região de Ribeirão Preto. Finalmente, a autora comparou sua versão reduzida com o BBT-Br masculino original, aplicando ambas as técnicas em 33 jovens estudantes do ensino médio público de Ribeirão Preto. Os resultados apontaram aparente equivalência entre as duas versões da técnica, indicando a possibilidade da aplicação da versão reduzida do BBT-Br, com resultados válidos e confiáveis, sendo sugeridos também, a realização de estudos para a elaboração de versão reduzida da forma feminina deste método de avaliação psicológica. Entretanto, a autora ressalta a importância da continuidade de estudos que avaliem e aprimorem não só o BBT-Br, mas também os demais instrumentos de avaliação psicológica para buscar o atendimento da diversidade sócio-cultural existente na realidade do Brasil.

Pode-se observar que esforços vêm sendo empreendidos na adaptação e na validação do BBT-Br para o contexto sócio-cultural brasileiro. Estas pesquisas realizadas com o instrumento buscaram aumentar seu rigor científico, garantindo-lhe confiabilidade e eficiência em sua utilização clínica. É importante destacar, também, que a utilização do BBT-Br deve ser agregada a outras técnicas de avaliação psicológica, de modo a alargar o campo observacional relativo a inferências sobre o comportamento humano e seus construtos internos, foco a seguir explorado brevemente.

\subsection{BBT-Br em associações a outros métodos de avaliação psicológica}

As ricas e diversificadas possibilidades interpretativas do BBT, propostas por Achtnich (1991), permitem sua utilização conjunta com outros instrumentos de avaliação psicológica. Neste sentido, algumas investigações dirigidas para a busca de evidências de validade tem sido realizadas com o BBT-Br, tanto para tentar embasar hipóteses interpretativas de Achtnich (1991), quanto para examinar a convergência de seus resultados diante de dados de outros instrumentos de avaliação psicológica, com destaque para aqueles também utilizados no campo da Orientação Vocacional/Profissional. São apresentados, a seguir, alguns desses estudos, ordenados cronologicamente, mas também organizados por temas investigados (e neste caso, podendo interferir na sequência cronológica da apresentação das pesquisas).

Jardim-Maran (2004), em Dissertação de Mestrado posteriormente publicada por Pasian e Jardim-Maran (1008), analisou possíveis associações entre o Questionário 
Desiderativo e o BBT-Br, aplicando os dois instrumentos de avaliação psicológica em 60 estudantes da terceira série do ensino médio em escolas públicas e particulares do interior paulista. Por meio da sistematização de indicadores de natureza qualitativa dos resultados, foi possível identificar relações entre os radicais de inclinação motivacional mais escolhidos e mais rejeitados no $\mathrm{BBT}-\mathrm{Br}$ com os mecanismos de defesa/conteúdos rejeitados do Questionário Desiderativo. Também foram encontradas diferenças em alguns elementos funcionais da psicodinâmica dos estudantes em função do sexo e origem escolar, indicando possíveis fatores de influência do contexto sócio-cultural no desenvolvimento psíquico dos adolescentes. A autora destaca os benefícios da utilização conjunta do BBT-Br e Questionário Desiderativo como forma promissora para melhor compreender os estudantes em seu processo de escolha profissional. Ressalta-se aqui, no entanto, que o Questionário Desiderativo, até o presente momento, encontra-se com parecer desfavorável para uso profissional, segundo análise do Conselho Federal de Psicologia (2011), exigindo novas evidências de pesquisa no Brasil. No entanto, para o trabalho de investigação científica, mostra-se um instrumento promissor para obtenção de informações sobre a dinâmica psíquica dos indivíduos, com bons indicadores de validade clínica (apontados, por exemplo, em Guimarães, Pasian \& Loureiro, 2008).

Por sua vez, Welter (2007) estudou evidências de validade do HumanGuide (HG) no contexto brasileiro recorrendo à correlação de seus resultados com dados do BBT-Br e do 16PF - Questionário dos 16 Fatores de Personalidade (Russell \& Karol, 2002). Destaca-se que o HG é um instrumento que busca identificar características de personalidade a partir das estruturas pulsionais do indivíduo, tendo como base teórica a Teoria do Destino de Szondi (1975), tal qual o BBT. A referida pesquisa foi realizada via internet, com a aplicação do HG em 815 profissionais (397 mulheres e 418 homens) e posterior aplicação coletiva do BBT-Br e 16PF em 87 participantes (52 mulheres e 35 homens), visando os estudos de correlação. Especificamente em relação ao BBT-Br, foram encontradas correlações significativas entre cinco radicais de inclinação de Achtnich e cinco dimensões do HumanGuide. A autora aponta os resultados como significativos da validade e utilização do HumanGuide no contexto brasileiro, reforçando a necessidade de novos estudos com instrumentos de avaliação de interesses.

Bordão-Alves (2008) examinou as possíveis relações entre interesses e inclinações profissionais com aspectos da personalidade, estudando a validade concorrente entre o BBTBr e as Escalas de Personalidade Comrey - CPS (Costa, 2003). Foram realizadas aplicações coletivas do CPS com posterior aplicação individual do BBT-Br, formas feminina e 
masculina, em 107 estudantes do ensino médio de escola particular de Ribeirão Preto (SP), de ambos os sexos. Os resultados apontaram moderadas correlações entre os oito radicais de inclinação do BBT-Br e as escalas do CPS, com evidências de que características de personalidade interferem nos interesses profissionais, mas não de modo linear, sofrendo possíveis influências decorrentes do contexto social, entre outros fatores a serem devidamente considerados nas análises interpretativas de cada caso, buscando compreender sua singularidade.

Noce (2008) buscou examinar as possibilidades informativas de algumas variáveis de natureza quantitativa e qualitativa do BBT-Br em relação ao nível de maturidade para escolha profissional, utilizando como critério os resultados da Escala de Maturidade para a Escolha Profissional - EMEP (Neiva, 1999). Para tanto, avaliou 93 estudantes, de ambos os sexos, do terceiro ano do ensino médio de uma escola pública de Ribeirão Preto (SP). A partir de resultados da aplicação coletiva da EMEP, a pesquisadora dividiu os 93 estudantes em um grupo com alta maturidade (GA), com 55 estudantes, e um grupo com baixa maturidade (GB), com 38 alunos. Procederam-se, então, as aplicações individuais do BBT-Br, comparando-se os resultados dos grupos, em função do sexo, por meio de análises estatísticas inferenciais (Teste Mann-Whitney com p<0,05). As comparações entre os resultados de GA e de GB no BBT-Br sinalizaram que o grupo de alta maturidade (GA), ou seja, que havia apresentado maiores escores na EMEP, sinalizaram maior abertura para diferentes possibilidades profissionais, selecionando mais fotos positivas e rejeitando menos fotos, em relação ao grupo de baixa maturidade (GB). Esses achados foram interpretados como confirmações empíricas de que os índices de produtividade do BBT-Br se alteram em relação ao nível de maturidade do respondente, como proposto por Achtnich (1991). Em vista destes resultados, a autora levanta a hipótese de que os jovens com maior maturidade tendem a se manter mais abertos a diferentes interesses, podendo realizar a escolha profissional com base em mais informações e conhecimentos, ou seja, realizando um comportamento exploratório mais amplo, mais completo e profundo. Ao contrário, jovens mais imaturos tenderam a restringir seus interesses, "facilitando" sua escolha pela seleção de um campo menor de atividades como opções para a escolha profissional.

Recentemente, estes achados acerca da relação entre nível de maturidade para escolha profissional e resultados no BBT-Br foram corroboradas pelos estudos de Junqueira (2010) e Shimada (2011). Essas duas autoras analisaram, respectivamente, resultados da EMEP e do BBT-Br de amostras de jovens que procuraram um serviço institucional de intervenção em Orientação Vocacional/Profissional. Os resultados de ambas indicaram que estas amostras 
clínicas apresentaram indicadores de menor maturidade geral na EMEP e menores índices de produtividade no BBT-Br. Considerando esses resultados, foi levantada a hipótese de que jovens que procuram um serviço de Orientação Vocacional/Profissional tendem a apresentar baixa maturidade para a escolha profissional, o que acaba por dificultar e limitar seus horizontes de escolha de carreira, decorrendo, provavelmente deste processo, a busca da intervenção de ajuda.

Especificamente ao trabalho de Shimada (2011), cabe um destaque especial, na medida em que conseguiu reunir importantes evidências de validade atual do BBT-Br. Essa autora investigou a estrutura de interesses profissionais de 532 jovens, mulheres e homens, que procuraram um serviço institucional de Orientação Vocacional/Profissional de Ribeirão Preto, interior do estado de São Paulo, no período entre 2003 a 2008, com idades entre 14 e 21 anos, sendo submetidos ao BBT-Br durante o processo de orientação. O estudo apresentou detalhamento sociográfico desses jovens e comparou, a partir dos dados do BBT-Br, as estruturas de interesse motivacional deste grupo clínico com as normas disponíveis para esse instrumento de avaliação psicológica (Jacquemin, 2000 e Jacquemin et al., 2006) e também com os resultados de estudantes de $3^{\mathrm{a}}$ série do ensino médio do Doutorado de Okino (2009), representando um grupo não-clínico mais atual de mesma escolaridade. Os resultados apontaram semelhanças nas estruturas de inclinação da amostra de Shimada (2011) e os dados normativos, mas com reduzido número de escolhas positivas por parte do grupo clínico em relação ao grupo normativo de Okino (2009). Esses dados corroboraram a hipótese de menor maturidade para escolha profissional por parte dos adolescentes que procuram o serviço de Orientação Profissional. Neste sentido, Shimada (2011) destaca a importância da utilização do BBT-Br como instrumento clarificador de interesses profissionais durante processos de Orientação Vocacional/Profissional. A pesquisadora destacou que dados do BBT-Br mostraram-se relevantes e úteis para o próprio planejamento da intervenção em Orientação Profissional, como, por exemplo, aumentar o foco em apresentar informações profissionais e desenvolver o comportamento exploratório dos orientandos, possibilitando a realização de escolhas profissionais mais maduras e conscientes. Pode-se pensar, portanto, que este estudo conseguiu reunir evidências de validade conseqüencial do BBT-Br, uma vez que este instrumento se mostrou auxiliar na compreensão de necessidades específicas dos orientandos, possibilitando a identificação de variáveis a serem focalizadas em intervenções em processos de Orientação Profissional.

Ao focalizar a pesquisa de evidências empíricas de validade de construto convergente / discriminante e validade de critério para a Escala de Aconselhamento Profissional - EAP 
(Noronha et al., 2007), Otatti (2009) buscou relacionar resultados desta escala com aqueles encontrados por meio do BBT-Br. Esta escala EAP é um instrumento de avaliação psicológica de auto-relato, com formato de escala do tipo Likert, e que avalia interesses por meio da elaboração de perfis profissionais. Para a realização do estudo, a pesquisadora aplicou o EAP e o BBT-Br na forma coletiva, em 196 estudantes, de ambos os sexos, do quinto ao sétimo semestres dos cursos de Ciência da Computação, Pedagogia e Odontologia de uma universidade particular da região de Campinas (SP). Ressalta-se que foram utilizadas as duas formas do BBT-Br, forma Feminina e forma Masculina, dividindo-se a amostra no momento da aplicação. Os resultados apontaram coeficientes de Correlação de Pearson significativos, variando de 0,31 a 0,53, entre as dimensões do EAP e os radicais de inclinação do BBT-Br. Especificamente, foram encontradas correlações entre os radicais V e G e a dimensão Ciências Exatas; entre os radicais Z, G e S e a dimensão Artes e Comunicação; entre os radicais $S$ e G e a dimensão Ciências Biológicas e da Saúde; entre os radicais $S, G, M, V, Z$, $\mathrm{O}$ e W e a dimensão Ciências Agrárias e Ambientais; entre os radicais V, G e Z e a dimensão Atividades Burocráticas; entre os radicais Z, V, G, S e M e a dimensão Ciências Humanas e Sociais Aplicadas; e a dimensão Entretenimento não apresentou correlações maiores que 0,30 com nenhum radical. Esses resultados foram considerados pela autora como bons indicadores de convergência entre os dois instrumentos de avaliação psicológica. Foram identificadas especificidades nos resultados, nos dois instrumentos usados, dos alunos de diferentes cursos de graduação, evidenciando a validade de critério destes métodos de avaliação de interesses, além de diferenças nos interesses profissionais por gênero.

Okino (2009), por sua vez, investigou evidências de validade do BBT-Br recorrendo ao método de validação convergente com o SDS - Questionário de Busca Auto-dirigida (Primi et al., 2010). Este último instrumento é uma adaptação brasileira do SDS - Self-DirectSearch Form CE (Carrer Explorer) de Holland e Powell (1994a; 1994b), método de avaliação de interesses baseado na teoria da Personalidade Vocacional proposta por Holland (1963).

Na concepção teórica de Holland (1963) os interesses profissionais são, na verdade, formas de expressão da personalidade, podendo ser agrupados em seis grandes dimensões obtidas por meio da análise fatorial: Realista (R), Investigador (I), Artístico (A), Social (S), Empreendedor (E) e Convencional (C), conhecidos pelo acrônimo RIASEC (Holland, 1997). Os três primeiros tipos, RIA, caracterizam indivíduos com menos pendor para interações sociais, já os três últimos, SEC, referem-se a pessoas com maior interesse em contatos interpessoais. O Tipo Realista caracteriza-se pelo pensamento prático, pelo conservadorismo, e prefere atividades de força física, atividades mais concretas. O Tipo Investigador prefere a 
reflexão e investigação, a persistência na resolução de problemas, a exploração intelectual, o pensar antes de agir. O Tipo Artístico utiliza-se da expressão criativa de idéias, da emoção e intuição. O Tipo Social apresenta maior senso social, interessando-se por relações sociais e interpessoais de ajuda, apresentando boa capacidade verbal e necessitando de muita interação social. O Tipo Empreendedor caracteriza pessoas mais dinâmicas, aventureiras, com habilidades de persuasão e liderança, preferindo atividades que impliquem em relações de dominância sobre os demais. Por fim, o Tipo Convencional refere-se a pessoas mais organizadas, com interesse pelo acúmulo de bens e posição social, preferindo atividades mais estruturadas e ordeiras.

Composto a partir dessa concepção teórica, o SDS constitui-se como um inventário de interesses em forma de questionário simples (sim e não), apresentando quatro agrupamentos de itens referentes a atividades, competências, carreiras e habilidades. No caso da última sessão (habilidades), é solicitado que o indivíduo se auto-avalie por meio de uma nota de 1 a 7 (sendo 1 o valor mais baixo), em diferentes habilidades, por exemplo, habilidade mecânica ou habilidade musical. Ao final da aplicação, o próprio indivíduo faz a soma de suas respostas em cada tipo do RIASEC, encontrando seus dois tipos principais (os mais elevados em valor total). O manual brasileiro do SDS (Primi et al., 2010) apresenta dados de validade fatorial, validade por correlação com outros instrumentos de avaliação e resultados relativos à precisão. São referidos ainda estudos que utilizaram e testaram o SDS no contexto brasileiro, tais como Mansão (2005), que realizou estudos de precisão e validade com o SDS; Primi, Moggi e Castellato (2004), que fizeram estudo de correlação entre o SDS e o Inventário Fatorial de Personalidade - IFP (Pasquali, Azevedo \& Ghesti, 1997); e Sartori (2007), com um estudo de correlação entre o SDS e o EAP.

Compreendidas as características gerais do SDS, pode-se retomar e descrever, com maior detalhamento, a pesquisa desenvolvida por Okino (2009), de modo a embasar suficientemente o presente trabalho. Esta referida pesquisadora avaliou 497 estudantes, entre 16 e 19 anos, do terceiro ano do ensino médio de uma escola pública de Ribeirão Preto (SP). O BBT-Br e o SDS foram aplicados coletivamente na mesma sessão, em ambiente escolar. Foram utilizadas as formas masculina e feminina do BBT-Br, respectivamente para cada sexo. A partir dos dados coletados, foram realizadas, dentre outras explorações dos resultados, a análise dos componentes principais (análise fatorial) e as análises de correlação entre o BBT$\mathrm{Br}$ e o SDS. Os resultados apontaram a existência de uma estrutura fatorial no BBT-Br que não era totalmente compatível com os oito radicais de inclinação motivacional de Achtnich (1991). Por outro lado, foram encontradas correlações positivas com o SDS, fortalecendo as 
hipóteses interpretativas do BBT-Br. Para os estudantes do sexo masculino, foram encontradas correlações acima de 0,30 entre o tipo Realista e os radicais de inclinação K, S, $\mathrm{V}$ e $\mathrm{M}$, sendo a mais alta com o radical $\mathrm{K}$; o tipo Intelectual apresentou correlações com os tipos G e V; o tipo Artístico apresentou correlações com os radicais Z e G; o tipo Social apresentou correlações com os radicais de inclinação G, W, S, Z, O e M, sendo as maiores com os radicais G, W e S; o tipo Empreendedor apresentou correlações com os radicais $\mathrm{O}$ e V; por fim, o tipo Convencional apresentou correlação significativa com o radical V. Já as correlações encontradas com os participantes do sexo feminino foram entre o tipo Realista e os radicais $\mathrm{K}, \mathrm{V}, \mathrm{Z}, \mathrm{M}$ e $\mathrm{G}$, sendo a maior correlação com o radical $\mathrm{K}$; entre o tipo Investigativo e os radicais $\mathrm{G}, \mathrm{V}$ e $\mathrm{M}$; entre o tipo Artístico e os radicais $\mathrm{Z}$ e $\mathrm{G}$; entre o tipo Social e os radicais de inclinação S, G e O; entre o tipo Empreendedor e os radicais V e Z; e entre o tipo Convencional e o radical de inclinação V. Segundo a autora, esses resultados reforçam os indicadores positivos de validade do BBT-Br no contexto brasileiro.

Cabe destacar, também, a realização de trabalho conjunto de investigação científica no Brasil e em Portugal, com estudos de validação e precisão do BBT-Br e SDS para amostras nesses dois países (Okino \& Pasian, 2008; Noce \& Melo-Silva, 2009; Okino, 2009; Pasian \& Okino, 2009; Teixeira, Figueiredo \& Janeiro, 2009). Esses trabalhos foram desenvolvidos pela cooperação entre o Centro de Pesquisas em Psicodiagnóstico (CPP) do Departamento de Psicologia e Educação da FFCLRP - USP, o Centro de Investigação em Psicologia da Faculdade de Psicologia da Universidade de Lisboa e o Laboratório de Avaliação Psicológica e Educacional (LabAPE) da Universidade São Francisco. Os resultados encontrados oferecem bons subsídios para as qualidades psicométricas desses instrumentos na avaliação de interesses profissionais de adolescentes nos dois países, alargando as possibilidades de sua aplicação clínica e em processos de Orientação Vocacional / Profissional.

Essas pesquisas com o Teste de Fotos de Profissões (BBT) demonstraram adequados índices técnicos, subsidiando o uso responsável e ético deste instrumento projetivo no contexto brasileiro. No entanto, a constante atualização de normas e estudos de validade fazem-se sempre necessários, visando melhorar sua qualidade e aperfeiçoar seu uso. Dentro deste contexto é que o presente trabalho busca investigar evidências empíricas de precisão e validade fatorial do $\mathrm{BBT}-\mathrm{Br}$, verificando a adequação deste instrumento ao contexto brasileiro, sobretudo em termos de demonstração do caráter estrutural dos interesses, conforme pressuposto por Achtnich (1991). 


\section{OBJETIVOS}

\section{1. Geral:}

O presente estudo tem como objetivo geral elaborar novos referenciais normativos do Teste de Fotos de Profissões (BBT-Br), em suas versões masculina e feminina, bem como verificar suas evidências empíricas de precisão e de validade, ou seja, atualizar dados relativos a suas características psicométricas.

\section{2. Específicos:}

$\checkmark$ Elaborar referenciais normativos do BBT-Br, formas feminina e masculina, embasado em banco integrado de dados, compilado no presente trabalho a partir de estudos prévios.

$\checkmark$ Examinar eventual efeito da série acadêmica ( $1^{\mathrm{a}}, 2^{\mathrm{a}}$ e $3^{\mathrm{a}}$ séries) e da origem escolar (escolas particulares e públicas) nos indicadores técnicos das versões feminina e masculina do BBT-Br.

$\checkmark$ Realizar análise fatorial exploratória das versões masculina e feminina do BBT-Br, por meio da Principal Axis Factoring (PAF).

$\checkmark$ Verificar os coeficientes de precisão dos radicais de inclinação de Achtnich (1991) das versões masculina e feminina do BBT-Br, por meio da análise da consistência interna (Alfa de Cronbach), bem como das fotos agrupadas na extração de seis fatores para ambas as versões do BBT-Br. 


\section{MÉTODO}

\subsection{Amostra}

No presente trabalho foram tomados para análise os protocolos das versões feminina e masculina do BBT-Br existentes num banco de dados específico, disponível no Centro de Pesquisas em Psicodiagnóstico do Departamento de Psicologia e Educação da Faculdade de Filosofia, Ciências e Letras de Ribeirão Preto da USP, sob coordenação da Profa. Dra. Sonia Regina Pasian, orientadora deste projeto. Os casos que compõem o referido banco de dados referem-se aos estudos normativos originais do BBT-Br no Brasil, publicados por Jacquemin (2000) e Jacquemin et al. (2006); ao estudo de Noce (2008) e ao trabalho de Okino (2009). Cabe apontar que os dois últimos estudos representam as evidências mais atuais disponíveis a respeito dos parâmetros de resposta a este método projetivo de avaliação psicológica. Estes dados foram coletados dentro de todas as especificações éticas. Os pesquisadores responsáveis por estes trabalhos prévios estavam cientes e de acordo com a presente proposta de investigação científica.

Para alcance dos objetivos propostos, foram utilizados, dentre os protocolos de BBT-Br das pesquisas citadas (que envolvem diferentes faixas etárias), apenas os referentes aos adolescentes do Ensino Médio (primeira até terceira séries), com idades entre 14 e 19 anos, objetivando-se concentrar a amostra no padrão de desenvolvimento típico deste nível de ensino do sistema educacional brasileiro. Além disso, o próprio BBT-Br tem sido indicado

para aplicação em processos de Orientação Vocacional/Profissional realizados com adolescentes, justificando a presente proposta técnica.

Considerando essa realidade, a presente amostra envolveu estudantes do Ensino Médio público e particular de Ribeirão Preto (SP), de 14 a 19 anos de idade, de ambos os sexos, sem atraso acadêmico ou história pessoal de grave transtorno psiquiátrico ou psicológico (avaliado por informações fornecidas em questionário informativo específico), além de ausência de deficiências cognitivas e/ou sensoriais aparentes. Estas amostras, portanto, tentaram retratar adolescentes com sinais de desenvolvimento típico, estando funcionalmente adaptados ao seu contexto sócio-cultural. 
A caracterização do banco de dados compilado para o presente estudo encontra-se na Tabela 1. Nela pode-se identificar o estudo original, seus participantes e os casos incorporados ao atual banco de dados.

Tabela 1 - Caracterização da amostra atual (n=1582) em função da versão do BBT-Br, série e origem escolar.

\begin{tabular}{|c|c|c|c|c|c|c|}
\hline \multirow{2}{*}{$\begin{array}{c}\text { Versão do } \\
\text { BBT-Br }\end{array}$} & \multirow{2}{*}{$\begin{array}{c}\text { Pesquisa } \\
\text { original }\end{array}$} & \multirow{2}{*}{$\begin{array}{l}\text { Série } \\
\text { escolar }\end{array}$} & \multicolumn{2}{|c|}{ Escola } & \multirow[t]{2}{*}{ Subtotal } & \multirow[t]{2}{*}{ Total } \\
\hline & & & Pública & Particular & & \\
\hline \multirow{4}{*}{ Feminina } & Jacquemin et al (2006) & $1^{a}$ série & 107 & 146 & 253 & \multirow{4}{*}{862} \\
\hline & & $2^{\mathrm{a}}$ série & 114 & 142 & 256 & \\
\hline & Noce (2008) & $3^{a}$ série & 58 & - & 58 & \\
\hline & Okino (2009) & $3^{a}$ série & 295 & - & 295 & \\
\hline \multirow{5}{*}{ Masculina } & Jacquemin (2000) & $1^{a}$ série & 106 & 156 & 262 & \multirow{5}{*}{720} \\
\hline & & $2^{a}$ série & 118 & 63 & 181 & \\
\hline & & $3^{a}$ série & 25 & - & 25 & \\
\hline & Noce (2008) & $3^{\mathrm{a}}$ série & 50 & - & 50 & \\
\hline & Okino (2009) & $3^{a}$ série & 202 & - & 202 & \\
\hline
\end{tabular}

A amostra original do trabalho de Jacquemin (2000), referente à versão masculina do BBT-Br, estava composta por 476 participantes, sendo que foram excluídos oito casos para o presente banco de dados, por apresentarem idade superior a 19 anos. Foram aqui incorporados, então, 468 rapazes, sendo 224 de alunos da rede particular e 244 alunos da rede pública de ensino de Ribeirão Preto (SP). No tocante à abrangência da amostra, ressalta-se que as coletas foram realizadas em seis escolas públicas e seis escolas particulares da cidade, buscando-se realizar a coleta em diferentes bairros da cidade, em uma tentativa de cobrir da melhor maneira possível a diversidade populacional da cidade. A pesquisa de Jacquemin et al. (2006), referente ao BBT-Br feminino, continha 512 participantes, sendo, para o presente trabalho, excluídos dois protocolos com idade superior a 19 anos e outro caso por não apresentar informação relativa à idade. Desse modo, o atual banco de dados incluiu 509 protocolos do BBT-Br feminino deste estudo, sendo 221 da rede particular e 288 da rede pública de ensino da cidade de Ribeirão Preto (SP). As coletas da normatização feminina foram realizadas em quatro escolas públicas e seis escolas particulares, também visando uma melhor representatividade da amostra.

Os casos avaliados por Noce (2008) foram integralmente incorporados ao presente banco de dados, correspondendo a produções de estudantes da de uma escola da rede pública de 
ensino de Ribeirão Preto (SP), sendo 50 protocolos masculinos e 58 protocolos femininos. Essa escola localizava-se na região central da cidade, agregando na amostra, indivíduos de diferentes bairros do município, conseguindo, deste modo, possibilitar o acesso a uma amostra supostamente variada de estudantes, buscando a representação de sua natural diversidade, sobretudo no tocante aos interesses profissionais. Por fim, da coleta de Okino (2009) foram analisados todos os 202 protocolos masculinos e 295 protocolos femininos, ambos de alunos da rede pública de ensino da cidade de Ribeirão Preto (SP), também oriundos de escola pública da região central da cidade.

A integração dos resultados relativos às produções destes adolescentes avaliados pelos pesquisadores do Centro de Pesquisas foi pensada de modo a sustentar análises estatísticas necessárias com as versões do BBT-Br, planejadas há algum tempo e, neste momento, implementadas. Desta forma, as análises realizadas no presente trabalho, envolvem um total de 1582 adolescentes, sendo 720 protocolos da forma masculina do BBT-Br e 862 protocolos da forma feminina do BBT-Br, todos provenientes de estudantes do Ensino Médio da cidade de Ribeirão Preto (SP). Ressalta-se que esta amostra pode ser considerada como quantitativamente adequada aos propósitos desta pesquisa, uma vez que o número de participantes pode ser considerado suficientemente grande para a realização das análises estatísticas delineadas.

\subsection{Materiais}

Para o presente estudo foi utilizado o material disponível no Banco de Dados do Centro de Pesquisas em Psicodiagnóstico (CPP) da FFCLRP-USP. Este material é constituído por:

1) Material completo do BBT-Br (Teste de Fotos de Profissões), versão Masculina (Jacquemin, 2000) e Feminina (Jacquemin et al., 2006), incluindo os protocolos dos casos coletados por estes estudos originais e pelos trabalhos de Noce (2008) e Okino (2009).

O BBT-Br é constituído por duas versões: a forma masculina e a feminina, sendo cada uma composta por 96 fotos pretas e brancas, em formato quadrado $(9 \mathrm{~cm} \mathrm{X} 9 \mathrm{~cm})$. Cada foto apresenta um profissional desempenhando uma atividade relacionada ao trabalho (representando o radical de inclinação principal, em letra maiúscula) e, por conseqüência, relacionando-se com os demais aspectos referidos pelo trabalho: objetos, instrumentos, meio (representando o radical de inclinação secundário, em letra minúscula). 
As fotos do BBT-Br buscam apresentar, em si só, um pareamento dos radicais de inclinação, ou seja, uma integração de elementos básicos para a satisfação de necessidades pessoais, expressas em interesses profissionais. Esta preocupação com a coexistência de dois radicais de inclinação em cada foto reflete a teoria proposta por Achtnich (1991), autor do instrumento original Berufsbilder Test (BBT), onde pressupõe-se que a distribuição e o agrupamento desses radicais de inclinação poderiam representar e ilustrar os interesses profissionais. Cada foto apresenta, em seu verso, seus respectivos radicais de inclinação, sendo o radical primário, relacionado à atividade que a pessoa representada está concretizando (identificado pela letra maiúscula) e o radical secundário, relacionado aos meios, instrumentos e ambientes representados na foto (identificado pela letra minúscula).

A aplicação do BBT-br é composta de duas partes. Na primeira, o sujeito deve escolher e separar as 96 fotos em três grupos: fotos de preferência “+” (que o agradam), fotos rejeitadas “_“ (que o desagradam) e fotos indiferentes "O” (que não o agradam, nem desagradam). Neste primeiro momento, é necessário que o aplicador enfatize ao avaliando que suas escolhas devem ser baseadas apenas em suas primeiras impressões sobre as fotos, buscando-se capturar o componente sensorial e afetivo implícito nestas apreciações dos estímulos. Busca-se, desta maneira, favorecer a projeção de aspectos inconscientes nas escolhas do indivíduo. Observa-se que, apesar desse favorecimento para a emergência de conteúdos projetados pelo analisando, suas respostas, nesta primeira parte da aplicação, ficam restritas a apenas três tipos de escore: quantidade de escolhas positivas (+), negativas (-) ou indiferentes $(\mathrm{O})$, identificados como os indicadores de produtividade diante deste método projetivo.

Na segunda fase da aplicação deste instrumento de avaliação psicológica, o indivíduo é convidado a agrupar as fotos previamente selecionadas como positivas. A formação dos grupos deve acontecer de acordo com critérios próprios do respondente, sendo sua tarefa apenas semi-dirigida (ajuntar escolhas positivas), procurando aspectos comuns entre as fotos. Posteriormente estes agrupamentos de fotos positivas devem ser hierarquizados, de acordo com a preferência do respondente.

Após a formação dos grupos, inicia-se o processo de investigação sobre as associações do respondente, analisando-se, grupo a grupo e foto a foto, como o indivíduo captou e interpretou cada foto. Focaliza-se esta investigação sobre os itens: qual era o profissional? Qual seu instrumento de trabalho? Qual o ambiente de trabalho? Qual o objetivo desta atividade? Este procedimento busca apreender qual foi a percepção que o indivíduo teve em 
cada uma de suas fotos de preferência, sendo esta influenciada por fatores internos ali projetados.

Para complementação das informações desta fase associativa do BBT-Br, Achtnich (1991) e Melo-Silva e Jacquemin (1997) sugerem que, como terceira parte da aplicação, o respondente selecione cinco fotos preferidas e, a partir delas, elabore uma história (com começo, meio e final). Desta forma, eleva-se a possibilidade de emergirem relevantes informações referentes a suas vivências afetivas diante dos estímulos propostos pelo BBT-Br.

A sistematização das produções nesse método projetivo de avaliação psicológica implica também em duas fases: uma quantitativa (análise da freqüência simples da distribuição das escolhas positivas, negativas e indiferentes, bem como dos respectivos radicais de inclinação: $\mathrm{W}, \mathrm{Z}, \mathrm{G}, \mathrm{V}, \mathrm{O}, \mathrm{S}, \mathrm{K}, \mathrm{M}$ (primários e secundários), e outra qualitativa (interpretação das estruturas de inclinação positiva e negativa, das associações sobre os agrupamentos das fotos positivas, bem como da história sobre as cinco fotos preferidas, assim como dos fatores adicionais da técnica). Achtnich (1991) considera que, por meio da identificação das áreas ocupacionais e motivacionais de preferência do indivíduo (fotos escolhidas como positivas) e de suas áreas de reduzida motivação (fotos escolhidas como negativas) torna-se possível elaborar estruturas representativas de suas inclinações de interesse e de rejeição, primárias e secundárias, conforme apresentado no manual original deste método projetivo. Ressalta-se que, para a elaboração das estruturas de inclinação motivacional, é necessária a realização da ponderação dos radicais de inclinação primários $\mathrm{S}$, $\mathrm{Z}, \mathrm{V}$ e G, uma vez que estes radicais são representados por 16 fotos no instrumento, enquanto os demais radicais são representados por oito fotos cada.

A normatização brasileira do Teste de Fotos de Profissões foi realizada por Jacquemin (2000 - forma masculina) e Jacquemin et. al (2006 - forma feminina). Além de estudantes do Ensino Médio, esses estudos de elaboração de referenciais normativos das duas versões do BBT-Br também envolveram alunos de nível superior das áreas de Ciências Biológicas, Ciências Exatas e Ciências Humanas.

Em relação a estudos de validade, no contexto brasileiro, podem-se identificar várias pesquisas dos índices psicométricos do $\mathrm{BBT}-\mathrm{Br}$, dentre os quais os estudos de validade interna (Jacquemin, 2000; Jacquemin et. al 2006), validade preditiva (Bernardes, 2000), validade de critério (Noce, 2008), validade concorrente (Bordão-Alves, 2008), validade convergente discriminante (Otatti, 2009) e validade convergente e fatorial (Okino, 2009). Ressalta-se que, até a última lista do SATEPSI, de Julho de 2011, o BBT-Br, formas feminina 
e masculina, aparece como adequado para uso em processos de avaliação psicológica no contexto brasileiro.

2) Software desenvolvido e utilizado pelo Centro de Pesquisas em Psicodiagnóstico (CPP) da Faculdade de Filosofia, Ciências e Letras de Ribeirão Preto da Universidade de São Paulo. Este software foi elaborado em estudos anteriores com o BBT, para registro e análise dos perfis individuais de produção nesse método projetivo, possibilitando a digitação das respostas, armazenamento e organização dos dados em relatórios pré-definidos. Este programa computacional possibilita a visualização das estruturas de interesse de cada participante e relatórios de grupos ou subgrupos de indivíduos, em função de variáveis independentes específicas e pré-selecionadas (Idade, Sexo, Escolaridade, dentre outros).

3) Software Statistical Package for the Social Sciences (SPSS), versão 16.0, para realização das análises estatísticas pretendidas.

\subsection{Procedimentos}

\subsubsection{Cuidados éticos:}

Inicialmente, este projeto foi submetido à apreciação do Comitê de Ética em Pesquisa com Seres Humanos da Faculdade de Filosofia, Ciências e Letras de Ribeirão Preto - USP, iniciando-se as análises somente após sua aprovação. Ressalta-se que os cuidados relativos à utilização de instrumentos de avaliação psicológica e de documentação dos respectivos protocolos foram devidamente assegurados, conforme princípios éticos e legais vigentes na Comissão Nacional de Ética em Pesquisa (CONEP) do Conselho Nacional de Saúde do Ministério da Saúde e no Conselho Federal de Psicologia (CFP).

\subsubsection{Elaboração do Banco de Dados:}

Em relação às pesquisas de Jacquemin (2000), Jacquemin et al. (2006) e Okino (2009), o método de aplicação do BBT-Br foi coletivo. Cabe ressaltar que os estudantes foram agrupados em turmas específicas, em função do sexo, e alocados em salas de suas próprias escolas para viabilizar a aplicação coletiva das duas versões do BBT-Br, conforme orientação técnica de seu autor (Achtnich, 1991), seguindo-se as instruções de Jacquemin (2000) e Jacquemin et al. (2006). Foram utilizados slides de cada uma das 96 fotos do instrumento, 
específica para cada versão (feminina ou masculina), e apresentados aos participantes em salas de aula disponibilizadas pelas próprias escolas. As fotos foram apresentadas numa tela branca, durante 10 a 15 segundos, solicitando-se aos participantes que assinalassem, no protocolo de respostas, o sinal + (atividade o agrada), - (atividade o desagrada) ou 0 (atividade o deixa indiferente ou indeciso) diante de cada uma das 96 fotos apresentadas.

As produções provenientes do trabalho de Noce (2008) foram obtidas em aplicações individuais do BBT-Br, realizadas em local adequado, também disponibilizados por suas próprias escolas. Para estas aplicações, também foram utilizadas as formas Feminina e Masculina do BBT-Br, conforme o sexo do voluntário, seguindo-se as instruções constantes nos manuais da técnica (Achtnich, 1991; Jacquemin, 2000; Jacquemin et al. 2006).

Os protocolos com as respostas ao BBT-Br foram digitados em um software elaborado para documentar e organizar as informações individuais. A partir da entrada das produções individuais, este programa computacional consegue elaborar perfis de áreas de interesse e de rejeição profissional para cada respondente, tendo em vista a disposição da estrutura de radicais de inclinação motivacional previstos na técnica. Posteriormente, este próprio software pode disponibilizar relatórios de resultados de grupos de indivíduos, em função de variáveis como a idade, o sexo e a origem escolar. A partir destes arquivos de resultados digitalizados (banco de dados) é que foram realizadas as análises estatísticas do presente estudo.

\subsubsection{Análise dos Resultados:}

Inicialmente, cabe destacar que as formas masculina e feminina do BBT-Br foram analisadas em separado, dadas as suas especificidades de representação das atividades ocupacionais (estímulos específicos), embora com os mesmos pressupostos e radicais de inclinação implícitos em suas análises a respeito dos interesses profissionais dos indivíduos, conforme proposição de Achtnich (1991). Desta maneira, todas as análises aqui descritas foram realizadas para a amostra feminina (862 participantes) e para a amostra masculina (720 participantes) de modo separado.

Para a realização das análises estatísticas, os 1582 protocolos de respostas ao BBT-Br, transpostos em planilhas do Microsoft Office Excel, foram trabalhados por meio do software Statistical Package for the Social Sciences (SPSS), versão 16.0. Foram atribuídos valores numéricos às escolhas das 96 fotos do BBT-Br pelos participantes, conforme a seguinte estratégia: para as fotos rejeitadas (““-“) foi atribuído o valor 1; para as fotos apontadas como indiferentes ("0") foi atribuído o valor 2; e para as fotos escolhidas positivamente (“+”) foi atribuído o valor 3. Esta atribuição de valores buscou preservar os pressupostos teóricos 
propostos por Achtnich (1991), relativos aos interesses e às inclinações motivacionais. Desse modo, uma foto escolhida positivamente representaria uma área de claro interesse do indivíduo, enquanto uma escolhida negativamente estaria a representar uma atividade por ele rejeitada. Assim, como descrito acima, foi atribuído o maior valor numérico (3) às fotos de preferência, um valor intermediário (2) às fotos indiferentes, e o menor valor (1) às fotos rejeitadas.

Feitas as atribuições de valores numéricos ao posicionamento dos indivíduos diante das fotos do BBT-Br, foram iniciadas as análises estatísticas. Inicialmente, procurou-se verificar se a distribuição dos resultados nesse método projetivo seguia distribuição normal, no tocante às variáveis ligadas à produtividade (freqüência de escolhas positivas, negativas e indiferentes) e aos radicais de inclinação motivacional (freqüência de escolhas primárias e secundárias dos radicais $\mathrm{W}, \mathrm{K}, \mathrm{S}, \mathrm{Z}, \mathrm{G}, \mathrm{V}, \mathrm{M}, \mathrm{O})$. Para tanto, foi aplicado o teste estatístico de Kolmogorov-Smirnov (utilizando-se nível de significância $\mathrm{p} \leq 0,05$ ) nestes resultados gerais de cada uma das versões do BBT-Br. Os resultados dessas análises confirmaram a distribuição normal das principais variáveis de natureza quantitativa deste método projetivo, possibilitando realização de estatísticas inferenciais paramétricas. As análises paramétricas permitem a identificação de diferenças sutis e válidas entre grupos e subgrupos de indivíduos e em função de variáveis técnicas do instrumento, agregando confiabilidade aos resultados.

Em seguida, considerando que a modalidade de aplicação do BBT-Br (individual ou coletiva) foi diferente nas pesquisas que compõem o presente banco de dados, foi realizada a verificação estatística da existência de possível influência das aplicações nas respostas aos estímulos do instrumento. Como já dito, as pesquisas normativas (Jacquemin, 2000 e Jacquemin et al., 2006) e a pesquisa de Okino (2009) utilizaram a aplicação coletiva, por meio de slides, do BBT-Br. Já na pesquisa de Noce (2008) foi realizada a aplicação individual da técnica. Diante desse contexto, adotou-se a estratégia de comparação estatística de resultados médios dos índices de produtividade (escolhas positivas, negativas e neutras) dos dados de Noce (2008) com os dados de Okino (2009), recorrendo-se ao Teste $t$ de Student $(p \leq 0,05)$. Estas amostras foram selecionadas para comparação estatística visto que avaliaram participantes de mesma origem escolar (escolas públicas) e série escolar ( $3^{\mathrm{a}}$ série do Ensino Médio), permitindo o controle de outras possíveis variáveis intervenientes. Os resultados não identificaram diferenças significativas entre o número de escolhas positivas $(p=0,204)$, negativas $(p=0,080)$ e neutras $(p=0,761)$ na amostra feminina. Em relação à amostra masculina, não foram identificadas diferenças nas escolhas positivas $(p=0,210)$. Já nas escolhas negativas $(p=0,030)$ e escolhas neutras $(p=0,033)$ foram encontradas diferenças. É 
importante ressaltar que grande parte da interpretação técnica do BBT-Br baseia-se principalmente na análise das escolhas positivas, variável, então, que aqui assumiu o foco central dessa análise estatística comparativa entre os estudos de Noce (2008) e Okino (2009). Os resultados foram considerados suficientes para a inserção dos dados de Noce (2008) no presente banco de dados, uma vez que não foram encontradas evidências de efeito significativo da forma de aplicação do instrumento sobre seus indicadores de produtividade na versão feminina do BBT-Br e não foram encontradas diferenças significativas entre os estudos referidos no tocante às escolhas positivas da versão masculina. Pode-se, portanto, inferir evidências de equivalência das duas formas de aplicação, individual e coletiva, para este instrumento de avaliação psicológica, aplicado a adolescentes do ensino médio público, como aqui demonstrado. No entanto, cabe a ressalva de que este foco investigativo ainda exigirá pesquisas específicas, ultrapassando o atual foco do presente trabalho. Considerou-se, contudo, necessário o atual cuidado metodológico de modo a embasar a composição de um único banco de dados do BBT-Br, específico para cada versão do instrumento, independentemente de sua forma de aplicação aos adolescentes, para se evitar possível efeito de variáveis subjacentes às análises aqui pretendidas.

Composto o banco de dados, de maneira certificada e cuidadosa, passou-se a buscar estratégias técnicas para a devida análise dos mesmos de modo a cumprir os objetivos delineados para o presente estudo. Cabe, neste momento, ressaltar que, diante do histórico do BBT-Br (criado na década de 1970, introduzido no Brasil na década de 1980, com cerca de três décadas de uso clínico e em pesquisas nesse contexto nacional, conforme apontado em Pasian et al., 2007), assumiu-se que o presente trabalho procuraria as evidências psicométricas deste método projetivo seguindo-se sua proposição teórica original, ou seja, composição em oito radicais de inclinação motivacional. Essa decisão técnica teve por meta preservar a comparabilidade dos achados historicamente acumulados desde sua criação e introdução no Brasil, embora avançando na apresentação de resultados contemporâneos relativos a referenciais normativos e indicadores de precisão, repensando as próprias evidências de sustentação teórica (evidências de validade) do método. Ou seja, procurou-se realizar análises fatoriais exploratórias das duas versões do $\mathrm{BBT}-\mathrm{Br}$, de modo a colecionar indicadores de sua própria estruturação interna em oito radicais de inclinação motivacional, conforme originalmente proposto por Achtnich (1991). Este tipo de investigação já foi explorado por Okino (2009), porém com amostra menor e apenas de alunos do terceiro ano do ensino médio público, além de ter recorrido ao método e Análise de Componentes Principais como estratégia para a análise fatorial. Neste momento, considerou-se necessário aprimorar a 
estratégia técnica da análise fatorial exploratória, realizando-se as PAF, e com amostras suficientemente grandes para embasar as análises realizadas, como alcançado no presente banco de dados.

Com base nessas considerações prévias, as análises fatoriais exploratórias (PAF) aqui realizadas com os resultados das versões masculina e feminina do BBT-Br foram rodadas com soluções pré-definidas de oito, sete, seis, cinco e quatro fatores, verificando-se a melhor solução fatorial para este método projetivo. Poder-se-ia questionar se esta etapa deveria ser a primeira a ser realizada (e não a última, como aqui efetivado). Reafirma-se que os objetivos aqui delineados foram de atualização dos referenciais normativos e dos indicadores de precisão do BBT-Br original (com oito radicais de inclinação), explorando-se, a seguir, a própria sustentação fatorial deste modelo teórico implícito no instrumento. Trata-se, portanto, de um trabalho de natureza investigativa que busca agregar evidências de validade ao BBT$\mathrm{Br}$, porém sem reformular o próprio instrumento em termos de sua estruturação interna, preservando, deste modo, a possibilidade de comparação com estudos prévios realizados ao longo de mais de três décadas de existência do método, com utilização em diferentes contextos e países.

A seguir, portanto, foram elaborados os padrões normativos das duas versões do BBT$\mathrm{Br}$, tendo por base esta ampla matriz de resultados: amostra feminina composta por 862 casos e amostra masculina com 720 casos. Foram examinados os índices de produtividade (frequiência de escolhas positivas, negativas e neutras) e as escolhas (primárias e secundárias), positivas e negativas, para cada radical de inclinação motivacional (W, K, S, Z, G, V, M, O). Os dados foram apresentados em termos de estatística descritiva (mediana, média e desvio padrão) para cada variável citada. Essas análises permitiram a identificação das estruturas de inclinação (áreas de interesse e de rejeição) das amostras feminina e masculina, permitindo conhecer os campos de maior interesse e rejeição destes grupos, a partir das respectivas versões do BBT-Br.

Também foram realizadas análises de variância (ANOVA one way) destas variáveis buscando-se comparar o desempenho no BBT-Br dos estudantes do Ensino Médio em função do sexo (ou seja, para cada versão desse método projetivo), utilizando-se nível de significância $\mathrm{p}<0,05$. Faz-se necessário, no entanto, apontar que esta análise comparativa dos resultados médios no BBT-Br em função do sexo tem por base a coleta de dados realizada com versões específicas deste instrumento projetivo (forma feminina e forma masculina), consideradas como equivalentes, embora com estímulos (fotos) específicos, o que precisa ser levado em conta no momento de interpretação deste tipo de resultados. 
As análises posteriores visando à caracterização dos referenciais normativos do BBT$\mathrm{Br}$ focalizaram eventuais especificidades de produção nos indicadores técnicos de cada forma deste instrumento (masculina e feminina), tomando como variável independente a origem escolar (pública ou particular) e a série escolar do Ensino Médio (1 $1^{\mathrm{a}}, 2^{\mathrm{a}}$ e $3^{\mathrm{a}}$ séries). Foram mais uma vez realizadas análises de variância (ANOVA one way) dos resultados médios do $\mathrm{BBT}-\mathrm{Br}$ relativos aos índices de produtividade (freqüência de escolhas positivas, negativas e indiferentes) e aos radicais de inclinação motivacional (freqüência de escolhas primárias e secundárias dos radicais $\mathrm{W}, \mathrm{K}, \mathrm{S}, \mathrm{Z}, \mathrm{G}, \mathrm{V}, \mathrm{M}, \mathrm{O})$, considerando-se $\mathrm{p}<0,05$.

A seguir, foram realizadas análises dos resultados das duas formas do BBT-Br, procurando-se evidências de sua validade por meio de análise fatorial exploratória. Para examinar a possibilidade de aplicação desta estratégia analítica dos resultados, inicialmente foram estudadas as correlações parciais das variáveis por meio da estimativa do coeficiente de Kaiser-Meyer-Olkin (KMO) e por meio do teste de esfericidade de Bartlett. Conforme Zerbini (2007), na medida em que os valores das correlações parciais entre as variáveis se aproximar do valor 1, ter-se-á evidências de que a matriz de resultados é favorável. As correlações encontradas significativas $(\mathrm{p}<0,000)$ apresentando KMO de 0,891 e para a amostra feminina e KMO de 0,929 para a amostra masculina. Efetuou-se a seguir, as análises fatoriais, recorrendo-se ao método de Principal Axis Factoring (PAF), com rotação Varimax. Optou-se por este método de análise a partir das considerações de Costello e Osborne (2005), uma vez que o método da PAF pressupõe a existência de variáveis latentes (no caso, os radicais de inclinação do BBT-Br) sem a necessidade da normalidade dos dados, proporcionando uma distribuição dos fatores de maneira mais indicada para instrumentos de avaliação psicológica. Em relação à rotação ortogonal Varimax, que têm por objetivo simplificar e clarificar a estrutura dos dados, Costello e Osborne (2005) sugerem que, por apresentar os fatores de maneira independente, esse tipo de rotação possibilita dados mais facilmente interpretáveis.

Cabe a ressalva, no entanto, que pelo tipo de distribuição de dados seria inicialmente indicada a utilização do método PAF com rotação Direct Oblimin, que pressupõe interrelações entre os fatores (Costello e Osborne, 2005). Entretanto, não foi possível prosseguir com esse recurso técnico, uma vez que, a análise inicial com oito fatores para a amostra masculina não apresentou as convergências necessárias para a realização da rotação. Sendo assim, optou-se por prosseguir com as análises pela rotação Varimax, que analisou os fatores independentemente.

É importante ressaltar que, ao se examinar os fatores extraídos a partir das análises fatoriais, alguns critérios de seleção devem ser seguidos, para garantir a validade dos 
resultados. Zerbini (2007) explica que, pelo critério de Harman, devem-se considerar apenas os fatores cuja variância explicada dos resultados, após a rotação da matriz, atinja pelo menos a proporção de 3\%. Em relação à análise dos itens do instrumento avaliado, esta pesquisadora sugere que deveriam permanecer, como ponto de corte, aqueles itens com carga fatorial mínima de 0,30 , positiva ou negativa.

Ao comentar sobre cuidados metodológicos necessários em processos de análise fatorial, Costello e Osborne (2005) apontam também para a necessidade dos fatores extraídos serem compostos por mais de três itens, sendo que cinco ou mais itens com boa carga fatorial (0,50 ou acima) são desejáveis para indicar um fator sólido e representativo do construto em foco naquela avaliação. Para obter melhores resultados com as técnicas de análise fatorial de resultados advindos de instrumentos de avaliação, esses autores sugerem que sejam realizadas várias extrações pré-definidas de fatores a partir da matriz dos dados. $\mathrm{O}$ exame detalhado dos achados destas análises fatoriais poderá subsidiar o pesquisador em seu processo de seleção da análise fatorial que melhor atende aos critérios estatísticos e teóricos, ou seja, aquela que apresenta resultados mais consistentes, representando corretamente os fatores latentes envolvidos no instrumento em questão.

Outro ponto importante a ser averiguado refere-se aos itens descartados, ou seja, com carga fatorial menor que 0,30. Assim, também foram aqui examinados os itens do BBT-Br (fotos) que não preenchiam este critério técnico. A análise dessas fotos (que, por indicações da análise fatorial poderiam ser retiradas do instrumento) possibilitou maior conhecimento sobre possíveis inconsistências internas do BBT-Br, uma vez que possibilita a identificação das fotos que não se correlacionam de maneira unívoca com as demais para representar um mesmo fator teórico, podendo prejudicar a estrutura interna do instrumento.

Com base nessas considerações prévias, as análises fatoriais exploratórias (PAF) aqui realizadas com os resultados das versões masculina e feminina do BBT-Br foram rodadas com soluções pré-definidas de oito, sete, seis, cinco e quatro fatores. A pré-definição dos fatores foi realizada considerando-se dois aspectos: os achados prévios do trabalho de Okino (2009) e o próprio processo de elaboração das fotos da técnica. Okino (2009), ao realizar a Análise dos Componentes Principais (ACP) com extração de oito fatores em uma amostra de protocolos do BBT-Br, encontrou o pareamento de dois radicais de inclinação motivacional de Achtnich em cada fator extraído pela ACP. Considerando-se a existência de oito radicais de inclinação e os resultados dessa extração, o presente estudo iniciou suas extrações com quatro fatores, buscando evidências empíricas deste pareamento de dois radicais de inclinação motivacional em cada fator a ser extraído pela PAF. Outro aspecto que influenciou na pré-definição da 
extração de quatro fatores foi o modo como Achtnich (1991) elaborou as fotos do BBT-Br, buscando, em cada foto, representar o pareamento de dois radicais, um primário e um secundário. Sendo assim, a própria composição dos itens (fotos) deste método projetivo permite que o indivíduo tenha duas interpretações diferentes para ele: ressaltando o radical primário (o que é mais esperado), ou ressaltando o radical secundário. Com a pré-extração inicial de quatro fatores, buscou-se reduzir, portanto, estes pareamentos dos radicais em apenas quatro dimensões distintas. No entanto, seguiu-se com as PAF com soluções prédefinidas de cinco, seis, sete e até oito fatores, de modo a se encontrar indicadores técnicos suficientes para pensar e examinar qual seria a melhor solução fatorial para as duas versões do BBT-Br.

Feitas estas análises, foi selecionada, para exame mais detalhado, aquela que melhor respondesse tanto aos critérios estatísticos de relevância dos fatores obtidos e tamanho das correlações quanto aos pressupostos teóricos de Achtnich (1991). Os resultados foram organizados de modo a descrever, de modo sucinto, as cinco PAF realizadas com cada versão do BBT-Br, detalhando-se as fotos pertencentes a cada fator, o autovalor de cada fator, a variância explicada de cada fator e a freqüência dos radicais de inclinação de Achtnich (1991) em cada fator da extração, seguidas das observações acerca do cumprimento ou não dos critérios técnicos pressupostos para estas análises e acima citados. Em seguida, foi analisada mais detalhadamente a extração considerada mais representativa dos dados, com descrição detalhada de cada fator foto a foto do BBT-Br. Foram também detalhadas a profissão representada pela foto, os radicais de inclinação de Achtnich acoplados à foto, a função do profissional retratado, os meios/instrumentos utilizados e a carga fatorial de cada foto. A ordem de apresentação dos resultados novamente iniciou-se pela forma feminina, seguida pelos resultados da forma masculina do BBT-Br.

Concluídas estas análises de caracterização do desempenho de adolescentes do Ensino Médio e Validade Fatorial nas duas versões do BBT-Br, focalizou-se o exame dos índices de precisão deste método projetivo de avaliação psicológica. Com o objetivo de estimar o índice de consistência interna das versões do BBT-Br, foi calculado o Alfa de Cronbach para cada conjunto de itens (fotos) representativas de cada um dos oito radicais de inclinação (W, K, Z, S, G, M, O, V) de Achtnich (1991). Foram adotados, para a interpretação destes coeficientes, as orientações técnicas apresentadas por Dancey e Reidy (2006).

Da mesma forma, visando estimar o índice de consistência interna dos seis fatores extraídos pela PAF de seis fatores, selecionada como a mais representativa dos dados em ambas as formas do BBT-Br, foi calculado o Alfa de Cronbach para cada conjunto de itens 
(fotos) aglutinados nos fatores extraídos. Novamente, foram adotadas as orientações técnicas propostas por Dancey e Reidy (2006) para interpretação dos coeficientes de precisão encontrados. Ressalta-se que este procedimento foi tomado de modo a complementar e a explorar os indicadores técnicos do BBT-Br nesta nova composição estrutural (com seis fatores), de modo a permitir análise e reflexão comparativa com as evidências com seu modelo original e com as evidências encontradas em Okino (2009). Este objetivo foi seguido com caráter exploratório e não para reorganizar o instrumento BBT-Br ou com a meta de propor uma nova versão para este método projetivo, tendo em vista suas robustas evidências de validade clínica acumuladas por várias décadas (nacionais e internacionais), difíceis de serem transpostas antes de estudos multicêntricos com este método projetivo, visto que as amostras aqui estudadas contemplam apenas estudantes do ensino médio do interior do Estado de São Paulo. 


\section{RESULTADOS}

Diante da peculiaridade do Teste de Fotos de Profissões BBT-Br possuir duas versões (feminina e masculina), os resultados do presente trabalho foram organizados em função desta sua característica técnica. Assim, a apresentação e a análise dos resultados foi realizada separadamente para as duas versões do BBT-Br.

Os resultados também foram organizados de modo a apresentar inicialmente novos referenciais normativos do BBT-Br, incluindo as análises estatísticas inferenciais de possível efeito da origem e da série escolar. Posteriormente virão os dados relativos à validade das versões (feminina e masculina) do BBT-Br e, por último, os estudos a respeito da precisão deste método projetivo, acompanhando os objetivos e os procedimentos analíticos delineados para a presente investigação.

\subsection{DADOS NORMATIVOS DO BBT-BR}

\subsection{1. Índices de Produtividade}

A codificação do BBT-Br, formas feminina e masculina, exige inicialmente a quantificação das escolhas positivas, negativas e indiferentes das 96 fotos, denominados índices de produtividade do instrumento. Eles oferecem um panorama do posicionamento do indivíduo diante dos estímulos da realidade (a ele apresentados sob o formato de fotos de atividades profissionais), permitindo análises relativas à dispersão ou concentração de interesses.

Os índices de produtividade (freqüência simples de escolhas positivas, negativas e neutras) do BBT-Br são examinados em termos de sua estatística descritiva (mediana, média e desvio padrão). Estes dados compõem a Tabela 2, estando organizados em função da versão específica do instrumento (feminina ou masculina), incluindo comparação estatística (por meio de ANOVA one way) dos resultados médios em função do sexo dos adolescentes. 
Tabela 2 - Estatística descritiva (mediana, média e desvio padrão) e inferencial (ANOVA) da produtividade do $B B T-B r(n=1582)$ em função do sexo.

\begin{tabular}{ccccccccc}
\hline Variável BBT-Br & \multicolumn{3}{c}{ Feminino $(\mathrm{n}=862)$} & \multicolumn{3}{c}{ Masculino $(\mathrm{n}=720)$} & \multicolumn{2}{c}{ ANOVA } \\
& Med. & Média & DP & Med. & Média & DP & F & Sig. \\
& & & & & & & & \\
\hline Escolhas + & 34 & 34,73 & 14,59 & 26 & 27,58 & 15,46 & 89,090 & 0,000 \\
Escolhas - & 41 & 42,46 & 16,07 & 47 & 48,75 & 19,86 & 48,537 & 0,000 \\
Escolhas 0 & 19 & 18,81 & 10,04 & 18,5 & 19,66 & 12,60 & 2,231 & 0,135 \\
\hline
\end{tabular}

Foram identificadas diferenças significativas nas escolhas positivas e negativas das fotos do BBT-Br em função do sexo, ou seja, das versões do instrumento. Pode-se observar que o grupo masculino apresentou menor número de escolhas positivas e maior número de escolhas negativas das fotos do instrumento, comparativamente ao grupo feminino. Estas evidências, segundo as diretrizes interpretativas deste método projetivo de avaliação psicológica, poderiam sinalizar interesses mais concentrados no grupo masculino e maior diversidade de inclinações motivacionais no grupo feminino.

\subsubsection{Estruturas de inclinação motivacional}

A análise quantitativa dos resultados do BBT-Br implica também no exame da freqüência de distribuição das escolhas positivas e negativas das fotos em função dos radicais de inclinação (primários e secundários), base da composição das chamadas estruturas moticacionais (positiva e negativa, primária e secundária). Desta forma, a Tabela 3, abaixo, apresenta a estatística descritiva (mediana, média e desvio padrão) dos resultados relativos às escolhas positivas dos radicais de inclinação (primários e secundários), em função do sexo, incluindo a comparação estatística (ANOVA one way) dessas variáveis. As escolhas positivas no BBT-Br representam, teoricamente, as áreas e os focos de interesse dos indivíduos que poderão ser realizados e implementados profissionalmente. 
Tabela 3 - Estatística descritiva (mediana, média e desvio padrão) e comparações entre médias (ANOVA) das escolhas positivas dos radicais de inclinação primários e secundários do BBT-Br, em função do sexo (versão do BBT-Br).

\begin{tabular}{ccccccccc}
\hline Variável & \multicolumn{3}{c}{ Feminino (n=862) } & \multicolumn{6}{c}{ Masculino (n=720) } & ANOVA \\
BBT-Br & Med. & Média & DP & Med. & Média & DP & F & Sig. \\
& & & & & & & & \\
\hline W+ & 3,0 & 3,19 & 1,93 & 1,0 & 1,39 & 1,49 & 379,621 & 0,000 \\
K+ & 1,0 & 1,17 & 1,24 & 2,0 & 2,13 & 1,82 & 132,253 & 0,000 \\
Spond+ & 4,0 & 3,79 & 1,79 & 3,0 & 2,79 & 1,59 & 136,925 & 0,000 \\
Zpond+ & 3,5 & 3,45 & 1,78 & 2,0 & 2,09 & 1,63 & 244,032 & 0,000 \\
Vpond+ & 2,5 & 2,48 & 1,47 & 2,5 & 2,60 & 1,71 & 2,158 & 0,142 \\
Gpond+ & 3,0 & 2,95 & 1,63 & 2,5 & 2,80 & 1,66 & 3,158 & 0,076 \\
M+ & 2,0 & 1,89 & 1,34 & 1,0 & 1,49 & 1,61 & 26,317 & 0,000 \\
O+ & 4,0 & 3,71 & 1,77 & 2,0 & 2,59 & 1,97 & 140,029 & 0,000 \\
w+ & 6,0 & 5,80 & 2,51 & 3,0 & 3,17 & 2,16 & 479,824 & 0,000 \\
k+ & 4,0 & 3,72 & 2,08 & 3,0 & 3,71 & 2,25 & 0,000 & 0,983 \\
s+ & 4,0 & 4,52 & 2,24 & 4,0 & 3,88 & 2,32 & 30,279 & 0,000 \\
Z+ & 5,0 & 5,20 & 2,52 & 4,0 & 3,97 & 2,48 & 94,856 & 0,000 \\
v+ & 3,0 & 3,57 & 2,08 & 3,0 & 3,41 & 2,36 & 1,923 & 0,166 \\
g+ & 4,0 & 4,29 & 2,31 & 3,0 & 3,60 & 2,29 & 34,629 & 0,000 \\
m+ & 4,0 & 4,48 & 2,32 & 3,0 & 2,99 & 2,31 & 157,936 & 0,000 \\
o+ & 3,0 & 3,76 & 2,19 & 3,0 & 3,32 & 2,36 & 13,909 & 0,000 \\
\hline
\end{tabular}

Pode-se observar que a estrutura de interesses primários positivos da amostra feminina apresenta, como elementos principais, os radicais de inclinação $\mathrm{S}, \mathrm{O}, \mathrm{Z}$ e W. Essa estrutura sugere o interesse por atividades que envolvam senso social; ajuda ao outro; contato com o outro; dinamismo, energia; comunicação; nutrição; apuro estético; necessidade de mostrar seu trabalho; bem como atitudes afetuosas, necessidade de tocar o outro. A estrutura de interesses secundários positivos apresenta os radicais $w, z, s$ e $m$ como elementos principais, sugerindo a necessidade de trabalhar em locais que favoreçam o contato social efetivado pela ajuda, dinamismo, pela maternagem, com reconhecimento pessoal e de seu trabalho; o uso de materiais diversificados, desde suaves até mais rústicos, artísticos (argila, tintas).

Em relação aos dados masculinos, os resultados apontaram uma estrutura de interesses primária positiva cujos radicais de inclinação principais são $\mathrm{G}, \mathrm{S}, \mathrm{V}$ e $\mathrm{O}$. Estes resultados indicam interesse por atividades que envolvem criatividade, inteligência; senso social, seja no contexto de ajuda, seja no contexto de dinamismo, energia; tarefas mais precisas, objetivas, que necessitem da racionalidade; e atividades relacionadas à oralidade, seja na comunicação, seja no preparo e cuidado de alimentos. Já para a estrutura secundária positiva, os radicais principais $z, s, k$ e $g$ apontam para a necessidade de trabalhar em ambientes onde é possível 
expor seu trabalho, ter seu trabalho apreciado e reconhecido; locais onde o dinamismo e contato social estejam presentes; ambientes onde seja exigida competitividade, combatividade; com possibilidade de inovação, uso da criatividade e imaginação.

Os resultados das comparações estatísticas entre as médias (ANOVA) de escolhas positivas, em função do sexo, apontaram diferenças significativas entre as freqüências de distribuição dos radicais de inclinação primários ponderados positivos. Estas diferenças foram encontradas entre seis dos oito radicais de inclinação: W, K, S, Z, M e O. Desta maneira, as escolhas positivas dos adolescentes do sexo feminino e masculino apresentaram semelhanças apenas nos radicais $\mathrm{V}$ e $\mathrm{G}$, sinalizando interesses comuns por atividades que impliquem uso da razão, objetividade, criatividade, inteligência e intuição, ou seja, atividades ligadas ao funcionamento lógico geral.

Da mesma forma, a comparação das médias de escolhas positivas dos radicais secundários em função do sexo apontou diferenças em seis radicais de inclinação motivacional. Foram encontradas diferenças nos radicais $w, s, z, g, m$ e $o$, sugerindo efeito significativo do sexo sobre interesses e modo como selecionam locais e instrumentos de atividades profissionais. No entanto, mais uma vez, encontra-se semelhança entre os grupos no tocante a menor interesse por ambientes relacionados aos radicais $k$ e $v$, ou seja, locais que envolvam competitividade, combatividade, agressividade, uso da razão, da objetividade e do espírito investigativo, talvez como uma marca típica do desenvolvimento da faixa etária aqui estudada (adolescentes de 14 a 19 anos).

Além de clarificar as principais áreas de interesse profissional, as possibilidades informativas do BBT-Br permitem visualizar também as áreas de maior rejeição. Estas evidências advêm dos indicadores relativos às escolhas negativas das fotos do instrumento, dados a seguir apresentados. A seguir, a Tabela 4 apresenta a estatística descritiva (mediana, média e desvio padrão) e comparação estatística (ANOVA one way) das escolhas negativas dos radicais de inclinação (primários e secundários), em função do sexo, ou seja, a partir de cada versão do BBt-Br. 
Tabela 4 - Estatística descritiva (mediana, média e desvio padrão) e comparações entre médias (ANOVA) das escolhas negativas dos radicais de inclinação primários e secundários do BBT-Br, em função do sexo (versão do BBT-Br).

\begin{tabular}{ccccccccc}
\hline Variável & \multicolumn{3}{c}{ Feminina (n=862) } & \multicolumn{7}{c}{ Masculina (n=720) } & ANOVA \\
BBT-Br & Med. & Média & DP & Med. & Média & DP & F & Sig. \\
& & & & & & & & \\
\hline W- & 3,0 & 3,56 & 2,03 & 6,0 & 5,39 & 2,07 & 307,259 & 0,000 \\
K- & 6,0 & 5,93 & 1,77 & 5,0 & 4,79 & 2,12 & 136,073 & 0,000 \\
Spond- & 2,5 & 2,78 & 1,66 & 3,5 & 3,67 & 1,78 & 105,725 & 0,000 \\
Zpond- & 2,5 & 2,81 & 1,82 & 4,5 & 4,23 & 2,03 & 216,027 & 0,000 \\
Vpond- & 4,0 & 3,94 & 1,69 & 3,0 & 3,43 & 2,04 & 28,760 & 0,000 \\
Gpond- & 3,0 & 3,24 & 1,69 & 3,5 & 3,58 & 1,94 & 13,988 & 0,000 \\
M- & 5,0 & 4,63 & 1,76 & 5,0 & 5,08 & 2,19 & 19,698 & 0,000 \\
O- & 3,0 & 2,99 & 1,74 & 4,0 & 3,82 & 2,19 & 68,453 & 0,000 \\
w- & 4,0 & 4,08 & 2,33 & 6,0 & 6,28 & 2,77 & 293,494 & 0,000 \\
k- & 6,0 & 5,78 & 2,41 & 6,0 & 5,89 & 2,64 & 0,701 & 0,403 \\
s- & 5,0 & 5,32 & 2,34 & 6,0 & 5,93 & 2,80 & 22,430 & 0,000 \\
z- & 4,0 & 4,57 & 2,55 & 6,0 & 5,70 & 2,90 & 66,810 & 0,000 \\
v- & 6,0 & 6,35 & 2,43 & 6,0 & 6,04 & 2,89 & 5,383 & 0,020 \\
g- & 5,0 & 5,07 & 2,56 & 6,0 & 6,11 & 2,73 & 61,178 & 0,000 \\
m- & 5,5 & 5,60 & 2,43 & 7,0 & 6,84 & 3,02 & 80,900 & 0,000 \\
o- & 6,0 & 5,91 & 2,61 & 6,0 & 6,18 & 3,01 & 3,418 & 0,065 \\
\hline
\end{tabular}

Os resultados das escolhas negativas do grupo feminino do BBT-Br evidenciaram rejeição principalmente aos radicais de inclinação $\mathrm{K}, \mathrm{M}$ e $\mathrm{V}$. Isso pode ser compreendido como sinal de rejeição, no grupo feminino, por atividades em que o uso da força física é necessário; atividades que envolvam a manipulação de objetos mais duros, rudes; atividades que requerem maior uso da razão, lógica, precisão e objetividade. A estrutura de interesses secundária negativa apontou rejeição aos radicais $v, o, k$ e $m$, indicando rejeição a ambientes de trabalho onde se exige objetividade, agressividade, força física, comunicações diretas, manipulação e conservação de materiais.

Já a estrutura de inclinação primária negativa da amostra masculina apresentou maior frequiência de escolhas dos radicais $\mathrm{W}, \mathrm{M}, \mathrm{K}$ e Z. Sinalizaram, portanto, rejeição às atividades que envolvam afetividade, contato direto, toque, meticulosidade, trabalho com materiais rústicos, uso da força física e de agressividade, além de rejeitarem atividades voltadas à estética e ao reconhecimento de si e de seu trabalho. Em relação à estrutura secundária negativa, com os radicais $m, w, o$ e $g$ como principais, destacam-se a rejeição de locais de trabalho que necessitem manipulação e conservação de materiais, sensibilidade e trabalho 
com materiais suaves, comunicação e/ou contato com alimento, além de ambientes que solicitem criatividade e imaginação.

As comparações estatísticas sobre as escolhas negativas das fotos do BBT-Br em função do sexo mostraram-se significativamente diferentes em todos os radicais de inclinação primários. Desta maneira, os resultados sugeriram especificidades de rejeições de atividades e de ambientes profissionais decorrentes do sexo dos adolescentes. No tocante aos radicais secundários, o grupo feminino diferenciou-se significativamente do masculino em seis radicais de inclinação: $w, s, z, v, g$ e $m$. Pode-se inferir, portanto, que entre os adolescentes investigados (do ensino médio) há uma tendência geral em rejeitarem ambientes de trabalho relacionados aos radicais $o$ e $k$, ou seja, meios e instrumentos de trabalho que envolvam elementos concretos, como lidar com alimentos e onde seja exigida força física e matizes de agressividade.

Os resultados dos índices de produtividade e radicais de inclinação motivacional (primários e secundários) do BBT-Br apontaram especificidades em função do sexo, indicando que os adolescentes avaliados tendem a se interessar e a rejeitar atividades e ambientes de maneira diferente. No entanto, cabe destacar que estas evidências empíricas estão pautadas no pressuposto de equivalência entre as versões do BBT-Br, o que deve ser levado em conta na interpretação dos resultados, visto que as fotos que as compõem são também diferentes, embora teoricamente representativas dos mesmos radicais de inclinação motivacional, como argumentado pelo autor do instrumento (Achtnich, 1991).

Diante da atual demonstração empírica de especificidades em função da versão (feminina e masculina) do BBT-Br, as análises da possível influência da origem escolar e da série escolar sobre os resultados neste método projetivo serão desenvolvidas separadamente. Os resultados dessas análises estão apresentados a seguir.

\subsubsection{Origem escolar e indicadores do BBT-Br}

O contexto sócio-cultural onde o indivíduo se desenvolve é reconhecido, sem grande dificuldade, como variável interferente no próprio desenvolvimento humano, oferecendo oportunidades mais ou menos dirigidas para o crescimento e para a construção da identidade, dos interesses, da personalidade, entre outros aspectos. Dessa forma, pode exercer influência relevante sobre os processos educacionais e sobre as escolhas ocupacionais e profissionais, refletidas na produção diante do Teste de Fotos de Profissões BBT-Br, como argumentava seu autor (Achtnich, 1991). 
Diante desse contexto, procurou-se examinar possível efeito de uma variável postulada como representante viável do contexto sócio-cultural de adolescentes do Ensino Médio: o seu ambiente escolar (escola pública ou particular). Foram consideradas as variáveis de produtividade e as estruturas de inclinação motivacional (positiva e negativa) do BBT-Br para essas análises, realizando-se estudo específico para cada versão (feminina e masculina) desse método projetivo de avaliação psicológica.

\subsubsection{Forma feminina}

A estatística descritiva (mediana, média, desvio padrão) e comparação entre os índices de produtividade (escolhas positivas, negativas e neutras) no BBT-Br do grupo feminino de estudantes de escolas particulares e públicas, compõem a Tabela 5.

Tabela 5 - Estatística descritiva (mediana, média e desvio padrão) e inferencial dos índices de produtividade da Amostra Feminino (n=862) em função da origem escolar.

\begin{tabular}{cccccccccc}
\hline Variável BBT-Br & \multicolumn{3}{c}{ Particular (n=221) } & \multicolumn{3}{c}{ Pública (n=641) } & \multicolumn{4}{c}{ ANOVA } \\
& Med. & Média & DP & Med. & Média & DP & F & Sig. \\
& & & & & & & & \\
\hline Escolhas + & 35 & 35,00 & 13,16 & 34 & 34,63 & 15,06 & 0,103 & 0,749 \\
Escolhas - & 42 & 42,94 & 14,42 & 41 & 42,29 & 16,61 & 0,262 & 0,609 \\
Escolhas 0 & 17 & 18,06 & 9,42 & 19 & 19,07 & 10,24 & 1,654 & 0,199 \\
\hline
\end{tabular}

Os resultados não apontaram diferenças significativas entre os índices de produtividade do BBT-Br das estudantes oriundas de escola particular e escola pública da amostra feminina. Desta maneira, pode-se concluir que o grupo feminino de estudantes, oriundas de diferentes contextos escolares, reagem aos estímulos do BBT-Br (forma feminina), de maneira semelhante, selecionando, rejeitando ou permanecendo indiferentes aos estímulos do instrumento em proporções semelhantes.

Em complemento examinou-se a estrutura de inclinação positiva diante da versão feminina do BBT-Br por este grupo de adolescentes. Estes resultados estão organizados na Tabela 6, apresentando a freqüência média de escolhas positivas do sexo feminino nos radicais primários e secundários de inclinação motivacional do $\mathrm{BBT}-\mathrm{Br}$, bem como a respectiva comparação estatística entre escolas públicas e particulares por meio de ANOVA one way. 
Tabela 6 - Estatística descritiva (mediana, média e desvio padrão) e inferencial da estrutura de inclinação motivacional positiva (primária e secundária) do BBT-Br da Amostra Feminina (n=862), em função da origem escolar.

\begin{tabular}{ccccccccc}
\hline Variável & \multicolumn{3}{c}{ Particular $(\mathrm{n}=221)$} & \multicolumn{3}{c}{ Pública $(\mathrm{n}=641)$} & \multicolumn{3}{c}{ ANOVA } \\
BBT-Br & Med. & Média & DP & Med. & Média & DP & F & Sig. \\
& & & & & & & & \\
\hline W+ & 3,0 & 3,00 & 1,82 & 3,0 & 3,27 & 1,96 & 3,068 & 0,080 \\
K+ & 1,0 & 0,93 & 1,15 & 1,0 & 1,27 & 1,26 & 11,799 & 0,001 \\
Spond+ & 4,0 & 3,85 & 1,61 & 4,0 & 3,77 & 1,84 & 0,329 & 0,567 \\
Zpond+ & 3,5 & 3,70 & 1,71 & 3,5 & 3,36 & 1,80 & 6,018 & 0,014 \\
Vpond+ & 2,0 & 2,25 & 1,36 & 2,5 & 2,56 & 1,50 & 7,451 & 0,006 \\
Gpond+ & 3,0 & 3,09 & 1,54 & 2,5 & 2,90 & 1,67 & 2,157 & 0,142 \\
M+ & 2,0 & 1,76 & 1,30 & 2,0 & 1,94 & 1,36 & 3,050 & 0,081 \\
O+ & 3,0 & 3,55 & 1,80 & 4,0 & 3,77 & 1,76 & 2,603 & 0,107 \\
w+ & 6,0 & 6,17 & 2,33 & 6,0 & 5,67 & 2,56 & 6,611 & 0,010 \\
k+ & 3,0 & 3,46 & 1,92 & 4,0 & 3,81 & 2,13 & 4,518 & 0,034 \\
s+ & 4,0 & 4,48 & 2,12 & 4,0 & 4,53 & 2,28 & 0,104 & 0,747 \\
Z+ & 5,0 & 5,20 & 2,51 & 5,0 & 5,20 & 2,52 & 0,001 & 0,980 \\
v+ & 3,0 & 3,42 & 2,09 & 3,0 & 3,62 & 2,07 & 1,519 & 0,218 \\
g+ & 4,0 & 4,37 & 2,29 & 4,0 & 4,27 & 2,32 & 0,287 & 0,592 \\
m+ & 4,0 & 4,24 & 2,24 & 4,0 & 4,56 & 2,35 & 3,118 & 0,078 \\
o+ & 4,0 & 3,67 & 2,21 & 3,0 & 3,79 & 2,19 & 0,518 & 0,472 \\
\hline
\end{tabular}

A comparação das médias de escolhas positivas do grupo feminino nos radicais de inclinação primários em função da origem escolar evidenciou diferenças significativas em três radicais de inclinação: $\mathrm{K}, \mathrm{Z}$ e V. No caso dos radicais $\mathrm{K}$ e V, as estudantes da escola pública apresentaram índices médios mais elevados, sugerindo maior interesse por atividades envolvendo força física, persistência, agressividade e atividades mais racionais, de observação e conhecimento. Já as estudantes da escola particular alcançaram médias maiores no radical Z, apontando maior interesse por atividades relacionadas a estética e ao embelezamento, além do desejo de reconhecimento de si e de seu trabalho.

A comparação estatística entre médias de escolhas positivas dos radicais de inclinação secundários do BBT-Br identificou diferenças significativas em dois radicais de inclinação: $w$ e $k$ em função da origem escolar da amostra feminina. Em média, as estudantes de escolas particulares selecionaram mais ambientes de trabalho relacionados ao radical $w$, ou seja, locais que oferecem o contato pessoal, o cuidado com o outro, o uso de materiais macios. Já as estudantes oriundas de escolas públicas selecionaram, em média, mais ambientes de trabalho relacionados ao radical $k$, onde é exigido maior uso de força física, de combatividade. 
Segundo as diretrizes técnicas do BBT-Br, em complemento ao exame das estruturas positivas de inclinação motivacional (que representam áreas de interesse), deve-se avaliar as estruturas negativas, permitindo acesso às áreas de rejeição motivacional do indivíduo. Dessa forma, foram elaboradas as estatísticas descritivas (mediana, média e desvio padrão) e inferenciais (ANOVA one way) das escolhas negativas dos radicais de inclinação primários e secundários, em função da origem escolar, das estudantes da amostra feminina. Estes dados compõem a Tabela 7.

Tabela 7 - Estatística descritiva (mediana, média e desvio padrão) e inferencial da estrutura de inclinação motivacional negativa (primária e secundária) do BBT-Br da Amostra Feminina ( $n=862$ ), em função da origem escolar.

\begin{tabular}{ccccccccc}
\hline Variável & \multicolumn{3}{c}{ Particular (n=221) } & \multicolumn{3}{c}{ Pública $(\mathrm{n}=641)$} & \multicolumn{3}{c}{ ANOVA } \\
BBT-Br & Med. & Média & DP & Med. & Média & DP & F & Sig. \\
& & & & & & & & \\
\hline W- & 3,0 & 3,55 & 1,93 & 3,0 & 3,57 & 2,07 & 0,013 & 0,908 \\
K- & 7,0 & 6,13 & 1,67 & 6,0 & 5,87 & 1,79 & 3,723 & 0,054 \\
Spond- & 2,5 & 2,80 & 1,56 & 2,5 & 2,77 & 1,69 & 0,063 & 0,801 \\
Zpond- & 2,5 & 2,57 & 1,63 & 2,5 & 2,89 & 1,88 & 5,170 & 0,023 \\
Vpond- & 4,0 & 4,22 & 1,64 & 4,0 & 3,84 & 1,70 & 8,733 & 0,003 \\
Gpond- & 3,0 & 3,20 & 1,65 & 3,0 & 3,26 & 1,71 & 0,151 & 0,697 \\
M- & 5,0 & 4,65 & 1,70 & 5,0 & 4,63 & 1,79 & 0,016 & 0,899 \\
O- & 3,0 & 3,03 & 1,83 & 3,0 & 2,98 & 1,70 & 0,150 & 0,699 \\
w- & 4,0 & 3,87 & 2,04 & 4,0 & 4,15 & 2,41 & 2,288 & 0,131 \\
k- & 6,0 & 5,99 & 2,35 & 6,0 & 5,71 & 2,43 & 2,205 & 0,138 \\
s- & 5,0 & 5,33 & 2,19 & 5,0 & 5,31 & 2,40 & 0,005 & 0,942 \\
z- & 4,0 & 4,52 & 2,42 & 4,0 & 4,59 & 2,60 & 0,127 & 0,722 \\
v- & 7,0 & 6,62 & 2,41 & 6,0 & 6,26 & 2,44 & 3,595 & 0,058 \\
g- & 5,0 & 5,03 & 2,31 & 5,0 & 5,08 & 2,64 & 0,059 & 0,808 \\
m- & 6,0 & 5,69 & 2,26 & 5,0 & 5,57 & 2,49 & 0,387 & 0,534 \\
o- & 6,0 & 5,91 & 2,52 & 6,0 & 5,92 & 2,64 & 0,001 & 0,978 \\
\hline
\end{tabular}

A comparação das médias de escolhas negativas da amostra feminina nos radicais de inclinação primários em função da origem escolar evidenciou diferenças significativas em dois radicais: $\mathrm{Z}$ e $\mathrm{V}$. $\mathrm{O}$ grupo feminino da escola particular apresentou médias maiores em $\mathrm{V}$, apontando maior rejeição por atividades relacionadas à razão, à lógica. Por sua vez, as estudantes da escola pública apresentaram médias maiores de escolhas negativas em Z, sugerindo maior rejeição de atividades relacionadas ao apuro estético e à necessidade de se mostrar e receber reconhecimento. Destaca-se também que o radical $\mathrm{K}$ apresentou nível de significância marginal na comparação estatística em função da origem escolar, ou seja, muito 
próximo do limite de significância $(\mathrm{p}=0,05)$, sugerindo tendência à diferenciação nas escolhas negativas das estudantes de escolas públicas e particulares diante deste radical entre os grupos de diferente origem escolar. Isso pode ser sugestivo de diferenciada sensibilidade nestas estudantes diante das fotos relacionadas a atividades que envolvam força física, agressividade.

A análise estatística comparativa das freqüências médias de escolhas negativas dos radicais secundários não apontou diferenças significativas decorrentes da origem escolar das estudantes. Apenas o radical de inclinação secundário $v$ obteve um nível de significância marginal, ou seja, muito próximo do limite $(\mathrm{p}=0,05)$, sugerindo que os ambientes que exigem racionalidade e objetividade tendem a ser rejeitados em proporções diferenciadas pelas adolescentes de escola pública e particular.

O conjunto das atuais evidências foram indicativos de algumas peculiaridades na produção diante do BBT-Br feminino por parte de estudantes do Ensino Médio em função de sua origem escolar. Diante disso, na interpretação de resultados deste método projetivo, o psicólogo deverá estar atento à procedência escolar do indivíduo de modo a favorecer hipóteses interpretativas adequadas sobre o mesmo, tendo em vista seu contexto sócio-cultural.

\subsubsection{Forma masculina}

Os resultados obtidos com a forma masculina do BBT-Br foram tratados de modo similar ao efetivado com sua versão feminina, anteriormente descrita. Desse modo, na Tabela 8 estão apresentadas a estatística descritiva (mediana, média, desvio padrão) e comparação entre os índices de produtividade (escolhas positivas, negativas e neutras) no BBT-Br do grupo masculino de estudantes de escolas particulares e públicas de ensino médio.

Tabela 8 - Estatística descritiva (mediana, média e desvio padrão) e inferencial (ANOVA) dos índices de produtividade da Amostra Feminina do BBT-Br $(n=720)$ em função da origem escolar.

\begin{tabular}{ccccccccc}
\hline Variável & \multicolumn{3}{c}{ Particular $(\mathrm{n}=224)$} & \multicolumn{3}{c}{ Pública $(\mathrm{n}=496)$} & \multicolumn{3}{c}{ ANOVA } \\
BBT-Br & Med. & Média & DP & Med. & Média & DP & F & Sig. \\
\hline Escolhas + & 21 & 22,80 & 14,26 & 29 & 29,74 & 15,51 & 32,436 & 0,000 \\
Escolhas - & 56 & 54,92 & 20,43 & 44 & 45,97 & 18,97 & 32,759 & 0,000 \\
Escolhas 0 & 17 & 18,27 & 13,41 & 19 & 20,29 & 12,18 & 3,974 & 0,047 \\
\hline
\end{tabular}


Os índices de produtividade (escolhas positivas, negativas e neutras) no BBT-Br de alunos de escolas particulares e públicas da amostra masculina mostraram-se significativamente diferentes. Os alunos de escolas particulares sinalizaram, em média, menor número de escolhas positivas e mais escolhas negativas das 96 fotos deste método projetivo de avaliação psicológica, indicando maior focalização em suas escolhas profissionais, enquanto os alunos de escolas públicas apresentaram sinais de maior variabilidade em seus interesses profissionais.

$\mathrm{Na}$ sequiência de exame dos resultados no BBT-Br masculino focalizou-se a distribuição das escolhas positivas pelos radicais de inclinação motivacional (primários e secundários). Desse modo, a Tabela 9 apresenta a estatística descritiva (mediana, média e desvio padrão) e inferencial (ANOVA one way) da média de escolhas positivas dos radicais de inclinação do BBT-Br, em função da origem escolar.

Tabela 9 - Estatística descritiva (mediana, média e desvio padrão) e inferencial da estrutura de inclinação motivacional positiva (primária e secundária) do BBT-Br da Amostra Masculina ( $n=720)$, em função da origem escolar.

\begin{tabular}{ccccccccc}
\hline Variável & \multicolumn{3}{c}{ Particular (n=224) } & \multicolumn{3}{c}{ Pública $(\mathrm{n}=496)$} & \multicolumn{3}{c}{ ANOVA } \\
BBT-Br & Med. & Média & DP & Med. & Média & DP & F & Sig. \\
& & & & & & & & \\
\hline W+ & 0,0 & 0,90 & 1,27 & 1,0 & 1,66 & 1,53 & 39,620 & 0,000 \\
K+ & 1,0 & 1,63 & 1,72 & 2,0 & 2,37 & 1,82 & 25,971 & 0,000 \\
Spond+ & 2,5 & 2,52 & 1,52 & 3,0 & 2,91 & 1,60 & 9,867 & 0,002 \\
Zpond+ & 1,5 & 1,71 & 1,50 & 2,0 & 2,27 & 1,66 & 18,913 & 0,000 \\
Vpond+ & 1,75 & 2,06 & 1,49 & 2,5 & 2,84 & 1,75 & 32,988 & 0,000 \\
Gpond+ & 2,0 & 2,38 & 1,59 & 3,0 & 2,99 & 1,66 & 21,104 & 0,000 \\
M+ & 1,0 & 1,08 & 1,49 & 1,0 & 1,71 & 1,63 & 23,288 & 0,000 \\
O+ & 1,0 & 1,86 & 1,74 & 3,0 & 2,93 & 1,98 & 48,184 & 0,000 \\
w+ & 2,0 & 2,49 & 2,01 & 3,0 & 3,49 & 2,16 & 33,783 & 0,000 \\
k+ & 3,0 & 3,19 & 2,22 & 4,0 & 3,95 & 2,22 & 18,029 & 0,000 \\
s+ & 3,0 & 3,21 & 2,24 & 4,0 & 4,19 & 2,29 & 28,236 & 0,000 \\
z+ & 3,0 & 3,27 & 2,30 & 4,0 & 4,28 & 2,49 & 26,545 & 0,000 \\
v+ & 2,0 & 2,61 & 2,18 & 3,5 & 3,79 & 2,36 & 40,107 & 0,000 \\
g+ & 3,0 & 3,01 & 2,15 & 4,0 & 3,88 & 2,30 & 22,493 & 0,000 \\
m+ & 2,0 & 2,25 & 2,23 & 3,0 & 3,34 & 2,28 & 35,133 & 0,000 \\
o+ & 2,0 & 2,76 & 2,22 & 3,0 & 3,58 & 2,38 & 19,156 & 0,000 \\
\hline
\end{tabular}

Os resultados da análise de variância das escolhas positivas aos radicais de inclinação primários ponderados entre estudantes de escola particular e pública da amostra masculina apontaram diferenças significativas em todos os oito radicais de inclinação de Achtnich 
(1991). O mesmo ocorreu diante das escolhas positivas aos radicais de inclinação secundários (diferenças significativas nos oito radicais). Pode-se observar que os estudantes oriundos de escolas públicas selecionaram, em média, mais fotos positivas do que os estudantes de escolas particulares, indicando maior abertura na escolha de atividades profissionais por parte dos alunos de escolas públicas.

Também foram analisadas as escolhas negativas aos radicais de inclinação primários e secundários na amostra masculina, em função da origem escolar. A Tabela 10 apresenta a estatística descritiva (mediana, média e desvio padrão) e inferencial (ANOVA one way) destes resultados da forma masculina do BBT-Br, em função da origem escolar.

Tabela 10 - Estatística descritiva (mediana, média e desvio padrão) e inferencial da estrutura de inclinação motivacional negativa (primária e secundária) do BBT-Br da Amostra Masculina (n=720), em função da origem escolar.

\begin{tabular}{ccccccccc}
\hline Variável & \multicolumn{3}{c}{ Particular (n=224) } & \multicolumn{3}{c}{ Pública $(\mathrm{n}=496)$} & & ANOVA \\
BBT-Br & Med. & Média & DP & Med. & Média & DP & F & Sig. \\
& & & & & & & & \\
\hline W- & 6,0 & 5,83 & 1,98 & 6,0 & 5,19 & 2,08 & 14,997 & 0,000 \\
K- & 6,0 & 5,22 & 2,14 & 5,0 & 4,60 & 2,09 & 13,316 & 0,000 \\
Spond- & 4,0 & 4,15 & 1,81 & 3,5 & 3,45 & 1,72 & 24,226 & 0,000 \\
Zpond- & 5,0 & 4,72 & 2,03 & 4,0 & 4,01 & 1,99 & 19,221 & 0,000 \\
Vpond- & 4,0 & 4,05 & 2,11 & 3,0 & 3,15 & 1,94 & 31,109 & 0,000 \\
Gpond- & 4,0 & 4,04 & 1,98 & 3,0 & 3,38 & 1,89 & 18,527 & 0,000 \\
M- & 6,0 & 5,52 & 2,23 & 5,0 & 4,88 & 2,15 & 13,427 & 0,000 \\
O- & 4,0 & 4,45 & 2,24 & 3,0 & 3,53 & 2,11 & 27,663 & 0,000 \\
w- & 7,0 & 7,00 & 2,93 & 6,0 & 5,95 & 2,64 & 23,108 & 0,000 \\
k- & 6,0 & 6,65 & 2,72 & 5,0 & 5,55 & 2,54 & 28,011 & 0,000 \\
s- & 7,0 & 6,78 & 2,90 & 5,0 & 5,54 & 2,67 & 31,359 & 0,000 \\
z- & 7,0 & 6,45 & 3,01 & 5,0 & 5,35 & 2,78 & 22,906 & 0,000 \\
v- & 7,0 & 6,83 & 2,98 & 5,0 & 5,67 & 2,78 & 25,465 & 0,000 \\
g- & 7,0 & 6,67 & 2,77 & 6,0 & 5,86 & 2,68 & 13,840 & 0,000 \\
m- & 8,0 & 7,64 & 3,13 & 7,0 & 6,47 & 2,91 & 23,925 & 0,000 \\
o- & 7,0 & 6,89 & 3,01 & 6,0 & 5,85 & 2,95 & 18,748 & 0,000 \\
\hline
\end{tabular}

A comparação estatística das médias de escolhas negativas dos radicais de inclinação primários ponderados do BBT-Br do grupo masculino apontaram diferenças significativas em todos os radicais, em função da origem escolar. Os estudantes de escolas particulares apresentaram maiores médias nos oito radicais de inclinação motivacional propostos por Achtnich (1991), sinalizando tendência geral de maior seletividade frente às escolhas das atividades profissionais (fotos) representadas no BBT-Br. Certamente este resultado 
relaciona-se ao dado geral de produtividade do grupo masculino no $\mathrm{BBT}-\mathrm{Br}$, onde o grupo de escola particular apresentou, como acima comentado, significativo maior número de escolhas negativas (tanto na estrutura primária quanto na secundária). Este perfil de produção pode influenciar, posteriormente, a distribuição de frequiência nos radicais de inclinação motivacional, como pareceu ocorrer neste caso. Dessa forma, os resultados foram sugestivos de tendência dos alunos de escolas particulares rejeitarem maior quantidade de opções de atividades profissionais fornecidas pelo BBT-Br, em comparação com a maior aceitação das mesmas pelos estudantes de escolas públicas, o que deverá ser devidamente considerado no processo de interpretação dos resultados..

Os dados apresentados nesta seção do estudo, relativos às duas versões do BBT-Br, apresentaram evidências empíricas de diferenciação nos interesses profissionais e inclinações ocupacionais de estudantes oriundos de diferentes contextos escolares, especialmente no caso da amostra masculina. Sendo assim, considerou-se adequado examinar, com mais detalhes, possível efeito da série escolar ( $1^{\mathrm{a}}, 2^{\mathrm{a}}$ ou $3^{\mathrm{a}}$ séries do Ensino Médio) sobre os resultados neste método projetivo de avaliação psicológica, o que será a seguir apresentado, em função da versão específica (feminina e masculina) do BBT-Br.

\subsubsection{Série escolar e indicadores do BBT-Br}

A evolução acadêmica no interior do Ensino Médio brasileiro prevê atividades de complexidade crescente, acompanhando o amadurecimento físico, cognitivo e afetivo do estudante. Dentro deste contexto e da evidência anterior de diferenças estatisticamente significativas entre as variáveis do BBT-Br de estudantes de escolas públicas e particulares, considerou-se que a série escolar poderia ser outra variável de influência sobre os resultados nesta técnica projetiva. Desta forma foram examinados os índices de produtividade no BBT$\mathrm{Br}$, bem como a distribuição de freqüência dos radicais de inclinação motivacional (estruturas de inclinação motivacional, positivas e negativas), em função do ano escolar, respeitando-se cada versão deste instrumento de avaliação psicológica.

\subsubsection{Forma feminina}

A estatística descritiva (mediana, média e desvio padrão) e inferencial da produtividade na versão feminina do BBT-Br foi sistematizada em função do ano escolar. 
Comparou-se, portanto, resultados das alunas de $1^{\mathrm{a}}, 2^{\mathrm{a}}$ e $3^{\mathrm{a}}$ séries do Ensino Médio por meio da ANOVA one way, dados que compõem a Tabela 11.

Tabela 11 - Estatística descritiva (mediana, média e desvio padrão) e inferencial (ANOVA) da produtividade do BBT-Br Feminino (n=862) em função da série escolar. As diferenças significativas foram destacadas para melhor visualização.

\begin{tabular}{llccccc}
\hline \multicolumn{2}{c}{ Variável BBT-Br } & & & & \multicolumn{2}{c}{ ANOVA } \\
& & Med. & Média & DP & F & Sig. \\
\hline Escolhas + & $1^{\text {a }}$ série & 37 & 38,13 & 15,11 & 18,466 & 0,000 \\
& $2^{\text {a }}$ série & 35 & 36,09 & 13,70 & & \\
& $3^{\text {a }}$ série & 31 & 31,30 & 14,14 & & \\
Escolhas - & $1^{\text {a }}$ série & 39 & 40,97 & 15,50 & 3,127 & 0,044 \\
& $2^{\text {a }}$ série & 41 & 41,72 & 15,69 & & \\
Escolhas 0 & $3^{\text {a }}$ série & 43 & 44,06 & 16,64 & & \\
& $1^{\text {a }}$ série & 16 & 16,89 & 9,53 & 11,203 & 0,000 \\
& $2^{\text {a }}$ série & 17,5 & 18,19 & 9,92 & & \\
& $3^{\text {a }}$ série & 21 & 20,64 & 10,20 & & \\
\hline
\end{tabular}

Foram encontradas diferenças estatisticamente significativas entre os índices de produtividade (escolhas positivas, negativas e neutras) das três séries escolares analisadas. Para identificar a direção dessas diferenças entre os níveis escolares, foi realizado o teste de Tukey, considerando $p<0,05$. Os resultados detalhados dessas análises (tabelas de homogeneidade obtidas) encontram-se no Apêndice A. Desta maneira, identificaram-se as seguintes diferenças:

- nas escolhas positivas: a $3^{\mathrm{a}}$. série apresentou significativo $(p=0,000)$ menor número de escolhas positivas do BBT-Br do que as outras duas séries.

- nas escolhas negativas: a diferença ocorreu de modo significativo $(p=0,051)$ entre a $1^{\mathrm{a}}$ série e a $3^{\mathrm{a}}$ série, com número médio maior de escolhas negativas no último ano.

- nas escolhas neutras: novamente foram identificadas diferenças entre a $3^{\mathrm{a}}$ série e as demais, com número médio maior de escolhas neutras por parte do último ano $\left(p=0,000\right.$ para $1^{\mathrm{a}}$ série, $p=0,008$ para $2^{\mathrm{a}}$ série).

Observou-se que as alunas da $3^{\text {a }}$ série tendem a restringir seus interesses, selecionando menos fotos positivas que as demais estudantes. Conseqüentemente, ocorreu o aumento de escolhas negativas e neutras por parte das estudantes do último ano, indicando maior rejeição e indiferença aos estímulos do BBT-Br feminino ou talvez maior foco em suas áreas motivacionais. 
Reconhecida esta diferenciação nos índices de produtividade do BBT-Br em função da série escolar, passo-se ao exame das estruturas de inclinação motivacional (positivas e negativas). Desse modo, a Tabela 12 apresenta a estatística descritiva (mediana, média e desvio padrão) e inferencial (ANOVA one way) das escolhas positivas dos radicais de inclinação motivacional, comparando-se resultados do grupo feminino de $1^{\mathrm{a}}, 2^{\mathrm{a}}$ e $3^{\mathrm{a}}$ séries do Ensino Médio.

Tabela 12 - Estatística descritiva (mediana, média e desvio padrão) e inferencial das estruturas de inclinação motivacional positiva (primária e secundária) do BBT-Br da Amostra Feminina (n=862), em função da série escolar.

\begin{tabular}{|c|c|c|c|c|c|c|c|c|c|c|c|}
\hline \multirow{2}{*}{$\begin{array}{l}\text { Variável } \\
\text { BBT-Br }\end{array}$} & \multicolumn{3}{|c|}{$1^{\mathrm{a}}$ Série $(\mathrm{n}=253)$} & \multicolumn{2}{|c|}{$2^{\text {a }}$ Série $(n=256)$} & \multicolumn{4}{|c|}{$3^{a}$ Série $(n=353)$} & \multicolumn{2}{|c|}{ ANOVA } \\
\hline & Med. & Média & DP & Med. & Média & DP & Med. & Média & DP & $\mathrm{F}$ & Sig. \\
\hline $\mathrm{W}+$ & 3,0 & 3,28 & 2,01 & 3,0 & 3,10 & 1,90 & 3,0 & 3,20 & 1,89 & 0,560 & 0,571 \\
\hline $\mathrm{K}+$ & 1,0 & 1,10 & 1,21 & 1,0 & 0,99 & 1,25 & 1,0 & 1,46 & 1,20 & 9,211 & 0,000 \\
\hline Spond+ & 4,0 & 4,13 & 1,75 & 4,0 & 3,91 & 1,75 & 3,5 & 3,47 & 1,79 & 11,292 & 0,000 \\
\hline Zpond+ & 4,0 & 3,94 & 1,81 & 3,5 & 3,66 & 1,62 & 3,0 & 2,94 & 1,75 & 27,558 & 0,000 \\
\hline Vpond+ & 2,5 & 2,64 & 1,51 & 2,0 & 2,45 & 1,43 & 2,0 & 2,38 & 1,48 & 2,303 & 0,101 \\
\hline Gpond+ & 3,5 & 3,35 & 1,66 & 3,0 & 3,14 & 1,60 & 2,5 & 2,52 & 1,55 & 22,270 & 0,000 \\
\hline M+ & 2,0 & 1,83 & 1,36 & 2,0 & 1,87 & 1,43 & 2,0 & 1,95 & 1,25 & 0,569 & 0,566 \\
\hline $\mathrm{O}+$ & 4,0 & 3,91 & 1,83 & 4,0 & 3,85 & 1,77 & 3,0 & 3,46 & 1,71 & 5,736 & 0,003 \\
\hline w+ & 6,0 & 6,33 & 2,51 & 6,0 & 6,08 & 2,42 & 5,0 & 5,21 & 2,46 & 17,641 & 0,000 \\
\hline $\mathrm{k}+$ & 4,0 & 3,91 & 2,08 & 4,0 & 3,84 & 2,11 & 3,0 & 3,47 & 2,05 & 3,920 & 0,020 \\
\hline s+ & 5,0 & 4,70 & 2,26 & 4,0 & 4,59 & 2,21 & 4,0 & 4,33 & 2,23 & 2,252 & 0,106 \\
\hline $\mathrm{z}+$ & 6,0 & 5,95 & 2,51 & 5,0 & 5,27 & 2,41 & 5,0 & 4,61 & 2,46 & 21,711 & 0,000 \\
\hline $\mathrm{v}+$ & 4,0 & 3,90 & 2,32 & 3,0 & 3,64 & 2,11 & 3,0 & 3,26 & 1,81 & 7,022 & 0,001 \\
\hline $\mathrm{g}+$ & 4,0 & 4,54 & 2,36 & 4,0 & 4,52 & 2,31 & 4,0 & 3,94 & 2,24 & 6,633 & 0,001 \\
\hline $\mathrm{m}+$ & 5,0 & 4,88 & 2,48 & 4,0 & 4,47 & 2,31 & 4,0 & 4,19 & 2,17 & 6,569 & 0,001 \\
\hline $\mathrm{O}+$ & 4,0 & 4,01 & 2,37 & 4,0 & 3,79 & 2,06 & 3,0 & 3,53 & 2,12 & 3,515 & 0,030 \\
\hline
\end{tabular}

As escolhas positivas dos radicais primários ponderados do grupo feminino de estudantes evidenciaram diferenças estatisticamente significativas entre as séries escolares em cinco radicais de inclinação: K, S, Z, G e O. Visando identificar entre quais séries escolares se encontravam as diferenças, foi realizada a prova de Tukey, que localiza as diferenças entre grupos, considerando $p<0,05$. Os Apêndices B e C apresentam as tabelas de homogeneidade obtidas nesta análise. Desta forma foi possível notar que as estudantes da $3^{\text {a }}$ série apresentaram menor média de escolhas positivas em quatro destes cinco radicais de inclinação motivacional. Apenas no radical de inclinação $\mathrm{K}$ as estudantes da $3^{\mathrm{a}}$ série apresentaram maior número de escolhas positivas, indicando maior interesse por atividades perseverantes e competitivas. Em relação aos demais radicais, as evidências foram sugestivas de menor interesse, no último do ensino médio, por atividades que envolvam, em termos gerais, 
elementos de senso social, apuro estético, criatividade e comunicação/nutrição. Essa peculiaridade deverá ser tomada em conta em processos interpretativos do BBT-Br.

Por sua vez, a comparação das estruturas positivas secundárias da amostra feminina apontou diferenças significativas em sete radicais secundários de inclinação: $w, k, z, v, g, m \mathrm{e}$ $o$. Utilizando-se o teste post hoc de Tukey $(p<0,05)$ as diferenças foram localizadas da seguinte maneira:

- Em $w$ e $g: 3^{a}$ série realizou menor número de escolhas positivas desses radicais secundários, sugerindo menor interesse por ambientes de trabalho que possibilitem o contato direto, afetuoso, com o outro, a criatividade, inovação.

- Em $k, v, m$ e $o$ : foram encontradas diferenças entre a $3^{\text {a }}$ série e a $1^{\text {a }}$ série do Ensino Médio, sendo que, em todos estes radicais, as diferenças associaram-se a menor número de escolhas destes radicais secundários nas estudantes do último ano. Desse modo, os dados sugerem menor interesse da $3^{a}$. série do grupo feminino com relação a atividades realizadas em ambientes que implicam uso da força física, racionalidade, trabalho meticuloso e cotidiano e comunicação/nutrição.

- Em z: apresentou diferenças significativas entre todos as séries, indicando variabilidade das estudantes no tocante ao apuro estético, o embelezar, o mostrar-se. Observou-se que as estudantes da $1^{\text {a }}$ série apresentaram mais respostas positivas nesse radical, seguidas, em ordem decrescente, pelas estudantes da $2^{\mathrm{a}}$ série e $3^{\mathrm{a}}$ série, respectivamente.

Identificadas as áreas de interesse, segue-se o exame das rejeições motivacionais, a partir das escolhas negativas diante das fotos do BBT-Br, compondo as estruturas negativas (primária e secundária). A Tabela 13, que segue na próxima página, apresenta a estatística descritiva (mediana, média e desvio padrão) e inferencial (ANOVA one way) das escolhas negativas dos radicais de inclinação do BBT-Br realizadas pelas estudantes de $1^{\mathrm{a}}, 2^{\mathrm{a}}$ e $3^{\mathrm{a}}$ séries do Ensino Médio. 
Tabela 13 - Estatística descritiva (mediana, média e desvio padrão) e inferencial das estruturas de inclinação motivacional negativa (primária e secundária) do BBT-Br da Amostra Feminina (n=862), em função da série escolar.

\begin{tabular}{ccccccccccccc}
\hline $\begin{array}{l}\text { Variável } \\
\text { BBT-Br }\end{array}$ & $1^{\text {a }}$ Série $(\mathrm{n}=253)$ & \multicolumn{3}{c}{$2^{\text {a }}$ Série $(\mathrm{n}=256)$} & & \multicolumn{3}{c}{$3^{\mathrm{a}}$ Série $(\mathrm{n}=353)$} & & \multicolumn{2}{c}{ ANOVA } \\
& & & & & & & & & & & & \\
& & Med. & Média & DP & Med. & Média & DP & Med. & Média & DP & F & Sig. \\
\hline W- & 3,0 & 3,48 & 1,92 & 3,0 & 3,53 & 2,09 & 3,0 & 3,65 & 2,06 & 0,589 & 0,555 \\
K- & 6,0 & 5,92 & 1,74 & 6,0 & 6,10 & 1,67 & 6,0 & 5,82 & 1,85 & 1,879 & 0,153 \\
Spond- & 2,5 & 2,63 & 1,61 & 2,5 & 2,73 & 1,65 & 2,5 & 2,92 & 1,68 & 2,538 & 0,080 \\
Zpond- & 2,0 & 2,50 & 1,71 & 2,5 & 2,63 & 1,74 & 3,0 & 3,15 & 1,91 & 11,498 & 0,000 \\
Vpond- & 4,0 & 3,91 & 1,71 & 4,0 & 3,96 & 1,68 & 4,0 & 3,93 & 1,69 & 0,043 & 0,958 \\
Gond- & 3,0 & 3,01 & 1,70 & 3,0 & 3,08 & 1,65 & 3,5 & 3,52 & 1,69 & 8,477 & 0,000 \\
M- & 5,0 & 4,75 & 1,64 & 4,0 & 4,52 & 1,83 & 5,0 & 4,64 & 1,80 & 1,111 & 0,330 \\
O- & 3,0 & 2,85 & 1,68 & 3,0 & 2,80 & 1,74 & 3,0 & 3,24 & 1,76 & 5,845 & 0,003 \\
w- & 3,0 & 3,73 & 2,21 & 4,0 & 3,98 & 2,30 & 4,0 & 4,40 & 2,39 & 6,628 & 0,001 \\
k- & 6,0 & 5,70 & 2,33 & 5,5 & 5,62 & 2,40 & 6,0 & 5,96 & 2,47 & 1,674 & 0,188 \\
s- & 5,0 & 5,25 & 2,26 & 5,0 & 5,25 & 2,33 & 5,0 & 5,42 & 2,42 & 0,562 & 0,570 \\
z- & 4,0 & 4,02 & 2,36 & 4,0 & 4,46 & 2,56 & 5,0 & 5,05 & 2,60 & 12,497 & 0,000 \\
v- & 6,0 & 6,28 & 2,41 & 6,0 & 6,36 & 2,45 & 6,0 & 6,40 & 2,45 & 0,164 & 0,849 \\
g- & 5,0 & 4,94 & 2,51 & 5,0 & 4,76 & 2,48 & 5,0 & 5,38 & 2,61 & 4,894 & 0,008 \\
m- & 5,0 & 5,45 & 2,41 & 5,5 & 5,53 & 2,43 & 6,0 & 5,76 & 2,44 & 1,303 & 0,272 \\
o- & 6,0 & 5,76 & 2,59 & 6,0 & 5,78 & 2,46 & 6,0 & 6,12 & 2,72 & 1,909 & 0,149 \\
\hline
\end{tabular}

Os resultados da comparação entre os dados médios das escolhas negativas dos radicais de inclinação primários ponderados das estudantes das três séries apresentaram diferenças significativas entre os radicais Z, G e O. As análises post hoc do teste de Tukey (Apêndices D e E) apontaram que a $3^{\mathrm{a}}$ série diferiu das demais, apresentando maior número de escolhas negativas nesses radicais de inclinação, ou seja, rejeitaram mais atividades relacionadas ao apuro estético, criatividade e comunicação/nutrição.

Em relação às escolhas negativas, a comparação das estudantes do grupo feminino, das três séries escolares, sinalizou diferenças significativas em três radicais de inclinação secundários: $w, z$ e $m$. O teste Tukey, com nível de significância $p<0,05$, identificou que essas diferenças se distribuíram da seguinte maneira:

- Em $w$ : foram encontradas diferenças entre $1^{\mathrm{a}}$ e $3^{\mathrm{a}}$ séries $(p=0,001)$. As estudantes da $1^{\mathrm{a}}$ série sinalizaram menor rejeição de ambientes relacionados ao afeto, contato.

- Em z: a $3^{\mathrm{a}}$ série apresentou significativo maior número de rejeições desse radical, sugerindo menor interesse por ambientes que envolvam elementos estéticos e de destaque pessoal e de seu trabalho ( $p=0,000$ para $1^{\mathrm{a}}$ série, $p=0,013$ para $2^{\mathrm{a}}$ série).

-Em $g$ : as diferenças encontradas foram entre $2^{\mathrm{a}}$ e $3^{\mathrm{a}}$ séries $(p=0,008)$, sendo que as estudantes do último ano rejeitaram mais este radical, sugerindo menor interesse em ambientes relacionados à criatividade, intuição. 
As evidências encontradas, portanto, indicam especificidades de produção diante do BBT-Br acompanhando a evolução acadêmica de adolescentes do sexo feminino, estudantes do Ensino Médio. Essas variáveis, portanto, deverão ser levadas em consideração em processos interpretativos dos resultados obtidos com este método projetivo de avaliação psicológica.

\subsubsection{Forma masculina}

A estatística descritiva (mediana, média e desvio padrão) e inferencial da produtividade na versão masculina do BBT-Br foi sistematizada em função do ano escolar. Comparou-se, portanto, resultados dos alunos de $1^{\mathrm{a}}, 2^{\mathrm{a}}$ e $3^{\mathrm{a}}$ séries do Ensino Médio por meio da ANOVA one way, dados que compõem a Tabela 14.

Tabela 14 - Estatística descritiva (valores mínimo e máximo, média e desvio padrão) e inferencial (ANOVA) dos índices de produtividade do BBT-Br Masculino (n=720) para os estudantes da $1^{a}$ série (262), $2^{a}$ série $(n=181)$ e $3^{a}$ série $(n=277)$ do ensino médio.

\begin{tabular}{lcccccc}
\hline \multicolumn{2}{c}{ Variável BBT-Br } & & & & \multicolumn{2}{c}{ ANOVA } \\
& & Med. & Média & DP & F & Sig. \\
\hline Escolhas + & $1^{\text {a }}$ série & 26,5 & 28,61 & 16,10 & 3,411 & 0,034 \\
& $2^{\text {a }}$ série & 23 & 25,01 & 15,26 & & \\
& $3^{\text {a }}$ série & 27 & 28,30 & 14,82 & & \\
Escolhas - & $1^{\text {a }}$ série & 50 & 50,64 & 20,12 & 9,256 & 0,000 \\
& $2^{\text {a }}$ série & 52 & 52,03 & 20,06 & & \\
Escolhas 0 & $3^{\text {a }}$ série & 42 & 44,83 & 18,89 & & \\
& $1^{\text {a }}$ série & 16 & 16,75 & 11,05 & 16,986 & 0,000 \\
& $2^{\text {a }}$ série & 18 & 18,96 & 13,44 & & \\
& $3^{\text {a }}$ série & 22 & 22,87 & 12,71 & & \\
\hline
\end{tabular}

Os resultados apontaram diferenças estatisticamente significativas em todos os índices de produtividade do BBT-Br, em função da série escolar. Para identificar a direção dessas diferenças entre grupos, foi realizado a prova post hoc de Tukey $(p<0,05)$, (tabelas de homogeneidade no Apêndice F) resultando nos seguintes achados:

- Em relação às escolhas positivas: a diferença localizou-se entre a $1^{\mathrm{a}}$ e a $2^{\mathrm{a}}$ séries $(\mathrm{p}=0,042)$, com número menor de escolhas positivas por parte do segundo ano. 
- Em relação às escolhas negativas: a diferença foi entre a $3^{\text {a }}$ série e as demais, devido à frequiência média menor de rejeições por parte do último ano $\left(p=0,002\right.$ para $1^{\mathrm{a}}$ série, $p=0,000$ para $2^{\mathrm{a}}$ série).

- Em relação às escolhas indiferentes: diferenças novamente entre a $3^{\mathrm{a}}$ série e as demais ( $p=0,000$ para $1^{\mathrm{a}}$ série, $p=0,003$ para $2^{\mathrm{a}}$ série), talvez devido ao aumento de respostas neutras destes estudantes.

Observou-se que os alunos da $2^{\text {a }}$ série do Ensino Médio tenderam a selecionar menos atividades de interesse que os alunos da $1^{\text {a }}$ série. Já os alunos da $3^{\text {a }}$ série acabaram por rejeitar menos fotos que os alunos das demais turmas, ao mesmo tempo em que apresentaram maior indiferença às atividades profissionais representadas pelas fotos do BBT-Br masculino.

Reconhecidas essas especificidades de produção na versão masculina do BBT-Br, passou-se ao exame das estruturas de inclinação motivacional (positivas e negativas) em função da série escolar do Ensino Médio. A Tabela 15 apresenta a estatística descritiva (mediana, média e desvio padrão) e comparação estatística (ANOVA one way) dos radicais de inclinação positivos dos estudantes de $1^{\mathrm{a}}, 2^{\mathrm{a}}$ e $3^{\mathrm{a}}$ séries.

Tabela 15 - Estatística descritiva (mediana, média e desvio padrão) e inferencial (ANOVA) das estruturas de inclinação motivacional positiva (primária e secundária) do BBT-Br da Amostra Masculina (n=720), em função da série escolar.

\begin{tabular}{|c|c|c|c|c|c|c|c|c|c|c|c|}
\hline \multirow{2}{*}{$\begin{array}{l}\text { Variavel } \\
\text { BBT-Br }\end{array}$} & \multicolumn{3}{|c|}{$1^{\mathrm{a}}$ Série $(\mathrm{n}=262)$} & \multicolumn{3}{|c|}{$2^{a}$ Série $(n=181)$} & \multicolumn{3}{|c|}{$3^{a}$ Série $(n=277)$} & \multicolumn{2}{|c|}{ ANOVA } \\
\hline & Med. & Média & DP & Med. & Média & DP & Med. & Média & DP & $\mathrm{F}$ & Sig. \\
\hline W+ & 1,0 & 1,34 & 1,44 & 0,0 & 0,98 & 1,34 & 1,0 & 1,85 & 1,57 & 16,892 & 0,000 \\
\hline $\mathrm{K}+$ & 2,0 & 2,34 & 1,95 & 1,0 & 1,71 & 1,76 & 2,0 & 2,21 & 1,67 & 6,796 & 0,001 \\
\hline Spond+ & 3,0 & 2,99 & 1,62 & 2,5 & 2,54 & 1,49 & 2,75 & 2,77 & 1,59 & 4,404 & 0,013 \\
\hline Zpond+ & 2,0 & 2,23 & 1,69 & 1,5 & 1,86 & 1,57 & 2,0 & 2,11 & 1,59 & 2,775 & 0,063 \\
\hline Vpond+ & 2,5 & 2,47 & 1,65 & 2,5 & 2,62 & 1,79 & 2,5 & 2,70 & 1,70 & 1,185 & 0,306 \\
\hline Gpond+ & 2,5 & 2,85 & 1,71 & 2,5 & 2,56 & 1,65 & 3,0 & 2,91 & 1,60 & 2,752 & 0,065 \\
\hline M+ & 1,0 & 1,34 & 1,64 & 1,0 & 1,13 & 1,43 & 1,0 & 2,01 & 1,61 & 16,445 & 0,000 \\
\hline $\mathrm{O}+$ & 2,0 & 2,50 & 1,98 & 2,0 & 2,03 & 1,90 & 3,0 & 3,07 & 1,89 & 15,985 & 0,000 \\
\hline $\mathrm{w}+$ & 3,5 & 3,24 & 2,25 & 2,0 & 2,71 & 2,07 & 3,0 & 3,41 & 2,09 & 6,013 & 0,003 \\
\hline $\mathrm{k}+$ & 4,0 & 4,13 & 2,43 & 3,0 & 3,32 & 2,25 & 3,0 & 3,58 & 1,99 & 8,081 & 0,000 \\
\hline $\mathrm{s}+$ & 4,0 & 3,90 & 2,36 & 3,0 & 3,55 & 2,34 & 4,0 & 4,09 & 2,23 & 3,032 & 0,049 \\
\hline $\mathrm{z}+$ & 4,0 & 4,05 & 2,49 & 3,0 & 3,65 & 2,52 & 4,0 & 4,10 & 2,43 & 2,064 & 0,128 \\
\hline $\mathrm{v}+$ & 3,0 & 3,35 & 2,43 & 3,0 & 3,06 & 2,40 & 3,0 & 3,72 & 2,24 & 4,464 & 0,012 \\
\hline $\mathrm{g}+$ & 3,5 & 3,66 & 2,32 & 3,0 & 3,29 & 2,28 & 4,0 & 3,76 & 2,24 & 2,379 & 0,093 \\
\hline $\mathrm{m}+$ & 3,0 & 3,06 & 2,44 & 2,0 & 2,52 & 2,32 & 3,0 & 3,25 & 2,13 & 5,512 & 0,004 \\
\hline $\mathrm{O}+$ & 3,0 & 3,22 & 2,44 & 2,0 & 2,91 & 2,28 & 3,0 & 3,70 & 2,28 & 6,395 & 0,002 \\
\hline
\end{tabular}

A comparação entre as respostas positivas dos radicais de inclinação ponderados primários de estudantes de $1^{\mathrm{a}}, 2^{\mathrm{a}}$ e $3^{\mathrm{a}}$ séries do ensino médio, da amostra masculina, apontou 
diferenças significativas em cinco radicais de inclinação: $\mathrm{W}, \mathrm{K}, \mathrm{S}, \mathrm{M}$ e $\mathrm{O}$. A realização do teste de Tukey, com $p<0,05$, com suas tabelas de homogeneidade apresentadas nos Apêndices $\mathrm{G}$ e $\mathrm{H}$, discriminou as diferenças da seguinte maneira:

- Em W e O: foram encontradas diferenças entre todas as séries $\left(p=0,025\right.$ entre $1^{\mathrm{a}}$ e $2^{\mathrm{a}}, p=0,001$ entre $1^{\mathrm{a}}$ e $3^{\mathrm{a}}, p=0,000$ entre $2^{\mathrm{a}}$ e $3^{\mathrm{a}}$ ), indicando que, em diferentes níveis de escolaridade, os jovens selecionaram diferentemente as fotos relacionadas à atividades de contato, afetividade e fotos relacionadas à comunicação ou nutrição. Os alunos da $1^{\mathrm{a}}$ série tenderam a selecionar mais fotos positivas em $\mathrm{W}$, seguidos pelos alunos da $3^{\mathrm{a}}$ série. Já para o radical $\mathrm{O}$, os alunos da $3^{\mathrm{a}}$ série selecionaram mais fotos positivas, seguidos pelos alunos da $1^{\mathrm{a}}$ série;

- Em K: a $2^{\mathrm{a}}$ série selecionou menor número de fotos ( $p=0,000$ para $1^{\mathrm{a}}$ série, $p=0,004$ para $3^{\mathrm{a}}$ série) relacionadas a atividades que envolvem força física e exercício da agressividade (radical K).

- Em S: diferenças foram entre $1^{\mathrm{a}}$ e $2^{\mathrm{a}}$ séries $(p=0,009)$, sendo que os estudantes da $2^{\mathrm{a}}$ série selecionaram, em média, menos fotos com atividades relacionadas ao senso social, ajuda e dinamismo.

- Em M: a $3^{\text {a }}$ série escolheu, em média, mais fotos ( $p=0,000$ para as demais séries) relacionadas a esse radical, ou seja, a atividades que envolvam materiais concretos, o trabalho repetitivo e organizado, associado ao controle.

Em relação às escolhas positivas dos radicais de inclinação secundários desses estudantes, a comparação estatística apontou diferenças significativas entre seis radicais de inclinação secundários: $w, k, s, v, m$ e $o$. A verificação post hoc com o teste Tukey $(p<0,05)$ permitiu identificar as diferenças entre as séries escolares:

- Em $w$ e $m$ : a $2^{\text {a }}$ série selecionou menos fotos ( $p=0,026$ para $1^{\text {a }}$ série, $p=0,002$ para $3^{\text {a }}$ série) relacionadas a ambientes de afeto, cuidado e tarefas rotineiras, de asseio e cuidado.

- Em $s$ e $v$ : as diferenças foram entre $2^{\mathrm{a}}$ e $3^{\mathrm{a}}$ séries $(p=0,38 \mathrm{em} s, p=0,010 \mathrm{em} v$ ), sendo que estudantes da $3^{\mathrm{a}}$ série selecionaram mais fotos desses radicais, sugerindo maior interesse por ambientes dinâmicos, sociais, práticos, objetivos, associados a produção do conhecimento.

- Em $k$ : a $1^{\mathrm{a}}$ série escolheu mais fotos ( $p=0,000$ para $2^{\mathrm{a}}$ série, 0,011 para $3^{\mathrm{a}}$ série) relacionadas a ambientes onde o uso de força física, agressividade se faz presente.

- Em $o$ : a $3^{\mathrm{a}}$. série selecionou mais fotos $\left(p=0,050\right.$ para $1^{\mathrm{a}}$ série, 0,002 para $2^{\mathrm{a}}$ série) relacionadas a ambientes de contato social com comunicação ou ambientes de preparo e cuidado de alimentos.

Foi observado que os estudantes do grupo masculino de diferentes séries escolares do ensino médio tendem a responder ao BBT-Br de maneira diferente em quatro radicais de inclinação motivacional. Esse resultado aponta para especificidades de interesses profissionais 
entre as três séries do ensino médio estudadas. De modo geral, na comparação entre as três séries, pode-se apontar que os alunos da $1^{\text {a }}$ série apresentaram maior interesse por atividades relacionadas ao radical de inclinação $\mathrm{W}$. Já os alunos da $2^{\mathrm{a}}$ série tenderam a apresentar maior interesse por atividades relacionadas ao radical de inclinação $\mathrm{O}$, enquanto os alunos da $3^{\mathrm{a}}$ série demonstraram maior interesse em atividades relacionadas ao radical $\mathrm{M}$.

Em relação aos radicais secundários foram encontradas diferenças significativas entre seis radicais de inclinação, indicando que, em relação aos ambientes de trabalho, os alunos das três séries do ensino médio tendem a apresentar maior diversificação de interesses. Sintetizando os resultados, encontrou-se maior interesse em ambientes descritos pelo radical $k$ nos alunos da $1^{\mathrm{a}}$ série; menor número de escolhas positivas nos radicais secundários $w$ e $m$ por parte dos alunos da $2^{\mathrm{a}}$ série; e maior interesse em ambientes relacionados ao radical secundário $o$ por parte dos alunos da $3^{\mathrm{a}}$ série.

Também foi realizada a análise das estruturas negativas de inclinação motivacional (primárias e secundárias) da versão masculina do BBT-Br. A Tabela 16 apresenta a estatística descritiva (mediana, média e desvio padrão) e comparação estatística (ANOVA one way) da frequiência de escolhas negativas dos radicais de inclinação primários e secundários realizadas pelos estudantes do sexo masculino de $1^{\mathrm{a}}, 2^{\mathrm{a}}$ e $3^{\mathrm{a}}$ séries do Ensino Médio.

Tabela 16 - Estatística descritiva (mediana, média e desvio padrão) e inferencial (ANOVA one way) das estruturas de inclinação motivacional negativa (primária e secundária) do BBT-Br da Amostra Masculina (n=720), em função da série escolar.

\begin{tabular}{|c|c|c|c|c|c|c|c|c|c|c|c|}
\hline \multirow{2}{*}{$\begin{array}{l}\text { Variável } \\
\text { BBT-Br }\end{array}$} & \multicolumn{3}{|c|}{$1^{\text {a }}$ Série $(n=262)$} & \multicolumn{3}{|c|}{$2^{\text {a }}$ Série $(n=181)$} & \multicolumn{3}{|c|}{$3^{\text {a }}$ Série $(n=277)$} & \multicolumn{2}{|c|}{ ANOVA } \\
\hline & Med & Média & DP & Med. & Média & DP & Med. & Média & DP & $\mathrm{F}$ & Sig. \\
\hline W- & 6,0 & 5,39 & 2,02 & 6,0 & 5,66 & 1,89 & 6,0 & 5,21 & 2,22 & 2,555 & 0,078 \\
\hline $\mathrm{K}-$ & 5,0 & 4,65 & 2,21 & 5,0 & 5,04 & 2,14 & 5,0 & 4,77 & 2,03 & 1,838 & 0,160 \\
\hline Spond- & 3,5 & 3,73 & 1,82 & 4,0 & 4,06 & 1,75 & 3,0 & 3,36 & 1,72 & 9,005 & 0,000 \\
\hline Zpond- & 4,5 & 4,41 & 2,01 & 4,5 & 4,48 & 2,04 & 4,0 & 3,89 & 1,99 & 6,288 & 0,002 \\
\hline Vpond- & 3,5 & 3,76 & 2,07 & 3,0 & 3,53 & 2,11 & 3,0 & 3,05 & 1,90 & 8,523 & 0,000 \\
\hline Gpond- & 4,0 & 3,85 & 2,01 & 4,0 & 3,81 & 1,98 & 3,0 & 3,18 & 1,79 & 9,698 & 0,000 \\
\hline M- & 5,0 & 5,16 & 2,19 & 6,0 & 5,34 & 2,19 & 5,0 & 4,82 & 2,18 & 3,378 & 0,035 \\
\hline O- & 4,0 & 3,96 & 2,22 & 4,0 & 4,21 & 2,29 & 3,0 & 3,41 & 2,04 & 7,986 & 0,000 \\
\hline w- & 6,0 & 6,20 & 2,77 & 7,0 & 6,82 & 2,70 & 6,0 & 5,99 & 2,78 & 5,048 & 0,007 \\
\hline $\mathrm{k}-$ & 6,0 & 5,81 & 2,68 & 6,0 & 6,40 & 2,65 & 5,0 & 5,63 & 2,56 & 4,803 & 0,008 \\
\hline S- & 6,0 & 6,09 & 2,83 & 6,0 & 6,33 & 2,93 & 5,0 & 5,51 & 2,64 & 5,436 & 0,005 \\
\hline Z- & 6,0 & 5,93 & 2,91 & 6,0 & 5,97 & 3,06 & 5,0 & 5,29 & 2,73 & 4,338 & 0,013 \\
\hline V- & 6,0 & 6,44 & 2,98 & 6,0 & 6,27 & 2,90 & 5,0 & 5,50 & 2,73 & 7,841 & 0,000 \\
\hline g- & 6,0 & 6,36 & 2,77 & 6,0 & 6,36 & 2,82 & 5,0 & 5,71 & 2,59 & 4,892 & 0,008 \\
\hline m- & 7,0 & 7,15 & 3,03 & 8,0 & 7,31 & 3,08 & 7,0 & 6,22 & 2,89 & 9,543 & 0,000 \\
\hline o- & 7,0 & 6,66 & 2,97 & 6,0 & 6,57 & 3,07 & 5,0 & 5,45 & 2,87 & 13,413 & 0,000 \\
\hline
\end{tabular}


A comparação das escolhas negativas dos radicais de inclinação primários ponderados entre estudantes do sexo masculino, das três séries do ensino médio, evidenciou diferenças significativas em seis radicais de inclinação: $\mathrm{S}, \mathrm{Z}, \mathrm{V}, \mathrm{G}, \mathrm{M}$ e $\mathrm{O}$. A realização do teste Tukey para discriminar as diferenças entre os grupos identificou que todas as diferenças são entre os estudantes da $3^{\mathrm{a}}$ série e os estudantes com menor escolaridade ( $1^{\mathrm{a}}$ se $2^{\mathrm{a}}$ séries), sendo que, para o radical $\mathrm{M}$, esta diferença foi encontrada apenas com os estudantes da $2^{\mathrm{a}}$ série . As diferenças apontaram que os estudantes do último ano do Ensino Médio rejeitaram menos fotos de atividades relacionadas a estes cinco radicais de inclinação. Esses resultados indicam que os estudantes da $3^{\mathrm{a}}$. série rejeitam menos atividades relacionadas ao senso social, apuro estético, racionalidade, criatividade, constância/rotina e oralidade. As tabelas de homogeneidade destas análises encontram-se nos Apêndices I e J.

A comparação entre as escolhas negativas dos radicais secundários desses estudantes apontou diferenças significativas em todos os radicais de inclinação. O teste post hoc de Turkey identificou essas diferenças entre a $3^{\mathrm{a}}$ série e $2^{\mathrm{a}}$ série, para os radicais secundários $w, k$ e $s$, e entre as duas séries iniciais e a $3^{\text {a }}$ série para os demais radicais $(s, z, v, g, m, o)$. Essas diferenças se devem ao fato dos jovens da $3^{\text {a }}$ série rejeitarem, em média, menos fotos que os demais estudantes nesses radicais secundários de inclinação motivacional.

Nas comparações entre as estruturas de rejeição motivacional, observou-se que os alunos da $3^{\mathrm{a}}$ série do Ensino Médio tendem a apresentar menor rejeição à maioria dos radicais de inclinação primários (seis) e secundários (oito), em relação a seus colegas das demais séries avaliadas. Sendo assim, os alunos da $3^{\text {a }}$ série apresentaram menor rejeição tanto às atividades profissionais quanto aos ambientes de trabalho representados nas fotos do BBT-Br masculino.

A realização das análises estatísticas inferenciais sobre os indicadores do BBT-Br em função da origem e da série escolar do Ensino Médio ofereceu elementos adicionais para análises interpretativas da produção diante desse método projetivo, tanto em sua forma feminina quanto a masculina. Essas evidências empíricas agregam informações relevantes aos próprios referenciais normativos gerais aqui elaborados para este instrumento projetivo de avaliação de interesses e de inclinação motivacional, devendo ser consideradas em processos de interpretação dos resultados do BBT-Br. 


\subsection{VALIDADE DO BBT-Br}

A estratégia utilizada para se pesquisar evidências de validade das duas versões do BBT-Br no presente trabalho foi a realização de análises fatoriais exploratórias dos resultados obtidos com adolescentes do sexo feminino $(n=862)$ e do sexo masculino $(n=720)$, como já descrito no método. Desse modo, os resultados referentes à validade do BBT-Br serão apresentados, inicialmente, para a forma feminina e, posteriormente, para a forma masculina.

As análises fatoriais foram realizadas com extrações de quatro, cinco, seis, sete e oito fatores, apresentando-se a descrição das fotos componentes de cada fator, listando-se os radicais de inclinação originalmente previstos para cada um desses conjuntos de fotos, além dos autovalores e variância explicada de cada fator. A seguir, foi retomada a análise detalhada da solução de seis fatores, para ambas as versões do BBT-Br, visto que melhor se enquadrou aos critérios estatísticos e teóricos utilizados.

\subsubsection{Validade fatorial do BBT-Br Feminino.}

Antes de iniciar os processos de análise fatorial dos resultados da amostra feminina no BBT-Br, foi estimado o coeficiente de Kaiser-Meyer-Olkin (KMO) e realizado o teste de esfericidade de Bartlett $(p)$, que analisam as correlações parciais das variáveis, averiguando se as matrizes de dados seriam fatoráveis. Os resultados apontaram $\mathrm{KMO}=0,891$ e p < 0,000, possibilitando a realização da Principal Axis Factoring $(P A F)$, com rotação Varimax. A Tabela 17, a seguir, apresenta os resultados (número de fatores, fotos por fator, autovalor, variância explicada e radicais de inclinação motivacional) encontrados para a extração de quatro fatores dos dados femininos. 
Tabela 17 - Resultados encontrados pela extração de quatro fatores, método Principal Axis Factoring com rotação Varimax, para a amostra feminina $(n=862)$.

\begin{tabular}{|c|c|c|c|c|}
\hline Fator & Fotos BBT-Br & Autovalor & $\begin{array}{l}\text { Variância } \\
\text { explicada }\end{array}$ & $\begin{array}{l}\text { Radicais de } \\
\text { Inclinação }\end{array}$ \\
\hline 1 & $\begin{array}{c}70,42,52,31,34,26,23,36,16,37,92 \\
30,18,84,54,7,75,33,87,41,47,79,50 \\
27,76,67,13,56,4,35,19,45,5,15,21\end{array}$ & 13,92 & $7,68 \%$ & $\begin{array}{c}\mathrm{V}_{9} \mathrm{~K}_{5} \mathrm{G}_{5} \mathrm{M}_{5} \mathrm{Z}_{4} \mathrm{~S}_{3} \\
\mathrm{O}_{2} \mathrm{~W}_{2}\end{array}$ \\
\hline 2 & $\begin{array}{c}20,74,78,69,12,25,60,81,90,77,82,6 \\
66,86,38,32,28,80,9\end{array}$ & 4,47 & $5,72 \%$ & $\mathrm{Z}_{10} \mathrm{~S}_{3} \mathrm{G}_{3} \mathrm{~W}_{2} \mathrm{O}_{1}$ \\
\hline 3 & $\begin{array}{c}65,51,93,17,11,3,68,8,43,73,85,49 \\
1,22\end{array}$ & 4,16 & $5,04 \%$ & $\mathrm{~S}_{8} \mathrm{~W}_{3} \mathrm{G}_{2} \mathrm{O}_{1}$ \\
\hline 4 & $\begin{array}{c}61,96,62,88,72,95,48,94,14,91,44 \\
40,46 .\end{array}$ & 3,62 & $4,68 \%$ & $\mathrm{G}_{6} \mathrm{~V}_{3} \mathrm{O}_{2} \mathrm{Z}_{2}$ \\
\hline TOTAL & 81 fotos & 26,17 & $23,12 \%$ & $\begin{array}{c}\mathrm{Z}_{16} \mathrm{G}_{16} \mathrm{~S}_{14} \mathrm{~V}_{12} \mathrm{~W}_{7} \\
\mathrm{O}_{6} \mathrm{~K}_{5} \mathrm{M}_{5}\end{array}$ \\
\hline
\end{tabular}

A extração de quatro fatores, na amostra feminina, apresentou um total de 81 fotos com carga fatorial acima de 0,30 . Os autovalores dos fatores foram todos maiores que 1,00, variando entre 13,92 e 3,62. Apesar dos quatro fatores apresentarem variância explicada maior que 3\%, obedecendo ao critério de Harman (Zerbini, 2007), a variância total desta solução com quatro fatores foi de $23,12 \%$, resultado este que pode ser considerado frágil para a explicação dos resultados obtidos com a versão feminina do Teste de Fotos de Profissões BBT-Br. A distribuição dos radicais de inclinação motivacional no BBT-Br dentro dos quatro fatores aqui extraídos não favoreceu a interpretação dos mesmos, com aglutinação de fotos aparentemente desarticuladas dos respectivos radicais de inclinação motivacional teoricamente associados a elas, conforme Achtnich (1991). O número de itens por fator variou entre 13 e 35 fotos, com grande concentração de fotos no primeiro fator da extração. A pouca representatividade dos quatro fatores, aliado à discrepância no número de fotos por fator, dificultam a correta interpretação dos oito radicais de inclinação de Achtnich (1991). Sendo assim, a extração de quatro fatores não se mostrou a melhor representação estatística e teórica dos dados.

Diante deste contexto, efetivou-se a PAF com solução de cinco fatores. A Tabela 18 apresenta a sistematização desses resultados relativos à extração de cinco fatores para a versão feminina do BBT-Br. 
Tabela 18 - Resultados encontrados pela extração de cinco fatores, método Principal Axis Factoring com rotação Varimax, para a amostra feminina $(n=862)$.

\begin{tabular}{ccccc}
\hline Fator & Fotos BBT-Br & Autovalor & $\begin{array}{c}\text { Variância } \\
\text { explicada }\end{array}$ & $\begin{array}{c}\text { Radicais de } \\
\text { Inclinação }\end{array}$ \\
\hline 1 & $20,69,74,41,27,81,7,70,30,67$, & 13,92 & $7,21 \%$ & $\mathrm{Z}_{12} \mathrm{~S}_{6} \mathrm{G}_{4} \mathrm{M}_{2} \mathrm{~W}_{1}$ \\
& $90,6,12,82,78,52,92,80,19$, & & & $\mathrm{K}_{1} \mathrm{~V}_{1}$ \\
& $23,42,86,4,77,66,28,59$ & & & \\
2 & $24,35,34,58,33,57,21,56,26$, & 4,47 & $5,02 \%$ & $\mathrm{~K}_{5} \mathrm{M}_{5} \mathrm{~W}_{2} \mathrm{~V}_{2} \mathrm{O}_{2} \mathrm{~S}_{1}$ \\
& $55,39,50,18,15,31,36,63,75$ & & & $\mathrm{Z}_{1}$ \\
3 & $65,93,51,17,3,8,68,11,43$, & 4,16 & $4,78 \%$ & $\mathrm{~S}_{8} \mathrm{~W}_{3} \mathrm{G}_{2} \mathrm{O}_{2} \mathrm{Z}_{1}$ \\
& $73,85,49,32,22,1,60$ & & & \\
& $61,62,96,88,72,95,48,94$, & 3,62 & $4,52 \%$ & $\mathrm{G}_{5} \mathrm{~V}_{4} \mathrm{O}_{2} \mathrm{Z}_{2}$ \\
5 & $14,91,40,44,53$ & & & \\
TOTAL & $54,84,38,76,5,16,47,37$ & 3,19 & $4,12 \%$ & $\mathrm{G}_{4} \mathrm{~V}_{2} \mathrm{O}_{1} \mathrm{M}_{1}$ \\
& 82 fotos & 29,36 & $24,65 \%$ & $\mathrm{Z}_{16} \mathrm{~S}_{15} \mathrm{G}_{15} \mathrm{~V}_{9} \mathrm{M}_{8}$ \\
& & & & $\mathrm{O}_{7} \mathrm{~W}_{6} \mathrm{~K}_{6}$ \\
\hline
\end{tabular}

Os resultados apontaram que, com a extração de cinco fatores para a amostra feminina, 82 fotos apresentaram carga fatorial acima de 0,30 . Os autovalores de cada fator variaram entre 3,19 e 13,92. Em relação à variância explicada, os percentuais variaram entre $4,12 \%$ e $7,21 \%$, totalizando $24,65 \%$. Novamente, os dados obedecem ao critério de Harman (Zerbini, 2007), mas a variância acumulada total apresenta um valor considerado frágil para a explanação dos resultados. Observa-se maior coerência no agrupamento dos radicais de inclinação do BBT-Br em cada fator, em relação à extração de quatro fatores, mas ainda não apresentou um agrupamento que permitisse uma interpretação coerente, do ponto de vista teórico, dos radicais de inclinação de Achtnich (1991). O número de itens por fator variou de oito até 27 fotos, apresentando concentração de fotos no primeiro fator da extração.

Considerando-se as dificuldades interpretativas dessa extração de cinco fatores, procurou-se realizar outra PAF de modo a tentar representar adequadamente a distribuição dos dados obtidos com a versão feminina do BBT-Br. Dessa forma, a Tabela 19 apresenta os resultados da PAF com extração de seis fatores para o conjunto dos dados da amostra feminina de adolescentes aqui estudada. 
Tabela 19 - Resultados encontrados pela extração de seis fatores, método Principal Axis Factoring com rotação Varimax, para a amostra feminina $(n=862)$.

\begin{tabular}{ccccc}
\hline Fator & Fotos BBT-Br & Autovalor & $\begin{array}{c}\text { Variância } \\
\text { explicada }\end{array}$ & $\begin{array}{c}\text { Radicais de } \\
\text { Inclinação }\end{array}$ \\
\hline 1 & $70,30,41,52,67,42,7,90,23,6$, & 13,92 & $6,48 \%$ & $\mathrm{Z}_{6} \mathrm{G}_{4} \mathrm{M}_{3} \mathrm{~S}_{2} \mathrm{~V}_{2} \mathrm{~W}_{1}$ \\
& $31,92,81,27,82,4,87,36,80$ & & & $\mathrm{~K}_{1}$ \\
2 & $20,74,25,60,69,78,32,77,12$, & 4,47 & $4,74 \%$ & $\mathrm{Z}_{6} \mathrm{~W}_{3} \mathrm{~S}_{2} \mathrm{O}_{2} \mathrm{~V}_{1}$ \\
& $40,49,28,29,9$ & & \\
3 & $24,58,35,57,21,39,33,55$, & 4,16 & $4,41 \%$ & $\mathrm{~K}_{5} \mathrm{M}_{3} \mathrm{~W}_{2} \mathrm{O}_{2} \mathrm{~S}_{1} \mathrm{~V}_{1}$ \\
& $56,34,26,50,15,18$ & & \\
4 & $51,93,65,68,17,3,8,11,43,73,85,22$ & 3,62 & $4,26 \%$ & $\mathrm{~S}_{8} \mathrm{G}_{2} \mathrm{~W}_{1} \mathrm{O}_{1}$ \\
5 & $96,62,61,88,95,72,48,94,14$, & 3,19 & $4,12 \%$ & $\mathrm{G}_{6} \mathrm{~V}_{4} \mathrm{Z}_{2} \mathrm{O}_{1}$ \\
6 & $46,91,44,79$ & & & \\
TOTAL & $54,38,84,76,5,16,47$ & 2,80 & $3,87 \%$ & $\mathrm{G}_{4} \mathrm{~V}_{1} \mathrm{O}_{1} \mathrm{M}_{1}$ \\
& 79 fotos & 32,16 & $27,88 \%$ & $\mathrm{G}_{16} \mathrm{Z}_{14} \mathrm{~S}_{13} \mathrm{~V}_{9} \mathrm{M}_{7}$ \\
& & & & $\mathrm{~W}_{7} \mathrm{O}_{7} \mathrm{~K}_{6}$ \\
\hline
\end{tabular}

$\mathrm{Na}$ extração de seis fatores para os resultados da amostra feminina, foram encontradas 79 fotos do BBT-Br com carga fatorial acima de 0,30. Os autovalores dos fatores variaram entre 2,80 e 13,92. A variância explicada dos fatores variou de 3,87\% até 6,38\%, preenchendo o critério de Harman (Zerbini, 2007). Já a variância explicada acumulada foi de 27,88\%, índice mais elevado que as soluções precedentes, embora ainda razoavelmente limitado, porém comumente encontrado em análises semelhantes com métodos projetivos de avaliação psicológica, tendo em vista a complexidade e multideterminação dos construtos por eles examinados.

Observa-se que os fatores encontrados apresentam boa distribuição da quantidade de itens, com sete fotos no menor fator e 19 fotos no maior fator, favorecendo a interpretação dos resultados. O agrupamento dos radicais de inclinação de Achtnich, embora variada, permitiu reconhecimento teórico de elementos comuns (a serem destacados a seguir), possibilitando interpretações razoáveis para os fatores aqui identificados. Considerando estes aspectos, a extração de seis fatores foi a que melhor representou os dados da versão feminina do BBT-Br, teórica e estatisticamente.

Esta solução fatorial permitiu agrupamento dos radicais de inclinação do BBT-Br com hipóteses interpretativas plausíveis perante o embasamento teórico do instrumento, mostrando-se a PAF mais promissora em relação às demais extrações com quatro, cinco, sete 
e oito fatores. Essas hipóteses serão detalhadas no próximo tópico desta seção de resultados do atual estudo, com as considerações fator a fator desta extração.

Visando averiguar outras possibilidades de análise fatorial exploratória (pela PAF com rotação Varimax), procedeu-se a análise da extração de sete fatores. A Tabela 20 apresenta os resultados encontrados por esta solução fatorial de sete fatores com base nos dados desta amostra de adolescentes diante da versão feminina do BBT-Br.

Tabela 19 - Resultados encontrados pela extração de sete fatores, método Principal Axis Factoring com rotação Varimax, para a amostra feminina $(n=862)$.

\begin{tabular}{ccccc}
\hline Fator & Fotos BBT-Br & Autovalor & $\begin{array}{c}\text { Variância } \\
\text { explicada }\end{array}$ & $\begin{array}{c}\text { Radicais de } \\
\text { Inclinação }\end{array}$ \\
\hline 1 & $70,30,90,52,7,42,31,41,4,23,36,66,67$, & 13,92 & $5,86 \%$ & $\mathrm{Z}_{7} \mathrm{G}_{4} \mathrm{M}_{3} \mathrm{~W}_{2} \mathrm{~V}_{2} \mathrm{~K}_{1}$ \\
& $80,6,82,33,92,79$ & & & \\
2 & $20,69,12,74,81,27,77,78,19,10,86,28$ & 4,47 & $4,28 \%$ & $\mathrm{Z}_{6} \mathrm{~S}_{5} \mathrm{~K}_{1}$ \\
3 & $51,65,93,17,68,11,8,3,73,43,85,22$ & 4,16 & $4,19 \%$ & $\mathrm{~S}_{8} \mathrm{G}_{2} \mathrm{~W}_{1} \mathrm{O}_{1}$ \\
4 & $50,35,21,15,34,18,55,58$, & 3,62 & $4,15 \%$ & $\mathrm{~K}_{5} \mathrm{M}_{3} \mathrm{~V}_{2} \mathrm{O}_{2} \mathrm{~W}_{1} \mathrm{~S}_{1}$ \\
& $26,39,57,24,56,71$ & & & \\
5 & $96,62,61,88,95,72,48,94,14,46,44$ & 3,19 & $4,06 \%$ & $\mathrm{G}_{6} \mathrm{~V}_{2} \mathrm{Z}_{2} \mathrm{O}_{1}$ \\
6 & $54,38,84,76,5,16,47$ & 2,80 & $3,77 \%$ & $\mathrm{G}_{4} \mathrm{~V}_{1} \mathrm{O}_{1} \mathrm{M}_{1}$ \\
7 & $32,60,25,40,49,29,91,53,9$ & 2,70 & $3,68 \%$ & $\mathrm{~W}_{3} \mathrm{~V}_{3} \mathrm{O}_{2} \mathrm{Z}_{1}$ \\
TOTAL & 84 fotos & 34,86 & $29,99 \%$ & $\mathrm{Z}_{16} \mathrm{G}_{16} \mathrm{~S}_{14} \mathrm{~V}_{10} \mathrm{M}_{7}$ \\
& & & & $\mathrm{~W}_{7} \mathrm{~K}_{7} \mathrm{O}_{7}$ \\
\hline
\end{tabular}

Os resultados da extração com sete fatores para os resultados da amostra feminina apontaram 84 fotos com carga fatorial acima de 0,30. Os autovalores variaram entre 2,70 e 13,92. Todos os fatores apresentaram variância explicada acima de 3\%, cumprindo o critério de Harman (Zerbini, 2007), variando de 3,68\% a 5,86\% e com um total de $29,99 \%$, que pode ser considerado moderado para a explicação dos resultados, mas ainda passível de interpretação. Os radicais de inclinação do BBT-Br distribuíram-se de maneira razoavelmente consistente entre os fatores encontrados, com certa repetição dos mesmos radicais entre os fatores cinco e seis da extração. O número de fotos por fator pareceu bem distribuído, variando entre sete e 19 itens. Entretanto, a explicação de sete fatores para os interesses profissionais não apresenta suficiente e atual sustentação teórica a partir da literatura científica da área.

A seguir, efetivou-se a PAF (rotação Varimax) dos resultados da versão feminina do BBT-Br a partir da extração de oito fatores. Estes resultados compõem a Tabela 21. 
Tabela 20 - Resultados encontrados pela extração de oito fatores, método Principal Axis Factoring com rotação Varimax, para a amostra feminina $(n=862)$.

\begin{tabular}{|c|c|c|c|c|}
\hline Fator & Fotos BBT-Br & Autovalor & $\begin{array}{l}\text { Variância } \\
\text { explicada }\end{array}$ & $\begin{array}{l}\text { Radicais de } \\
\text { Inclinação }\end{array}$ \\
\hline 1 & $\begin{array}{c}70,30,90,52,42,7,31,80,66 \\
4,36,23,82,33,92,79\end{array}$ & 13,92 & $5,68 \%$ & $\overline{\mathrm{Z}_{7} \mathrm{G}_{3} \mathrm{M}_{3} \mathrm{~W}_{1} \mathrm{~K}_{1} \mathrm{~V}_{1}}$ \\
\hline 2 & $51,65,93,17,68,11,8,73,3,43,85,22$ & 4,47 & $4,19 \%$ & $\mathrm{~S}_{8} \mathrm{G}_{2} \mathrm{~W}_{1} \mathrm{O}_{1}$ \\
\hline 3 & $\begin{array}{c}50,35,21,55,15,34,18,58 \\
26,39,57,24,56,71\end{array}$ & 4,16 & $4,15 \%$ & $\mathrm{~K}_{5} \mathrm{M}_{3} \mathrm{~V}_{2} \mathrm{O}_{2} \mathrm{~W}_{1} \mathrm{~S}_{1}$ \\
\hline 4 & $96,62,61,88,95,72,48,94,14,46,44$ & 3,62 & $4,05 \%$ & $\mathrm{G}_{6} \mathrm{~V}_{2} \mathrm{Z}_{2} \mathrm{O}_{1}$ \\
\hline 5 & $54,38,84,76,5,16,47$ & 3,19 & $3,77 \%$ & $\mathrm{G}_{4} \mathrm{~V}_{1} \mathrm{O}_{1} \mathrm{M}_{1}$ \\
\hline 6 & $32,60,25,40,49,29,91,53$ & 2,80 & $3,74 \%$ & $\mathrm{~V}_{3} \mathrm{~W}_{2} \mathrm{O}_{2} \mathrm{Z}_{1}$ \\
\hline 7 & $81,27,19,69,77,78,10,28,86$ & 2,70 & $3,60 \%$ & $\mathrm{~S}_{5} \mathrm{Z}_{3} \mathrm{~K}_{1}$ \\
\hline 8 & $6,41,67,74,20,12$ & 2,12 & $2,38 \%$ & $\mathrm{Z}_{3} \mathrm{~W}_{1} \mathrm{G}_{1} \mathrm{~V}_{1}$ \\
\hline TOTAL & 83 fotos & 36,98 & $31,56 \%$ & $\begin{array}{l}\text { Z16 G16 M7 W6 } \\
\text { K7 V10 S14 O7 }\end{array}$ \\
\hline
\end{tabular}

A extração de oito fatores para os resultados da forma feminina do BBT-Br, como teoricamente proposto por Achtnich (1991), resultou em 83 fotos com carga fatorial adequada (acima de 0,30). Os autovalores encontrados variaram entre 2,12 e 13,92. A variância explicada dos fatores variou entre $2,38 \%$ e $5,68 \%$, não atingindo, portanto, o critério de Harman (Zerbini, 2007) de representatividade dos fatores. Já a variância acumulada foi de $31,56 \%$, um resultado que pode ser considerado parcialmente suficiente para a explicação dos resultados. Os radicais de inclinação do BBT-Br distribuíram-se de maneira razoavelmente coerente entre os fatores, apresentando, no entanto, repetições de radicais, como nos fatores quatro e cinco da tabela.

Pode-se notar ainda que os radicais de inclinação motivacional propostos por Achtnich (1991) não se distribuíram da maneira teoricamente prevista nos dados encontrados. O número de itens por fator foi equilibrado, variando de seis até 16 fotos. Considerando que o critério de Harman não foi obedecido e o agrupamento dos radicais de inclinação propostos por Achtnich (1991) não favorecia a interpretação dos dados, esta extração não foi considerada como a mais representativa dos dados.

Diante das evidências encontradas a partir das cinco PAF aqui realizadas, com diferentes números de fatores extraídos, ponderou-se que a extração de seis fatores apresentou melhores características estatísticas (variância explicada maior que 3\% para todos os fatores, 
número equilibrado de fotos por fator) e qualitativas (agrupamentos dos radicais de inclinação favorecendo a interpretação dos dados). Sendo assim, esta extração foi a selecionada como a melhor representação empírica dos dados obtidos pelo BBT-Br feminino e será detalhada no tópico 5.2.1.2., com análises foto a foto de cada fator. A seguir, são descritas as fotos rejeitadas, ou seja, que não atingiram a carga fatorial mínima de 0,30 em cada extração, de modo a buscar retratar e compreender a questão da representatividade das ocupações do BBTBr em seus estímulos (fotos).

\subsubsection{Fotos descartadas nas análises fatoriais exploratórias da versão feminina do BBT-Br:}

A análise das fotos rejeitadas nas extrações dos fatores das PAF realizadas também acrescenta informações importantes para o bom entendimento dos dados, pois oferece possibilidade de observar quais fotos apresentaram menor correlação com as demais, nas cinco extrações feitas. A Tabela 22 apresenta as fotos que não atingiram carga fatorial mínima de 0,30 nas PAFs realizadas com extração de quatro, cinco, seis, sete e oito fatores para a amostra feminina.

Tabela 21 - Itens (fotos) que não atingiram carga fatorial mínima $(0,30)$ nas PAFs (rotação Varimax) de quatro, cinco, seis, sete e oito fatores, da forma feminina do BBT-Br ( $n=862)$.

\begin{tabular}{clc}
\hline Extração PAF & \multicolumn{1}{c}{ Fotos com baixa carga fatorial } & Total fotos \\
\hline 4 fatores & $2,10,24,29,39,53,55,57,58,59,63,64$, & 15 \\
& $71,83,89$ & 14 \\
5 fatores & $2,9,10,13,25,29,45,46,64,71,79,83$, & \\
& 87,89 & 17 \\
6 fatores & $1,2,10,13,19,37,45,53,59,63,64,66$, & 12 \\
7 fatores & $71,75,83,86,89$, & 13 \\
8 fatores & $1,2,13,37,45,59,63,64,75,83,87,89$, & \\
\hline
\end{tabular}

Observa-se que a número de fotos da versão feminina do BBT-Br que não atingiram carga fatorial mínima de 0,30 variou de 12 até 17 fotos, a depender da quantidade de fatores extraídos nas PAF. A extração que apresentou maior número de fotos descartadas foi a extração de seis fatores, selecionada como mais representativa para o conjunto dos dados 
disponíveis sobre o grupo feminino de estudantes do ensino médio. Por outro lado, a PAF com oito fatores foi a que apontou menor número de fotos com baixa carga fatorial (total de 13 fotos).

Merece ainda destaque especial o dado relativo à baixa carga fatorial de oito fotos da versão feminina do BBT-Br, identificadas na maioria das PAF realizadas. A foto 2 (Cabeleireira para Homens), 64 (Balconista de Bar), 83 (Professora de Física/Matemática) e 89 (Veterinária) não atingiram a carga fatorial mínima $(0,30)$ nas cinco extrações realizadas. Já as fotos 59 (Guia de Turismo), 63 (Empregada em Antiquário), 13 (Torneira Mecânica), 45 (Técnica Eletrônica) foram descartadas em quatro das cinco extrações feitas. A ocorrência de baixas cargas fatoriais destas fotos pode ser sugestiva da necessidade de reformulação das mesmas, o que será devidamente discutido futuramente no presente trabalho (na discussão). Vale apenas destacar apenas a necessidade de reflexão teórico-metodológica sobre estes achados, inéditos sobre a versão feminina do BBT-Br até o momento.

No próximo tópico, portanto, será retomada a apresentação e a descrição dos resultados obtidos com a PAF de seis fatores realizada com os dados da versão feminina do BBT-Br, pensada aqui como uma solução fatorial mais conciliadora e explicativa do conjunto de resultados disponíveis com este método projetivo.

\subsubsection{Solução de seis fatores para versão feminina do BBT-Br:}

A realização da Principal Axis Factoring (PAF), com rotação Varimax e extração de seis fatores apresentou os melhores resultados na versão feminina do BBT-Br a partir da atual amostra de adolescentes, considerando-se os critérios estatísticos e teóricos. Visando detalhar esses resultados, foram sistematizadas tabelas apresentando os seis fatores encontrados, com descrições foto a foto de profissão, radical de inclinação teoricamente atrelado por Achtnich (1991), função, meios e instrumentos daquela atividade representada, bem como a carga fatorial identificada para cada foto. As colunas referentes à Função e Meios/Instrumentos, tiveram suas descrições aqui adaptadas a partir do manual normativo do BBT-Br Feminino (Jacquemin et. al, 2006).

Os resultados relativos a esta análise serão apresentados fator a fator, compondo seis tabelas. Inicialmente a Tabela 23 apresenta as descrições de fotos, profissionais representados, radical de inclinação, função, meios/instrumentos e carga fatorial do fator 1 obtido pela PAF com solução de seis fatores. 
Tabela 22 - Itens (fotos) da forma feminina do BBT-Br (n=862) que compõem o Fator 1 da PAF (rotação Varimax) de seis fatores, com respectivos radicais de inclinação de Achtnich.

\begin{tabular}{|c|c|c|c|c|c|}
\hline Foto & Profissional & Radical & Função & Meios/Instrumentos & $\begin{array}{l}\text { Carga } \\
\text { Fatorial } \\
\end{array}$ \\
\hline 70 & Mosaista & Zk & Montar obra de arte & $\begin{array}{c}\text { Senso artístico e estético, } \\
\text { força natural }\end{array}$ & 0,590 \\
\hline 30 & Pintora & $\mathrm{Gz}$ & Fazer obra de arte & $\begin{array}{c}\text { Imaginação, material de } \\
\text { desenho e pintura }\end{array}$ & 0,571 \\
\hline 41 & Harpista & $\mathrm{Wg}$ & $\begin{array}{c}\text { Interpretar de maneira } \\
\text { criativa }\end{array}$ & $\begin{array}{l}\text { Mãos, criatividade, força de } \\
\text { representação, intuição }\end{array}$ & 0,570 \\
\hline 52 & $\begin{array}{l}\text { Restauradora } \\
\text { de Arte }\end{array}$ & $\mathrm{Zm}$ & Embelezar, recriar & $\begin{array}{l}\text { Senso estético, tintas, } \\
\text { pincéis }\end{array}$ & 0,518 \\
\hline 67 & $\begin{array}{l}\text { Professora de } \\
\text { Piano }\end{array}$ & Vw & Ensinar, sensibilidade & Notas de música & 0,513 \\
\hline 42 & Escultora & $\mathrm{Kg}$ & $\begin{array}{c}\text { Talhar, utilizar sua força } \\
\text { de maneira criativa }\end{array}$ & Talha, cinzel, martelo, idéia & 0,509 \\
\hline 7 & Ceramista & Mw & Modelar, tocar, apalpar & $\begin{array}{l}\text { Argila, torno de ceramista, } \\
\text { recipientes, mãos }\end{array}$ & 0,493 \\
\hline 90 & $\begin{array}{l}\text { Organizadora } \\
\text { de Exposições }\end{array}$ & $\mathrm{Zm}$ & $\begin{array}{l}\text { Decorar, expor seu } \\
\text { trabalho }\end{array}$ & $\begin{array}{c}\text { Senso estético, luvas, meios } \\
\text { de conservação }\end{array}$ & 0,476 \\
\hline 23 & Horticultora & Ms & Trabalhar a terra & Mãos, amor à natureza & 0,458 \\
\hline 6 & Violonista & Gw & $\begin{array}{c}\text { Fazer música, execução } \\
\text { criativa }\end{array}$ & $\begin{array}{l}\text { Alma, instrumento de } \\
\text { música, sensibilidade lírica }\end{array}$ & 0,454 \\
\hline 31 & $\begin{array}{l}\text { Pintora de } \\
\text { Paredes }\end{array}$ & $\mathrm{Mz}$ & Misturar, mexer, pintar & $\begin{array}{c}\text { Tintas, pincéis, potes, senso } \\
\text { estético, discriminação } \\
\text { visual de cores }\end{array}$ & 0,431 \\
\hline 92 & Paleontóloga & $\mathrm{Gm}$ & Pesquisar, procurar origem & $\begin{array}{c}\text { Curiosidade investigativa, } \\
\text { livro, mapa }\end{array}$ & 0,416 \\
\hline 82 & Fotógrafa & $\mathrm{Zv}$ & Mostrar, tornar visível & $\begin{array}{l}\text { Senso de beleza, máquina } \\
\text { fotográfica, acessórios } \\
\text { técnicos }\end{array}$ & 0,383 \\
\hline 4 & Florista & $\mathrm{Zw}$ & Compor, ornar & $\begin{array}{c}\text { Senso estético, meios de } \\
\text { decoração, mãos }\end{array}$ & 0,379 \\
\hline 87 & $\begin{array}{l}\text { Engenheira } \\
\text { Florestal }\end{array}$ & $\mathrm{Vg}$ & Olhar, observar, examinar & $\begin{array}{l}\text { Conhecimentos científicos, } \\
\text { seguir instruções, } \\
\text { curiosidade investigativa }\end{array}$ & 0,371 \\
\hline 36 & Ourives & $\mathrm{Zv}$ & Modelar artesanalmente & $\begin{array}{l}\text { Senso estético, senso de } \\
\text { formas, instrumentos de } \\
\text { precisão }\end{array}$ & 0,365 \\
\hline 80 & Estilista & $\mathrm{Gz}$ & Criar, desenhar roupa & $\begin{array}{l}\text { Pensamento, imaginação, } \\
\text { criatividade, bom gosto, } \\
\text { lápis de cor, tabela de cores, } \\
\text { papel }\end{array}$ & 0,339 \\
\hline
\end{tabular}

O Fator 1 da extração de seis fatores pelo método da Principal Axis Factoring (PAF) englobou 17 fotos do BBT-Br, sendo seis associadas ao radical de inclinação primário Z, quatro associados ao radical primário $\mathrm{G}$, três ao radical primário $\mathrm{M}$, duas ao radical primário $\mathrm{V}$, uma associada ao radical primário $\mathrm{W}$ e uma associada ao radical primário K. Em relação aos radicais de inclinação secundários: quatro fotos associaram-se ao radical $w$; os radicais secundários $z, g$ e $m$ apareceram em três fotos cada; duas fotos ligadas ao radical $v$; e os radicais secundários $k$ e $s$, vertente $s_{e}$, tiveram uma foto cada. Observando as profissões representadas pelas fotos agrupadas 
neste fator, podemos notar sinais de focalização na estética, no belo, na arte, tanto quanto no uso da criatividade, da sensibilidade, da imaginação e inteligência no trabalho sobre materiais, sobre objetos concretos prioritariamente. Algumas fotos, como a foto 23 (Horticultora), a foto 92 (Paleontóloga) e a foto 87 (Engenheira Florestal) apresentam profissões que, à primeira vista, não parecem relacionadas com as demais. Entretanto, ao analisar as fotos representativas destas profissionais, pode-se observar que as atividades retratadas podem ser relacionadas ao cuidado estético, ao apuro no trabalho, podendo ser interpretadas também como atividades mais voltadas para a realização de trabalhos belos, admiráveis, socialmente reconhecidos, sobretudo na contemporaneidade (valorização da sensibilidade aos cuidados ambientais). Os ambientes agrupados neste fator relacionaram-se a locais onde as atividades normalmente são realizadas com auxílio de diversos instrumentos e ferramentas, muitas vinculadas a trabalho ao ar livre, bem como a ambientes culturalmente identificados como mais femininos, que possibilitam uso da sensibilidade e da criatividade, assim como o trabalho com materiais rústicos e artísticos.

Considerou-se, portanto, como hipótese compreensiva para este fator 1 da extração, que seria representativo dos seguintes radicais de inclinação motivacional de Achtnich (1991): associação dos radicais primários $\mathrm{Z}$ e $\mathrm{G}+$ radicais de inclinação secundários $w, z, g$ e $m$. De acordo com os pressupostos de Achtnich (1991), este fator 1 representaria o senso estético sobre materiais, a arte, o desejo de contato com o belo e com as necessidades estéticas, socialmente reconhecidas.

Prosseguindo a apresentação dos fatores obtidos pela PAF com solução de seis fatores dos dados femininos, apresenta-se a Tabela 24, que segue na próxima página. Os dados seguem a mesma sistematização dos resultados anteriores, embora focalizando o segundo fator desta análise fatorial exploratória. 
Tabela 23 - Itens (fotos) da forma feminina do BBT-Br (n=862) que compõem o Fator 2 da PAF (rotação Varimax) de seis fatores, com respectivos radicais de inclinação de Achtnich.

\begin{tabular}{|c|c|c|c|c|c|}
\hline Foto & Profissional & Radical & Função & Meios/Instrumentos & $\begin{array}{l}\text { Carga } \\
\text { Fatorial }\end{array}$ \\
\hline 20 & Artista de Circo & $\mathrm{Zs}$ & $\begin{array}{l}\text { Apresentar-se, } \\
\text { fazer acrobacia }\end{array}$ & Vestimenta, equilíbrio & 0,577 \\
\hline 74 & Bailarina & Zs & $\begin{array}{l}\text { Expressar-se } \\
\text { artisticamente }\end{array}$ & Corpo, figurino, ritmo, mobilidade & 0,501 \\
\hline 60 & $\begin{array}{l}\text { Vendedora de } \\
\text { Confecções }\end{array}$ & Zo & $\begin{array}{l}\text { Mostrar seu } \\
\text { trabalho }\end{array}$ & $\begin{array}{l}\text { Bom gosto, senso estético, } \\
\text { comunicação }\end{array}$ & 0,470 \\
\hline 69 & $\begin{array}{l}\text { Professora de } \\
\text { Educação Física }\end{array}$ & $\mathrm{S}_{\mathrm{h} / \mathrm{e}} \mathrm{k}$ & $\begin{array}{l}\text { Educar através } \\
\text { do movimento }\end{array}$ & Movimento, esportes, orça física & 0,469 \\
\hline 78 & Manequim & $\mathrm{Zz}$ & $\begin{array}{l}\text { Exibir-se, } \\
\text { apresentar }\end{array}$ & $\begin{array}{c}\text { Artigos de moda, vestimentas } \\
\text { bonitas }\end{array}$ & 0,465 \\
\hline 32 & $\begin{array}{l}\text { Vendedora de } \\
\text { Perfumaria }\end{array}$ & $\mathrm{O}_{\mathrm{r}} \mathrm{z}$ & $\begin{array}{l}\text { Demonstrar } \\
\text { perfume }\end{array}$ & Palavra, informação & 0,464 \\
\hline 77 & Aeromoça & $\mathrm{S}_{\mathrm{h} / \mathrm{e}} \mathrm{Z}$ & $\begin{array}{l}\text { Voar, viajar, } \\
\text { cuidar, ajudar }\end{array}$ & $\begin{array}{l}\text { Avião, disponibilidade, } \\
\text { apresentação cuidada, bonita }\end{array}$ & 0,444 \\
\hline 12 & $\begin{array}{c}\text { Atleta (em } \\
\text { apresentação) }\end{array}$ & $\mathrm{Zk}$ & Apresentar-se & $\begin{array}{l}\text { Expressão corporal, força, } \\
\text { persistência }\end{array}$ & 0,440 \\
\hline 40 & $\begin{array}{l}\text { Operadora de } \\
\text { Telemarketing }\end{array}$ & $\mathrm{O}_{\mathrm{r}} \mathrm{v}$ & $\begin{array}{l}\text { Informar, } \\
\text { atender }\end{array}$ & $\begin{array}{l}\text { Voz, telefone, microfone, } \\
\text { computador }\end{array}$ & 0,413 \\
\hline 49 & Esteticista & $\mathrm{Wm}$ & $\begin{array}{l}\text { Tratar da pele, } \\
\text { cuidar }\end{array}$ & Mãos, creme & 0,372 \\
\hline 28 & $\begin{array}{l}\text { Modelo } \\
\text { Fotográfico }\end{array}$ & $\mathrm{Zz}$ & $\begin{array}{l}\text { Apresentar-se, } \\
\text { mostrar-se }\end{array}$ & $\begin{array}{l}\text { Sua própria beleza corporal, } \\
\text { modelos bonitos }\end{array}$ & 0,361 \\
\hline 29 & $\begin{array}{l}\text { Programadora } \\
\text { Visual }\end{array}$ & $\mathrm{Vz}$ & $\begin{array}{l}\text { Usar } \\
\text { computador }\end{array}$ & Computador, atenção & 0,324 \\
\hline 9 & $\begin{array}{l}\text { Massagista } \\
\text { Fisioterapeuta }\end{array}$ & Wk & $\begin{array}{l}\text { Massagear com } \\
\text { força }\end{array}$ & Mãos & 0,323 \\
\hline $81 *$ & Alpinista & $\mathrm{S}_{\mathrm{e}} \mathrm{V}$ & $\begin{array}{l}\text { Fazer exercício, } \\
\text { treinamento }\end{array}$ & $\begin{array}{c}\text { Tênis, equilíbrio, atenção, } \\
\text { concentração, equipamento de } \\
\text { segurança }\end{array}$ & 0,315 \\
\hline $27 *$ & Esquiadora & $\mathrm{S}_{\mathrm{e}} \mathrm{z}$ & $\begin{array}{l}\text { Correr, deslizar } \\
\text { nas encostas }\end{array}$ & Esqui, coragem & 0,334 \\
\hline
\end{tabular}

*Fotos apresentaram crossloading e foram realocadas aqui por representar interesses profissionais semelhantes aos demais agrupados neste fator.

O Fator 2 da extração de seis fatores para a amostra feminina aglutinou 15 fotos, sendo que duas (fotos 81 e 27) apresentavam crossloadings com maior carga fatorial no Fator 1, mas foram aqui agrupadas devido a suas características interpretativas. Desta maneira, seis fotos associaram-se ao radical de inclinação primário Z; quatro ao radical primário S; duas ligadas ao radical primário $\mathrm{W}$; duas ao radical primário $\mathrm{O}$ (vertente $\mathrm{O}_{\mathrm{r}}$ ); e uma associada ao radical primário V. Quanto aos radicais de inclinação secundários, seis fotos representavam o radical $z$; três o radical $k$; duas o radical secundário $s$ (vertente $s_{e}$ ); outras duas fotos o radical secundário $v$; e os radicais $o$ (vertente $o_{r}$ ) foram representados em uma foto cada. Observando estas fotos, pode-se concluir que estas atividades profissionais profissões associam-se prioritariamente a tarefas que implicam o senso estético, envolvendo o mostrar-se, mostrar seu corpo, implicando em uso de energia e dinamismo, mesmo em relações que necessitam da 
ajuda, como no caso da aeromoça. Destaca-se aqui a utilização do corpo como arte, como um objeto a ser mostrado e socialmente reconhecido, apresentando um aspecto de dominação, persuasão, tanto em atividades de venda (como na foto 60, Vendedora) como da persuasão por meio do corpo, do trabalho e de ações corporais concretas. Os ambientes de trabalho também se relacionaram, prioritariamente, a contextos onde é valorizado o senso estético, a qualidade do trabalho, e mesmo a agressividade e a força necessária para a realização deste trabalho, associados a elementos concretos e ao próprio corpo do indivíduo.

Pode-se hipotetizar, portanto, que o fator 2 extraído desta PAF é representativo, pelos pressupostos teóricos de Achtnich (1991), dos radicais de inclinação primários $\mathrm{Z}$ e $\mathrm{S}_{\mathrm{e}}$ associados aos radicais de inclinação secundários $z$ e $k$. Poder-se-ia, dessa forma, pressupor que este fator 2 envolveu fotos que apresentam atividades de movimento, dinamismo, persuasão e reconhecimento social, com apresentação artística do trabalho.

A seqüência da presente análise implica no exame do fator 3 da PAF de seis fatores do BBT-Br feminino. Visando apresentar a diagramação dos resultados em página única, a Tabela 25 será apresentada na próxima página. 
Tabela 24 - Itens (fotos) da forma feminina do BBT-Br (n=862) que compõem o Fator 3 da PAF (rotação Varimax) de seis fatores, com respectivos radicais de inclinação de Achtnich.

\begin{tabular}{|c|c|c|c|c|c|}
\hline Foto & Profissional & Radical & Função & Meios/Instrumentos & $\begin{array}{l}\text { Carga } \\
\text { Fatorial }\end{array}$ \\
\hline 24 & Cozinheira & $\mathrm{O}_{\mathrm{n}} \mathrm{s}$ & Cozinhar & $\begin{array}{l}\text { Orgãos gustativos, cardápio, fogo, } \\
\text { forno, calor }\end{array}$ & 0,464 \\
\hline 58 & Açougueira & Ko & Cortar, abater & Faca & 0,455 \\
\hline 35 & Motorista de Táxi & $\mathrm{S}_{\mathrm{e}} \mathrm{V}$ & $\begin{array}{l}\text { Conduzir, } \\
\text { transportar, }\end{array}$ & $\begin{array}{l}\text { Carro, consciência profissional, } \\
\text { confiabilidade }\end{array}$ & 0,452 \\
\hline 57 & Garçonete & Wo & $\begin{array}{l}\text { Servir, servir } \\
\text { alimentos }\end{array}$ & Alimentos e bebidas & 0,451 \\
\hline 21 & Policial de Trânsito & Vs & $\begin{array}{l}\text { Organizar o } \\
\text { trânsito }\end{array}$ & Atenção, coragem & 0,450 \\
\hline 39 & Dona de Casa & $\mathrm{Mv}$ & $\begin{array}{l}\text { Lavar, limpar, } \\
\text { organizar }\end{array}$ & Produtos de limpeza, cuidado & 0,432 \\
\hline 33 & Costureira & Wv & $\begin{array}{l}\text { Costurar, uso } \\
\text { de tecidos }\end{array}$ & Mãos, fios, máquina de costura & 0,420 \\
\hline 55 & $\begin{array}{l}\text { Encarregada de } \\
\text { Lavanderia }\end{array}$ & $\mathrm{Mm}$ & Lavar, limpar & $\begin{array}{l}\text { Sabão, produtos de limpeza, } \\
\text { máquina de lavar }\end{array}$ & 0,417 \\
\hline 56 & Padeira Pasteleira & $\mathrm{O}_{\mathrm{n}} \mathrm{m}$ & $\begin{array}{l}\text { Cozinhar, } \\
\text { amassar }\end{array}$ & Farinha, massa & 0,411 \\
\hline 34 & Marceneira & $\mathrm{Kv}$ & $\begin{array}{l}\text { Aplainar, uso } \\
\text { da força física }\end{array}$ & Plaina, bancada de carpinteiro & 0,401 \\
\hline 26 & Torneadora & $\mathrm{Kz}$ & $\begin{array}{c}\text { Tornear, } \\
\text { modelar } \\
\text { artesanalmente }\end{array}$ & $\begin{array}{c}\text { Torno, bancada para tornear, senso } \\
\text { estético }\end{array}$ & 0,368 \\
\hline 50 & $\begin{array}{l}\text { Mecânica de } \\
\text { Automóveis }\end{array}$ & $\mathrm{Km}$ & $\begin{array}{l}\text { Apertar, } \\
\text { consertar carro }\end{array}$ & $\begin{array}{c}\text { Chave de fenda, ferramenta, } \\
\text { esforço físico }\end{array}$ & 0,365 \\
\hline 15 & Caseira de Sítio & Mk & $\begin{array}{l}\text { Trabalhar com } \\
\text { sítio }\end{array}$ & Forcado, garfão, força & 0,352 \\
\hline 18 & Amoladora & Ks & Afiar, aguçar & $\begin{array}{l}\text { Lixa para afiar, força da mão } \\
\text { (trabalho manual) }\end{array}$ & 0,349 \\
\hline $25^{*}$ & Cabeleireira & $\mathrm{Wz}$ & $\begin{array}{l}\text { Arrumar } \\
\text { cabelo }\end{array}$ & Escova, mãos & 0,326 \\
\hline
\end{tabular}

*Esta foto apresentou crossloading e foi realocada aqui por representar interesses profissionais semelhantes aos demais agrupados neste fator.

O Fator 3 resultante da extração de seis fatores da PAF do BBT-Br feminino agrupou 15 fotos, sendo que uma (foto 25) apresentou crossloading com maior carga fatorial no Fator 2, mas foi aqui realocada devido a suas possibilidades interpretativas. Neste agrupamento, cinco fotos representavam o radical de inclinação primário $\mathrm{K}$; três fotos com $\mathrm{M}$ e $\mathrm{W}$; duas com o radical primário $\mathrm{O}$ (vertente $\mathrm{O}_{\mathrm{n}}$ ); uma foto de $\mathrm{S}$ (vertente $\mathrm{S}_{\mathrm{e}}$ ) e outra de $\mathrm{V}$. Em relação aos radicais de inclinação secundários, quatro fotos associavam-se ao radical secundário $v$; três fotos de $m$ e de $s$ (vertente $\mathrm{s}_{\mathrm{e}}$ ); duas fotos de $o$ (vertentes $\mathrm{o}_{\mathrm{n}}$ e $\mathrm{o}_{\mathrm{r}}$ ) e de $z$; e uma foto associada ao radical secundário $k$. Este fator apresentou agrupamento de fotos de atividades profissionais relacionadas principalmente ao uso da força aplicada a objetos, a materiais, sem a exigência de relações interpessoais. A necessidade de afetuosidade e cuidado presente nos agrupamentos relacionou-se principalmente a objetos do trabalho, e não a outro indivíduo. Em relação aos ambientes de trabalho, emergiu destaque para locais que implicam no uso da 
razão, da lógica, com materiais rústicos, realização de atividades cotidianas e exigência de dinamismo, energia e disposição.

Levantou-se, portanto, a hipótese interpretativa de que este fator 3 agrupou os radicais de inclinação primários $\mathrm{K}, \mathrm{M}$ e W, relacionando-se com os radicais de inclinação secundários $v, s_{e}$ e $m$, pela teoria proposta por Achtnich (1991). Dessa forma, depreende-se que este terceiro fator está a representar elementos vinculados a atividades que exigem força física, principalmente aplicada em objetos, sem implicar relações interpessoais diretas.

A mesma sistematização dos resultados foi realizada para o próximo fator extraído pela solução de seis fatores. A seguir, a Tabela 26 apresenta os resultados referentes ao fator 4 da PAF de seis fatores do BBT-Br feminino.

Tabela 25 - Itens (fotos) da forma feminina do BBT-Br (n=862) que compõem o Fator 4 da PAF (rotação Varimax) de seis fatores, com respectivos radicais de inclinação de Achtnich.

\begin{tabular}{|c|c|c|c|c|c|}
\hline Foto & Profissional & Radical & Função & Meios/Instrumentos & $\begin{array}{l}\text { Carga } \\
\text { Fatorial }\end{array}$ \\
\hline 51 & $\begin{array}{l}\text { Enfermeira de } \\
\text { Idosos }\end{array}$ & $\mathrm{S}_{\mathrm{h}} \mathrm{m}$ & Ajudar, cuidar & $\begin{array}{c}\text { Disponibilidade a ajudar, vontade } \\
\text { de cuidar }\end{array}$ & 0,600 \\
\hline 93 & Fonoaudióloga & $\mathrm{S}_{\mathrm{h}} \mathrm{O}$ & $\begin{array}{l}\text { Ajudar, fazer } \\
\text { exercícios de }\end{array}$ & $\begin{array}{l}\text { Empatia, voz, gesto com a boca, } \\
\text { articulação verbal }\end{array}$ & 0,588 \\
\hline 65 & Pediatra & $\mathrm{S}_{\mathrm{h}} \mathrm{W}$ & $\begin{array}{l}\text { voz } \\
\text { Cuidar, curar, } \\
\text { tomar cuidado }\end{array}$ & Meios medicinais de ajuda & 0,559 \\
\hline 68 & Psicóloga Infantil & Gw & $\begin{array}{l}\text { Questionar, } \\
\text { refletir }\end{array}$ & $\begin{array}{l}\text { Estudo, imaginação, brinquedo, } \\
\text { instrumento lúdico, intuição }\end{array}$ & 0,548 \\
\hline 17 & Musicoterapeuta & Ws & $\begin{array}{l}\text { Ajudar, } \\
\text { trabalhar com } \\
\text { música }\end{array}$ & Instrumentos musicais, dedicação & 0,528 \\
\hline 3 & Professora Maternal & $\mathrm{S}_{\mathrm{h}} \mathrm{W}$ & $\begin{array}{l}\text { Cuidar de, } \\
\text { ajudar, ensinar }\end{array}$ & Bondade, alma, atenção terna & 0,492 \\
\hline 8 & Mãe com Criança & $\mathrm{O}_{\mathrm{r}} \mathrm{w}$ & $\begin{array}{l}\text { Brincar, dar } \\
\text { atenção }\end{array}$ & Brinquedos, atenção terna & 0,487 \\
\hline 11 & Enfermeira & $\mathrm{S}_{\mathrm{h}} \mathrm{k}$ & $\begin{array}{l}\text { Cuidar, curar, } \\
\text { ajudar, }\end{array}$ & $\begin{array}{c}\text { Vontade de ajudar, paciência, } \\
\text { compreensão, soro endovenoso, } \\
\text { força }\end{array}$ & 0,471 \\
\hline 43 & Professora Primária & $\mathrm{S}_{\mathrm{h} / \mathrm{e}} \mathrm{g}$ & $\begin{array}{l}\text { Conversar, } \\
\text { educar }\end{array}$ & Pedagogia, pensamento & 0,462 \\
\hline 73 & $\begin{array}{c}\text { Cooperante ao } \\
\text { Desenvolvimento }\end{array}$ & $\mathrm{S}_{\mathrm{h} / \mathrm{e}} \mathrm{S}$ & $\begin{array}{l}\text { Ajudar, assumir } \\
\text { responsabilidad } \\
\text { es }\end{array}$ & $\begin{array}{l}\text { Consolo, compreensão, } \\
\text { encorajamento, atitude religiosa }\end{array}$ & 0,426 \\
\hline 85 & Psicoterapeuta & $\mathrm{S}_{\mathrm{h}} \mathrm{g}$ & $\begin{array}{l}\text { Ajudar, } \\
\text { conversar, } \\
\text { cuidar }\end{array}$ & $\begin{array}{l}\text { Interesse pela pessoa, alma, } \\
\text { intuição, empatia }\end{array}$ & 0,403 \\
\hline 22 & Psicóloga em Grupo & Gs & $\begin{array}{l}\text { Entender, } \\
\text { refletir, ajudar }\end{array}$ & Empatia, interesse pela pessoa & 0,352 \\
\hline
\end{tabular}

O Fator 4 resultante da extração de seis fatores da PAF do BBT-Br feminino ficou composto por 12 fotos, sendo que oito delas associavam-se ao radical de inclinação primário 
S (sendo oito especificas na vertente $S_{h}$ ), duas fotos associadas a $G$; uma associada ao radical primário $\mathrm{W}$ e outra a $\mathrm{O}$ (vertente Or). Em relação aos radicais de inclinação secundários, quatro fotos estavam associadas ao radical de inclinação secundário $w$; três fotos associavamse ao radical secundário $s$ (vertente $s_{h}$ ); duas fotos associavam-se a $g$; e uma foto de cada radical secundário: $k, m$ e $o$ (vertente $o_{r}$ ). Este fator apresenta claramente o agrupamento de atividades profissionais relacionadas à ajuda, ao cuidar do outro. Os ambientes a que eles se referem também envolvem cuidado com o outro e relações interpessoais de ajuda. Desta maneira, pode-se observar que este fator agrupa fotos relacionadas ao radical de inclinação primário $\mathrm{S}$ (vertente $\mathrm{S}_{\mathrm{h}}$ ) e aos radicais de inclinação secundários $w$ e $s_{h}$, propostos por Achtnich (1991), envolvendo atividades de cuidado, proteção, relações de ajuda e afeto.

A seqüência da presente análise implica no exame do fator 5 da PAF de seis fatores do BBT-Br feminino. Estes resultados compõem a Tabela 27.

Tabela 26 - Itens (fotos) da forma feminina do BBT-Br (n=862) que compõem o Fator 5 da PAF (rotação Varimax) de seis fatores, com respectivos radicais de inclinação de Achtnich.

\begin{tabular}{|c|c|c|c|c|c|}
\hline Foto & Profissional & Radical & Função & Meios/Instrumentos & $\begin{array}{l}\text { Carga } \\
\text { Fatorial }\end{array}$ \\
\hline 96 & Conferencista & Go & $\begin{array}{c}\text { Convencer } \\
\text { pela fala, da } \\
\text { palestra }\end{array}$ & $\begin{array}{c}\text { Pensamento, informação, expressão } \\
\text { verbal, microfone }\end{array}$ & 0,599 \\
\hline 62 & Política & Go & $\begin{array}{l}\text { Discursar, } \\
\text { convencer pela } \\
\text { fala }\end{array}$ & $\begin{array}{l}\text { Idéias, força de persuasão, } \\
\text { comunicação, microfone, fala }\end{array}$ & 0,588 \\
\hline 61 & $\begin{array}{l}\text { Secretária } \\
\text { Estenógrafa }\end{array}$ & Vo & $\begin{array}{l}\text { Atenção, } \\
\text { escrever }\end{array}$ & $\begin{array}{l}\text { Escrita, máquina de escrever, } \\
\text { computador, comunicação }\end{array}$ & 0,566 \\
\hline 88 & Escritora & $\mathrm{Gg}$ & Criatividade & Pensamento, idéias & 0,538 \\
\hline 95 & $\begin{array}{l}\text { Empresária, } \\
\text { Mulher de } \\
\text { Negócios }\end{array}$ & Vo & Administrar & $\begin{array}{l}\text { Conhecimento, inteligência, } \\
\text { informação }\end{array}$ & 0,516 \\
\hline 72 & Advogada & $\mathrm{Gk}$ & $\begin{array}{l}\text { Questionar, } \\
\text { convencer pela } \\
\text { fala }\end{array}$ & $\begin{array}{l}\text { Força de persuasão, faro, dureza } \\
\text { psicológica }\end{array}$ & 0,494 \\
\hline 48 & $\begin{array}{c}\text { Repórter } \\
\text { Entrevistadora }\end{array}$ & $\mathrm{O}_{\mathrm{r}} \mathrm{g}$ & $\begin{array}{l}\text { Questionar, } \\
\text { transmitir }\end{array}$ & Palavra, contato, microfone & 0,412 \\
\hline 94 & $\begin{array}{c}\text { Apresentadora de } \\
\text { TV }\end{array}$ & Zo & $\begin{array}{l}\text { Apresentar, } \\
\text { transmitir } \\
\text { notícias }\end{array}$ & $\begin{array}{c}\text { Câmeras, boa aparência, microfone, } \\
\text { notícias/acontecimentos }\end{array}$ & 0,396 \\
\hline 14 & Delegada & Gk & Investigar & Poder de argumentação, algemas & 0,391 \\
\hline 46 & Estudante & $\mathrm{Gg}$ & $\begin{array}{l}\text { Compreender, } \\
\text { refletir }\end{array}$ & Pensamento, idéia & 0,343 \\
\hline 91 & $\begin{array}{l}\text { Bibliotecária } \\
\text { Arquivista }\end{array}$ & Vm & $\begin{array}{l}\text { Organizar, } \\
\text { administrar }\end{array}$ & Computador & 0,340 \\
\hline 44 & Publicitária & $\mathrm{Zg}$ & $\begin{array}{l}\text { Expor seu } \\
\text { trabalho }\end{array}$ & $\begin{array}{l}\text { Meios publicitários, fotos, } \\
\text { criatividade, capacidade de } \\
\text { convencimento }\end{array}$ & 0,334 \\
\hline 79 & Arquiteta & $\mathrm{Vz}$ & $\begin{array}{l}\text { Medir, } \\
\text { desenhar }\end{array}$ & $\begin{array}{l}\text { Computador, mesa de desenho, } \\
\text { régua, lápis, papel, caneta, senso } \\
\text { artístico e estético, criatividade }\end{array}$ & 0,313 \\
\hline
\end{tabular}


O Fator 5 resultante da extração de seis fatores da PAF do BBT-Br feminino agrupou 13 fotos, sendo seis delas associadas ao radical de inclinação primário G; quatro fotos associadas a $\mathrm{V}$; duas fotos de $\mathrm{Z}$ e uma foto associada ao radical primário $\mathrm{O}$ (vertente $\mathrm{O}_{\mathrm{r}}$ ). Em relação aos radicais de inclinação secundários, observamos que cinco fotos associavam-se ao radical secundário $o$ (vertente $o_{r}$ ), quatro ao radical secundário $g$; duas fotos de $k$ e uma foto cada dos radicais secundários $m$ e $z$. Observa-se que este fator agrupou fotos relacionadas a atividades que exigem inteligência, uso da razão, ou seja, tarefas que exigem relação interpessoal de comunicação criativa interligada com aspectos de fala (casos da foto 96, Conferencista, por exemplo) e aspectos mais concretos, com máquinas ou ferramentas (como nas fotos 79 e 91, Arquiteta e Bibliotecária, respectivamente). Os ambientes agrupados representaram, em sua maioria, facilitadores desta comunicação e locais de maior organização e sistematização lógica e abstrata locais de busca e aprimoramento do conhecimento.

Desta maneira, podemos hipotetizar que este fator seria representativo, pela teoria de Achtnich (1991), dos radicais de inclinação primários G e V, e dos radicais de inclinação secundários $o$ (vertente $o_{r}$ ) e $g$, englobando interesses em atividades de comunicação criativa, persuasão, criatividade.

Finalizando os resultados relativos à validade do BBT-Br Feminino, a Tabela 28 apresenta o fator 6 obtido pela PAF com solução de seis fatores realizada com dados da amostra feminina de adolescentes.

Tabela 27 - Itens (fotos) da forma feminina do BBT-Br (n=862) que compõem o Fator 6 da PAF (rotação Varimax) de seis fatores, com respectivos radicais de inclinação de Achtnich.

\begin{tabular}{|c|c|c|c|c|c|}
\hline Foto & Profissional & Radical & Função & Meios/Instrumentos & $\begin{array}{l}\text { Carga } \\
\text { Fatorial }\end{array}$ \\
\hline 54 & $\begin{array}{l}\text { Laboratorista } \\
\text { Clínica }\end{array}$ & $\mathrm{Gm}$ & $\begin{array}{l}\text { Pesquisar, } \\
\text { refletir }\end{array}$ & Pensamento científico, intuição & 0,721 \\
\hline 38 & $\begin{array}{l}\text { Laboratorista } \\
\text { Química }\end{array}$ & $\mathrm{Gv}$ & $\begin{array}{l}\text { Pesquisar, } \\
\text { refletir }\end{array}$ & $\begin{array}{l}\text { Pensamento, concentração, } \\
\text { computador, aparelhos }\end{array}$ & 0,702 \\
\hline 84 & Bióloga & Gv & $\begin{array}{l}\text { Pesquisar, } \\
\text { refletir }\end{array}$ & $\begin{array}{l}\text { Curiosidade investigativa, } \\
\text { microscópio, lupa, livro }\end{array}$ & 0,668 \\
\hline 76 & $\begin{array}{c}\text { Pesquisadora em } \\
\text { Física }\end{array}$ & Gs & $\begin{array}{l}\text { Pesquisar, } \\
\text { refletir }\end{array}$ & $\begin{array}{l}\text { Curiosidade investigativa, } \\
\text { independência e liberdade de espírito } \\
\text { como pressupostos à descoberta de } \\
\text { algo melhor, mais elaborado, genial, } \\
\text { aparelhos/máquinas elétricas }\end{array}$ & 0,612 \\
\hline 5 & $\begin{array}{l}\text { Controladora de } \\
\text { Qualidade Têxtil }\end{array}$ & Vw & $\begin{array}{l}\text { Verificar, } \\
\text { analisar }\end{array}$ & Microscópio, atenção, mãos & 0,555 \\
\hline 16 & Vidreira & $\mathrm{O}_{\mathrm{r} / \mathrm{n}} \mathrm{k}$ & $\begin{array}{l}\text { Soprar, mexer } \\
\text { vidro }\end{array}$ & Boca, ferramentas & 0,480 \\
\hline 47 & Tintureira & $\mathrm{Mg}$ & $\begin{array}{l}\text { Lavar, tratar } \\
\text { os produtos }\end{array}$ & $\begin{array}{l}\text { Produtos de limpeza, produtos } \\
\text { químicos }\end{array}$ & 0,356 \\
\hline
\end{tabular}


O último fator da PAF do BBT-Br feminino com solução de seis fatores aglutinou sete fotos. Quatro delas estavam associadas ao radical de inclinação primário $\mathrm{G}$ e as outras três fotos associavam-se, respectivamente, aos radicais primários $\mathrm{V}, \mathrm{O}$ e $\mathrm{M}$. Em relação aos radicais de inclinação secundários, duas fotos associavam-se ao radical secundário $v$ e as outras cinco associavam-se aos radicais secundários $m, s$ (vertente $s_{e}$ ), $w, k$ e $g$. Pode-se observar que este fator agrupou atividades profissionais que necessitam de criatividade e inteligência aplicadas ao concreto, à racionalidade e à lógica, realizando trabalhos de maior rigor e precisão e, ao mesmo tempo, de atividades analíticas. Na relação com os ambientes de trabalho, estas atividades mostraram-se vinculadas a diferentes contextos físicos, como laboratórios ou fábricas têxteis, porém sempre favorecedores do uso da sistematização, da razão e da inteligência, do trabalho lógico pautado sobre elementos concretos da realidade.

Diante dessas evidências, portanto, e dos pressupostos teóricos de Achtnich (1991), este sexto fator poderia ser pensado como agrupamento das fotos relacionadas aos radicais de inclinação $\mathrm{G}$ e $\mathrm{V}$, prioritariamente, tendo como radical secundário mais relevante o radical de inclinação $v$. Os interesses representados por essas atividades estariam, dessa forma, relacionados prioritariamente a objetividade, uso da lógica e da racionalidade, ao trabalho concreto, à concretude.

A PAF com extração de seis fatores, realizada com os dados da amostra feminina do $\mathrm{BBT}-\mathrm{Br}$, apresentou os melhores resultados, agrupando as fotos e os radicais de inclinação motivacional de Achtnich (1991) de maneira facilitadora da interpretação de resultados com este método projetivo de avaliação psicológica. Maiores considerações sobre esta extração serão realizadas posteriormente, na discussão dos atuais achados.

\subsubsection{Validade fatorial do BBT-Br Masculino.}

Assim como para os dados da amostra feminina, antes de iniciar os processos de análise fatorial dos dados da amostra masculina no BBT-Br, foi estimado o coeficiente de Kaiser-Meyer-Olkin (KMO) e realizado o teste de esfericidade de Bartlett ( $p$ ), para analisar as correlações parciais das variáveis, averiguando se as matrizes de dados seriam fatoráveis. Os resultados apontaram para KMO $=0,929$ e $\mathrm{p}<0,000$ possibilitando a realização da Principal Axis Factoring (PAF), com rotação Varimax.

Inicialmente serão apresentados os resultados (número de fatores, fotos por fator, autovalor, variância explicada e os radicais de inclinação) encontrados com a PAF com 
extração de quatro fatores dos dados da amostra masculina de adolescentes. Estes dados compõem a Tabela 29.

Tabela 28 - Resultados encontrados pela extração de quatro fatores, método Principal Axis Factoring com rotação Varimax, para a amostra masculina $(n=720)$.

\begin{tabular}{|c|c|c|c|c|}
\hline Fator & Fotos & Autovalor & $\begin{array}{l}\text { Variância } \\
\text { explicada }\end{array}$ & $\begin{array}{l}\text { Radicais de } \\
\text { Inclinação }\end{array}$ \\
\hline 1 & $\begin{array}{c}23,41,52,47,78,90,33,93,25,80,24,57 \\
8,31,86,91,81,43,30,63,39,55,66,88 \\
74,9,46,6,4,49,51,15,65,68,56,67\end{array}$ & 18,72 & $9,99 \%$ & $\begin{array}{c}\mathrm{Z}_{7} \mathrm{M}_{7} \mathrm{~W}_{6} \mathrm{G}_{6} \mathrm{~S}_{5} \mathrm{O}_{3} \\
\mathrm{~V}_{2}\end{array}$ \\
\hline 2 & $\begin{array}{c}83,76,54,45,84,37,75,71,38,92,87,79 \\
13,36,21\end{array}$ & 4,31 & $5,91 \%$ & $\mathrm{~V}_{9} \mathrm{G}_{5} \mathrm{Z}_{1}$ \\
\hline 3 & $\begin{array}{c}94,62,48,72,95,44,16,82,60,40,28,85 \\
96,70,61,14,22,20\end{array}$ & 3,98 & $5,72 \%$ & $\mathrm{Z}_{7} \mathrm{G}_{5} \mathrm{O}_{3} \mathrm{~V}_{2} \mathrm{~S}_{1}$ \\
\hline 4 & $\begin{array}{c}26,10,11,34,42,58,12,35,69,50,18,19 \\
27,2,64,53\end{array}$ & 3,11 & $5,56 \%$ & $\mathrm{~K}_{8} \mathrm{~S}_{5} \mathrm{O}_{1} \mathrm{~V}_{1} \mathrm{Z}_{1}$ \\
\hline TOTAL & 84 fotos & 30,12 & $27,18 \%$ & $\begin{array}{c}\mathrm{Z}_{16} \mathrm{G}_{16} \mathrm{~V}_{13} \mathrm{~S}_{11} \mathrm{~K}_{8} \\
\mathrm{M}_{7} \mathrm{O}_{7} \mathrm{~W}_{6}\end{array}$ \\
\hline
\end{tabular}

Os resultados da PAF do BBT-Br masculino, extraindo-se quatro fatores dos dados da amostra masculina, identificaram 84 fotos com carga fatorial acima de 0,30. Os autovalores dos fatores variaram entre 3,11 e 18,72, apresentando um total acumulado de 30,12. Já a variância explicada acumulada de $27,18 \%$ pode ser considerada frágil para a explicação dos resultados, mesmo que a proporção individual de cada fator na explicação dos resultados tenha sido maior do que 3\%, obedecendo ao critério de Harman (Zerbini, 2007). O número de itens por fator variou entre 16 e 36 fotos, com grande concentração de fotos no primeiro fator da extração. Este fator preencheu os critérios estatísticos, apesar da baixa variância acumulada. No entanto, o agrupamento das fotos por fator dificultou a interpretação dos resultados, pela análise dos radicais de inclinação de Achtnich (1991). Sendo assim, esta extração de quatro fatores não pareceu se configurar como uma alternativa plausível para compreender e sintetizar os dados do BBT-Br da amostra masculina de adolescentes.

Prosseguindo com as análises fatoriais, foi realizada a extração de cinco fatores. A seguir, a Tabela 30 apresenta os resultados para a PAF dessa extração nos dados dos adolescentes frente ao BBT-Br masculino. 
Tabela 29 - Resultados encontrados pela extração de cinco fatores, método Principal Axis Factoring com rotação Varimax, para a amostra masculina $(n=720)$.

\begin{tabular}{|c|c|c|c|c|}
\hline Fator & Fotos & Autovalor & $\begin{array}{l}\text { Variância } \\
\text { explicada }\end{array}$ & $\begin{array}{l}\text { Radicais de } \\
\text { Inclinação }\end{array}$ \\
\hline 1 & $\begin{array}{c}23,41,47,52,90,31,78,57,24,25,55,58 \\
80,33,8,93,86,30,66,50,39,63,43,91, \\
15,81,51,88,2,4,6,56,68,64\end{array}$ & 18,72 & $10,23 \%$ & $\begin{array}{c}\mathrm{M}_{7} \mathrm{Z}_{6} \mathrm{G}_{5} \mathrm{~W}_{4} \mathrm{~S}_{4} \mathrm{O}_{4} \\
\mathrm{~K}_{3} \mathrm{~V}_{1}\end{array}$ \\
\hline 2 & $\begin{array}{c}94,62,48,95,72,60,82,40,96,16,70,28 \\
44,85,20,74,61,14\end{array}$ & 4,31 & $5,97 \%$ & $\mathrm{Z}_{8} \mathrm{G}_{4} \mathrm{O}_{3} \mathrm{~V}_{2} \mathrm{~S}_{1}$ \\
\hline 3 & $\begin{array}{c}83,76,45,54,37,84,71,75,38,92,87,79 \\
13,36,67\end{array}$ & 3,98 & $5,80 \%$ & $\mathrm{~V}_{9} \mathrm{G}_{5} \mathrm{Z}_{1}$ \\
\hline 4 & $\begin{array}{c}26,42,10,11,35,12,34,69,19,27,21,77 \\
53,18\end{array}$ & 3,11 & $4,21 \%$ & $\mathrm{~S}_{6} \mathrm{~K}_{5} \mathrm{~V}_{2} \mathrm{Z}_{1}$ \\
\hline 5 & $3,73,49,17,22,9,89,7$ & 2,57 & $2,87 \%$ & $\mathrm{~S}_{3} \mathrm{~W}_{3} \mathrm{G}_{1} \mathrm{M}_{1}$ \\
\hline TOTAL & 89 fotos & 32,69 & $29,08 \%$ & $\begin{array}{c}\mathrm{Z}_{16} \mathrm{G}_{15} \mathrm{~V}_{14} \mathrm{~S}_{14} \mathrm{M}_{8} \\
\mathrm{~K}_{8} \mathrm{~W}_{7} \mathrm{O}_{7}\end{array}$ \\
\hline
\end{tabular}

A extração de cinco fatores, na amostra masculina, identificou 89 fotos do BBT-Br com carga fatorial adequada, ou seja, acima de 0,30. Os autovalores dos fatores variaram entre 2,57 e 18,72. Já a variância explicada de cada fator variou de 2,87\% a 10,23\%, sendo que o fator 5 pouco contribui para a explanação dos resultados, desobedecendo ao critério de Harman (Zerbini, 2007). A variância explicada total dos fatores foi de 29,08\%, indicando certa fragilidade na explanação geral dos resultados. Apesar de ocorrer melhor aglutinamento dos radicais de inclinação nos fatores em relação à extração anterior de quatro fatores, buscou-se efetivar outra PAF, de modo a tentar encontrar uma melhor forma de explicação e de explanação dos resultados do BBT-Br masculino. O número de itens por fator variou de oito até 34 fotos, com grande concentração de fotos no primeiro fator da extração. Esta extração de cinco fatores dos dados masculinos não atendeu plenamente ao critério estatístico de Harman, não apresentando, portanto, os melhores resultados para a compreensão dos resultados do BBT-Br masculino com adolescentes do ensino médio.

Diante desse contexto, a tabela 31 foi elaborada para apresentar os resultados da PAF do BBT-Br masculino com solução de seis fatores a partir dos dados da amostra masculina de adolescentes. 
Tabela 30 - Resultados encontrados pela extração de seis fatores, método Principal Axis Factoring com rotação Varimax, para a amostra masculina $(n=720)$.

\begin{tabular}{ccccc}
\hline Fator & Fotos & Autovalor & $\begin{array}{c}\text { Variância } \\
\text { explicada }\end{array}$ & $\begin{array}{c}\text { Radicais de } \\
\text { Inclinação }\end{array}$ \\
\hline 1 & $58,55,57,31,50,34,24,23,25,10,8,33$, & 18,72 & $7,87 \%$ & $\mathrm{~K}_{6} \mathrm{M}_{5} \mathrm{~W}_{4} \mathrm{O}_{4} \mathrm{~S}_{3} \mathrm{Z}_{2}$ \\
& $15,78,11,41,93,66,39,18,51,56,2,64$ & & & \\
2 & $83,76,45,54,75,37,84,71$, & 4,31 & $5,72 \%$ & $\mathrm{~V}_{8} \mathrm{G}_{5} \mathrm{Z}_{1}$ \\
& $38,92,87,13,79,36$ & & & \\
3 & $95,94,62,72,82,96,16,48,40$, & 3,98 & $5,39 \%$ & $\mathrm{Z}_{6} \mathrm{~V}_{4} \mathrm{G}_{4} \mathrm{O}_{3} \mathrm{~S}_{1}$ \\
4 & $85,61,60,70,44,28,14,67,53$ & & & \\
5 & $68,80,86,6,90,47,74,52,30,20,59$ & 3,11 & $5,15 \%$ & $\mathrm{Z}_{5} \mathrm{G}_{4} \mathrm{~S}_{1} \mathrm{M}_{1}$ \\
6 & $3,73,49,9,17,22,89,7$ & 2,57 & $3,43 \%$ & $\mathrm{~W}_{3} \mathrm{~S}_{3} \mathrm{G}_{1} \mathrm{M}_{1}$ \\
TOTAL & $26,42,35,69,27,21,12,19,77,46$ & 2,30 & $3,22 \%$ & $\mathrm{~S}_{5} \mathrm{~K}_{2} \mathrm{Z}_{1} \mathrm{~V}_{1} \mathrm{G}_{1}$ \\
& 85 fotos & 34,99 & $30,78 \%$ & $\mathrm{Z}_{15} \mathrm{G}_{15} \mathrm{~V}_{13} \mathrm{~S}_{13} \mathrm{~K}_{8}$ \\
& & & & $\mathrm{M}_{7} \mathrm{~W}_{7} \mathrm{O}_{7}$ \\
\hline
\end{tabular}

A extração de seis fatores, na amostra masculina, apresentou 85 fotos com boas cargas fatoriais (acima de 0,30). Os autovalores dos fatores variaram de 2,30 até 18,72. A variância explicada dos fatores ficou entre 3,22\% e 7,87\%, adequando-se ao critério de Harman (Zerbini, 2007). A variância acumulada foi de 30,78\%, um resultado que pode ser considerado limitado, mas passível de interpretações fator a fator, além de ser melhor que as soluções anteriormente apresentadas até o momento. Os radicais de inclinação do BBT-Br se aglutinaram de maneira coerente, possibilitando a interpretação de cada fator encontrado. Ressalta-se que a distribuição das fotos entre os fatores apresentou alguma variação, mas no geral foi adequada, com o menor fator apresentando oito fotos e o maior apresentando 24 fotos. Esta PAF apresentou os melhores resultados, obedecendo aos critérios estatísticos e às proposições teóricas pressupostas por Achnitch (1991), sendo aqui selecionada como a melhor explanação dos dados obtidos pelo BBT-Br Masculino.

De todo modo, assim como para a amostra feminina, prosseguiu-se com novas extrações de fatores, com a finalidade exploratória e comparativa das várias possibilidades de explanação dos resultados de adolescentes no BBT-Br masculino. A seguir, a Tabela 32 apresenta os resultados obtidos pela extração de sete fatores nos dados da amostra masculina. 
Tabela 31 - Resultados encontrados pela extração de sete fatores, método Principal Axis Factoring com rotação Varimax, para a amostra masculina $(n=720)$.

\begin{tabular}{ccccc}
\hline Fator & Fotos & Autovalor & $\begin{array}{c}\text { Variância } \\
\text { explicada }\end{array}$ & $\begin{array}{c}\text { Radicais de } \\
\text { Inclinação }\end{array}$ \\
\hline 1 & $58,55,57,31,50,34,24,23,10,25,8,33$, & 18,72 & $7,75 \%$ & $\mathrm{~K}_{6} \mathrm{M}_{5} \mathrm{~W}_{4} \mathrm{O}_{4} \mathrm{~S}_{3} \mathrm{Z}_{2}$ \\
& $11,15,78,41,93,18,66,39,51,56,2,64$ & & & \\
2 & $83,76,45,54,75,37,71,84$, & 4,31 & $5,78 \%$ & $\mathrm{~V}_{9} \mathrm{G}_{5} \mathrm{Z}_{1}$ \\
& $38,92,13,87,79,36,29$ & & \\
3 & $68,80,86,6,90,47,74,52,30,20,59$ & 3,98 & $5,27 \%$ & $\mathrm{Z}_{5} \mathrm{G}_{4} \mathrm{~S}_{1} \mathrm{M}_{1}$ \\
4 & $95,94,62,72,82,96,16,48,40,85$, & 3,11 & $5,24 \%$ & $\mathrm{Z}_{6} \mathrm{~V}_{4} \mathrm{G}_{4} \mathrm{O}_{3} \mathrm{~S}_{1}$ \\
& $61,60,70,44,28,14,67,53$ & & & \\
5 & $3,73,49,9,17,22,89,7$ & 2,57 & $3,51 \%$ & $\mathrm{~W}_{3} \mathrm{~S}_{3} \mathrm{G}_{1} \mathrm{M}_{1}$ \\
7 & $42,77,26,27,35,19,69,21$ & 2,30 & $3,02 \%$ & $\mathrm{~S}_{5} \mathrm{~K}_{2} \mathrm{~V}_{1}$ \\
TOTAL & 32 & 1,87 & $1,41 \%$ & $\mathrm{O}_{1}$ \\
& 85 fotos & 36,86 & $31,98 \%$ & $\mathrm{Z}_{14} \mathrm{~V}_{14} \mathrm{G}_{14} \mathrm{~S}_{13} \mathrm{~K}_{8}$ \\
& & & & $\mathrm{O}_{8} \mathrm{M}_{7} \mathrm{~W}_{7}$ \\
\hline
\end{tabular}

Os resultados da extração de sete fatores na amostra masculina indicaram 85 fotos com carga fatorial maior que 0,30 . Os autovalores dos fatores encontrados variaram de 1,87 até 18,72. Já a variância explicada dos fatores variou entre 1,41\% e 7,75\%, com valor acumulado de 31,98\%. Apesar dessa extração alcançar valores de variância explicada dos resultados maior que as anteriores, há fatores identificados que não cumprem o critério de Harman (Zerbini, 2007). Observa-se que o sétimo fator não apresentou variância acima de $3 \%$, podendo ser considerado irrelevante, pelo critério de Harman, para auxiliar na explanação dos resultados do grupo masculino de adolescentes no BBT-Br masculino.

Os radicais de inclinação do BBT-Br distribuíram-se de maneira razoavelmente interpretável pelos fatores, com exceção do sétimo fator, composto por apenas uma foto. A distribuição dos itens (fotos) entre os fatores não foi uniforme, com apenas uma foto no menor fator e 24 fotos no maior. Esse fator com item solitário é pouco indicado para a adequada interpretação dos resultados, segundo Costello e Osborne (2005). Portanto, esta extração não pode ser considerada a mais representativa dos dados obtidos pelo BBT-Br Masculino.

Finalizando a apresentação dos resultados das PAF sobre os achados do BBT-Br masculino, a tabela 33 sistematiza os achados da extração de oito fatores nos dados da amostra masculina. 
Tabela 32 - Resultados encontrados pela extração de oito fatores, método Principal Axis Factoring com rotação Varimax, para a amostra masculina $(n=720)$.

\begin{tabular}{|c|c|c|c|c|}
\hline Fator & Fotos & Autovalor & $\begin{array}{l}\text { Variância } \\
\text { explicada }\end{array}$ & $\begin{array}{l}\text { Radicais de } \\
\text { Inclinação }\end{array}$ \\
\hline 1 & $\begin{array}{c}55,58,57,50,31,34,10,24,23,11,15,25 \\
8,18,78,33,66,64,56,2,51,39\end{array}$ & 18,72 & $7,15 \%$ & $\mathrm{~K}_{6} \mathrm{M}_{5} \mathrm{O}_{4} \mathrm{~W}_{3} \mathrm{~S}_{2} \mathrm{Z}_{2}$ \\
\hline 2 & $\begin{array}{c}83,76,45,54,75,84,37,71,38 \\
92,13,87,79,36,21,61\end{array}$ & 4,31 & $5,70 \%$ & $\mathrm{~V}_{10} \mathrm{G}_{5} \mathrm{Z}_{1}$ \\
\hline 3 & $80,68,86,6,90,47,52,30,74,41,20,59$ & 3,98 & $5,21 \%$ & $\mathrm{Z}_{5} \mathrm{G}_{4} \mathrm{~W}_{1} \mathrm{M}_{1} \mathrm{~S}_{1}$ \\
\hline 4 & $\begin{array}{c}94,48,62,40,60,44,95,72 \\
53,16,32,28,70\end{array}$ & 3,11 & $4,34 \%$ & $\mathrm{Z}_{5} \mathrm{O}_{4} \mathrm{G}_{2} \mathrm{~V}_{2}$ \\
\hline 5 & $96,46,82,81,88,65,93,67,91,85$ & 2,57 & $3,34 \%$ & $\mathrm{~S}_{4} \mathrm{G}_{3} \mathrm{~V}_{2} \mathrm{Z}_{1}$ \\
\hline 6 & $3,73,49,17,9,22,89,7$ & 2,30 & $3,24 \%$ & $\mathrm{~W}_{3} \mathrm{~S}_{3} \mathrm{G}_{1} \mathrm{M}_{1}$ \\
\hline 7 & $42,26,77,27,35,69,19,14$ & 1,87 & $2,79 \%$ & $\mathrm{~S}_{5} \mathrm{~K}_{2} \mathrm{G}_{1}$ \\
\hline 8 & Não tem fotos com carga acima de 0,30 . & 1,66 & $1,26 \%$ & Não tem radicais \\
\hline TOTAL & 89 fotos & 38,52 & $33,03 \%$ & $\begin{array}{c}\mathrm{G}_{16} \mathrm{~S}_{15} \mathrm{Z}_{14} \mathrm{~V}_{14} \mathrm{~K}_{8} \\
\mathrm{O}_{8} \mathrm{M}_{7} \mathrm{~W}_{7}\end{array}$ \\
\hline
\end{tabular}

A extração de oito fatores, como propostos teoricamente por Achtnich (1991), na amostra masculina, apresentou 89 fotos com carga fatorial maior que 0,30. Os autovalores destes fatores variaram entre 1,66 e 18,72. A variância explicada dos fatores variou entre 1,26\% e 7,15\%, apresentando dois fatores com variância menor do que 3\%, sendo, portando, descartados pelo critério de Harman (Zerbini, 2007). A variância acumulada dos fatores foi de $33,03 \%$, indicando parcial explanação dos resultados, embora superior às anteriores extrações, já apresentadas. Os radicais de inclinação se distribuíram de maneira pouco clara entre os fatores, apresentando, inclusive, um fator (fator 8) sem nenhuma foto representativa com carga fatorial acima de 0,30. A distribuição dos itens entre os fatores foi de zero até 22 fotos, com a presença de um fator sem nenhum item com carga fatorial adequada, o que desfavorece a explicação dos dados, segundo Costello e Osborne (2005). Considerando o critério de Harman e o fator sem fotos, esta extração não pode ser considerada a mais representativa dos dados obtidos.

A PAF com solução de seis fatores relativos ao resultados dos adolescentes no BBTBr masculino apresentou, assim como para a amostra feminina, os melhores resultados. As variâncias explicadas foram maiores que 3\% para cada um dos fatores, o número de fotos por fator foi o mais equilibrado dentre as extrações e os agrupamentos dos radicais de inclinação de Achtnich (1991) permitiram hipóteses interpretativas mais promissoras. Deste modo, esta 
solução fatorial será esmiuçada no presente trabalho, no tópico 5.2.2.2, sendo precedida agora pela exploração das fotos do BBT-Br masculino que apresentaram baixa carga fatorial (inferior a 0,30) no conjunto dos resultados da amostra masculina de adolescentes, presentemente avaliada.

\subsubsection{Fotos descartadas nas análises fatoriais exploratórias da versão masculina do BBT-Br:}

Visando um melhor conhecimento dos resultados obtidos pelas PAFs, faz-se importante, neste momento, apresentar as fotos descartadas a partir de cada extração fatorial. Trata-se do exame das fotos (itens) da versão masculina do BBT-Br que não atingiram carga fatorial mínima de 0,30 , indicando baixa correlação com os demais itens e o próprio conteúdo avaliado pelo instrumento em si. A Tabela 34 sistematiza este tipo de resultados obtidas pela análise fatorial exploratória dos dados do BBT-Br da amostra masculina.

Tabela 33 - Itens (fotos) que não atingiram carga fatorial mínima $(0,30)$ nas PAFs (rotação Varimax) de quatro, cinco, seis, sete e oito fatores, da forma Masculina do BBT-Br $(n=720)$.

\begin{tabular}{ccc}
\hline Extração PAF & Fotos com baixa carga fatorial & Total fotos \\
\hline 4 fatores & $1,3,5,7,17,29,32,59,73,77,89$ & 11 \\
5 fatores & $1,5,29,32,46,59,65$ & 7 \\
6 fatores & $1,4,5,29,32,43,63,65,81,88,91$ & 11 \\
7 fatores & $1,4,5,12,43,46,63,65,81,88,91$ & 11 \\
8 fatores & $1,4,5,12,29,43,63$ & 7 \\
\hline
\end{tabular}

As PAFs realizadas com os resultados do BBT-Br masculino com extração de quatro, cinco, seis, sete e oito fatores evidenciaram que sete a 11 fotos apresentaram baixa carga fatorial. Os resultados apresentados indicam que três fotos da versão Masculina do BBT-Br acabaram por apresentar carga fatorial abaixo de 0,30 na maioria das extrações realizadas. Pode-se observar que a foto 1 (Peleiro, Forrador), 5 (Verificador Têxtil) foram descartadas nas cinco extrações feitas. Já a foto 29 (Tipógrafo) apresentou carga fatorial abaixo de 0,30 em quatro das cinco extrações. Esses resultados merecem a devida consideração e análise, o 
que será feito na discussão dos dados, tendo em vista a própria representatividade desses itens em relação ao construto em foco neste método projetivo de avaliação psicológica.

$\mathrm{Na}$ sequência de apresentação dos resultados, a PAF com extração de seis fatores é melhor detalhada. Procurar-se-á evidenciar as características técnicas que apontaram ser esta a extração a melhor solução fatorial para explanar e buscar compreender os resultados da versão masculina do BBT-Br em adolescentes do sexo masculino, estudantes do ensino médio.

\subsubsection{Solução de seis fatores para versão masculina do BBT-Br:}

A realização da Principal Axis Factoring (PAF), com rotação Varimax e extração de seis fatores também apresentou os melhores resultados fatoriais para o BBT-Br na amostra masculina. Visando detalhar esses achados, foram sistematizadas tabelas para cada um dos seis fatores encontrados, com descrições de cada foto que o compõem, seu radical de inclinação motivacional teoricamente previsto por Achtnich (1991), além da função, meios e instrumentos de cada uma dessas atividades profissionais, atrelada a respectiva carga fatorial encontrada para cada foto na presente análise fatorial exploratória. As descrições apresentadas na coluna da Função e Meios/Instrumentos foram adaptadas do manual normativo do BBT-Br Masculino (Jacquemin, 2000). Nesse contexto, a Tabela 35, que segue na próxima página, apresenta os resultados referentes ao fator 1 da PAF dos resultados obtidos com o BBT-Br masculino, com extração de seis fatores. 
Tabela 34 - Itens (fotos) da forma masculina do BBT-Br (n=720) que compõem o Fator 1 da PAF (rotação Varimax) de seis fatores, com respectivos radicais de inclinação de Achtnich.

\begin{tabular}{|c|c|c|c|c|c|}
\hline Foto & Profissional & Radical & Função & Meios/Instrumentos & $\begin{array}{c}\text { Carga } \\
\text { Fatorial }\end{array}$ \\
\hline 58 & Açougueiro & Ko & Cortar, abater & Faca, palavra & 0,632 \\
\hline 55 & Pedreiro & $\mathrm{Mm}$ & $\begin{array}{l}\text { Misturar, } \\
\text { pavimentar }\end{array}$ & Tábua, caixa de pedreiro & 0,624 \\
\hline 57 & Garçom & Wo & Servir & Prontidão & 0,573 \\
\hline 31 & Pintor de paredes & $\mathrm{Mz}$ & $\begin{array}{l}\text { Misturar, } \\
\text { mexer, pintar }\end{array}$ & $\begin{array}{l}\text { Pincel, espátula, selha, tintas; } \\
\text { senso de cor, senso estético }\end{array}$ & 0,558 \\
\hline 50 & Carregador & $\mathrm{Km}$ & $\begin{array}{l}\text { Uso da força } \\
\text { física }\end{array}$ & Mãos & 0,551 \\
\hline 34 & Serralheiro & $\mathrm{Kv}$ & $\begin{array}{l}\text { Trabalhos } \\
\text { físicos de } \\
\text { precisão }\end{array}$ & Cinzel, força física, planos técnicos & 0,523 \\
\hline 24 & Cozinheiro & $\mathrm{O}_{\mathrm{n}} \mathrm{s}$ & Cozinhar & Paladar, gêneros, fogo, forno, calor & 0,517 \\
\hline 23 & Jardineiro & Ms & $\begin{array}{l}\text { Cuidar de } \\
\text { plantas }\end{array}$ & $\begin{array}{c}\text { Mãos, instrumentos de arar, amor à } \\
\text { natureza }\end{array}$ & 0,485 \\
\hline 25 & $\begin{array}{l}\text { Cabeleireiro/ } \\
\text { Barbeiro }\end{array}$ & $\mathrm{Wz}$ & $\begin{array}{c}\text { Arrumar } \\
\text { cabelo, pentear }\end{array}$ & $\begin{array}{c}\text { Pente, escova, loções, mãos, } \\
\text { produtos de beleza, artigos de } \\
\text { perfumaria }\end{array}$ & 0,459 \\
\hline 10 & Trab. da Const. Civil & $\mathrm{Kk}$ & $\begin{array}{l}\text { Furar, utilizar } \\
\text { sua força }\end{array}$ & Furadora, britadeira, força física & 0,456 \\
\hline 8 & Padeiro/Pasteleiro & $\mathrm{O}_{\mathrm{n}} \mathrm{w}$ & $\begin{array}{l}\text { Preparar os } \\
\text { alimentos }\end{array}$ & Farinha, ingredientes & 0,447 \\
\hline 33 & Alfaiate & Wv & $\begin{array}{l}\text { Trabalhar com } \\
\text { tecidos }\end{array}$ & $\begin{array}{c}\text { Vestimentas, fita métrica, modelo } \\
\text { de corte }\end{array}$ & 0,438 \\
\hline 15 & Caseiro de Sítio & $\mathrm{Mk}$ & $\begin{array}{l}\text { Trabalhar com } \\
\text { sitio }\end{array}$ & Forquilha, vassoura & 0,424 \\
\hline 11 & $\begin{array}{l}\text { Motorista de } \\
\text { Caminhão }\end{array}$ & $\mathrm{S}_{\mathrm{e}} \mathrm{k}$ & $\begin{array}{l}\text { Conduzir, } \\
\text { transportar }\end{array}$ & Veículo, caminhão, carro & 0,420 \\
\hline 93 & Fonoaudiólogo & $\mathrm{S}_{\mathrm{h}} \mathrm{O}$ & $\begin{array}{l}\text { Ajudar, fazer } \\
\text { exercícios de } \\
\text { voz }\end{array}$ & $\begin{array}{c}\text { Interesse pelo outro, palavra, } \\
\text { contato }\end{array}$ & 0,390 \\
\hline 66 & Professor de Balé & $\mathrm{Zw}$ & $\begin{array}{l}\text { Expressar-se } \\
\text { artisticamente }\end{array}$ & Dança, fantasias, mão & 0,384 \\
\hline 39 & Curtidor de Peles & $\mathrm{Mv}$ & $\begin{array}{l}\text { Trabalhar com } \\
\text { peles }\end{array}$ & Produtos químicos, fita métrica & 0,383 \\
\hline 18 & Lenhador & Ks & Abater, serrar & Machado, serra, força física & 0,378 \\
\hline 51 & Carteiro & $\mathrm{S}_{\mathrm{h} / \mathrm{e}} \mathrm{m}$ & $\begin{array}{l}\text { Prestar serviço } \\
\text { público }\end{array}$ & Sacola & 0,358 \\
\hline 56 & $\begin{array}{l}\text { Empregado em } \\
\text { Mercearia }\end{array}$ & $\mathrm{O}_{\mathrm{n} / \mathrm{r}} \mathrm{m}$ & $\begin{array}{l}\text { Vender, } \\
\text { trabalhar com } \\
\text { alimentos }\end{array}$ & $\begin{array}{c}\text { Contato, palavra, gêneros } \\
\text { alimentícios, seções, prateleiras, } \\
\text { caixa }\end{array}$ & 0,356 \\
\hline 2 & Marceneiro & $\mathrm{Kw}$ & $\begin{array}{l}\text { Aplainar, uso } \\
\text { da força física }\end{array}$ & Plaina, banca de marceneiro, mão & 0,345 \\
\hline 64 & Barman & $\mathrm{O}_{\mathrm{n} / \mathrm{r}} \mathrm{O}$ & $\begin{array}{l}\text { Servir bebidas, } \\
\text { tagarelar }\end{array}$ & Palavra, facilidade de contatos & 0,344 \\
\hline
\end{tabular}

O Fator 1 da PAF com extração de seis fatores para os resultados do BBT-Br masculino englobou 22 fotos do instrumento. Dessas fotos, seis estavam associadas ao radical de inclinação motivacional primário $\mathrm{K}$, cinco ao radical $\mathrm{M}$, quatro a $\mathrm{O}$ (sendo duas especificas na vertente $\mathrm{O}_{\mathrm{n}}$ ), três fotos associadas ao fator $\mathrm{W}$, outras três ao fator $\mathrm{S}$ (sendo uma específica à vertente $S_{e}$ e outra à específica vertente $S_{h}$ ) e uma foto associada ao radical primário Z. Já 
em relação aos radicais secundários, foram identificadas quatro fotos representativas de $m$ e $o$ (vertente $o_{r}$ ), três fotos associadas ao radical secundário $w, k, s$ (vertente $s_{e}$ ) e $v$, além de duas fotos associadas ao radical secundário $z$. Pode-se observar que, apesar da aparente diversidade de radicais de inclinação agrupados neste fator, existe um destaque para atividades profissionais relacionadas ao uso da força física, agressividade, seja ela direcionada para o trabalho com materiais ou o trabalho com o próprio corpo. As fotos 25 (Cabeleireiro) e 93 (Fonoaudiólogo), embora apresentem relações de contato interpessoal, de ajuda, caminham na mesma direção das demais fotos na medida em que implicam em atividades permeadas por materiais ou partes concretas do corpo humano Em relação aos ambientes de trabalho, foram identificados locais variados, em sua maioria envolvendo ambientes fechados, que, em diferentes medidas, possibilitam este trabalho com materiais ou com o próprio corpo, implicando em esforço físico.

Depreende-se, portanto, que este fator pareceu relacionado aos radicais de inclinação motivacional primários $\mathrm{K}$ e $\mathrm{M}$, e aos radicais de inclinação secundários $m$ e $o$ (vertente $o_{r}$ ), pressupostos por Achtnich (1991). Este fator abarcou, dessa forma, interesses em atividades que envolvem a força física, o trabalho sobre materiais, sobre a matéria ou sobre o próprio corpo humano enquanto objeto de ação.

A sequiência de sistematização dos resultados dos resultados da PAF com seis fatores destaca o fator 2 obtido pela análise fatorial exploratória. A Tabela 36, diagramada em folha única na próxima página, apresenta o fator 2 do BBT-Br masculino. 
Tabela 35 - Itens (fotos) da forma masculina do BBT-Br (n=720) que compõem o Fator 2 da PAF (rotação Varimax) de seis fatores, com respectivos radicais de inclinação de Achtnich.

\begin{tabular}{|c|c|c|c|c|c|}
\hline Foto & Profissional & Radical & Função & Meios/Instrumentos & $\begin{array}{l}\text { Carga } \\
\text { Fatorial }\end{array}$ \\
\hline 83 & Engenheiro Industrial & $\mathrm{Vv}$ & $\begin{array}{l}\text { Controlar, } \\
\text { calcular }\end{array}$ & Cálculos, aparelhos de medida & 0,657 \\
\hline 76 & Engenheiro Elétrico & Gs & $\begin{array}{l}\text { Pesquisar, } \\
\text { refletir }\end{array}$ & Sagacidade, observação & 0,626 \\
\hline 45 & Técnico de TV & $\mathrm{Vg}$ & $\begin{array}{l}\text { Revisar, } \\
\text { concertar }\end{array}$ & $\begin{array}{l}\text { Esquema, plano, instrumento de } \\
\text { medida, instrumento de precisão, } \\
\text { intuição }\end{array}$ & 0,540 \\
\hline 54 & $\begin{array}{l}\text { Laboratorista } \\
\text { Químico }\end{array}$ & $\mathrm{Gm}$ & $\begin{array}{l}\text { Pesquisar, } \\
\text { refletir }\end{array}$ & Reflexão científica (aparelhagens) & 0,534 \\
\hline 75 & Chefe de Obras & Vs & $\begin{array}{l}\text { Planificar, } \\
\text { organizar }\end{array}$ & $\begin{array}{c}\text { Planta de construção, meios } \\
\text { técnicos para dominar e explorar a } \\
\text { natureza }\end{array}$ & 0,512 \\
\hline 37 & Mecânico Aferidor & Vv & $\begin{array}{l}\text { Traçar, } \\
\text { calcular }\end{array}$ & $\begin{array}{l}\text { Ponta para traçar, instrumentos de } \\
\text { medida, instrumentos de precisão }\end{array}$ & 0,511 \\
\hline 84 & $\begin{array}{l}\text { Pesquisador } \\
\text { (Biólogo) }\end{array}$ & $\mathrm{Gv}$ & $\begin{array}{l}\text { Pesquisar, } \\
\text { refletir }\end{array}$ & Observação, microscópio & 0,505 \\
\hline 71 & Engenheiro Mecânico & $\mathrm{Vk}$ & $\begin{array}{l}\text { Elaborar } \\
\text { planos, } \\
\text { calcular }\end{array}$ & Planta & 0,499 \\
\hline 38 & Laboratorista Físico & $\mathrm{Gv}$ & $\begin{array}{l}\text { Pesquisar, } \\
\text { refletir }\end{array}$ & Sagacidade, aparelhos, observação & 0,470 \\
\hline 92 & Geólogo & $\mathrm{Gm}$ & $\begin{array}{l}\text { Pesquisar, } \\
\text { refletir }\end{array}$ & Perspicácia, espírito de pesquisa & 0,466 \\
\hline 87 & $\begin{array}{l}\text { Des. Industrial } \\
\text { (Arquiteto) }\end{array}$ & $\mathrm{Vg}$ & $\begin{array}{l}\text { Medir, } \\
\text { desenhar }\end{array}$ & Planta, desenho, idéia & 0,394 \\
\hline 13 & Torneiro Mecânico & Vk & $\begin{array}{l}\text { Trabalhar } \\
\text { planejadame } \\
\text { nte }\end{array}$ & $\begin{array}{l}\text { Instrumentos de precisão, torno de } \\
\text { metais }\end{array}$ & 0,392 \\
\hline 79 & Crítico de Arte & $\mathrm{Vz}$ & $\begin{array}{l}\text { Criticar, } \\
\text { examinar }\end{array}$ & $\begin{array}{l}\text { Conhecimentos especializados, } \\
\text { imprensa, evista de arte }\end{array}$ & 0,379 \\
\hline 36 & Joalheiro/Ourives & $\mathrm{Zv}$ & $\begin{array}{l}\text { Modelar } \\
\text { artesanalme } \\
\text { nte }\end{array}$ & $\begin{array}{l}\text { Senso estético, gosto pelas formas, } \\
\text { instrumentos de medida e precisão }\end{array}$ & 0,325 \\
\hline $67 *$ & $\begin{array}{l}\text { Diretor de Produção } \\
\text { Têxtil }\end{array}$ & Vw & $\begin{array}{l}\text { Controlar, } \\
\text { organizar }\end{array}$ & Amostras & 0,309 \\
\hline $21 *$ & Controlador Aéreo & Vs & $\begin{array}{l}\text { Atenção, } \\
\text { controlar }\end{array}$ & Radar e comunicações de rádio & 0,301 \\
\hline
\end{tabular}

*Fotos apresentaram crossloading e foram realocadas aqui por representar interesses profissionais semelhantes aos demais agrupados neste fator.

O Fator 2 da PAF com extração de seis fatores agrupou 16 fotos do BBT-Br, sendo que duas delas (foto 67 e foto 21) apresentaram crossloadings com outro fator. Apesar de não apresentarem suas maiores cargas fatoriais neste fator 2, por suas características interpretativas, foram aqui agrupadas. Neste contexto foi possível notar que 10 fotos representavam o radical de inclinação motivacional primário $\mathrm{V}$, cinco o $\mathrm{G}$ e uma associou-se ao radical primário Z de Achtnich (1991). Em relação aos radicais de inclinação secundários, cinco fotos representavam $v$; três estavam associadas ao radical secundário $s$ (vertente $s_{e}$ ); duas fotos estavam associadas a cada um dos radicais secundários $k, g$ e $m$; uma foto ao 
radical secundário $z$ e outra a $w$. O agrupamento de fotos de atividades profissionais, neste fator, privilegiou tarefas relacionadas ao rigor lógico, à racionalidade, à concentração, precisão e inteligência, ao uso da criatividade de maneira lógica. Os profissionais retratados demonstravam elevada concentração em suas atividades neste grupo de atividades profissionais (fotos). Os ambientes de trabalho agrupados favoreceram, em sua maioria, o trabalho rigoroso, metódico e intelectual.

Pode-se hipotetizar, portanto, que este Fator 2, em relação aos pressupostos de Achtnich (1991), agrupa os radicais de inclinação primários V e G, relacionados prioritariamente ao radical secundário $v$. Implica, desse modo, em atividades relacionadas ao rigor lógico, à racionalidade, ao trabalho cuidadoso e preciso com objetos.

A seguir apresenta-se a Tabela 37. Esta traz os resultados referentes ao fator 3 da PAF do BBT-Br masculino, com extração de seis fatores dos dados dos adolescentes do sexo masculino. Visando a diagramação em folha única, que permite melhor visualização dos resultados, essa tabela será apresentada na próxima página. 
Tabela 36 - Itens (fotos) da forma masculina do BBT-Br $(n=720)$ que compõem o Fator 3 da PAF (rotação Varimax) de seis fatores, com respectivos radicais de inclinação de Achtnich.

\begin{tabular}{|c|c|c|c|c|c|}
\hline Foto & Profissional & Radical & Função & Meios/Instrumentos & $\begin{array}{l}\text { Carga } \\
\text { Fatorial }\end{array}$ \\
\hline 95 & $\begin{array}{l}\text { Empresários em } \\
\text { Reunião }\end{array}$ & Vo & $\begin{array}{l}\text { Administrar, } \\
\text { discutir }\end{array}$ & $\begin{array}{c}\text { Meios de planificação, contato, } \\
\text { palavra }\end{array}$ & 0,542 \\
\hline 94 & $\begin{array}{c}\text { Apresentador de } \\
\text { TV }\end{array}$ & Zo & Apresentar & Aparelhagem de TV, palavra & 0,535 \\
\hline 62 & Político, Jornalista & Go & $\begin{array}{l}\text { Discursar, } \\
\text { convencer pela } \\
\text { fala }\end{array}$ & Sagacidade, entrevistas, contato & 0,483 \\
\hline 72 & Advogado & Gk & $\begin{array}{l}\text { Questionar, } \\
\text { convencer pela } \\
\text { fala }\end{array}$ & $\begin{array}{l}\text { Modo de pensar psicológico, } \\
\text { sagacidade }\end{array}$ & 0,478 \\
\hline 82 & Diplomata & $\mathrm{Zv}$ & $\begin{array}{l}\text { Fazer-se } \\
\text { reconhecer, ser } \\
\text { respeitado }\end{array}$ & $\begin{array}{l}\text { Comunicação de massa, imprensa, } \\
\text { declarações, causas sociais, } \\
\text { assembléias, meios e poder, leis, } \\
\text { decretos, "protocolo" }\end{array}$ & 0,467 \\
\hline 96 & Filósofo (Orador) & Go & Difundir idéias & Espírito, palavra & 0,463 \\
\hline 16 & Corretor da Bolsa & $\mathrm{O}_{\mathrm{r}} \mathrm{k}$ & $\begin{array}{l}\text { Discutir, } \\
\text { negociar }\end{array}$ & Palavra, superioridade & 0,452 \\
\hline 48 & $\begin{array}{c}\text { Repórter } \\
\text { entrevistador }\end{array}$ & $\mathrm{O}_{\mathrm{r}} \mathrm{g}$ & $\begin{array}{l}\text { Questionar, } \\
\text { transmitir }\end{array}$ & Palavra, contato & 0,448 \\
\hline 40 & $\begin{array}{l}\text { Recepcionista de } \\
\text { Hotel }\end{array}$ & $\mathrm{O}_{\mathrm{r}} \mathrm{v}$ & $\begin{array}{l}\text { Informar, } \\
\text { conversar }\end{array}$ & $\begin{array}{l}\text { Palavra, contato fácil, hóspedes, } \\
\text { fichário, registro, planta dos } \\
\text { quartos }\end{array}$ & 0,442 \\
\hline 85 & Padre & $\mathrm{S}_{\mathrm{h}} \mathrm{g}$ & $\begin{array}{l}\text { Ajudar, } \\
\text { consolar }\end{array}$ & $\begin{array}{l}\text { Vontade de ajudar, aptidão às } \\
\text { relações humanas, atenção, religião }\end{array}$ & 0,424 \\
\hline 61 & $\begin{array}{l}\text { Homem de } \\
\text { Negócios }\end{array}$ & Vo & $\begin{array}{l}\text { Comandar, ser } \\
\text { objetivo }\end{array}$ & $\begin{array}{l}\text { Máquinas de escritório, secretária } \\
\text { eletrônica, classificadores, contato }\end{array}$ & 0,391 \\
\hline 60 & $\begin{array}{l}\text { Apresentador/Ani } \\
\text { mador }\end{array}$ & Zo & $\begin{array}{l}\text { Expressar-se } \\
\text { através do } \\
\text { trabalho }\end{array}$ & $\begin{array}{l}\text { Mímica, gestos, atrações, } \\
\text { sociabilidade, humor }\end{array}$ & 0,388 \\
\hline 70 & $\begin{array}{l}\text { Repórter } \\
\text { Fotográfico }\end{array}$ & $\mathrm{Zk}$ & $\begin{array}{l}\text { Expor seu } \\
\text { trabalho }\end{array}$ & $\begin{array}{l}\text { Foto, filme, câmera, "olhada" para } \\
\text { ver tudo, vontade de se impor }\end{array}$ & 0,385 \\
\hline 44 & Publicitário & $\mathrm{Zg}$ & $\begin{array}{l}\text { Expor seu } \\
\text { trabalho }\end{array}$ & $\begin{array}{c}\text { Suporte publicitário, efeito de } \\
\text { surpresa, meios de comunicação de } \\
\text { massa }\end{array}$ & 0,378 \\
\hline 28 & Manequim & $\mathrm{Zz}$ & $\begin{array}{l}\text { Exibir-se, } \\
\text { apresentar }\end{array}$ & Modelo, artigo de moda & 0,376 \\
\hline 14 & $\begin{array}{l}\text { Delegado de } \\
\text { Polícia }\end{array}$ & Gk & $\begin{array}{l}\text { Reflexão, } \\
\text { investigação }\end{array}$ & Arma, documentos, sagacidade & 0,322 \\
\hline 53 & Caixa & $\mathrm{Vm}$ & Calcular & $\begin{array}{l}\text { Máquina de calcular, máquina } \\
\text { contábil, caixa }\end{array}$ & 0,311 \\
\hline
\end{tabular}

O Fator 3 obtido pela PAF com extração de seis fatores dos dados do BBT-Br obtidos com a amostra masculina agrupou 17 fotos. Estas fotos estavam assim associadas: seis delas ao radical de inclinação motivacional primário $\mathrm{Z}$; quatro fotos ao radical primário $\mathrm{G}$; três fotos relacionadas a $\mathrm{V}$ e outras três a $\mathrm{O}$ (vertente $\mathrm{Or}$ ) e uma foto vinculada ao radical primário $\mathrm{S}$ (vertente $\mathrm{S}_{\mathrm{h}}$ ). Em relação aos radicais secundários: seis fotos associaram-se ao radical de inclinação secundário $o$ (vertente $o_{r}$ ); quatro a $k$; três a $g$; duas a $v$; uma ao radical secundário $z$ e outra a $m$. Este fator 3, portanto, agrupou fotos relacionadas a atividades que exigem senso 
estético, criatividade, inteligência, oratória e uso da razão na comunicação, ou seja, ocupações que exigem relação interpessoal e comunicação criativa para persuadir ou como demonstração de poder, de controle. A foto 53 (Caixa), agrupada neste grupo (com a menor carga fatorial), exibe um trabalhador contando cédulas de dinheiro em uma caixa registradora, sendo agrupada aqui, talvez, pela possível interpretação relativa ao poder financeiro, concreto, talvez aglutinando o sentido de poder e controle presente nas demais atividades representadas neste fator. Os ambientes agrupados foram, em sua maioria, facilitadores de atividades de comunicação e da manifestação de impulsividade agressiva por meio de palavras e de ações de controle e persuasão.

Diante dessas evidências, pode-se inferir que este fator representaria, pelos pressupostos de Achtnich (1991), os radicais de inclinação motivacional Z e G, além dos radicais secundários $o$ (vertente $o_{r}$ ) e $k$. Envolveriam, dessa forma, atividades que exigem comunicação criativa, relação interpessoal com exercício de persuasão, dominação.

A mesma sistematização dos resultados foi realizada para o fator 4 da PAF com seis fatores. Na próxima página, a Tabela 38 apresenta os resultados deste fator 4 . 
Tabela 37 - Itens (fotos) da forma masculina do BBT-Br $(n=720)$ que compõem o Fator 4 da PAF (rotação Varimax) de seis fatores, com respectivos radicais de inclinação de Achtnich.

\begin{tabular}{|c|c|c|c|c|c|}
\hline Foto & Profissional & Radical & Função & Meios/Instrumentos & $\begin{array}{l}\text { Carga } \\
\text { Fatorial }\end{array}$ \\
\hline 68 & Compositor & Gw & Criar, compor & Imaginação criativa & 0,554 \\
\hline 80 & Artista/Pintor & $\mathrm{Gz}$ & Fazer obra de arte & $\begin{array}{l}\text { Imaginação, fantasia } \\
\text { Tintas (pincel) }\end{array}$ & 0,543 \\
\hline 86 & Maestro & $\mathrm{Zg}$ & $\begin{array}{l}\text { Ser admirado, } \\
\text { comandar }\end{array}$ & $\begin{array}{l}\text { Gestos, mímicas, "pathos”, } \\
\text { expressão, fascinação }\end{array}$ & 0,527 \\
\hline 6 & Violinista & Gw & $\begin{array}{c}\text { Executar de } \\
\text { maneira criativa }\end{array}$ & $\begin{array}{l}\text { Instrumento de música, "alma", } \\
\text { partitura, dedos, mãos }\end{array}$ & 0,523 \\
\hline 90 & $\begin{array}{l}\text { Restaurador de } \\
\text { Arte }\end{array}$ & $\mathrm{Zm}$ & Embelezar, recriar & $\begin{array}{l}\text { Senso estético, tinta, pincel, meios } \\
\text { de conservação }\end{array}$ & 0,479 \\
\hline 47 & Ceramista & $\mathrm{Mg}$ & $\begin{array}{l}\text { Modelar, tocar, } \\
\text { apalpar }\end{array}$ & $\begin{array}{l}\text { Mão, torno de ceramista, } \\
\text { imaginação, idéias }\end{array}$ & 0,468 \\
\hline 74 & Ator de Teatro & Zs & $\begin{array}{l}\text { Representar, } \\
\text { expressar-se }\end{array}$ & $\begin{array}{c}\text { Mímica, gestos, arte de expressão, } \\
\text { vivacidade de reação, sentimentos, } \\
\text { afetos }\end{array}$ & 0,453 \\
\hline 52 & Mosaísta & $\mathrm{Zm}$ & $\begin{array}{l}\text { Expressar-se } \\
\text { artesanalmente }\end{array}$ & $\begin{array}{l}\text { Senso estético e artístico, placas de } \\
\text { cimento }\end{array}$ & 0,447 \\
\hline 30 & $\begin{array}{l}\text { Criador } \\
\text { (Artista) }\end{array}$ & $\mathrm{Gz}$ & Projetar, criar & $\begin{array}{c}\text { Imaginação, idéias, meios de } \\
\text { decoração }\end{array}$ & 0,444 \\
\hline $41 *$ & Florista & $\mathrm{Wg}$ & $\begin{array}{l}\text { Trabalhar com } \\
\text { sensibilidade }\end{array}$ & $\begin{array}{l}\text { Criatividade, meios de decoração, } \\
\text { mãos }\end{array}$ & 0,366 \\
\hline 20 & $\begin{array}{c}\text { Cameraman/Dir } \\
\text { etor }\end{array}$ & Zs & $\begin{array}{l}\text { Representar de } \\
\text { maneira estética }\end{array}$ & $\begin{array}{c}\text { Filme, câmera, cenários, } \\
\text { acessórios, capacidade de enfrentar } \\
\text { o imprevisto }\end{array}$ & 0,359 \\
\hline 59 & Guia Turístico & $\mathrm{S}_{\mathrm{h} / \mathrm{e}} \mathrm{O}$ & $\begin{array}{l}\text { Viajar, guiar, } \\
\text { cuidar }\end{array}$ & $\begin{array}{c}\text { Avião, veículos, palavra, gosto de } \\
\text { contatos }\end{array}$ & 0,348 \\
\hline $78^{*}$ & Mímico & $\mathrm{Zz}$ & $\begin{array}{l}\text { Expressar-se pelo } \\
\text { trabalho }\end{array}$ & Mímicas, gestos, fantasias & 0,317 \\
\hline
\end{tabular}

*Fotos apresentaram crossloading e foram realocadas aqui por representar interesses profissionais semelhantes aos demais agrupados neste fator.

O Fator 4 da PAF dos resultados da versão masculina do BBT-Br com extração de seis fatores englobou 13 fotos. As fotos 41 e 78 apresentaram crossloadings, evidenciando maior carga fatorial para o Fator 1, porém foram aqui realocadas por suas características de maior similaridade às demais fotos aqui agrupadas (fator 4). Neste contexto, nota-se que seis fotos associaram-se ao radical de inclinação primário $\mathrm{Z}$, quatro fotos ao radical $\mathrm{G}$, uma foto ao radical $\mathrm{M}$, outra associada a $\mathrm{W}$ e ainda outra a $\mathrm{S}$. Em relação aos radicais de inclinação secundários, três fotos eram associadas ao radical secundário $z$ e outras três fotos ao radical $g$. Por sua vez, os radicais secundários $w, m$ e $s$ (vertente $s_{e}$ ) estiveram presentes em duas fotos cada, além de uma foto associar-se ao radical secundário $o$ (vertente $o_{r}$ ). Nota-se que este quarto fator agrupou fotos representativas de atividades que exigem senso estético e criatividade, produção artística com impacto social, imaginação e exibição de seu trabalho. No caso dos ambientes, as atividades envolvem retratos e locais que privilegiavam manifestações artísticas e criativas, possibilitando o contato social pela arte. A foto 59 (Guia 
Turístico) que em princípio poderia parecer deslocada neste fator, de fato representa um homem guiando um grupo por uma mata, o que pode permitir a compreensão de que este guia está a apresentar aquele ambiente (uma mata) aos demais indivíduos. Assim, a foto possibilita contato afetuoso e apreciação de locais (como a mata) ou obras de arte, convidando ao apuro estético, atividades comumente encontradas no trabalho dos guias turísticos, justificando sua interpretação conjunta com as demais fotos deste quarto fator da PAF do BBT-Br masculino.

Essas evidências fazem pensar que este fator 4 representaria, pelos pressupostos teóricos de Achtnich (1991), os radicais de inclinação primários Z e G e os radicais de inclinação secundários também $z$ e $g$. Em decorrência, poder-se-ia inferir que este fator representaria atividades que envolvem o senso estético e a criatividade, a arte, o belo, o apuro estético com impacto social.

Na sequência das análises, tem-se a Tabela 39. Ela traz os resultados referentes ao fator 5 da PAF do BBT-Br masculino, com extração de seis fatores dos dados dos adolescentes do sexo masculino.

Tabela 38 - Itens (fotos) da forma masculina do BBT-Br $(n=720)$ que compõem o Fator 5 da PAF (rotação Varimax) de seis fatores, com respectivos radicais de inclinação de Achtnich.

\begin{tabular}{|c|c|c|c|c|c|}
\hline Foto & Profissional & Radical & Função & Meios/Instrumentos & $\begin{array}{l}\text { Carga } \\
\text { Fatorial }\end{array}$ \\
\hline 3 & Enfermeiro & $\mathrm{S}_{\mathrm{h}} \mathrm{W}$ & $\begin{array}{l}\text { Cuidar, curar, } \\
\text { ajudar }\end{array}$ & $\begin{array}{l}\text { Vontade de ajudar, } \\
\text { medicamentos, mão }\end{array}$ & 0,532 \\
\hline 73 & Médico & $\mathrm{S}_{\mathrm{h}} \mathrm{S}$ & $\begin{array}{l}\text { Curar, ajudar, } \\
\text { aconselhar }\end{array}$ & $\begin{array}{c}\text { Medicamentos, interesse pelo } \\
\text { outro, palavra }\end{array}$ & 0,523 \\
\hline 49 & Esteticista & $\mathrm{Wm}$ & $\begin{array}{l}\text { Tratar a pele } \\
\text { cuidar }\end{array}$ & $\begin{array}{l}\text { Mão, cosméticos, pincel, óleos, } \\
\text { pinturas }\end{array}$ & 0,478 \\
\hline 9 & Massagista & Wk & $\begin{array}{l}\text { Massagear com } \\
\text { força }\end{array}$ & Mão, força física & 0,440 \\
\hline 17 & Fisioterapeuta & Ws & Massagear & Mãos, vontade de ajudar & 0,433 \\
\hline 22 & Psicólogo & Gs & Refletir, entender & $\begin{array}{c}\text { Intuição, vontade de ajudar, } \\
\text { "escuta" }\end{array}$ & 0,429 \\
\hline 89 & Veterinário & $\mathrm{S}_{\mathrm{h}} \mathrm{m}$ & $\begin{array}{l}\text { Curar, ajudar, } \\
\text { cuidar de } \\
\text { animais }\end{array}$ & Medicamentos, amor aos animais & 0,374 \\
\hline 7 & Tintureiro & Mw & $\begin{array}{l}\text { Cuidar de } \\
\text { materiais }\end{array}$ & Produtos de limpeza, mão & 0,359 \\
\hline
\end{tabular}

O Fator 5 da PAF dos resultados da versão masculina do BBT-Br com extração de seis fatores agrupou oito fotos, sendo três delas associadas ao radical de inclinação motivacional primário $S$ (vertente $S_{h}$ ) e outras três fotos do radical primário $\mathrm{W}$, além de $\mathrm{G}$ e $\mathrm{M}$ estarem representados, cada um, em uma foto. No agrupamento dos radicais de inclinação secundários, três fotos associavam-se a $s$ (vertente $s_{h}$ ), duas fotos ao radical secundário $w$ e outras duas fotos ao radical secundário $m$, incluindo uma foto vinculada ao radical secundário 
$k$. Desta maneira, pode-se depreender que este fator aglutinou atividades profissionais relacionadas ao cuidado, à proteção e às relações de ajuda ao outro. A foto 7 (Tintureiro), provavelmente foi agrupada neste fator principalmente pela sua representação de cuidado afetuoso e organizado com a vestimenta do outro, relacionando-se dessa forma também com as atividades de ajuda presentes nas demais fotos deste quinto fator do BBT-Br masculino aqui identificado. Em termos de contexto ambiental, destacaram-se, com maior frequiência, locais facilitadores de interações sociais de ajuda, de maternagem, de contato interpessoal onde se oferece cuidado (material e afetivo) ao outro.

Portanto, este fator pareceu agregar os radicais de inclinação motivacional, propostos por Achtnich (1991), relacionados ao cuidar, ao ajudar, ou seja, os radicais primários S (vertente $S_{h}$ ) e W, e seus respectivos radicais secundários s (vertente $s_{h}$ ) e w. Neste fator, desse modo, agruparam-se atividades cujo foco remete ao cuidado, à proteção, à maternagem e às relações de ajuda.

Finalizando a sistematização dos resultados da PAF do BBT-Br masculino com extração de seis fatores, segue-se a Tabela 40. Nela estão contidos os resultados referentes ao sexto fator identificado nesta análise fatorial exploratória referida.

Tabela 39 - Itens (fotos) da forma masculina do BBT-Br $(n=720)$ que compõem o Fator 6 da PAF (rotação Varimax) de seis fatores, com respectivos radicais de inclinação de Achtnich.

\begin{tabular}{|c|c|c|c|c|c|}
\hline Foto & Profissional & Radical & Função & Meios/Instrumentos & $\begin{array}{l}\text { Carga } \\
\text { Fatorial }\end{array}$ \\
\hline 26 & Boxeador & $\mathrm{Kz}$ & Lutar, treinar & Punhos, força física & 0,499 \\
\hline 42 & $\begin{array}{l}\text { Policial (à } \\
\text { espreita) }\end{array}$ & $\mathrm{Kg}$ & $\begin{array}{l}\text { Combater, } \\
\text { perseverança }\end{array}$ & $\begin{array}{c}\text { Armas, cassetete, força, faro, } \\
\text { sagacidade }\end{array}$ & 0,480 \\
\hline 35 & Marinheiro & $\mathrm{S}_{\mathrm{e}} \mathrm{V}$ & $\begin{array}{l}\text { Afrontar os } \\
\text { elementos }\end{array}$ & Navio, aparelhos de navegação & 0,395 \\
\hline 69 & $\begin{array}{c}\text { Professor de Artes } \\
\text { Marciais }\end{array}$ & $\mathrm{S}_{\mathrm{h} / \mathrm{e}} \mathrm{k}$ & $\begin{array}{c}\text { Dinamismo, } \\
\text { vontade de } \\
\text { ajudar }\end{array}$ & Punhos, força física & 0,392 \\
\hline 27 & $\begin{array}{l}\text { Corredor } \\
\text { automobilista }\end{array}$ & $\mathrm{S}_{\mathrm{e}} \mathrm{Z}$ & $\begin{array}{l}\text { Afrontar os } \\
\text { perigos, correr }\end{array}$ & $\begin{array}{c}\text { Carro de corrida, demonstração } \\
\text { de velocidade }\end{array}$ & 0,386 \\
\hline 12 & Domador & $\mathrm{Zk}$ & $\begin{array}{l}\text { Apresentar-se, } \\
\text { exibir-se }\end{array}$ & $\begin{array}{l}\text { Representação, condição física, } \\
\text { chicote }\end{array}$ & 0,375 \\
\hline 19 & Bombeiro & $\mathrm{S}_{\mathrm{h} / \mathrm{e}} \mathrm{S}$ & $\begin{array}{l}\text { Superar o perigo, } \\
\text { salvar, ajudar }\end{array}$ & $\begin{array}{c}\text { Coragem, escada, água, material } \\
\text { de salvamento }\end{array}$ & 0,368 \\
\hline 77 & Piloto & $\mathrm{S}_{\mathrm{e}} \mathrm{Z}$ & $\begin{array}{l}\text { Voar, atividades } \\
\text { com riscos }\end{array}$ & Avião, coragem e resolução & 0,362 \\
\hline $46 *$ & Estudante & $\mathrm{Gg}$ & $\begin{array}{l}\text { Compreender, } \\
\text { refletir }\end{array}$ & Espírito, intuição, combinação & $-0,305$ \\
\hline
\end{tabular}

*A foto 46 está INVERSAMENTE relacionada a este fator, sendo, portanto, excluída das análises deste sexto fator.

O último fator identificado nesta PAF do BBT-Br masculino com solução de seis fatores agrupou nove fotos, sendo que, o último item do fator (foto 46), mostrou-se 
inversamente relacionada a ele, não apresentando carga fatorial suficiente para ser realocada em nenhum outro fator. As evidências sugeriram que este sexto fator, de fato, aglutinou oito fotos relacionadas entre si. Destas fotos, cinco associavam-se ao radical de inclinação motivacional primário $\mathrm{S}$ (três específicas na vertente $\mathrm{S}_{\mathrm{e}}$ ), duas fotos de $\mathrm{K}$ e uma foto de $\mathrm{Z}$. Os radicais de inclinação secundários $z, g, v$ e $s$ estiveram presentes em três fotos cada, além de duas fotos de $k$. Depreende-se que este fator agrupou fotos de atividades profissionais relacionadas ao dinamismo, ao enfrentamento de desafios e ao uso de força física e da agressividade para superá-los. Os ambientes ali representados refletem também esta situação de enfrentamento e de elementos de agressividade, com destaque para o reconhecimento e a admiração do trabalho executado.

Neste fator também foi agrupada a foto 46, do Estudante, que não atingiu carga fatorial acima de 0,30 em nenhum outro fator. No entanto, esta foto apresenta carga negativa acima de 0,30 neste fator, indicando que está inversamente relacionada às fotos aqui agrupadas, reforçando a característica de trabalho concreto, físico das atividades agrupadas neste fator, uma vez que a foto do Estudante representa uma atividade prioritariamente relacionada à abstração, reflexão. Sendo assim, os radicais de inclinação acoplados à foto 46 (Gg) não foram considerados na soma dos radicais deste sexto fator, eliminando-a das análises.

Desta maneira, pode-se hipotetizar que este fator 6 da PAF do BBT-Br masculino agrupou, dentre os radicais de inclinação pressupostos por Achtnich (1991), os radicais primários $\mathrm{S}$ (vertente $\mathrm{S}_{\mathrm{e}}$ ) e $\mathrm{K}$, além de seus respectivos radicais secundários $z$ e $k$. Em outras palavras, este fator 6 pareceu agrupar atividades representativas de interesses relacionados ao dinamismo, ao enfrentamento de desafios e aspectos de perseverança, permeados pela força física.

\subsubsection{Análise Fatorial Exploratória (PAF) com extração de seis fatores: Comparação de} achados na versão Feminina e Masculina do BBT-Br.

Realizada a descrição de cada um dos seis fatores extraídos pela análise fatorial exploratória (por meio da PAF) dos resultados das duas versões (feminina e masculina) do BBT-Br, faz-se importante visualizar semelhanças e diferenças encontradas, favorecendo a explanação didática destes achados. O Quadro 1 apresenta um quadro comparativo entre os seis fatores identificados na versão feminina e na versão masculina do BBT-Br, extraídos pelas PAFs com rotação Varimax, e aqui interpretados em função das características 
representadas nas fotos que compõem cada fator, conforme delineado nas análises específicas de cada versão do instrumento, anteriormente apresentadas.

Quadro 1 - Quadro comparativo da interpretação dos fatores identificados pela PAF com extração de seis fatores dos resultados do BBT-Br feminino $(n=862)$ e masculino $(n=720)$.

\begin{tabular}{|c|c|c|c|c|}
\hline \multirow{2}{*}{$\begin{array}{c}\text { Fatores } \\
\text { Extraídos } \\
\text { Pela PAF }\end{array}$} & \multicolumn{2}{|l|}{$\begin{array}{l}\text { BBT-Br feminino } \\
\qquad(\mathrm{n}=862)\end{array}$} & \multicolumn{2}{|c|}{$\begin{array}{l}\text { BBT-Br masculino } \\
\qquad(\mathrm{n}=720)\end{array}$} \\
\hline & Atividade representada & $\begin{array}{l}\text { Radical } \\
\text { Achtnich }\end{array}$ & Atividade representada & $\begin{array}{l}\text { Radical } \\
\text { Achtnich }\end{array}$ \\
\hline Fator 1 & $\begin{array}{l}\text { Atividades artísticas, } \\
\text { uso da afetividade } \\
\text { em trabalhos concretos. }\end{array}$ & $\overline{Z G}$ & $\begin{array}{l}\text { Trabalho cotidiano com } \\
\text { máquinas, ferramentas, } \\
\text { organização. }\end{array}$ & KM \\
\hline Fator 2 & $\begin{array}{l}\text { Uso do corpo como arte, } \\
\text { atividades físicas, } \\
\text { persuasão pelo corpo. }\end{array}$ & $\mathrm{ZS}_{\mathrm{e}}$ & $\begin{array}{l}\text { Trabalho com o concreto, } \\
\text { atividades de precisão, } \\
\text { de investigação. }\end{array}$ & VG \\
\hline Fator 3 & $\begin{array}{c}\text { Trabalhos concretos, } \\
\text { organizados, com ferramentas. }\end{array}$ & KMW & $\begin{array}{l}\text { Atividades de comunicação } \\
\text { persuasiva, criativa. }\end{array}$ & $\mathrm{ZG}$ \\
\hline Fator 4 & $\begin{array}{l}\text { Atividades de ajuda e de } \\
\text { cuidados com o outro. }\end{array}$ & $\mathrm{S}_{\mathrm{h}}$ & $\begin{array}{l}\text { Atividades artísticas, de apuro } \\
\text { estético e apreço ao belo. }\end{array}$ & $\mathrm{ZG}$ \\
\hline Fator 5 & $\begin{array}{c}\text { Atividades criativas, abstratas e } \\
\text { uso da razão, } \\
\text { persuasão pela fala. }\end{array}$ & GV & $\begin{array}{c}\text { Atividades de ajuda, cuidado, } \\
\text { para com o outro e com } \\
\text { materiais. }\end{array}$ & $\mathrm{S}_{\mathrm{h}} \mathrm{W}$ \\
\hline Fator 6 & $\begin{array}{l}\text { Atividades de precisão, } \\
\text { investigativas, com } \\
\text { ferramentas. }\end{array}$ & GV & $\begin{array}{l}\text { Atividades físicas, } \\
\text { competitivas, persuasão } \\
\text { pela dominação. }\end{array}$ & $\mathrm{S}_{\mathrm{e}} \mathrm{K}$ \\
\hline
\end{tabular}

Observando o quadro comparativo entre os fatores extraídos pelas PAFs, rotação Varimax, das duas versões (feminina e masculina) do BBT-Br, pode-se identificar fatores que agruparam fotos com atividades, ou necessidades, semelhantes. Sendo assim, pode-se classificar fatores relativos predominantemente a atividades artísticas (fator 1 feminino e fator 4 masculino); atividades físicas de persuasão e dominação (fator 2 feminino e fator 6 masculino); atividades mais organizadas, de trabalho com ferramentas (fator 3 feminino e 1 masculino); atividades de ajuda e de cuidado (fator 4 feminino e 5 masculino); atividades de contato e persuasão pela fala (fator 5 feminino e 3 masculino) e atividades de maior precisão, investigação (fator 6 feminino e fator 2 masculino). Estes achados devem ser devidamente explorados em suas hipóteses interpretativas, procurando-se sua explanação no tocante às 
evidências de validade deste método projetivo de avaliação psicológica, o que será efetivado na seção de discussão dos resultados, no tocante à validade fatorial do instrumento em foco.

\subsection{PRECISÃO DO BBT-Br}

Visando avaliar a fidedignidade do BBT-Br, formas feminina e masculina, foi realizada a análise de consistência interna de seus resultados pelo coeficiente Alfa de Cronbach $(\alpha)$. A análise da consistência interna foi efetivada por meio de duas análises:

a) exame da consistência interna dos dados das duas versões (feminina e masculina) originais do BBT-Br, ou seja, com oito radicais de inclinação propostos por Achtnich (1991).

b) exame da consistência interna dos dados das duas versões (feminina e masculina) do BBT$\mathrm{Br}$ configurado pela solução fatorial aqui encontrada pelas PAFs, ou seja, com seis fatores.

A Tabela 41 apresenta os coeficientes de precisão de cada radical de inclinação de Achtnich (1991) nas versões feminina e masculina originais do BBT-Br (com oito fatores). Para esta análise foram usados os dados relativos ao conjunto das 96 fotos do instrumento.

Tabela 40 - Precisão (coeficientes Alfa de Cronbach) das versões originais (feminina e masculina) do BBT-Br (com oito radicais de inclinação motivacional).

\begin{tabular}{ccc}
\hline $\begin{array}{c}\text { Radicais de inclinação } \\
\text { BBT-Br }\end{array}$ & $\begin{array}{c}\text { Amostra Feminina } \\
(\mathrm{n}=862)\end{array}$ & $\begin{array}{c}\text { Amostra Masculina } \\
(\mathrm{n}=720)\end{array}$ \\
\hline W & 0,69 & 0,71 \\
K & 0,60 & 0,72 \\
S & 0,77 & 0,76 \\
Z & 0,79 & 0,82 \\
V & 0,74 & 0,82 \\
G & 0,75 & 0,79 \\
M & 0,61 & 0,74 \\
O & 0,57 & 0,71 \\
\hline
\end{tabular}

Os indicadores de consistência interna específicos para cada radical de inclinação motivacional variaram entre 0,57 e 0,82 , valores que podem ser classificados como indicadores medianos de precisão do instrumento, segundo Sisto (2007). Especificamente 
quanto às formas do BBT-Br, os coeficientes gerais da versão feminina variaram entre $0,57 \mathrm{e}$ 0,79 e os coeficientes da versão masculina entre 0,71 a 0,82 . Pode-se afirmar que estes valores constituem-se em índices razoáveis de fidedignidade para ambas as versões do BBT-Br, confirmando adequada consistência interna nos dados das amostras aqui analisadas de adolescentes do ensino médio.

Após a definição da extração de seis fatores como a que melhor representava a amostra, foi verificada a precisão destes fatores também por meio do coeficiente Alfa de Cronbach ( $\alpha$ ). Para esta análise foram usados os dados relativos ao conjunto de fotos do BBT$\mathrm{Br}$ identificadas em suas respectivas soluções fatoriais. Ou seja, para a versão feminina considerou-se um total de 79 fotos, enquanto para a versão masculina esta análise pautou-se em dados obtidos com as escolhas dos adolescentes realizadas frente a 85 fotos do BBT-Br. A Tabela 42 apresenta os coeficientes de precisão para cada um dos seis fatores extraídos nas PAF dos resultados das versões feminina e masculina do BBT-Br.

Tabela 41 - Precisão (coeficientes Alfa de Cronbach) das versões feminina e masculina do BBT-Br a partir das PAF com solução de seis fatores.

\begin{tabular}{ccc}
\hline Fator & $\begin{array}{c}\text { Amostra Feminina } \\
(\mathrm{n}=862)\end{array}$ & $\begin{array}{c}\text { Amostra Masculina } \\
(\mathrm{n}=720)\end{array}$ \\
\hline 1 & 0,87 & 0,90 \\
2 & 0,81 & 0,86 \\
3 & 0,80 & 0,83 \\
4 & 0,83 & 0,85 \\
5 & 0,80 & 0,73 \\
6 & 0,83 & 0,72 \\
\hline
\end{tabular}

Os indicadores de consistência interna específicos para os seis fatores extraídos pelas PAFs dos resultados das duas versões do BBT-Br variaram entre 0,72 e 0,90 , valores que podem ser classificados como bons indicadores de precisão do instrumento, segundo Sisto (2007). Especificamente quanto às formas do BBT-Br, os coeficientes gerais da versão feminina variaram entre 0,80 e 0,87 , enquanto os indicadores de precisão da versão masculina alcançaram índices entre 0,72 a 0,90. Pode-se notar evidências de adequada consistência interna dos seis fatores extraídos em ambas as versões do BBT-Br, mas com maior homogeneidade (todos os coeficientes acima de 0,80 ) em sua versão feminina.

Ambos os resultados, tanto para os radicais de inclinação teoricamente propostos por Achtnich (1991) quanto os coeficientes encontrados na extração com seis fatores podem ser 
considerados bons indicadores da precisão do BBT-Br. Esses dados agregam evidências claras da consistência interna dos itens que compõem o instrumento, fortalecendo possibilidades de identificação de informações relevantes sobre as inclinações motivacionais de adolescentes do ensino médio, como teoricamente previsto por este instrumento projetivo de avaliação psicológica. 


\section{DISCUSSÃO}

Esta seção do trabalho tem por objetivo retomar os resultados obtidos e relacioná-los às evidências disponíveis na literatura científica da área. Sendo assim, a discussão foi dividida em quatro partes, visando contemplar os objetivos propostos para esta investigação. A primeira parte tratará dos resultados gerais (produtividade e estruturas de inclinação motivacional, positivas e negativas) do BBT-Br, nas formas feminina e masculina. O segundo tópico discutirá as análises estatísticas inferenciais específicas, por origem e série escolar, para ambas as formas do BBT-Br. A terceira parte focalizará considerações sobre a fidedignidade deste método projetivo de avaliação psicológica. Por fim, o quarto tópico será centrado nas questões de validade fatorial do instrumento.

\subsection{Sobre os Dados Normativos:}

Um dos requisitos mais importantes para adequado uso e interpretação dos resultados de instrumentos de avaliação psicológica refere-se a suas pesquisas de normatização para o contexto sócio-cultural onde será utilizado. Segundo Urbina (2007), as normas referem-se ao desempenho no teste psicológico de um ou mais grupos de referência, sendo, geralmente, apresentadas na forma de tabelas com estatísticas descritivas, resumindo resultados de caracterização de respostas de determinado grupo ou grupos de indivíduos. Essas referências normativas são, então, utilizadas para a interpretação do instrumento de avaliação psicológica, possibilitando a comparação dos resultados obtidos em uma aplicação específica com os padrões do respectivo grupo de referência.

A amostra normativa deve, portanto, refletir da melhor maneira possível as características da população para a qual o teste psicólogo é utilizado. Urbina (2007) ao dar o exemplo de um teste para avaliar habilidades de leitura afirma que "a constituição demográfica da população nacional em variáveis como gênero, etnia, linguagem, status socioeconômico, residência urbana ou rural, distribuição geográfica e matrícula em escolas públicas ou privadas deve estar refletida na amostra normativa para este teste” (Urbina, 2007, p. 89). Neste sentido, diversos autores (Draime \& Jacquemin, 1989; Villemor-Amaral \& Pasqualini-Casado, 2006; Urbina, 2007; Fensterseifer \& Werlang, 2008) ressaltam a 
importância de atualizações nas pesquisas de normatização dos instrumentos avaliativos usados no Brasil, visando o aprimoramento e maior abrangência dos referenciais normativos. Considerando a imensa extensão territorial brasileira, idealmente os estudos de normatização deveriam ser realizados com a maior amostra possível, permitindo representar a diversidade de reações humanas frente àquelas atividades focalizadas no instrumento em questão.

Neste contexto, o presente trabalho procurou, por meio da utilização do Banco de Dados do Centro de Pesquisas em Psicodiagnóstico do Departamento de Psicologia da Faculdade de Filosofia, Ciências e Letras de Ribeirão Preto - USP, agregar os resultados coletados nas pesquisas de Jacquemin (2000), Jacquemin et al. (2006), Noce (2008) e Okino (2009), elaborando, assim, uma nova amostra normativa de conveniência, mais abrangente e completa, para as duas versões (feminina e masculina) do BBT-Br. Na avaliação dos resultados, há de se considerar o espaço de tempo decorrido nos processos de coleta dos dados, uma vez que abarcou quase dez anos, desde Jacquemin (2000) até Okino (2009). No entanto, a composição do banco de dados com tamanho atual demanda tempo e recursos que tornariam pouco viável sua completa realização em menor período de tempo com equipes reduzidas de pesquisadores, como é o caso da maioria dos trabalhos de investigação científica desenvolvidos no Brasil.

Dadas as dificuldades financeiras e de psicólogos treinados para a realização de mais aplicações, a utilização do presente Banco de Dados permitiu o acúmulo de grande número de protocolos do BBT-Br e a elaboração dos novos referenciais normativos, com tabelas referentes ao sexo, origem e série escolar de estudantes. Especificamente em relação à série escolar, as novas normas aqui apresentadas buscam abranger os três anos do Ensino Médio brasileiro, uma vez que as normas atuais (Jacquemin, 2000; Jacquemin et al, 2006) apresentam tabelas descritivas apenas de alunos de $1^{\mathrm{a}}$ e $2^{\mathrm{a}}$ séries. Considerando a realização dos vestibulares e exigências sócio-culturais para a realização da escolha profissional após o término da $3^{\mathrm{a}}$ série, espera-se que os referenciais atuais possam ser úteis para identificação dos interesses profissionais desses adolescentes em processo de escolha.

Cabe ainda destacar que, com base no presente banco de dados, foi possível comparar os índices de produtividade no BBT-Br de adolescentes em função da forma de aplicação (coletiva ou individual) desse instrumento projetivo, comparando-se os dados de Okino (2009) e de Noce (2008). Foram identificadas semelhanças estatísticas no número de escolhas positivas obtidos pela aplicação coletiva de Okino (2009) e a aplicação individual de Noce (2008). Essa semelhança serviu como justificativa para a inclusão dos dados encontrados neste último trabalho no presente Banco de Dados, apesar de ter utilizado a aplicação 
individual do BBT-Br, já que os indicadores de inclinação vocacional e o estudo das associações da técnica referem-se prioritariamente aos dados obtidos pelas escolhas positivas. Pode-se pensar que, considerando a abrangência da amostra estudada, os resultados descritos neste trabalho podem ser considerados como os mais completos e atualizados referenciais normativos das duas versões do BBT-Br.

Para a sistematização das normas, foram realizadas análises quanto ao número de escolhas positivas, negativas e neutras dos participantes das duas amostras, feminina e masculina. Cabe aqui ressaltar novamente que as formas feminina e masculina do BBT-Br são compostas por estímulos (fotos) diferentes, embora retratem os mesmos radicais de inclinação motivacional de Achtnich (1991). Considerando esta diferenciação entre as versões, é preciso lembrar que as análises estatísticas referentes à comparação entre sexos, de fato, retratam evidências advindas de instrumentos diferentes, embora teoricamente equivalentes. Esta questão ainda precisará ser aprofundada em futuros trabalhos, ultrapassando as possibilidades atuais.

As participantes da amostra feminina selecionaram, em média, aproximadamente 34 fotos positivas, compondo as seguintes estruturas de inclinação motivacional: S O Z W G V M K (primária) e w z s m g o k v (secundária). No caso da estrutura de motivação primária, os radicais $\mathrm{S}, \mathrm{O}, \mathrm{Z}$ e $\mathrm{W}$ foram os principais, revelando o interesse em atividades com maior senso social, tanto de ajuda quanto de dinamismo, atividades de relação interpessoal, comunicação ou tarefas relacionadas à nutrição, atividades que exigem senso estético e o mostrar a si ou a seu trabalho, além de atividades relacionadas à maternagem. Em relação às escolhas negativas, as estudantes do sexo feminino apresentaram média de 42 fotos e estruturas negativas (rejeições) de inclinação motivacional assim distribuídas: K M V W G O $\mathrm{Z} S$ (primária) e v o k m s g z w (secundária). Essa rejeição primária aos radicais $\mathrm{K}, \mathrm{M}, \mathrm{V}$ sugere reduzido interesse por atividades que envolvam força física, imposição, trabalho com o concreto, com asseio, uso de materiais rústicos, atividades com alto investimento racional.

Já os participantes da amostra masculina selecionaram, em média, 27 fotos positivas, resultando nas seguintes estruturas positivas de inclinação motivacional: G S V O K Z M W (primária) e z s k g v o w m (secundária). Os radicais principais, G, S, V e O revelam que os adolescentes do sexo masculino tenderam a apresentar maior interesse em atividades criativas, com uso da imaginação, atividades de envolvimento social, de dinamismo ou ajuda, atividades de rigor lógico e objetividade, além de comunicação, de alimentação. Em contrapartida, o grupo masculino apresentou média de 48 escolhas negativas, resultando nas estruturas de rejeição motivacional: $\mathrm{W} \mathrm{M} \mathrm{K} \mathrm{Z} \mathrm{O} \mathrm{S} \mathrm{G} \mathrm{V} \mathrm{(primária)} \mathrm{e} \mathrm{m} \mathrm{w} \mathrm{o} \mathrm{g} \mathrm{v} \mathrm{s} \mathrm{k} \mathrm{z}$ 
(secundária). Os radicais de inclinação com maior rejeição foram W, M, K e Z, indicando reduzido interesse por atividades mais afetuosas, de cuidado, de asseio e limpeza, além de atividades permeadas por componentes de agressividade, com uso de força física e aquelas que exigem maior apuro estético, apreciação do belo.

Observou-se, desta maneira, especificidades nas estruturas de interesse e de rejeição motivacional em função do sexo, a partir das duas versões do BBT-Br. Enquanto o grupo feminino sinalizou maior interesse por atividades que exigem maior afeto, cuidado e emotividade, o grupo masculino preferiu atividades mais racionais, com maior uso da lógica. Esses achados são coerentes com as interpretações clínicas elaboradas pela vasta experiência enquanto orientador profissional de Achtnich (1991), e ressaltam a importância da existência de versões diferentes do BBT-Br específicas para cada sexo, possibilitando captação dos interesses profissionais dos adolescentes.

Cabe destacar que esta diferenciação de interesses em função do gênero é encontrada também em outros instrumentos de avaliação psicológica dos interesses no contexto brasileiro. Observando-se o manual do SDS - Questionário de Busca Auto-Dirigida (Primi et al., 2010), pode-se observar especificidades nos tipos de interesses principais encontrados para homens e mulheres. Enquanto na amostra feminina de normatização deste instrumento foi constatada maior preferência pelo tipo Social, na amostra masculina essa preferência por um tipo específico dentre os propostos por Holland não foi tão clara, com maior distribuição entre os seis tipos do RIASEC na amostra. Outro instrumento para avaliação de interesses profissionais, o AIP - Avaliação dos Interesses Profissionais (Levenfus \& Bandeira, 2009) apresentou, em sua amostra normativa, diferenças entre padrões de escolhas de homens e mulheres. De modo geral, as mulheres apresentaram maior interesse pelo Campo Comportamental/Educacional, relacionado ao comportamento humano, enquanto os homens apresentaram maiores médias no Campo Físico/Matemático, relacionado ao interesse por Física e Matemática, e no Campo Cálculo/Finanças, relacionado aos interesses estatísticos e financeiros. Pode-se depreender, portanto, que, os interesses e as inclinações motivacionais ressentiriam influência da variável gênero, expectativa compartilhada em vários contextos sócio-culturais, inclusive no Brasil, como evidenciaram os estudos acima referidos sobre as normas diferenciadas dos instrumentos de avaliação psicológica.

Ainda sobre os dados normativos aqui elaborados para o BBT-Br cabe sua análise comparativa frente aos achados do recente estudo de Shimada (2011). Neste trabalho, entre outras análises, a pesquisadora compara os índices de produtividade e média de escolha dos radicais de inclinação motivacional de Achtnich (1991) no BBT-Br de grupo clínico de 
adolescentes da terceira série do ensino médio (usuários de serviço de orientação profissional, $\mathrm{n}=118$ ) em relação aos dados de Okino (2009), oriundos de adolescentes da mesma escolaridade, representando um grupo não-clínico mais atual de mesma escolaridade. Shimada (2011) demonstrou que as estruturas de inclinação motivacional do grupo clínico foram bastante semelhantes às encontradas nos adolescentes de Okino (2009), com exceção do rapazes oriundos de escolas particulares que apresentaram reduzido número de escolhas positivas. Identificou, portanto, evidências de estabilidade no padrão de escolhas positivas, negativas e indiferentes das fotos do BBT-Br, ainda que a partir de grupos diferenciados de adolescentes.

Outro dado interessante do estudo de Shimada (2011) foi a observação de menor média de escolhas positivas por parte da maioria da amostra clínica, tanto dos estudantes de $1^{\text {a }}$ e $2^{\text {a }}$ séries do ensino médio, quanto no estudo complementar com estudantes de $3^{\mathrm{a}}$ série, em comparação com as amostras normativas (Jacquemin, 2000; Jacquemin et al., 2006 e Okino, 2009). Essa menor média de escolhas positivas parece corroborar uma tendência dos achados de Noce (2008), apontando que jovens com menor maturidade, ou prontidão, para a realização da escolha ocupacional/profissional tendem a vivenciar dificuldades de escolha diante dos próprios estímulos propostos pelo BBT-Br. Assim também pareceriam estar os adolescentes que procuraram atendimento clínico no Serviço de Orientação Profissional (população clínica) estudado por Shimada (2011) que também apresentaram, no BBT-Br, reduzido número de escolhas positivas, restringindo suas opções profissionais. No mesmo sentido, o trabalho de Junqueira (2010), utilizando-se de instrumento específico para a avaliação da maturidade para escolha profissional, a Escala de Maturidade para Escolha Profissional (EMEP), identificou menor maturidade para escolha profissional em relação ao grupo normativo da EMEP (Neiva, 1999), em uma amostra clínica de 748 jovens que procuraram, no período de 2001 até 2006, o mesmo serviço de Orientação Profissional estudado por Shimada (2011).

Esses achados parecem corroborar a utilidade do BBT-Br como instrumento técnico auxiliar em processos de Orientação Vocacional/Profissional. Dessa forma, dados provenientes de avaliações psicológicas por meio do BBT-Br poderiam ser levados em consideração para a possível elaboração e implementação de serviços de atendimento a adolescentes em processos de escolha de carreira. 


\subsection{Sobre a origem escolar:}

Dados os diferentes contextos escolares nos quais foram realizadas as aplicações do BBT-Br do presente banco de dados, considerou-se sensato realizar análises estatísticas inferenciais sobre os resultados para identificar possíveis diferenças na maneira de responder ao instrumento dos alunos de escolas particulares e públicas. Observou-se que a variável do procedência/origem escolar influencia as escolhas das fotos do BBT-Br, principalmente no grupo masculino, como a seguir será detalhado para cada versão específica deste instrumento projetivo de avaliação psicológica.

\subsubsection{Origem escolar na versão feminina do BBT-Br}

No tocante aos índices de produtividade do BBT-Br (número de escolhas positivas, negativas e neutra) não foram encontradas diferenças significativas em função da procedência escolar dos adolescentes de ensino médio. Tanto as alunas de escolas particulares quanto as alunas de escolas públicas tenderam a selecionar interesses e rejeições profissionais de maneira similar. Esses resultados se contrapõem aos encontrados por Pasian e Jardim-Maran (2008), que identificaram diferenças nos índices de produtividade de estudantes do sexo feminino em função da origem escolar. Uma vez que estas autoras tiveram uma amostra de 30 estudantes do sexo feminino, pode-se pensar em uma possível influência do tamanho da amostra nos resultados das médias obtidas, podendo-se relativizar os achados para peculiaridades dos grupos estudados.

Em relação às estruturas de inclinação motivacional, o grupo feminino de estudantes de escolas particulares apresentou a estrutura SZOGWVMK. Este resultado caracteriza interesses voltados para atividades com maior senso social, de ajuda ou dinamismo, apuro estético, apreciação do belo, necessidade de comunicação e interação com o outro, nutrição e realização de atividades criativas, imaginativas. Já o grupo das estudantes de escolas públicas apresentou a estrutura de inclinação motivacional SOWZGVMK. Essa estrutura indica interesse por atividades que envolvam maior senso social, atividades de ajuda ou participação dinâmica, atividades de contato interpessoal, de manuseio de alimentos, atividades afetuosas, de cuidado, atividades de maior apuro estético, apreciação do belo e exibição de seu trabalho. As estruturas de inclinação secundárias de ambos os grupos fortaleceram as estruturas primárias, apresentando coerência na sua disposição de radicais de inclinação motivacional. Nota-se que as estruturas dos dois grupos são bem semelhantes, evidenciando interesses 
profissionais parecidos. As diferenças estatisticamente significativas encontradas entre os subgrupos femininos foram nos radicais $\mathrm{K}, \mathrm{Z}$ e $\mathrm{V}$ e se deveram ao fato das estudantes de escola pública selecionarem mais fotos relacionadas aos radicais $\mathrm{K} \mathrm{e} \mathrm{V}$, enquanto as alunas de escola particular demonstraram maior interesse nas fotos relacionadas ao radical Z. Pode-se interpretar assim, possível tendência a maior interesse em atividades que envolvam força física, perseverança, objetividade e organização nas alunas de escola pública e maior interesse na exposição do trabalho, no apuro estético por parte das alunas de escola particular.

As estruturas de inclinação motivacional encontradas por Pasian e Jardim-Maran (2008) foram bastante semelhantes às encontradas no presente estudo. As alunas de escola particular dessa pesquisa apresentaram a estrutura ZWSOGVMK, enquanto as alunas de escola pública apresentaram a estrutura ZSOGWVMK. Realizando-se uma comparação visual entre os atuais achados e os desse citado trabalho, observa-se a alta freqüência dos radicais $\mathrm{Z}$, S e O. Pode-se levantar a hipótese de que dos interesses profissionais relacionados ao apuro estético, à valorização do belo e de seu trabalho, ao senso social, à comunicação e nutrição, mostraram-se, nos dois estudos, característicos de adolescentes do sexo feminino do ensino médio.

Quanto às estruturas de rejeição motivacional das adolescentes oriundas de diferentes origens escolares, encontrou-se para ambos os grupos os radicais de inclinação $\mathrm{K}, \mathrm{M}$ e V, como principais. Os achados indicam, portanto, rejeição por atividades com uso de força física, agressividade (física ou psicológica), perseverança, trabalho com materiais rústicos, atividades que requeiram o uso acentuado da razão e organização. Do mesmo modo, as estruturas secundárias indicaram rejeição a ambientes propícios ao uso da força física, do trabalho com materiais rústicos e trabalhos lógicos e precisos. Pasian e Jardim-Maran (2008) identificaram também os radicais de inclinação $\mathrm{K}, \mathrm{M}$ e $\mathrm{V}$ como os mais rejeitados em estudantes do sexo feminino. Pode-se pensar, novamente, em uma rejeição relativamente comum a atividades ligadas a esses radicais de inclinação motivacional por parte das adolescentes, uma vez que, em nosso contexto sócio-cultural, atividades de uso de força física, de trabalho com materiais rústicos e atividades de limpeza tendem a ser menos valorizados que atividades de outra natureza (mais aprimorada), ao mesmo tempo em que atividades relacionadas ao raciocínio lógico, à objetividade, podem ser rejeitadas no sexo feminino em favor de atividades com maior envolvimento emocional e afetivo, talvez acompanhando estereótipos sócio-culturais. 
É importante ressaltar que as hipóteses aqui levantadas têm por objetivo apenas promover a reflexão sobre os temas referidos. Para comprovação das mesmas, fazem-se necessários novos estudos com objetivos e métodos adequados a esses propósitos.

\subsubsection{Origem escolar na versão masculina do BBT-Br}

A comparação estatística inferencial entre os índices de produtividade dos estudantes oriundos de escolas particulares e escolas públicas apontou diferenças significativas nos indicadores das escolhas positivas, negativas e neutras do BBT-Br. Os alunos de escolas particulares tenderam a selecionar menos escolhas positivas e neutras, rejeitando mais fotos que os alunos de escolas públicas. Essa tendência dos alunos de escolas particulares possuírem menor amplitude de interesses profissionais também foi observada no trabalho de Pasian e Jardim-Maran (2008). Segundo essas autoras, o maior número de escolhas positivas dos estudantes de escolas públicas pode estar relacionado à hipótese desses jovens vivenciarem o momento da aplicação do BBT-Br como uma oportunidade de explorar as atividades do mundo real, não delimitando maior grau de especificidade às suas escolhas profissionais. Desta maneira, talvez os estudantes de escolas públicas tenham trabalhado com o BBT-Br como um exercício de exploração e livre expressão de seus interesses por meio das fotos, sem compromisso explícito com a operacionalização destas escolhas na vida cotidiana. Outra hipótese levantada pelas autoras refere-se a uma possível insegurança na inserção profissional destes estudantes de escolas públicas, refletida na diversificação de interesses, que possibilitaria maior diversidade de áreas e de atuação profissional.

Em contrapartida, como já assinalado anteriormente, o trabalho de Noce (2008) indicou que adolescentes com maior maturidade para a escolha profissional tendem a selecionar mais fotos positivas, ampliando suas opções de escolha profissional. Pode-se pensar aqui que, considerando o contexto sócio-escolar que freqüentam, os estudantes das escolas públicas podem desenvolver mais rapidamente a maturidade profissional, justamente pelas necessidades relativas à inserção rápida no mercado de trabalho, muita vezes com menor moratória social em sua adolescência.

Em relação à estrutura de inclinação motivacional positiva, tanto os alunos oriundos de escolas particulares (SGVOZKMW), quanto os oriundos de escolas particulares (GSOVKZMW) apresentaram, como radicais de inclinação primários principais, os radicais $\mathrm{S}, \mathrm{G}, \mathrm{V}$ e O. Essa estrutura motivacional indica interesse por atividades relacionadas ao senso social, atividades de ajuda e dinamismo, atividades criativas e imaginativas, atividades 
lógicas, com uso da razão, e atividades que envolvam relacionamento interpessoal, comunicativas. As estruturas de inclinação secundárias positivas de ambos os grupos confirmaram a estrutura primária, com destaque também para ambientes de valorização do trabalho e perseverança no grupo oriundo de escolas particulares.

No trabalho de Pasian e Jardim-Maran (2008), as estruturas positivas de inclinação motivacional encontradas foram SGOZVKMW, para os alunos de escola particular, e GVSZOWMK para os alunos de escola pública. Resultados semelhantes também foram observados na pesquisa de Noce (2003), na aplicação do BBT-Br Masculino em 33 adolescentes da $1^{\mathrm{a}}$ e $2^{\mathrm{a}}$ séries do ensino médio, identificando a seguinte estrutura de inclinação motivacional: GSOVZWKM. Pela análise descritiva das estruturas dos dois trabalhos citados e da presente análise, pode-se perceber que os radicais de inclinação $S, G, O$ e V apareceram como importantes na constituição dos interesses profissionais de adolescentes do sexo masculino.

Já a análise descritiva das estruturas negativas de inclinação motivacional (rejeições) dos estudantes de escola particular (WMKZOSVG) e escola pública (WMKZOSGV) apontou os radicais $\mathrm{W}, \mathrm{M}, \mathrm{K}$ e $\mathrm{Z}$ como principais. Esses dados sugerem reduzido interesse por atividades de maternagem, afeto, trabalho com substâncias químicas e rústicas, uso da agressividade, tanto física como mental, e atividades que necessitem de maior apuro estético, de exibição contínua de si ou do seu trabalho. As estruturas secundárias novamente confirmaram as primárias, com a rejeição de ambientes relacionados aos radicais primários já apontados.

As estruturas negativas de inclinação motivacional descritas por Pasian e JardimMaran (2008) para estudantes do sexo masculino foram: WMKVZGOS (escola particular) e KMWOZSVG (escola pública). Já a pesquisa de Noce (2003) encontrou a estrutura de rejeição motivacional KMWZOGSV. Pela comparação descritiva visual dessas estruturas, pode-se identificar os radicais de inclinação $\mathrm{W}, \mathrm{K}$ e $\mathrm{M}$ como freqüentemente rejeitados pelos estudantes do sexo masculino. Essa rejeição pode estar associada ao caráter mais afetivo das atividades relacionadas ao radical $\mathrm{W}$ e a eventual desvalorização de atividades profissionais relacionadas aos radicais $\mathrm{K}$ e $\mathrm{M}$, em nosso contexto sócio-cultural, que tende a valorizar mais atividades intelectuais e que envolvem maior elaboração lógica, incluindo criatividade (Jacquemin, 2000; Jacquemin et al, 2006, Ottati, 2009). 


\subsection{Sobre a série escolar:}

Atualmente o ensino médio brasileiro encontra-se seriado em três anos, envolvendo etapas de complexidade crescente nos conteúdos propostos ao longo desse período. Ao final do terceiro ano, ou seja, da $3^{\mathrm{a}}$ série, os estudantes concluem o ensino médio, ingressando no ensino superior, ensino técnico ou diretamente no mercado de trabalho. Neste contexto, seja na continuação dos estudos acadêmicos, seja na atuação profissional direta, é esperado que os estudantes do último ano estejam mais envolvidos na questão da escolha profissional. Sendo assim, outra variável importante a ser avaliada na presente pesquisa refere-se à série escolar em que se encontravam os participantes e como ela afetaria, ou não, o padrão de escolhas e de respostas ao Teste de Fotos de Profissões (BBT-Br). Para tanto, foram comparados estatisticamente os índices de produtividade e estruturas de inclinação motivacional (positivas e negativas) dos estudantes das três séries do ensino médio encontrados no Banco de Dados aqui compilado.

\subsubsection{Série escolar na versão feminina do BBT-Br}

A análise estatística comparativa dos índices de produtividade (escolhas positivas, negativas e neutras) do BBT-Br feminino entre as três séries do ensino médio encontrou diferenças significativas nestes indicadores do instrumento. Essas diferenças ocorreram devido ao número menor de escolhas positivas por parte das alunas da $3^{\mathrm{a}}$ série, que conseqüentemente aumentou o número de escolhas negativas e neutras ao instrumento. Visto que as alunas do último ano do ensino médio tenderam a restringir seus interesses profissionais evocados pelas fotos do BBT-Br, pode-se pensar numa hipótese interpretativa ligada a vivências de ansiedade contaminando (e restringindo, defensivamente) as escolhas dessas jovens.

O terceiro ano do ensino as coloca na iminência de realizar uma decisão por uma ocupação ou profissão, o que pode disparar angústia e ansiedade, na medida em que envolve a própria definição pessoal e a sistematização de elementos formadores e reafirmadores da própria identidade. Erikson (1976), um importante teórico do desenvolvimento, considera o momento da escolha profissional como bastante inquietante para o adolescente. Considerando o elevado nível de ansiedade e as exigências ambientais decorrentes (vestibular, pressão dos

pais e da escola), pode-se levantar a hipótese de que as adolescentes do sexo feminino procuraram restringir seus interesses profissionais como uma medida psíquica de defesa, não 
necessariamente consciente. Ao restringir seu leque de opções, a ansiedade decorrente do processo de escolha poderia ser, eventualmente, amenizada. Essa possibilidade, no entanto, exigirá o devido aprofundamento, ultrapassando, mais uma vez, o foco principal deste trabalho.

Em complemento a estes achados, a análise das estruturas positivas de inclinação primárias das estudantes das três séries foram bastante semelhantes. As alunas da $1^{\mathrm{a}}$ série apresentaram a estrutura de inclinação SZOWGVMK. As estudantes da $2^{\mathrm{a}}$ série, por sua vez, apresentaram a estrutura SOZWGVMK. Por fim, as alunas do ultimo ano tiveram a seguinte estrutura de interesses: SOWZGVMK. Pela comparação descritiva visual dessas estruturas, localizam-se, como radicais principais, $\mathrm{S}, \mathrm{Z}, \mathrm{O}$ e W. Esta configuração indica interesse por atividades que envolvem senso social, dinamismo, ajuda, apuro estético e apreciação do belo, interesse por comunicação e/ou manuseio de alimentos e atividades mais afetivas, de cuidado e maternagem. As estruturas de inclinação secundária das estudantes confirmaram esses interesses primários, com a seleção de radicais ligados a ambientes propícios à realização dessas atividades. Essas diretrizes gerais já estavam apontadas no perfil geral do grupo feminino, anteriormente abordado neste trabalho.

A análise estatística inferencial destas estruturas motivacionais positivas, em função das séries escolares, apontou que as estudantes do $3^{\mathrm{a}}$ ano selecionaram menor número de fotos relacionadas aos radicais de inclinação $\mathrm{S}, \mathrm{Z}, \mathrm{G}$ e $\mathrm{O}$ e maior número de fotos relacionadas ao radical K. Isto é, as alunas do último ano tenderam a apresentar menor interesse, em relação às demais estudantes, em atividades que envolvem elementos de senso social, apuro estético, criatividade e comunicação/nutrição. Ao mesmo tempo, sinalizaram maior interesse por atividades com maior teor de agressividade, competitividade, sugerindo que este interesse pode estar relacionado ao contexto de vida das adolescentes do $3^{\mathrm{a}}$ ano, que, em sua maioria, se encontram em preparação para prestar vestibular, configurando realidade de natureza competitiva. Estes resultados apontam para uma tendência de formação diferenciada de interesses nas alunas do último ano do ensino médio, que deve ser levada em consideração nos processos interpretativos do BBT-Br feminino.

Especificamente em relação aos radicais secundários, as alunas da $3^{\mathrm{a}}$ série selecionaram menos fotos relacionadas a ambientes de trabalho com maior contato afetuoso (radical $w$ ) e uso da criatividade, imaginação (radical $g$ ). Também foram encontradas diferenças significativas entre os ambientes selecionados pelas alunas da $3^{\mathrm{a}}$ série e as alunas da $1^{\text {a }}$ série nos radicais $k, v, m$ e $o$, sugerindo menor interesse das alunas do último ano em ambientes onde se faz necessário uso da força física, o trabalho racional, meticuloso, o 
trabalho de limpeza, asseio ou ambientes de maior comunicação/nutrição. Essas diferenças podem estar relacionadas a certo afastamento, por parte das alunas do $3^{\mathrm{a}}$ ano, de ambientes de trabalho culturalmente mais masculinos (radicais $k$ e $v$ ) ou ambientes de trabalho menos valorizados em nosso contexto (radicais $m$ e $o$ ).

Assim como para as estruturas positivas de inclinação motivacional, as estruturas negativas (de rejeição) das estudantes de diferentes séries mostrou-se qualitativamente semelhante. Observando-se as estruturas de rejeição da $1^{\mathrm{a}}$ série (KMVWGOSZ), $2^{\mathrm{a}}$ série (KMVWGOSZ) e $3^{\text {a }}$ série (KMVWGOZS) encontram-se, como radicais mais rejeitados, K, M, V e W. Essas estruturas, confirmadas pelas estruturas secundárias, refletem rejeição por atividades que envolvem uso da força física e agressividade física ou mental, trabalho com materiais rústicos e tarefas rotineiras, e atividades de cuidado, maternagem e afeto com o outro.

$\mathrm{Na}$ comparação estatística inferencial das três séries escolares, emergiram diferenças significativas nas escolhas negativas dos radicais $\mathrm{Z}, \mathrm{G}$ e $\mathrm{O}$, oriundas do maior número de rejeições a esses radicais por parte das estudantes do último ano. Esses achados apontam para maior rejeição, nas adolescentes da $3^{\mathrm{a}}$ série, de atividades relacionadas ao apuro estético, à valorização do belo, ao uso da criatividade e imaginação e atividades de relações interpessoais de comunicação ou nutrição, em comparação com as estudantes dos dois primeiros anos do ensino médio. Nos radicais secundários, as diferenças nos radicais $w, z$ e $g$, também decorreram da maior rejeição das estudantes da $3^{\mathrm{a}}$ série, indicando reduzido interesse por atividades realizadas em ambientes de contato afetuoso, de exibição ou valorização do trabalho e do uso da criatividade. Novamente, essas características do último ano do ensino médio devem ser levadas em consideração ao interpretar os dados do BBT-Br feminino.

Mais uma vez é interessante notar que, apesar de diferenças pontuais em relação a interesses específicos e produtividade, tanto as estruturas de inclinação quanto de rejeição motivacional das estudantes das três séries analisadas foram bastante semelhantes qualitativamente. Esses achados reforçam a estabilidade das normas do BBT-Br feminino, uma vez que o presente banco de dados foi composto por pesquisas realizadas ao longo de cerca de cinco anos: Jacquemin et al. (2006) até Okino (2009).

\subsubsection{Série escolar na versão masculina do BBT-Br}

A comparação entre os índices de produtividade (escolhas positivas, negativas e neutras) dos estudantes do sexo masculino de diferentes séries escolares mostrou 
particularidades no modo desses jovens selecionarem as fotos do BBT-Br. Observou-se menor rejeição e maior número de escolhas indiferentes às fotos por parte dos alunos da $3^{\mathrm{a}}$ série, em relação às demais séries. Pasian e Jardim-Maran (2008) ao encontraram grande número de respostas indiferentes por parte dos alunos da $3^{\mathrm{a}}$ série, sugeriram que este modo de responder ao BBT-Br pode estar associado à necessidade de efetivamente escolher uma profissão (dada a proximidade do fim dos estudos no ensino médio), gerando maior indecisão (e maior número de escolhas indiferentes) nestes estudantes.

Focalizando já as estruturas positivas de inclinação motivacional em si, pode-se notar semelhança entre as séries escolares dos estudantes do sexo masculino (como se passou também no BBT-Br feminino). Os alunos da $1^{a}$ série selecionaram SGVOKZWM, enquanto a $2^{\mathrm{a}}$ série apresentou a estrutura VSGOZKMW e, os estudantes da $3^{\mathrm{a}}$ série, OGSVKZMW. Em todas as séries, os radicais de inclinação principais foram $S, G, V$ e $O$, denotando o interesse dos adolescentes do sexo masculino por atividades que envolvam senso social, dinamismo e relações de ajuda, atividades criativas e imaginativas, atividades que necessitam da razão e lógica e atividades de cunho interpessoal, que exigem comunicação e servir ao outro. Esses interesses profissionais também foram refletidos nas estruturas secundárias, por meio do grande interesse em ambientes relacionados a essas atividades.

Em complemento a estas análises gerais, no entanto, as comparações estatísticas inferenciais entre os radicais da estrutura positiva de inclinação motivacional apontaram especificidades nos interesses dos adolescentes das três séries. Em linhas gerais, pode-se afirmar que, na comparação entre as séries, os alunos da $1^{\mathrm{a}}$ série apresentaram maiores interesses em atividades de contato afetuoso, de cuidado (radical W). Os alunos da $2^{\mathrm{a}}$ série, por sua vez, interessam-se mais por atividades de comunicação, de contato interpessoal de nutrição (radical O). Já os alunos do último ano apresentaram maior interesse nas atividades rotineiras, de asseio e cuidado (radical M).

Do mesmo modo, foram encontradas especificidades nos interesses aos radicais secundários. Os alunos da $1^{\mathrm{a}}$ série selecionaram mais ambientes de trabalho físico, de uso da agressividade e perseverança (radical secundário $k$ ). Já os alunos da $2^{\text {a }}$ série selecionaram menos ambientes relacionados ao cuidado, ao contato afetuoso com o outro (radical secundário $w$ ) e atividades mais rotineiras, de trabalho com materiais rústicos (radical secundário $m$ ). Por sua vez, os alunos da $3^{\mathrm{a}}$ série apresentaram maior interesse em ambientes de contato interpessoal por meio da comunicação ou alimentação (radical secundário $o$ ).

Passando ao exame das estruturas negativas de inclinação motivacional dos estudantes das três séries analisadas, pode-se identificar as seguintes formações: WMKZOGSV (1 ${ }^{\mathrm{a}}$ 
série), WMKZOSGV (2 $2^{\text {a }}$ série) e WKMZOSGV ( $3^{\mathrm{a}}$ série). Novamente, a análise descritiva visual das estruturas permite identificar, como radicais predominantemente rejeitados pelos adolescentes das três séries os radicais W, M, K e Z. Sendo assim, os estudantes de diferentes séries escolares sinalizaram menor interesse por atividades mais afetivas, de maternagem, de atividades rústicas, com uso de materiais químico-orgânicos e atividades rotineiras, além de atividades que exigem maior agressividade e uso da força física, apuro estético, apreciação do belo. A rejeição por ambientes relacionados a estas atividades também foi bastante encontrada nos alunos das três séries avaliadas.

Nas comparações estatísticas inferenciais entre as estruturas negativas de inclinação motivacional, os alunos da $3^{\text {a }}$ série do ensino médio apresentaram menor rejeição à maioria dos radicais de inclinação primários (seis) e secundários (oito) que os estudantes das demais séries avaliadas. Pode-se pensar, no entanto, que esta redução no número de escolhas negativas esteja relacionada ao alto número de escolhas indiferentes, possíveis sinalizadoras de ansiedade.

Em complemento a este raciocínio interpretativo deste tipo de dado, poder-se-ia tomar as evidências encontradas em Noce (2008), ao investigar as relações entre a maturidade para a escolha profissional e o BBT-Br. Seus dados indicaram que adolescentes com maior maturidade para a escolha tendiam a expandir seu leque de opções das atividades profissionais representadas pelas fotos do BBT-Br, apresentando um comportamento exploratório mais amplo que os jovens com baixa maturidade. Neste sentido, o menor número de rejeições apresentadas pelos alunos do último ano do ensino médio, mesmo que provocada pelo aumento das respostas indiferentes (que não são uma escolha de fato, mas também não refletem a rejeição total à atividade) pode ser indicativo da maior preocupação e maturidade com as questões da escolha profissional nestes adolescentes, em comparação com os estudantes mais jovens.

Assim como para a amostra feminina, apesar de alguns pontos de especificidade, as estruturas de inclinação e rejeição motivacional encontradas nos adolescentes de diferentes séries escolares foram semelhantes, sobretudo em termos qualitativos. Estes dados empíricos reforçam a estabilidade das normas do BBT-Br masculino, uma vez que, as pesquisas que compõem o banco de dados foram realizadas em um período de cerca de dez anos, de Jacquemin (2000) até Okino (2009), reforçando as possibilidades de utilização deste material na prática profissional do psicólogo brasileiro. 


\subsection{Sobre a validade fatorial do BBT-Br.}

Neste ponto da discussão, é importante ressaltar a questão da dificuldade em encontrar estudos de análise fatorial não só com o BBT-Br, mas com os métodos projetivos em geral. Especificamente como BBT-Br, apenas o trabalho de Okino (2009), cujos dados compõem o presente banco de dados, utilizou-se de um método de análise fatorial (Análise dos Componentes Principais) para examinar a distribuição de resultados com esse instrumento em 497 adolescentes do terceiro ano do Ensino Médio (295 do sexo feminino e 202 do sexo masculino). Sendo assim, serão realizadas algumas comparações descritivas com dos achados atuais em relação ao trabalho dessa pesquisadora, uma vez que o método de extração dos fatores foi diferente, e o conjunto total da presente amostra (1562 participantes, sendo 862 mulheres e 720 homens) é consideravelmente maior (embora inclua os dados de Okino, 2009).

Ressalta-se que o tamanho da amostra é um critério importante a ser examinado para indicar (ou não) a possibilidade de realização de análises fatoriais exploratórias de resultados de instrumentos de avaliação psicológica. Pasquali (2005) sugeriu, como regra geral, um mínimo de 100 sujeitos por fator medido ou um mínimo de cinco sujeitos por item do instrumento analisado. Considerando os oito radicais de inclinação de Achtnich (1991), o tamanho mínimo das amostras deveria ser de 800 sujeitos. Em contrapartida, considerando os 96 itens (fotos) do BBT-Br, pode-se pensar em um mínimo de 480 participantes. Sendo assim, pode-se notar que o tamanho das amostras atuais permitiu análises suficientemente embasadas e passíveis de interpretação, com rigor psicométrico.

Visando investigar evidências de validade no BBT-Br, formas feminina e masculina, foram realizadas análises fatoriais (pelo Método de Principal Axis Factoring - PAF), com rotação Varimax e extração pré-definida de quatro, cinco, seis, sete e oito fatores. Dentre essas extrações, o modelo de seis fatores foi o que melhor preencheu tanto os requisitos estatísticos quanto os teóricos, descritos no método do presente trabalho. Para a análise dos dados da versão feminina do BBT-Br, a extração de seis fatores conseguiu explicar 27,88\% da variância dos resultados, sendo que a variância explicada de cada fator assumiu valores entre $3,87 \%$ e 6,38\%, preenchendo o critério de Harman (Zerbini, 2007). No caso da versão masculina do BBT-Br, a variância explicada dos resultados foi de $30,78 \%$, sendo que cada um dos seis fatores atingiu valores de variância explicada entre 3,22\% e 7,87\%, também atendendo de modo satisfatório o critério estatístico. Para ambas as versões do BBT-Br, os valores de variância explicada podem ser considerados como apenas razoáveis para 
explanação dos resultados, embora bastante úteis do ponto de vista clínico, sobretudo tendo em vista a complexidade das inclinações motivacionais, construto em foco neste método projetivo de avaliação psicológica.

Para a forma feminina do BBT-Br, a distribuição dos radicais de inclinação de Achtnich (1991) deu-se da seguinte maneira na PAF com extração de seis fatores. O fator 1 apresentou fotos representativas dos radicais de inclinação primários $\mathrm{Z}$ e G, e secundários $w$ e $z$, caracterizando um perfil de atividades relacionadas ao senso estético sobre materiais, criatividade, arte, ao exibir o próprio trabalho de maneira criativa (por exemplo, fotos da mosaísta e pintora). $\mathrm{O}$ fator 2 apresentou fotos relacionadas aos radicais de inclinação $\mathrm{Z}$ e $\mathrm{S}_{\mathrm{e}}$, e aos radicais secundários $z$ e $k$, agrupando atividades relacionadas ao espírito empreendedor, ao dinamismo, ao mostrar e valorizar o corpo humano, ao uso do corpo como instrumento de beleza, de persuasão e de poder (por exemplo, bailarina e manequim). O fator 3 incorporou atividades relacionadas aos radicais de inclinação primários $\mathrm{K}, \mathrm{M}$ e $\mathrm{W}$, tendo como principais radicais secundários $v, s_{e}$ e $m$, representando assim um perfil de atividades relacionadas ao trabalho físico com objetos, à perseverança e meticulosidade no trabalho, com uso de ferramentas e instrumentos e sem a necessidade de intenso contato interpessoal (por exemplo, dona de casa e mecânica de automóveis). O fator 4 aqui identificado aglutinou principalmente fotos relacionadas ao radical primário $\mathrm{S}_{\mathrm{h}}$, em conjunto aos radicais secundários $w$ e $s_{h}$, destacando-se assim, atividades de ajuda, cuidado e proteção (enfermeira e pediatra, por exemplo). $\mathrm{O}$ fator 5 desta análise fatorial exploratória apresentou predomínio dos radicais primários $\mathrm{G}$ e $\mathrm{V}$, e secundários $o_{r}$ e $g$, representando o interesse em atividades de comunicação criativa, persuasão, convencimento do outro por meio da criatividade (por exemplo, política e advogada). Por fim, o fator 6 também contou com o predomínio dos radicais primários $\mathrm{G}$ e $\mathrm{V}$, com destaque para o radical secundário $v$, apontando marcas de representação do interesse por atividades objetivas, de pesquisa, pela racionalidade e pelo rigor lógico (laboratoristas e pesquisadora, por exemplo)..

A mesma análise fatorial exploratória (PAF com extração pré-definida de seis fatores) possibilitou identificar a composição dos fatores presentes nos resultados de adolescentes do sexo masculino no BBT-Br masculino. O fator 1 agrupou um perfil de atividades relacionadas aos radicais de inclinação primários $\mathrm{K}$ e $\mathrm{M}$, e secundários $m$ e $o_{r}$, representando o interesse por atividades de força física, trabalho com ferramentas, trabalhos rotineiros envolvendo o corpo (como, por exemplo, nas fotos do pedreiro e serralheiro). O fator 2 aglutinou fotos prioritariamente relacionadas aos radicais primários $\mathrm{V}$ e $\mathrm{G}$, e ao radical secundário $v$, identificando o interesse em profissões que exigem atividades lógicas, ao trabalho de precisão 
com materiais (laboratorista químico e chefe de obras, por exemplo). No fator 3 destacaramse fotos relacionadas aos radicais primários $\mathrm{Z} \mathrm{e} \mathrm{G}$, e aos radicais secundários $o_{r}$ e $k$, indicando o interesse por atividades de persuasão, comunicação criativa e atraente ao outro (por exemplo, as fotos do orador e do advogado). O fator 4 também agrupou fotos representativas dos radicais primários $\mathrm{Z}$ e $\mathrm{G}$, porém agora agregados aos radicais secundários $z$ e $g$, abarcando atividades dependentes do senso estético, do uso da criatividade para criação do belo, das artes (por exemplo, o compositor e o maestro). $\mathrm{O}$ fator 5 congregou fotos relacionadas aos radicais de inclinação primários $\mathrm{S}_{\mathrm{h}} \mathrm{e} \mathrm{W}$, e os radicais secundários $s_{h} \mathrm{e} w$, indicando um perfil de interesses relacionados à ajuda, ao cuidado e à proteção do outro (fotos do médico e fisioterapeuta, por exemplo). Finalizando, o fator 6 agrupou fotos relacionadas aos radicais primários $\mathrm{S}_{\mathrm{e}} \mathrm{e} \mathrm{K}$, e secundários $z$ e $k$, destacando o interesse por atividades relacionadas ao dinamismo, a atividades físicas e competitivas, à superação do outro pela força física, ao enfrentamento de desafios e perseverança (fotos do bombeiro e do marinheiro, por exemplo).

Assim como na pesquisa de Okino (2009), o agrupamento dos radicais de inclinação motivacional de Achtnich (1991) nos fatores destas PAF das duas versões do BBT-Br apresentou indícios de coerência interna, sem, no entanto, apresentar um único radical de inclinação por fator, como seria esperado dentro dos pressupostos de Achtnich (1991) na elaboração das fotos. Ao criar o Teste de Fotos de Profissões BBT, Achtnich procurou selecionar fotos que representassem o pareamento de dois radicais de inclinação motivacional, com base em sua experiência clínica e na ênfase da multifatoriedade das profissões, que envolvem diferentes interesses na realização de suas atividades, bem como multideterminações para os mesmos. O próprio caráter projetivo deste método de avaliação psicológica permite e estimula que o respondente não fique restrito à seleção de um único interesse/atividade por foto, podendo projetar suas necessidades nos estímulos apresentados. Achtnich (1991) já ressaltava que a fase das associações pode informar mais sobre os orientandos do que as próprias estruturas de inclinação motivacional, considerando a importância de apreender o que, de fato, o indivíduo havia identificado e classificado em cada uma das 96 fotos do BBT-Br. Okino (2009) aponta os resultados obtidos em suas Análises do Componentes Principais (ACP) como representativos da diversidade dos elementos presentes nos oito radicais de inclinação motivacional de Achtnich (1991), encontrando evidências empíricas de validade fatorial deste método projetivo de avaliação psicológica na realidade do Brasil.

Uma exploração interessante sobre estes achados do atual estudo refere-se à correspondência teórica entre os fatores encontrados para as duas formas do BBT-Br, 
feminina e masculina. Em ambas as formas, foram identificados fatores relacionados ao senso estético e artístico (fator 1 na forma feminina e fator 4 na forma masculina), fatores relacionados à atividades físicas de persuasão e dominação (fator 2 na forma feminina e fator 6 na forma masculina), fatores relacionados ao trabalho com ferramentas e objetos (fator 3 na forma feminina e fator 1 na forma masculina), fatores relacionados ao cuidado, à maternagem e relações de ajuda (fator 4 na forma feminina e fator 5 na forma masculina), fatores relacionados atividades de contato e persuasão pela fala (fator 5 na forma feminina e fator 3 na forma masculina) e fatores relacionados à pesquisa, ao rigor científico, à racionalidade (fator 6 na forma feminina e fator 2 na forma masculina). Pode-se pensar que, apesar das duas formas do $\mathrm{BBT}-\mathrm{Br}$ apresentarem fotos diferentes, os instrumentos sinalizaram avaliar, empiricamente, os mesmos tipos de interesses, conforme proposto originalmente por Achtnich (1991).

Por outro lado, os resultados obtidos no presente trabalho permitem pensar que o BBT-Br poderia avaliar seis dimensões de interesse, ao invés das oito propostas pelo seu autor (Achtnich, 1991). Essa nova caracterização do BBT-Br permitiria aproximações com a Teoria da Personalidade Vocacional de Holland (1997), bastante estudada e relevante no contexto internacional e brasileiro (Nunes et al., 2008; Okino, 2009).

Essas possibilidades associativas entre Achtnich (BBT) e Holland (SDS) constituiram o tema central da tese de Doutorado de Okino (2009). Esta pesquisadora identificou correlações positivas significativas, pelo Coeficiente de Correlação de Pearson, entre os radicais de inclinação de Achtnich (1991) e os tipos de Holland (1997), utilizando o BBT-Br, formas feminina e masculina e o SDS (Primi et al., 2010). O referido trabalho apontou que cada um dos seis tipos de Holland (Realista, Investigativo, Artístico, Social, Empreendedor e Convencional) correlacionava-se com mais do que um radical de inclinação motivacional de Achtnich (1991), reforçando as evidências do caráter multifatorial dos interesses profissionais, com algumas especificidades pontuais de representação desse construto em função da versão (feminina ou masculina) do BBT-Br.

Considerando-se também a premissa tipológica do RIASEC, onde cada tipo constituise a partir da interação entre uma herança determinada e uma variedade de fatores culturais e pessoais (Primi et al., 2010), ressalta-se a multifatoriedade não só das profissões, mas também dos ambientes de trabalho. Raramente uma profissão pode ser definida apenas por um único tipo ou classe de interesses específicos, uma vez que a ampla gama de possíveis atividades profissionais abrange vários aspectos das inclinações motivacionais dos indivíduos e vários aspectos do próprio ambiente, facilitadores ou não destas atividades. O próprio Holland, no 
Caderno de Carreiras do SDS (Holland \& Powell, 2010), apresenta algumas carreiras (ou profissões) caracterizadas sempre pela integração de dois tipos de seu modelo RIASEC, visando abranger melhor os interesses, atividades e ambientes envolvidos na realização das atividades profissionais destacadas.

Neste sentido, visando aproximar e explorar hipóteses interpretativas para os resultados das investigações de interesses desenvolvidas a partir do BBT-Br, pode-se tentar relacionar os sentidos teóricos atribuídos aos seis fatores extraídos pelas PAFs de cada versão deste método projetivo com a tipologia do RIASEC de Holland (1997). Aqui é importante ressaltar que, dadas as características de construção das fotos do BBT-Br, que visa representar dois radicais de inclinação motivacional por foto (um principal e um secundário), realçando o caráter multidimensional dos interesses, optou-se por realizar estas aproximações teóricas atribuindo também dois tipos do RIASEC a cada fator extraído dos resultados de cada versão (feminina e masculina) do BBT-Br.

Embasado nesses princípios lógicos, a PAF com extração de seis fatores nos resultados do BBT-Br identificou que o Fator 1 (versão feminina) e Fator 4 (versão masculina) representam, prioritariamente, o tipo Artístico de Holland (1997), associado ao tipo Realista (na versão feminina) e ao tipo Investigativo (na versão masculina). As diferenças identificadas na análise dos resultados dos grupos feminino e masculino podem estar associadas à própria composição das fotos que, na forma feminina do BBT-Br priorizam aspectos de apuro estético sobre materiais e, na forma masculina, priorizam elementos relacionados a abstração e imaginação.

O Fator 2 da versão feminina e Fator 6 da versão masculina do BBT-Br pareceu fortemente associado ao tipo Empreendedor de Holland, agregando ainda características do tipo Artístico (versão feminina) e do tipo Realista (versão masculina). Nestes fatores identificados pelas PAF dos resultados do BBT-Br é interessante observar a maneira como a característica de persuasão e dominação do tipo Empreendedor podem ser manifestas em nosso contexto sócio-cultural: enquanto as atividades de persuasão e controle femininas estão prioritariamente relacionadas a questões de beleza e sedução nas fotos femininas, essa mesma persuasão e domínio do outro é caracterizada em atividades dinâmicas, de força física, nas fotos masculinas. Pode-se, portanto, levantar a hipótese da influência de expectativas de papéis sociais influenciarem na formação e na elaboração de perfis de interesses em grupos de adolescentes do sexo feminino e masculino, apontando relevância à variável gênero no estudo dos interesses, como apontado por vários trabalhos da área (Bueno, Lemos \& Tomé, 2004; Levenfus e Bandeira, 2007; Nunes \& Noronha, 2009; Otatti, 2009; Sartori, Noronha \& Nunes, 
2009; Levenfus \& Bandeira, 2010, Primi et al., 2010, Shimada, 2011). Estes trabalhos, de modo geral, apontam para o maior interesse feminino em atividades de ajuda e contato interpessoal e o maior interesse masculino em atividades implicadas em rigor lógico e praticidade. No entanto, essa hipótese deve ser especificamente investigada em estudos futuros com o BBT-Br.

O Fator 3 da versão feminina e o Fator 1 da versão masculina do BBT-Br pareceram agrupar atividades vinculadas ao tipo Convencional de Holland (1997), com forte influência também do tipo Realista. Há de se destacar a presença de elementos de componentes de maternagem, de afetividade, nas atividades representadas nas fotos da forma feminina do $\mathrm{BBT}-\mathrm{Br}$ neste agrupamento fatorial.

Já o tipo Social de Holland (1997) sinalizou-se fortemente no Fator 4 da versão feminina e no Fator 5 da versão masculina do BBT-Br, agrupando prioritariamente fotos representativas de atividades de cuidado e de ajuda ao outro. Neste contexto, a foto 7 (Tintureiro), do BBT-Br masculino, possivelmente obteve elevada correlação com este fator por suas características ambientais/instrumentais: o tecido suave, sedoso, que, na proposição de Achtnich (1991) relaciona-se a aspectos mais afetuosos, representados pelo radical secundário $w$. Pode-se levantar a hipótese que este cuidado e afeto ao tratar do tecido, retratado na foto (representando também um tipo de cuidado com o outro), influenciou na correlação desta foto com os demais itens (fotos) do fator 5 do BBT-Br masculino.

O Fator 5 da versão feminina e o Fator 3 da versão masculina do BBT-Br pareceram caracterizar os tipos Empreendedor e Investigativo de Holland (1997). Em ambos as versões do instrumento foram encontradas fotos que representam atividades de contato pessoal permeado pela comunicação, pela persuasão, além de elementos de um espírito investigador, ainda que vinculados a componentes concretos e objetivos das atividades profissionais ali representadas.

Por fim, o Fator 6 da versão feminina e o Fator 2 da versão masculina do BBT-Br agruparam atividades relacionadas aos tipos Realista e Investigativo de Holland (1997). Em ambas as versões do BBT-Br, foram agrupadas atividades de trabalho pautadas em instrumentos e em ferramentas operacionais, com metas pré-definidas, além de diretrizes investigativas e de busca de precisão.

Pode-se considerar, portanto, que esses seis fatores extraídos das atuais análises fatoriais exploratórias (pelas PAF) do BBT-Br pareceram aproximar-se do modelo RIASEC de Holland (1997). Esses achados oferecem suporte adicional para as próprias interpretações 
do Teste de Fotos de Profissões BBT-Br, vista a larga demonstração empírica da Teoria da Personalidade Vocacional, elaborada e proposta pelo referido autor.

Ainda em relação à validade fatorial do BBT-Br, é importante analisar não apenas as fotos agrupadas no procedimento das PAFs com extração de seis fatores, mas também as fotos que não atingiram carga fatorial acima de 0,30, apresentando pouca correlação com os demais estímulos deste método projetivo. Um dos objetivos do procedimento de análise fatorial é reduzir o número de itens de um instrumento de avaliação psicológica, obtendo a configuração mais representativa e válida dos dados com o menor número possível de variáveis (fatores ou dimensões). Neste sentido, a investigação das fotos descartadas pode apresentar informações relevantes para o aprimoramento do BBT-Br.

De modo geral, as análises fatoriais com a versão masculina do BBT-Br apresentaram menor número de fotos com carga fatorial abaixo do mínimo aceitável, em comparação com a versão feminina do instrumento. Este dado pode ser indicativo de consistência interna na versão masculina do BBT-Br, uma vez que mais fotos apresentaram boas correlações entre si nessa versão.

Em relação às fotos descartadas em todas as extrações fatoriais aqui realizadas, foi possível notar que há quatro fotos da versão feminina do BBT-Br que não atingiram carga fatorial mínima de 0,30. Estes quatro estímulos da prova são fotos originais (Jacquemin et al., 2006), ou seja, são fotos que no início da adaptação do BBT ao contexto brasileiro, foram identificadas empiricamente como boas representantes dos radicais de inclinação aos quais estavam teoricamente relacionadas, sem passarem por processo de revisão em seu conteúdo e representação da atividade na adaptação sócio-cultural do método. Por outro lado, há duas fotos da versão Masculina do BBT-Br que tiveram carga fatorial inferior a 0,30 em todas as extrações PAF aqui realizadas. Esses estímulos são fotos reelaboradas, ou seja, fotos nas quais foi detectada a necessidade de reestruturação para melhor representar os radicais de inclinação no contexto brasileiro, passando por reformulação no processo de adaptação sócio-cultural do instrumento. Observando-se esses resultados, pode-se comentar que a baixa carga fatorial de algumas fotos das versões do BBT-Br pareceram ocorrer de modo independente do processo de adaptação do instrumento ao contexto brasileiro. Ressalta-se, entretanto, que esta hipótese carece de maiores estudos para ser devidamente compreendida, aspecto não focalizado no presente trabalho.

Procurou-se, identificar possíveis hipóteses associadas à baixa carga fatorial de algumas fotos do BBT-Br (versão feminina e masculina) nas cinco extrações das PAF realizadas com os adolescentes do ensino médio. Um dos caminhos exploratórios foi a 
verificação da relação que estas fotos possuíam com aquelas listadas como as fotos mais rejeitadas ou escolhidas pelos estudantes da amostra normativa original (Jacquemin, 2000 e Jacquemin et al., 2006). Desse modo foi possível identificar que apenas a foto 2 (Cabeleireira para Homens) da versão feminina do BBT-Br destaca-se dentre as fotos aqui descartadas pela carga fatorial abaixo de 0,30. Com base nos resultados alcançados pelas análises do presente trabalho, pode-se considerar que a frequiência de escolha das fotos pareceu não influenciar diretamente as correlações (carga fatorial) destas fotos mais freqüentemente descartadas pelas PAFs.

Por fim, para concluir as análises referentes às fotos descartadas, recorreu-se ao estudo de Noce (2003) para investigar se as fotos da versão masculina do BBT-Br mais descartadas pelas PAFs corresponderiam às fotos eliminadas no processo de elaboração da versão reduzida deste método projetivo. Essa autora buscou reduzir o número de fotos do BBT-Br masculino por meio da identificação e seleção das fotos mais representativas, dentre as fotos "normais" e as fotos "linha", para os radicais de inclinação S, Z, V e G. Dessa maneira, foi diminuído o número de fotos relacionadas a esses fatores de 16 (oito fotos com radicais "normais" somados às oito fotos com radicais "linha") para oito, homogeneizando o número de fotos representativas de cada radical de inclinação de Achnich (1991). A elaboração dessa versão reduzida, com 64 fotos, foi realizada a partir de dois tipos de critérios: a) quantitativo (frequiência de escolha em cada foto); b) qualitativo (julgamento de três avaliadores independentes, com experiência no uso do instrumento, sobre a qualidade de representação dos radicais de inclinação motivacional nas fotos). Observando as fotos descartadas por Noce (2003) e as fotos descartadas na extração de seis fatores para a amostra masculina, selecionada como mais representativa da amostra na presente pesquisa, notou-se que, das 11 fotos que não obtiveram carga fatorial acima de 0,30 , cinco também haviam sido descartadas pelo procedimento da referida pesquisadora. Essas cinco fotos, a saber: foto 4 (Decorador de Vitrines), foto 65 (Assistente Social), foto 81 (Professor), foto 88 (Escritor) e foto 91 (Bibliotecário Arquivista), apresentaram baixa carga fatorial e foram descartadas também pelos critérios quantitativos e qualitativos de Noce (2003), devendo ser analisadas mais profundamente em estudos futuros, talvez até sugerindo necessidade de reformulação de suas imagens. No entanto, é importante ressaltar que o método de trabalho utilizado por Noce (2003), em especial a análise de juízes independentes, não visa apresentar os mesmos resultados que um tratamento estatístico, como a Análise Fatorial, uma vez que é uma análise mais qualitativa e subjetiva, bastante baseada na experiência clínica e fundamentação teórica dos avaliadores do instrumento em si. 


\subsection{Sobre a Precisão do BBT-Br}

A análise de precisão do BBT-Br foi realizada pela averiguação da consistência interna de seus itens, utilizando-se do Alfa de Cronbach ( $\alpha$ ). Em relação aos oito radicais de inclinação de Achtnich (1991), foram encontrados os seguintes coeficientes: a) versão feminina: de 0,57 a 0,79 ; b) versão masculina: de 0,71 a 0,82, valores apontados por Sisto (2007) como medianos para precisão do instrumento. Esses resultados inicialmente apontam para menor precisão na forma feminina do BBT-Br. Entretanto, considerando o aspecto projetivo do instrumento, que permite interpretação ambígua do estímulo (fotos), pode-se levantar a hipótese de que, na amostra feminina, ocorreu maior diversidade de interpretações, aumentando o número de percepções mais pessoais dos radicais de inclinação, e conseqüentemente diminuindo a consistência interna, psicométrica, do BBT-Br. Okino (2009), cuja pesquisa apresentou índices semelhantes aos aqui encontrados, ressalta que, dado o caráter projetivo do BBT-Br, os atuais resultados podem ser considerados índices bastante razoáveis de precisão deste instrumento de avaliação psicológica.

O primeiro estudo da fidedignidade do BBT no contexto brasileiro (Sbardelini, 1997) utilizou procedimentos longitudinais de teste-reteste, em uma amostra de apenas 19 participantes e ênfase clínica no tratamento e interpretação dos dados, obtendo resultados indicativos de razoável precisão nos achados obtidos a partir do BBT-Br. Doze anos depois, Okino (2009) realizou a análise da consistência interna do BBT-Br, obtendo índices que variavam entre 0,57 e 0,80 no grupo feminino e 0,64 e 0,80 no grupo masculino de adolescentes do ensino médio, evidenciando indicadores de razoável precisão deste método projetivo. Ao agregar os dados recentes de Noce (2008) e Okino (2009) com as pesquisas de normatização (Jacquemin, 2000; Jacquemin et al., 2006), considera-se que o presente trabalho têm o mérito de investigar esse extenso banco de dados, apresentando dados empíricos que reforçam as características psicométricas do BBT-Br, com destaque para a boa consistência interna em suas duas versões.

Já em relação à consistência interna das extrações de seis fatores do BBT-Br, formas feminina e masculina, os resultados encontrados apontaram para bons índices de fidedignidade, variando entre 0,80 e 0,87 para a forma feminina e 0,72 e 0,90 na forma masculina. É interessante notar, no entanto, que os coeficientes Alfa de Cronbach desta extração de seis fatores alcançaram maiores índices do que os mesmos coeficientes referentes aos oito radicais de inclinação de Achtnich (1991) descritos anteriormente. Esses resultados 
sugerem que a interpretação do BBT-Br utilizando-se seis fatores, ao invés dos oito radicais de inclinação de Achtnich (1991) tende a apresentar resultados mais acurados, precisos

Um dos poucos estudos internacionais que focalizou a questão dos indicadores psicométricos do Teste de Fotos de Profissões BBT foi o trabalho desenvolvido por Lievyns (1987) na Bélgica. Analisou a consistência interna do BBT em uma amostra de estudantes belgas, recorrendo ao método estatístico de Kuder Richardson. Para a amostra feminina, composta por 289 estudantes do sexo feminino em processos de orientação profissional $(n=125)$ e reorientação $(n=164)$, os índices de precisão encontrados para os oito radicais de inclinação variaram de 0,59 a 0,71. Já para a amostra masculina, 217 estudantes do sexo masculino foram avaliados (73 em orientação profissional e 144 em reorientação profissional), sendo que os índices de precisão variaram entre 0,69 até 0,89 . A autora considerou estes resultados como bons índices de fidedignidade do BBT para o contexto belga. Numa perspectiva comparativa entre este estudo belga e o presentemente realizado, pode-se dizer o que os índices encontrados por Lievyns (1987) foram bastante semelhantes aos atuais. As evidências empíricas aqui identificadas, relativas aos índices de consistência interna das duas versões do BBT-Br, atestam adequada fidedignidade para este instrumento projetivo, reforçando suas possibilidades interpretativas.

No entanto, a presente pesquisa não teve por objetivo a reorganização do BBT-Br em termos estruturais, mas sim verificar qual seria a melhor composição fatorial para o instrumento, recorrendo-se a critérios psicométricos clássicos. Desse modo, os atuais dados relativos à precisão de uma forma alternativa do BBT-Br (com seis fatores/dimensões) devem ser averiguados com cuidado e replicados por outros grupos de indivíduos, de modo a sustentar esse modelo fatorial de seis dimensões. Isso se relaciona também aos argumentos apresentados por Ambiel et al. (2011), no sentido de que a existência de bons indicadores de precisão é condição indispensável para que um método de avaliação psicológica demonstre validade. No entanto, apenas esse indicador (precisão) não é suficiente para atestar a validade do instrumento, pois, apesar de improvável, é possível que uma técnica apresente boa precisão sem maiores evidências de validade. Apenas novos estudos referentes à verificação da validade de uma forma alternativa de interpretação do BBT-Br (com seis fatores) poderiam confirmar ou rejeitar esses indicadores de melhoria na precisão do instrumento com uma estrutura interna de avaliação das inclinações motivacionais pautada em seis dimensões. 


\section{CONSIDERAÇÕES FINAIS}

Diante da proposta original e do percurso decorrido, considera-se que o presente trabalho atingiu os objetivos propostos. Os resultados obtidos apresentaram dados suficientes para a elaboração de novos referenciais normativos para a versão feminina e masculina do Teste de Fotos de Profissões (BBT-Br) e as análises fatoriais exploratórias possibilitaram o levantamento de evidências de validade de estrutura interna desse instrumento de avaliação psicológica, bem como a investigação de índices de precisão pelo Alpha de Cronbach.

Em relação aos novos referenciais normativos do BBT-Br, o presente estudo buscou utilizar uma amostra mais abrangente e completa do que as amostras normativas presentes nos manuais disponíveis para as versões masculina e feminina do instrumento (Jacquemin, 2000 e Jacquemin et al., 2006). Ao contemplar alunos de $1^{\mathrm{a}}, 2^{\mathrm{a}}$ e $3^{\mathrm{a}}$ séries do Ensino Médio, a presente amostra buscou representar melhor a principal população alvo da técnica, ou seja, jovens que se encontra em momento de escolha profissional, frequentemente atrelada à realização dos exames vestibulares. Neste sentido, as diferenças encontradas entre os jovens de diferentes níveis escolares devem ser levadas em consideração ao realizar as interpretações deste método projetivo. Pode-se considerar, ainda, que a diferenciação entre as escolhas dos jovens das três séries escolares do ensino médio pode ser compreendida como evidência de validade de critério do BBT-Br, na medida em que os dados obtidos por este método projetivo acabaram se diferenciando em função das séries escolares, implicando em indicadores de processos maturacionais, acompanhando expectativas teóricas relativas às escolhas profissionais. Mostrou-se também importante observar as especificidades das escolhas dos estudantes do ensino médio em função de sua origem escolar (pública ou particular) para efetuar as interpretações dos dados do BBT-Br, em especial na versão masculina deste método projetivo de avaliação psicológica.

Ainda em relação aos dados normativos, é importante destacar que os resultados do presente estudo sugerem que, de fato, existem diferenças entre o modo de processar escolhas de atividades profissionais/ocupacionais entre o grupo feminino e o grupo masculino de estudantes do ensino médio. De maneira geral, os resultados aqui encontrados apontam para a necessidade da existência de duas versões do BBT-Br, evidenciada pelas diferenças encontradas entre as escolhas de interesses profissionais em função do sexo. Como já 
apontado acima, no contexto brasileiro é esperada certa diferenciação de interesses profissionais entre homens e mulheres. Considerando o caráter projetivo deste instrumento, pode-se hipotetizar que a representação de profissionais do mesmo sexo do avaliando nas fotos possibilita maior identificação com as mesmas, favorecendo a projeção de suas necessidades motivacionais. Entretanto, esta hipótese exige estudos específicos para ser comprovada. Sugere-se, neste sentido, estratégia de pesquisa que aplique as duas versões, feminina e masculina, do BBT-Br em uma única amostra, possibilitando assim comparações empíricas entre dados de ambas as formas deste instrumento de avaliação psicológica.

Em relação às análises fatoriais realizadas na presente pesquisa, optou-se pelo método da Principal Axis Factoring, com rotação Varimax, para identificar os fatores de maneira independente uns dos outros. Decidiu-se também que seriam realizadas as análises das extrações de quatro, cinco, seis, sete e oito fatores, conforme propósito inicial deste estudo, mesmo com a identificação da melhor solução fatorial como a extração de seis fatores. Dado o caráter investigativo e exploratório deste trabalho, considerou-se a análise de todas as extrações mais enriquecedora para o melhor conhecimento dos dados obtidos por meio do BBT-Br.

Feitas todas as extrações, foi selecionada como mais representativa dos dados a extração de seis fatores, tanto para a amostra feminina como para a amostra masculina. A análise qualitativa das fotos agrupadas nos fatores encontrados possibilitou aproximações com o modelo do RIASEC de Holland (1997), teoria aceita e bastante estudada internacionalmente. Apesar dos resultados encontrados possibilitarem esse tipo de interpretação, é importante destacar alguns aspectos metodológicos destas análises realizadas.

É consenso entre os pesquisadores que trabalham com métodos projetivos, ou de Autoexpressão, que o rigor psicométrico agrega cientificidade aos instrumentos (Cunha, 2000; Anastasi \& Urbina, 2000; Noronha \& Alchieri, 2005; Urbina, 2007, Nunes \& Primi, 2010). Entretanto, também se faz necessário estudar e desenvolver metodologias capazes de identificar essas evidências neste tipo de instrumentos de avaliação psicológica. Como bem apontado por Villemor-Amaral (2009), identificar evidências psicométricas em métodos projetivos é bastante trabalhoso e até polêmico, devido, principalmente, ao fato dessas técnicas se basearem primariamente em pressupostos teóricos. Em contrapartida, inventários e escalas de auto-relato, construídos com base em fundamentos psicométricos, logicamente adaptam-se melhor a métodos de investigação psicométricos de validade.

A referida pesquisadora aponta a importância da clareza dos objetivos a serem atingidos com o uso do instrumento, para a compreensão da validade das técnicas projetivas. 
Pode-se pensar, portanto, que metodologias desenvolvidas com instrumentos de avaliação psicológica do tipo de autorelato, ou objetivas, podem apresentar um nível de exigência incompatível com as técnicas projetivas. No que se refere à análise fatorial, por exemplo, considerando a estruturação e construção do BBT-Br, que pressupõe que a mesma foto apresente um pareamento de dois radicais de inclinação, primário e secundário, torna-se pouco provável que um item seja identificado com correlações apenas em um fator. Esperar que uma foto do BBT-Br seja representativa apenas de uma dimensão de interesses vai contra o próprio processo que pautou a construção desta foto pelo autor original do instrumento. Talvez a ambigüidade pretendida com a apresentação de um estímulo favorecedor da projeção dificulte esse enquadre em apenas um único fator. É importante lembrar também que é na segunda parte da aplicação da técnica, na parte relativa às associações e explicações sobre as fotos, é que emergirão as dimensões motivacionais ali captadas ou projetadas nos estímulos (fotos). Uma vez que o presente estudo utilizou-se apenas de protocolos resultantes da primeira parte da aplicação do BBT-Br, pautada na somatória quantitativa das escolhas das fotos e que não agrega informações de natureza qualitativa. Desse modo, pode-se propor novas pesquisas que avancem para além dessa limitação metodológica, analisando também as associações obtidas em cada foto. Outra opção interessante de estudo seria a realização de um procedimento de Análise Fatorial Confirmatória do BBT-Br a partir de resultados obtidos com amostras grandes e representativas, além de diversificadas em termos de características sócio-demográficas.

Diante dos argumentos e considerações prévios, pode-se concluir o presente trabalho ponderando que há bons e suficientes indicadores de validade, de precisão e de referenciais normativos para as duas versões do BBT-Br, aplicados a adolescentes do ensino médio. Estes achados são consistentes com as evidências empíricas encontradas em Okino (2009) e Shimada (2011). Desta maneira, este método projetivo de avaliação psicológica pode ser considerado válido e útil para a clarificação de interesses motivacionais de jovens em processo de escolha profissional no contexto brasileiro, com adequados indicadores de validade e precisão, além de padrões normativos atualizados. 


\section{REFERÊNCIAS ${ }^{1}$}

Achtnich, M. (1991). O BBT, Teste de Fotos de Profissões: Método projetivo para a clarificação da inclinação profissional. São Paulo: Centro Editor de Testes e Pesquisas em Psicologia.

Alchieri, J.C., Noronha, A.P.P., \& Primi, R. (2003). Guia de referência: testes psicológicos comercializados no Brasil. São Paulo: Casa do Psicólogo.

Ambiel, R. A. M., Rabelo, I. S., Pacanaro, S. V., Alves, G. A. S. \& Leme, I. F. A. S. (2011). Avaliação Psicológica: guia de consulta para estudantes e profissionais de psicologia. São Paulo: Casa do Psicólogo.

Anastasi, A. (1988). Psychological testing. 6th ed. New York: Macmillan.

Anastasi, A. \& Urbina, S. (2000). Testagem Psicológica. Porto Alegre: Artes Médicas.

APA - American Psychological Association (2000). Report of the Task Force on Test User Qualifications. Washington, DC: Author. Recuperado em 19/03/2011 em http://www.apa.org/science/tuq.pdf.

Bernardes, E.M. (2000). O Teste de Fotos de Profissões (BBT) de Achtnich: Um estudo longitudinal com adolescentes. Dissertação de Mestrado, Departamento de Psicologia e Educação, Faculdade de Filosofia, Ciências e Letras de Ribeirão Preto, Universidade de São Paulo, Ribeirão Preto.

Bessa, P. P. (1998). Teste do Catálogo de Livros Bessa-Tramer: Manual. Rio de Janeiro: CEPA.

Bohoslavsky, R. (1977). Orientação vocacional: A estratégia clínica. São Paulo: Martins Fontes.

Bordão-Alves, D. P. (2008). O BBT-Br e a Avaliação da Personalidade: um estudo de validação com adolescentes. Dissertação de mestrado, Departamento de Psicologia e Educação, Faculdade de Filosofia, Ciências e Letras de Ribeirão Preto, Universidade de São Paulo, Ribeirão Preto.

\footnotetext{
${ }^{1}$ Segundo referenciais USP (2009)
} 
Bordin, E. S., Nachmann, B., \& Segal, S. J. (1963). An Articulated Framework for Vocational Development. Journal of Counseling Psychology, 10 (2), 108-116.

Bueno, J. M.; Lemos, C. G. \& Tomé, F. A. (2004). Interesses profissionais de um grupo de estudantes de psicologia e suas relações com inteligência e personalidade. Psicologia em Estudo, 9 (2), 271-278.

Conselho Federal de Psicologia (2003). Resolução CFP nº 002/2003, de 24 de Março de 2003. Define e regulamenta o uso, a elaboração e a comercialização de testes psicológicos e revoga a Resolução CFP n ${ }^{o}$ 025/2001. Jornal do Conselho Federal de Psicologia. Brasília, $18(75)$.

Conselho Federal de Psicologia (2011). Sistema de avaliação de testes psicológicos: Lista de testes aprovados. Brasília, DF: Autor. Recuperado em 11/10/2011 do Psicologia Online em www2.pol.org.br/satepsi/sistema/admin.cfm?lista1=sim.

Costa, F. R. (2003) CPS: Escala de Personalidade de Comrey. (2 ${ }^{\mathrm{a}}$ Ed. Revisada). São Paulo: Vetor.

Costello, A. B. \& Osborne, J. W. (2005). Best practices in exploratory factor analysis: four recommendations for getting the most from your analysis. Practical Assessment Research \& Evaluation, 10 (7). Recuperado em 25/05/10 em http://pareonline.net/pdf/v10n7.pdf.

Cunha, J. A. (2000). Psicodiagnóstico V: $5^{a}$ Edição revisada e ampliada. Porto Alegre: Artmed.

Dancey, C. P. \& Reidy, J. (2006). Estatística sem matemática para psicologia. Porto Alegre: Artmed.

Del Nero, C. (1975). Levantamento de Interesses Profissionais (LIP): Manual (2a ed.). São Paulo: Vetor.

Draime, J. \& Jacquemin, A. (1989). Os testes em orientação vocacional e profissional. Arquivos Brasileiros de Psicologia, 41 (3), 95-99.

Erikson, E. H. (1976). Identidade, juventude e crise. (2 ${ }^{\mathrm{a}}$ Ed.) Trad, Álvaro Cabral. Rio de Janeiro: Zahar Editores.

Fachel. J.M.G. \& Camey, S. (2000). Avaliação Psicométrica: a qualidade das medidas e o entendimento dos dados. In J.A. Cunha (Org.). Psicodiagnóstico V: $5^{a}$ Edição revisada e ampliada (pp. 158-170). Porto Alegre: Artmed. 
Fensterseifer, L. \& Werlang B.S.G. (2008). Apontamentos sobre o status científico das técnicas projetivas. In A.E Villemor-Amaral \& B.S.G. Werlang (Orgs.), Atualizações em métodos projetivos para avaliação psicológica (pp. 15-33). São Paulo: Casa do Psicólogo.

Foulon, R. (1981). Contribuition à la validation du Berufisbilder-Test de Martin Achtnich. Mémoire inédit, Faculté de Psychologie et des Sciences de 1'Education, Université Catholique de Louvain, Louvain la Neuve, Bélgica.

Geist, A. (s.d.). Inventário Ilustrado de Interesses: Manual. Rio de Janeiro: CEPA.

Guimarães, N. M.; Pasian, S. R. \& Loureiro, S. R. (2008) O Questionário Desiderativo: Possibilidades teóricas e empíricas na atualidade. In A. E. Villemor-Amaral \& B. S.a G. Werlang (Orgs.), Atualizações em Métodos Projetivos para Avaliação Psicológica. (pp. 391-414). São Paulo: Casa do Psicológo.

Güntert, A.E.V.A (2001) Técnicas projetivas: o geral e o singular em Avaliação psicológica. In F.F. Sisto, E.T.B. Sbardelini \& R. Primi (Orgs), Contextos e Questões da Avaliação Psicológica (pp .77-84). São Paulo: Casa do Psicólogo.

Holland, J. L. (1963). Explorations of a theory of vocational choice and achievement: II: A four-year prediction study. Psychological Reports, 12, 547-594.

Holland, J. L. (1975). Técnica de la eleción vocacional: Tipos de personalidad y modelos ambientales (F.P. López, Trad.). México: Trillas.

Holland, J. L. (1997). Making vocational choices: A theory of vocational personalities and work environments (3rd ed.). Odessa: Psychological Assesment Resources.

Holland, J. L. \& Powell, A. B. (1994a). SDS Career Explorer: Exploring Your Future with the SDS. Florida: Psychological Assessment Resources, Inc.

Holland, J. L. \& Powell, A. B. (1994b). SDS Career Explorer: Self-Assessment Booklet. Florida: Psychological Assessment Resourcers, Inc.

Holland, J. L. \& Powell, A. B. (2010). SDS: conhecendo as profissões: caderno de carreiras. (M. F. O. Nunes, trad.). São Paulo: Casa do Psicólogo.

Hutz, C. S. (2009) Avanços e Polêmicas em Avaliação Psicológica. São Paulo: Casa do Psicólogo. 
Jacquemin, A. (1982). Novas perspectivas em orientação vocacional e profissional. Arquivos brasileiros de Psicologia, 34 (4), 127-132.

Jacquemin, A. (1989). L'etat des recherches sur le BBT au Brésil. Bulletin de Psychologie Scolaire e d'Orientation, 41 (3), 95-99.

Jacquemin, A. (1995). Lê BBT chez lês étudiants brésiliens: quelques resultants préliminaires. In Anais da International Conference of International Association For Educational and Vocational Guidance (pp. 307-312). Lisboa, Portugal.

Jacquemin, A. (2000). O BBT-Br - Teste de Fotos de Profissões: Normas, Adaptação Brasileira, Estudos de Caso. São Paulo: Centro Editor de Testes e Pesquisas em Psicologia.

Jacquemin, A. \& Nunes, S. L. (1990). Le Berufsbilder-Test de Achtnich chez des étudiants brésiliennes. In Resumos da XIII International Congress of Rorschach and Projective Techniques (pp. 232). Paris, França.

Jacquemin, A. \& Pasian, S. R. (1991). O BBT no Brasil. In M. Achtnich, O BBT, Teste de Fotos de Profissões: método projetivo para a clarificação da inclinação profissional (pp. 208-222). São Paulo: Centro Editor de Testes e Pesquisas em Psicologia.

Jacquemin, A., Noce, M. A., Santos, C. O., Marcos, M., Assoni, R. F. \& Bianchi, S. H. (1998). O Berufsbilder Test (BBT) de Martin Achtnich: adaptação para o contexto cultural brasileiro. (Relatório científico). Faculdade de Filosofia, Ciências e Letras de Ribeirão Preto, Universidade de São Paulo, Ribeirão Preto.

Jacquemin, A., Noce, M. A., Assoni, R. F., Okino, E. T. K., Prado, A. P. B. A. \& Zeoti, D. M. (2000). O Teste de Fotos de Profissões (BBT) no contexto brasileiro: estudo da validade interna da forma feminina. In Anais do II Congresso Nacional da Sociedade Brasileira de Rorschach e outros métodos projetivos (pp. 251-257). Porto Alegre: AGE Editora.

Jacquemin, A. Noce, M. A., Assoni, R. F., Okino, E. T. K., Kawakami, E. A. \& Pasian, S. R. (2001). O Berufsbilder Test (BBT) de Achtnich: adaptação brasileira da forma feminina. In IV Encontro da Sociedade Brasileira de Rorschach e Outros Métodos Projetivos (pp. 130). São Paulo: Casa do Psicólogo.

Jacquemin, A., Pasian, S. R., Assoni, R. F., Okino, E. T. K., Corlatti, C. T., Kawakami, E. A., Frazatto, L. \& Jardim, M. L. C. (2003). O Berufsbilder Test (BBT) de Martin Achtnich: adaptação da forma feminina para o contexto cultural brasileiro. (Relatório de Pesquisa). Faculdade de Filosofia, Ciências e Letras de Ribeirão Preto, Universidade de São Paulo, Ribeirão Preto. 
Jacquemin, A.; Okino, E.T.K., Noce, M.A.; Assoni, R.F., Pasian, S.R. (2006). $O B B T-B r$ Feminino - Teste de Fotos de Profissões: Adaptação brasileira, normas e estudos de caso. São Paulo: Centro Editor de Testes e Pesquisas em Psicologia.

Jardim-Maran, M. L. C. (2004). Dinamismo psicológico na adolescência diante da escolha profissional: uma contribuição do BBT-Br e do Questionário Desiderativo. Dissertação de Mestrado, Departamento de Psicologia e Educação, Faculdade de Filosofia, Ciências e Letras de Ribeirão Preto, Universidade de São Paulo, Ribeirão Preto.

Junqueira, M. L. (2010). Maturidade para a escolha da carreira em adolescentes de um serviço de orientação profissional. Dissertação de Mestrado, Departamento de Psicologia, Faculdade de Filosofia, Ciências e Letras de Ribeirão Preto, Universidade de São Paulo, Ribeirão Preto.

Kuder, G. F. (2000). Kuder - Inventário de Interesses: Manual. Rio de Janeiro: CEPA.

Leitão, L. B. C. O. G. M. (1993). Contributos para um modelo de avaliação dinâmica dos interesses. Tese de doutorado. Faculdade de Psicologia e de Ciências da Educação da Universidade de Coimbra, Coimbra, Portugal.

Leitão, L. M. \& Ramos, L. A. (2004). A entrevista em orientação escolar e profissional. In L. M. Leitão (Coord.), Avaliação Psicológica em Orientação Profissional e Escolar (pp. 4575). Coimbra: Quarteto.

Levenfus, R. S. \& Bandeira, D. R. (2007). Avaliação dos Interesses Profissionais (AIP): um estudo sbre as diferenças de gênero. In Congresso Latino-Americano de Orientação Profissional da ABOP,1; Simpósio Brasileiro de Orientação Vocacional \& Profissional, 8. (pp. 122-123). São Paulo: Vetor.

Levenfus, R. S. \& Bandeira, D. R. (2009). AIP - Avaliação dos Interesses Profissionais. São Paulo: Vetor.

Levenfus, R. S. \& Bandeira, D. R. (2010). Teste de Avaliação dos Interesses Profissionais (AIP): uma proposta de interpretação psicodinâmica. In R. S. Levenfus \& R. S. Soares (Orgs.) Orientação Vocacional Ocupacional (pp. 173-182). São Paulo: Artmed.

Levenfus, R. S. \& Soares, R. S. (2010). Orientação Vocacional Ocupacional. (2a Ed.). São Paulo: Artmed.

Lievyns, C. (1987). Le Berufsbilder-Test de M. Achtnich: tentative de standardization d'une population belge âgée de 17 ans 6 mois à moins de 24 ans. Mémoire. Faculté de Psychologie et des Sciences de 1'Education, Université Cacholique de Louvain, LouvainLa Neuve, Bélgica. 
Mansão, C. S. M. (2005). Interesses profissionais: validação do Self-Directed Search Career Explorer-SDS. Tese de Doutorado, Pontifícia Universidade Católica de Campinas, Campinas.

Melo-Silva, L. L. \& Jacquemin, A. (1997) L'histoire dês cinq photos préférées au BBT à deux momentes du processus d'orientation professionelle. Reviste de Pedagogie, NR 1-12, 6569.

Melo-Silva, L. L. \& Jacquemin, A. (2001). Intervenção em orientação vocacional / profissional: avaliando resultados e processos. São Paulo: Vetor.

Meyer, G. J. \& Kurtz, J. E. (2006). Advancing Personality Assessment Terminology: Time to Retire "Objective" and "Projective" As Personality Test Descriptors. Journal of Personality Assessment, 87 (3), 223-225.

Minicucci, A. (1983). Teste das Estruturas Vocacionais: Manual. São Paulo: Vetor.

Neiva, K. M. C. (1999). Escala de Maturidade para a Escolha Profissional (EMEP): Manual. São Paulo: Vetor.

Noce, M. A. (2003) O BBT-Br - Teste de Fotos de Profissões: proposta de versão reduzida da forma masculina e seus padrões normativos. Dissertação de Mestrado, Departamento de Psicologia e Educação, Faculdade de Filosofia, Ciências e Letras de Ribeirão Preto, Universidade de São Paulo, Ribeirão Preto.

Noce, M. A. (2008). O BBT-Br e a maturidade para a escolha profissional: Evidências empíricas de validade. Tese de Doutorado, Departamento de Psicologia e Educação, Faculdade de Filosofia, Ciências e Letras de Ribeirão Preto, Universidade de São Paulo, Ribeirão Preto.

Noce, M. A. \& Melo-Silva, L. L. (2009). Investigação com SDS e BBT-Br: Cooperação Internacional Brasil e Portugal - Método e procedimentos [CD-ROM]. In Resumos do IV Congresso Brasileiro de Avaliação Psicológica; XIV Conferência Internacional de Avaliação Psicológica: Formas e contextos; V Congresso da Associação Brasileira de Rorschach e Métodos Projetivo. Campinas: Universidade São Francisco.

Noronha, A. P. P.; Freitas, F. A. \& Otatti, F. (2003). Análise de Instrumentos de Avaliação de Interesses Profissionais. Psicologia: Teoria e Pesquisa, 19 (3), 287-291.

Noronha, A. P. P. \& Alchieri, J. C. (2005). Reflexões sobre os instrumentos de avaliação psicológica. In R. Primi (org.), Temas em avaliação psicológica (pp.19-36). São Paulo, Casa do Psicólogo. 
Noronha, A. P. P., Sisto, F. F. \& Santos, A. A. A. (2007). Escala de Aconselhamento Profissional- EAP Manual de Aplicação. São Paulo: Vetor.

Nunes, M. F. O., Okino, E. T. K., Noce, M. A. \& Jardim-Maran, M. L. C. (2008). Interesses profissionais: perspectivas teóricas e instrumentos de avaliação. Avaliação Psicológica, 7 (3), 403-414.

Nunes, M. F. O. \& Noronha, A. P. P. (2009). Interesses e personalidade: um estudo com adolescentes em orientação profissional. Revista Galego-portuguesa de Psicoloxía e Educatión, 17 (1,2), 1138-1663.

Nunes, C. H. S. S. \& Primi, R. (2010). Aspectos técnicos e conceituais da ficha de avaliação dos testes psicológicos. In Conselho Federal de Psicologia, Avaliação psicológica: diretrizes na regulamentação da Profissão. Brasília: CFP.

Okino, E. T. K. (2009). O SDS e o BBT-Br em Orientação Profissional: Evidências de validade e precisão. Tese de doutorado, Departamento de Psicologia e Educação, Faculdade de Filosofia, Ciências e Letras de Ribeirão Preto, Universidade de São Paulo, Ribeirão Preto.

Okino, E. T. K., Noce, M. A., Assoni, R. F., Corlatti, C. T., Pasian, S. R. \& Jacquemin, A. (2003). A adaptação do BBT - Teste de Fotos de Profissões - para o contexto sociocultural brasileiro. Revista Brasileira de Orientação Profissional, 4 (1/2), 87-96.

Okino, E. T. K. \& Pasian, S. R. (2008). Possibilidades associativas entre o BBT-Br de Achtnich e o SDS de Holland [CD-ROM]. In Resumos do V Encontro da Associação Brasileira de Rorschach e Métodos Projetivos. Ribeirão Preto: Universidade de São Paulo.

Oliveira, R. (1982). Questionário Vocacional de Interesses (QVI): Manual. São Paulo: Vetor.

Otatti, F. (2009). Escala de Aconselhamento Profissional (EAP) e BBT-Br: Estudo de evidências de validade. Dissertação de mestrado, Universidade São Francisco, Itatiba.

Ottati, F., Noronha, A.P.P. \& Salvatti, M. (2003). Parâmetros psicométricos de instrumentos de interesse profissional. Interação em Psicologia, 7 (1), 65-71.

Pasian, S. R.; Okino, E.T.K. \& Melo-Silva, L.L. (2007) O Teste de Fotos de Profissões (BBT) de Achtnich: histórico e pesquisas desenvolvidas no Brasil. Psico-USF, 12 (2), 173-187.

Pasian, S. R. \& Jardim-Maran, M. L. C. (2008). Padrões normativos do BBT-BR em adolescentes: Uma verificação da atualidade das normas disponíveis. Revista Brasileira de Orientação Profissional, 9 (1), 61-74. 
Pasian, S. R. \& Okino, E. T. K. (2009). Investigação com SDS e BBT-Br: Cooperação internacional Brasil e Portugal - histórico e objetivos [CD-ROM]. In Resumos do IV Congresso Brasileiro de Avaliação Psicológica; XIV Conferência Internacional de Avaliação Psicológica: Formas e contextos; V Congresso da Associação Brasileira de Rorschach e Métodos Projetivo. Campinas: Universidade São Francisco.

Pasquali, L. (2001). Técnicas de Exame Psicológico - TEP: manual. São Paulo: Casa do Psicólogo.

Pasquali, L. (2005). Análise Fatorial Para Pesquisadores. Brasília: LabPAM.

Pasquali, L. (2009). Psicometria: teoria dos testes na psicologia e na educação. Petrópolis: Vozes.

Pasquali, L. (2010). Instrumentação psicológica: fundamentos e práticas. Porto Alegre: Artmed.

Pasquali, L., Azevedo, M. M., \& Ghesti, I. (1997). Inventário Fatorial de Personalidade: Manual técnico e de avaliação. São Paulo: Casa do Psicólogo.

Primi, R.; Moggi, M. A.; \& Caselato, E. O. (2004). Estudo correlacional do Inventário de Busca Autodirigida (Self-Directed Search) com o IFP. Psicologia Escolar e Educacional, $8(1), 47-54$.

Primi, R.; Muniz, M. \& Nunes, C. H. S. S. (2009). Definições Contemporâneas de Validade dos Testes Psicológicos. In C. S. Hutz (Org.), Avanços e Polêmicas em Avaliação Psicológica (pp. 243-265). São Paulo: Casa do Psicólogo.

Primi, R; Mansão, C. M.; Muniz, M.; \& Nunes, M. F. O. (2010). SDS - Questionário de Busca Autodirigida. Manual Técnico da versão brasileira. São Paulo: Casa do Psicólogo.

Ritzler, B. (2006). Aplicações culturais do Rorschach, Testes de Apercepção e Desenhos de Figuras. In N. A. S. Neto \& D. M. Amparo (Orgs.), Métodos projetivos: instrumentos atuais para a investigação psicológica e da cultura. IV Congresso Nacional da Sociedade de Rorschach e Métodos Projetivos (pp. 22-45). Brasília: ASBRo.

Roe, A. (1957). Early Determinants of Vocational Choice. Journal of Counseling Psychology, 4 (3), 212-217.

Russell, M. T. \& Karol, D. L. (2002). 16PF, quinta edição: manual. Atualizado e adaptado pelo Departamento de Estudos do CEPA. Rio de Janeiro: CEPA. 
Sartori, F. A. (2007). Estudo correlacional entre a Escala de AconselhamentoProfissional $(E A P)$ e o SDS. Dissertação de mestrado não publicada, Universidade São Francisco, Itatiba.

Sartori, F. A, Noronha, A. P. P., \& Nunes, M. F. O. (2009). Comparações entre EAP e SDS: Interesses profissionais emalunos de Ensino Médio. Boletim de Psicologia, 59 (130), 17-2.

Sbardelini, E. T. B. (1997). A reopção de curso na Universidade Federal do Paraná. Tese de Doutorado, Faculdade de Medicina de Ribeirão Preto, Universidade de São Paulo, Ribeirão Preto.

Shimada, M. (2011). O BBT-Br em contexto interventivo: um estudo com adolescentes em processo de Orientação Vocacional. Dissertação de Mestrado, Departamento de Psicologia, Faculdade de Filosofia, Ciências e Letras de Ribeirão Preto, Universidade de São Paulo, Ribeirão Preto.

Sisto, F. F. (2007). Delineamento correlacional. In M. N. Baptista \& D. C. Campos (Orgs.), Metodologias de Pesquisa em Ciências: Análises quantitativa e qualitativa (pp. 90-101). Rio de Janeiro: LTC.

Sparta, M.; Bardagi, M. P. \& Teixeira, M. A. P. (2006) Modelos e Instrumentos de Avaliação em Orientação Profissional: Perspectiva Histórica e Situação no Brasil. Revista Brasileira de Orientação Profissional, 7 (2), 19-32.

Souza Filho, M. L., Belo, R. \& Gouveia, V. V. (2006). Testes psicológicos: análise da produção científica brasileira no período de 2000-2004. Psicologia: Ciência e Profissão, $26,478-489$.

Super, D. E., Savickas, M. L. \& Super, C. M. (1996). The life-span, life-space approach to careers. In D. Brown \& L. Brooks (Orgs.), Career choice and development (pp.121-178). San Fransisco: Jossey-Bass Publishers.

Szondi, L. (1975). Introdução à Psicologia do Destino. São Paulo: Editora Manole.

Tavares, M. (2003). Validade clínica. Psico USF, 8 (2), 125-136.

Teixeira, M. O., Figueiredo, A. \& Janeiro, I. (2009). Investigação com SDS e BBT-Br: Cooperação Internacional Brasil e Portugal - Principais resultados [CD-ROM]. In Resumos do IV Congresso Brasileiro de Avaliação Psicológica; XIV Conferência Internacional de Avaliação Psicológica: Formas e Contextos; V Congresso da Associação Brasileira de Rorschach e Métodos Projetivos. Campinas: Universidade São Francisco. 
Thurstone, L. L., Angelini, A. L. \& Angelini, H. R. C. (2002). Inventário de Interesses Profissionais: Manual. ( $3^{\mathrm{a} e d .) .}$ Rio de Janeiro: CEPA.

Universidade de São Paulo (2009). Sistema Integrado de Bibliotecas da Universidade de São Paulo. Diretrizes para apresentação de dissertações e teses da USP: documento eletrônico $e$ impresso, parte II (APA). São Paulo: Sistema Integrado de Bibliotecas da USP. Recuperado em 10/01/2011, de http://www.teses.usp.br.

Urbina, S. (2007). Fundamentos da Testagem Psicológica. Porto Alegre: Artmed.

Villemor-Amaral, A.E. \& Pasqualini-Casado, L. (2006). A cientificidade das técnicas projetivas em debate. Psico-USF, 11 (2), 185-193.

Villemor-Amaral, A. E. (2009). Métodos Projetivos em Avaliações Compulsórias: Indicadores e Perfis. In C. S. Hutz (Org.), Avanços e Polêmicas em Avaliação Psicológica (pp. 157-174). São Paulo: Casa do Psicólogo.

Welter, G. M. R. (2007). Humanguide: evidências de validade na versão brasileira. Dissertação de mestrado, Universidade São Francisco, Itatiba.

Zacharias, J. J. M. (2000). Questionário de Avaliação Tipológica: manual. São Paulo: Vetor.

Zerbini, T. (2007). Avaliação da Transferência de Treinamento em Curso a Distância. Tese de Doutorado, Instituto de Psicologia, Universidade de Brasília, Brasília. 


\title{
9. ANEXOS E APÊNDICES
}

\author{
ANEXO A - Autorização do Comitê de Ética em Pesquisa \\ UNIVERSIDADE DE SÃO PAULO \\ FACULDADE DE FILOSOFIA, CIÉNCIAS E LETRAS DE RIBEIRÃO PRETO \\ COMITE DE ETICA EM PESQUISA - CEP
}

Of.CEtPIFFCLRP-USP. 093/2009 - 3/12//2009

Senhor(a) Pesquisador(a):

Comunicamos a V. Sa. que o trabalho intitulado "O TESTE

DE FOTOS DE PROFISSÕES(BBT-Br) EM ADOLESCENTES:

EVIDÊNCIAS PSICOMÉTRICAS", foi analisado pelo Comitê de Ética em Pesquisa da FFCLRP-USP, e, enquadrado na categoria: APROVADO, de acordo com o Processo CEP-FFCLRP no 461/2009 - 2009.1.1756.59.1.

Atenciosamente,

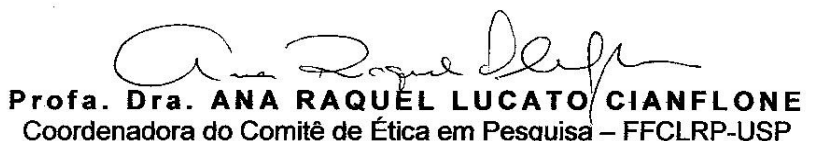

llustríssimo(a) Senhor(a)

RAFAEL PAZ LANDIM BARRENHA

Aluno do programa de PG em Psicologia

c.c: Profa. Dra. Sonia Regina Pasian

Docente do Departamento de Psicologia e Educação

desta FFCLRP-USP

CEP-FFCLRP-USP - Fone: (016) 602-3653 - Fax: (016) 633-5015

Avenida Bandeirantes, 3900 - Bloco A - 14040-901 - Ribeirão Preto - SP - Brasil 
APÊNDICE A - Homogeneidade da Produtividade por série escolar feminina (n=862)

TOTAL Escolhas Positivas

Tukey HSD

\begin{tabular}{|c|c|c|c|}
\hline \multirow[b]{2}{*}{ Escolaridade } & \multirow[b]{2}{*}{$\mathrm{N}$} & \multicolumn{2}{|c|}{ Subset for alpha $=0.05$} \\
\hline & & 1 & 2 \\
\hline 3르 SERIE E. M. & 353 & 31,3003 & \\
\hline 2를 SERIE E. M. & 256 & & 36,0898 \\
\hline 1르 SERIE E. M. & 253 & & 38,1344 \\
\hline Sig. & & 1,000 & 208 \\
\hline
\end{tabular}

Means for groups in homogeneous subsets are

displayed.

TOTAL Escolhas Negativas

Tukey HSD

\begin{tabular}{|c|c|c|c|}
\hline \multirow[b]{2}{*}{ Escolaridade } & \multirow[b]{2}{*}{$\mathrm{N}$} & \multicolumn{2}{|c|}{ Subset for alpha $=0.05$} \\
\hline & & & \\
\hline 1ㄹ SERIE E. M. & 253 & & 40,9723 \\
\hline $2^{\mathrm{a}}$ SERIE E. M. & 256 & & 41,7188 \\
\hline $3^{\text {a }}$ SERIE E. M. & 353 & & 44,0623 \\
\hline Sig. & & 059 & \\
\hline
\end{tabular}

Means for groups in homogeneous subsets are displayed.

TOTAL Escolhas Neutras

Tukey HSD

\begin{tabular}{|c|c|c|c|}
\hline \multirow[b]{2}{*}{ Escolaridade } & \multirow[b]{2}{*}{$\mathrm{N}$} & \multicolumn{2}{|c|}{ Subset for alpha $=0.05$} \\
\hline & & 1 & 2 \\
\hline 1a SERIE E. M. & 253 & 16,8933 & \\
\hline $2^{\mathrm{a}}$ SERIE E. M. & 256 & 18,1914 & \\
\hline $3^{\text {a }}$ SERIE E. M. & 353 & & 20,6374 \\
\hline Sig. & & ,268 & 1,000 \\
\hline
\end{tabular}

Means for groups in homogeneous subsets are displayed. 


\section{APÊNDICE B - Homogeneidade dos Radicais Primários Positivos por série escolar feminina $(n=862)$}

\section{Radical W+}

Tukey HSD

\begin{tabular}{|l|c|r|}
\hline & & \multicolumn{2}{|c|}{ Subset for alpha $=0.05$} \\
\cline { 3 - 3 } Escolaridade & $\mathrm{N}$ & 1 \\
\hline 2o SÉRIE E.M. & 256 & 3.1016 \\
3ㅇ SÉRIE E.M. & 321 & 3.1994 \\
1ㅇ SÉRIE E.M. & 251 & 3.2829 \\
Sig. & & .517 \\
\hline
\end{tabular}

Means for groups in homogeneous subsets are displayed.

Radical K+

Tukey HSD

\begin{tabular}{|c|c|c|c|}
\hline \multirow[b]{2}{*}{ Escolaridade } & \multirow[b]{2}{*}{$\mathrm{N}$} & \multicolumn{2}{|c|}{ Subset for alpha $=0.05$} \\
\hline & & 1 & 2 \\
\hline 2 SÉRIE E.M. & 252 & .9881 & \\
\hline 1 SÉRIE E.M. & 246 & 1.1016 & \\
\hline 3 SÉRIE E.M. & 209 & & 1.4641 \\
\hline Sig. & & .575 & 1.000 \\
\hline
\end{tabular}

Means for groups in homogeneous subsets are displayed.

\section{Radical S+}

Tukey HSD

\begin{tabular}{|l|r|r|r|}
\hline \multirow{2}{*}{ Escolaridade } & & \multicolumn{2}{|c|}{ Subset for alpha $=0.05$} \\
\cline { 3 - 4 } & $\mathrm{N}$ & 1 & \multicolumn{1}{c|}{2} \\
\hline 3ํ SÉRIE E.M. & 353 & 3.4660 & \\
2º SÉRIE E.M. & 256 & & 3.9102 \\
1ㅇ SÉRIE E.M. & 253 & & 4.1324 \\
Sig. & & 1.000 & .296 \\
\hline
\end{tabular}

Means for groups in homogeneous subsets are displayed.
Radical Z+

Tukey HSD

\begin{tabular}{|l|c|c|c|}
\hline & & \multicolumn{2}{|c|}{ Subset for alpha $=0.05$} \\
\cline { 3 - 4 } Escolaridade & $\mathrm{N}$ & 1 & \multicolumn{1}{c|}{2} \\
\hline 3ํ SÉRIE E.M. & 353 & 2.9363 & \\
2º SÉRIE E.M. & 256 & & 3.6621 \\
1ํ SÉRIE E.M. & 253 & & 3.9387 \\
Sig. & & 1.000 & .141 \\
\hline
\end{tabular}

Means for groups in homogeneous subsets are displayed.

Radical V+

Tukey HSD

\begin{tabular}{|l|c|c|}
\hline & & \multicolumn{2}{|c|}{ Subset for alpha $=0.05$} \\
\cline { 3 - 3 } Escolaridade & $\mathrm{N}$ & 1 \\
\hline $3^{\circ}$ SÉRIE E.M. & 353 & 2.3839 \\
$2^{\circ}$ SÉRIE E.M. & 256 & 2.4512 \\
1ㅇ SÉRIE E.M. & 253 & 2.6403 \\
Sig. & & .098 \\
\hline
\end{tabular}

Means for groups in homogeneous subsets are displayed.

\section{Radical G+}

Tukey HSD

\begin{tabular}{|l|c|c|c|}
\hline \multirow{2}{*}{ Escolaridade } & & \multicolumn{2}{|c|}{ Subset for alpha $=0.05$} \\
\cline { 3 - 4 } & $\mathrm{N}$ & 1 & \multicolumn{1}{c|}{2} \\
\hline 3ㅇ SÉRIE E.M. & 353 & 2.5241 & \\
2ㅇ SÉRIE E.M. & 256 & & 3.1387 \\
1ㅇ SÉRIE E.M. & 253 & & 3.3498 \\
Sig. & & 1.000 & .261 \\
\hline
\end{tabular}

Means for groups in homogeneous subsets are displayed. 
Radical M+

Tukey HSD

\begin{tabular}{|l|c|c|}
\hline & & \multicolumn{2}{|c|}{ Subset for alpha $=0.05$} \\
\cline { 3 - 3 } Escolaridade & $\mathrm{N}$ & 1 \\
\hline 1ㅇ SÉRIE E.M. & 247 & 1.8340 \\
2ㅇ SÉRIE E.M. & 254 & 1.8701 \\
3o SÉRIE E.M. & 285 & 1.9544 \\
Sig. & & .563 \\
\hline
\end{tabular}

Means for groups in homogeneous subsets are

displayed.

\section{Radical O+}

Tukey HSD

\begin{tabular}{|l|r|r|r|}
\hline & & \multicolumn{2}{|c|}{ Subset for alpha $=0.05$} \\
\cline { 3 - 4 } Escolaridade & $\mathrm{N}$ & 1 & \multicolumn{1}{c|}{2} \\
\hline 3o SÉRIE E.M. & 339 & 3.4631 & \\
2º SÉRIE E.M. & 255 & & 3.8510 \\
1ㅇ SÉRIE E.M. & 252 & & 3.9087 \\
Sig. & & 1.000 & .921 \\
\hline
\end{tabular}

Means for groups in homogeneous subsets are displayed. 


\section{APÊNDICE C - Homogeneidade dos Radicais Secundários Positivos por série escolar feminina $(n=862)$}

Radical w+

Tukey HSD

\begin{tabular}{|l|c|c|c|}
\hline \multirow{2}{*}{ Escolaridade } & & \multicolumn{2}{|c|}{ Subset for alpha = 0.05 } \\
\cline { 3 - 4 } & $\mathrm{N}$ & 1 & 2 \\
\hline 3o SÉRIE E.M. & 348 & 5,2069 & \\
20 SÉRIE E.M. & 256 & & 6,0781 \\
1ㅇ SÉRIE E.M. & 253 & & 6,3320 \\
Sig. & & 1,000 &, 442 \\
\hline
\end{tabular}

Means for groups in homogeneous subsets are displayed.

Radical k+

Tukey HSD

\begin{tabular}{|l|r|r|r|}
\hline \multirow{2}{*}{ Escolaridade } & & \multicolumn{2}{|c|}{ Subset for alpha = 0.05 } \\
\cline { 3 - 4 } & $\mathrm{N}$ & 1 & \multicolumn{1}{c|}{2} \\
\hline 3ํ SÉRIE E.M. & 333 & 3,4715 & \\
2º SÉRIE E.M. & 255 & 3,8431 & 3,8431 \\
1ㅇ SÉRIE E.M. & 252 & & \multicolumn{2}{|c|}{3,9127} \\
Sig. & &, 090 &, 918 \\
\hline
\end{tabular}

Means for groups in homogeneous subsets are displayed.

\section{Radical s+}

Tukey HSD

\begin{tabular}{|c|c|c|c|}
\hline \multirow[b]{2}{*}{ Escolaridade } & \multirow[b]{2}{*}{$\mathrm{N}$} & \multicolumn{2}{|c|}{ Subset for alpha $=0.05$} \\
\hline & & & \\
\hline 3ํ SÉRIE E.M. & 346 & & 4,3266 \\
\hline 2 SÉRIE E.M. & 256 & & 4,5938 \\
\hline 1 SÉRIE E.M. & 253 & & 4,6996 \\
\hline Sig. & & , 120 & \\
\hline
\end{tabular}

Means for groups in homogeneous subsets are displayed.
Radical Z+

Tukey HSD

\begin{tabular}{|l|r|r|r|r|}
\hline \multirow{2}{*}{ Escolaridade } & & \multicolumn{3}{|c|}{ Subset for alpha $=0.05$} \\
\cline { 3 - 5 } & $\mathrm{N}$ & 1 & \multicolumn{1}{c|}{ 1 } & \multicolumn{1}{c|}{3} \\
\hline 3o SÉRIE E.M. & 346 & 4,6098 & & \\
20 SÉRIE E.M. & 255 & & 5,2706 & \\
1ㅇ SÉRIE E.M. & 252 & & & 5,9484 \\
Sig. & & 1,000 & 1,000 & 1,000 \\
\hline
\end{tabular}

Means for groups in homogeneous subsets are displayed.

Radical v+

Tukey HSD

\begin{tabular}{|l|c|r|r|}
\hline \multirow{2}{*}{ Escolaridade } & & \multicolumn{2}{|c|}{ Subset for alpha $=0.05$} \\
\cline { 3 - 4 } & $\mathrm{N}$ & 1 & \multicolumn{1}{c|}{2} \\
\hline 3o SÉRIE E.M. & 336 & 3,2649 & \\
2o SÉRIE E.M. & 255 & 3,6431 & 3,6431 \\
1o SÉRIE E.M. & 253 & & 3,8972 \\
Sig. & &, 079 &, 317 \\
\hline
\end{tabular}

Means for groups in homogeneous subsets are displayed.

\section{Radical g+}

Tukey HSD

\begin{tabular}{|l|c|c|c|}
\hline & & \multicolumn{2}{|c|}{ Subset for alpha =0.05 } \\
\cline { 3 - 4 } Escolaridade & $\mathrm{N}$ & 1 & 2 \\
\hline 3o SÉRIE E.M. & 335 & 3,9403 & \\
20 SÉRIE E.M. & 254 & & 4,5157 \\
1ㅇ SÉRIE E.M. & 252 & & 4,5437 \\
Sig. & & 1,000 &, 989 \\
\hline
\end{tabular}

Means for groups in homogeneous subsets are displayed. 


\section{Radical m+}

Tukey HSD

\begin{tabular}{|l|r|r|r|}
\hline \multirow{2}{*}{ Escolaridade } & & \multicolumn{2}{|c|}{ Subset for alpha =0.05 } \\
\cline { 3 - 4 } & $\mathrm{N}$ & 1 & \multicolumn{1}{c|}{2} \\
\hline 3o SÉRIE E.M. & 343 & 4,1866 & \\
2o SÉRIE E.M. & 256 & 4,4688 & 4,4688 \\
1ㅇ SÉRIE E.M. & 252 & & 4,8810 \\
Sig. & &, 321 &, 089 \\
\hline
\end{tabular}

Means for groups in homogeneous subsets are displayed.

\section{Radical o+}

Tukey HSD

\begin{tabular}{|l|r|r|r|}
\hline \multirow{2}{*}{ Escolaridade } & & \multicolumn{2}{|c|}{ Subset for alpha = 0.05 } \\
\cline { 3 - 4 } & $\mathrm{N}$ & 1 & \multicolumn{1}{c|}{2} \\
\hline 3 SÉRIE E.M. & 322 & 3,5280 & \\
2o SÉRIE E.M. & 254 & 3,7913 & 3,7913 \\
1ㅇ SÉRIE E.M. & 252 & & \multicolumn{2}{|c|}{4,0119} \\
Sig. & &, 338 &, 467 \\
\hline
\end{tabular}

Means for groups in homogeneous subsets are displayed. 


\section{APÊNDICE D - Homogeneidade dos Radicais Primários Negativos por série escolar feminina $(n=862)$}

\section{Radical W}

Tukey HSD

\begin{tabular}{|c|c|c|}
\hline \multirow[b]{2}{*}{ Escolaridade } & \multirow[b]{2}{*}{$\mathrm{N}$} & Subset for alpha $=0.05$ \\
\hline & & 1 \\
\hline 1 SÉRIE E.M. & 248 & 3.4798 \\
\hline 2 SÉRIE E.M. & 255 & 3.5255 \\
\hline 3ํ SÉRIE E.M. & 338 & 3.6538 \\
\hline Sig. & & .574 \\
\hline
\end{tabular}

Means for groups in homogeneous subsets are displayed.

Radical K

Tukey HSD

\begin{tabular}{|l|c|r|}
\hline & & \multicolumn{2}{|c|}{ Subset for alpha $=0.05$} \\
\cline { 3 - 3 } Escolaridade & $\mathrm{N}$ & 1 \\
\hline 3ㅇ SÉRIE E.M. & 353 & 5.8215 \\
1ㅇ SÉRIE E.M. & 253 & 5.9209 \\
2o SÉRIE E.M. & 256 & 6.1016 \\
Sig. & & .145 \\
\hline
\end{tabular}

Means for groups in homogeneous subsets are displayed.

\section{Radical S}

Tukey HSD

\begin{tabular}{|l|r|r|}
\hline & & \multicolumn{2}{|c|}{ Subset for alpha $=0.05$} \\
\cline { 3 - 3 } Escolaridade & $\mathrm{N}$ & 1 \\
\hline 1ㅇ SÉRIE E.M. & 253 & 2.6265 \\
$2^{\circ}$ SÉRIE E.M. & 256 & 2.7305 \\
3ํ SÉRIE E.M. & 353 & 2.9235 \\
Sig. & & .085 \\
\hline
\end{tabular}

Means for groups in homogeneous subsets are displayed.
Radical Z

Tukey HSD

\begin{tabular}{|l|c|r|r|}
\hline \multirow{2}{*}{ Escolaridade } & & \multicolumn{2}{|c|}{ Subset for alpha $=0.05$} \\
\cline { 3 - 4 } & $\mathrm{N}$ & 1 & \multicolumn{1}{c|}{2} \\
\hline 1ㅇ SÉRIE E.M. & 253 & 2.5000 & \\
2o SÉRIE E.M. & 256 & 2.6270 & \\
3o SÉRIE E.M. & 353 & & 3.1544 \\
Sig. & & .682 & 1.000 \\
\hline
\end{tabular}

Means for groups in homogeneous subsets are displayed.

Radical V

Tukey HSD

\begin{tabular}{|l|r|r|}
\hline & & \multicolumn{2}{|c|}{ Subset for alpha $=0.05$} \\
\cline { 3 - 3 } Escolaridade & $\mathrm{N}$ & 1 \\
\hline 1 SÉRIE E.M. & 253 & 3.9130 \\
3o SÉRIE E.M. & 353 & 3.9348 \\
2o SÉRIE E.M. & 256 & 3.9570 \\
Sig. & & .949 \\
\hline
\end{tabular}

Means for groups in homogeneous subsets are displayed.

\section{Radical G}

Tukey HSD

\begin{tabular}{|l|r|r|r|}
\hline & & \multicolumn{2}{|c|}{ Subset for alpha $=0.05$} \\
\cline { 3 - 4 } Escolaridade & $\mathrm{N}$ & \multicolumn{1}{c|}{1} & \multicolumn{1}{c|}{2} \\
\hline 1 SÉRIE E.M. & 253 & 3.0099 & \\
2o SÉRIE E.M. & 256 & 3.0840 & \\
3o SÉRIE E.M. & 353 & & 3.5227 \\
Sig. & & .860 & 1.000 \\
\hline
\end{tabular}

Means for groups in homogeneous subsets are displayed. 
Radical M

Tukey HSD

\begin{tabular}{|l|c|c|}
\hline & & \multicolumn{2}{|c|}{ Subset for alpha $=0.05$} \\
\cline { 3 - 3 } Escolaridade & $\mathrm{N}$ & 1 \\
\hline 2o SÉRIE E.M. & 256 & 4.5156 \\
3ㅇ SÉRIE E.M. & 351 & 4.6382 \\
1ㅇ SÉRIE E.M. & 251 & 4.7490 \\
Sig. & & .262 \\
\hline
\end{tabular}

Means for groups in homogeneous subsets are displayed.

Radical 0

Tukey HSD

\begin{tabular}{|l|r|r|r|}
\hline \multirow{2}{*}{ Escolaridade } & & \multicolumn{2}{|c|}{ Subset for alpha $=0.05$} \\
\cline { 3 - 4 } & $\mathrm{N}$ & 1 & \multicolumn{1}{c|}{2} \\
\hline 2o SÉRIE E.M. & 255 & 2.8039 & \\
1ㅇ SÉRIE E.M. & 251 & 2.8526 & \\
3o SÉRIE E.M. & 333 & & 3.2432 \\
Sig. & & .942 & 1.000 \\
\hline
\end{tabular}

Means for groups in homogeneous subsets are displayed. 


\section{APÊNDICE E - Homogeneidade dos Radicais Secundários Negativos por série escolar feminina $(n=862)$}

Radical w-

Tukey HSD

\begin{tabular}{|c|c|c|c|}
\hline \multirow[b]{2}{*}{ Escolaridade } & \multirow[b]{2}{*}{$\mathrm{N}$} & \multicolumn{2}{|c|}{ Subset for alpha $=0.05$} \\
\hline & & 1 & 2 \\
\hline 1 SÉRIE E.M. & 252 & 3,7262 & \\
\hline 20 SÉRIE E.M. & 255 & 3,9765 & 3,9765 \\
\hline 3o SÉRIE E.M. & 350 & & 4,4029 \\
\hline Sig. & &, 407 & 075 \\
\hline
\end{tabular}

Means for groups in homogeneous subsets are displayed.

Radical k-

Tukey HSD

\begin{tabular}{|l|l|r|}
\hline & & \multicolumn{2}{|c|}{ Subset for alpha $=0.05$} \\
\cline { 3 - 3 } Escolaridade & $\mathrm{N}$ & \multicolumn{1}{|c|}{1} \\
\hline 2o SÉRIE E.M. & 256 & 5,6211 \\
1ㅇ SÉRIE E.M. & 251 & 5,7012 \\
3o SÉRIE E.M. & 352 & 5,9602 \\
Sig. & & \\
\hline
\end{tabular}

Means for groups in homogeneous subsets are displayed.

\section{Radical s-}

Tukey HSD

\begin{tabular}{|c|c|c|c|}
\hline \multirow[b]{2}{*}{ Escolaridade } & \multirow[b]{2}{*}{$\mathrm{N}$} & \multicolumn{2}{|c|}{ Subset for alpha $=0.05$} \\
\hline & & & \\
\hline 1 SÉRIE E.M. & 253 & & 5,2451 \\
\hline 2 SÉRIE E.M. & 256 & & 5,2461 \\
\hline 3ํ SÉRIE E.M. & 349 & & 5,4183 \\
\hline Sig. & & ,657 & \\
\hline
\end{tabular}

Means for groups in homogeneous subsets are displayed.
Radical z-

Tukey HSD

\begin{tabular}{|l|c|r|r|}
\hline & & \multicolumn{2}{|c|}{ Subset for alpha $=0.05$} \\
\cline { 2 - 4 } Escolaridade & $\mathrm{N}$ & 1 & \multicolumn{1}{c|}{2} \\
\hline 1º SÉRIE E.M. & 251 & 4,0199 & \\
2º SÉRIE E.M. & 256 & 4,4609 & \\
3 3 SÉRIE E.M. & 341 & & 5,0528 \\
Sig. & &, 098 & 1,000 \\
\hline
\end{tabular}

Means for groups in homogeneous subsets are displayed.

Radical v-

Tukey HSD

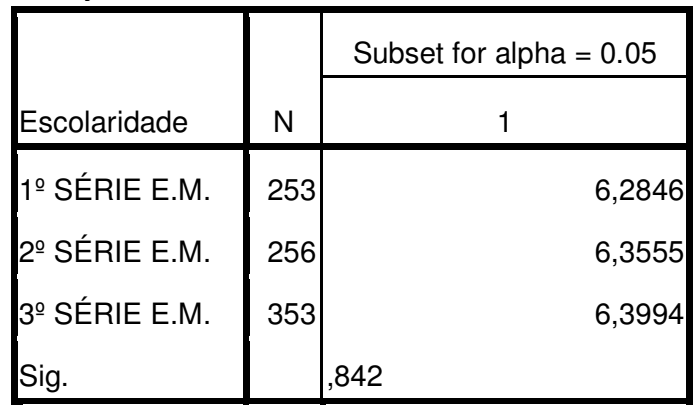

Means for groups in homogeneous subsets are displayed.

Radical g-

Tukey HSD

\begin{tabular}{|l|c|r|r|}
\hline \multirow{2}{*}{ Escolaridade } & & \multicolumn{2}{|c|}{ Subset for alpha $=0.05$} \\
\cline { 3 - 4 } & $\mathrm{N}$ & 1 & \multicolumn{1}{c|}{2} \\
\hline 2o SÉRIE E.M. & 256 & 4,7578 & \\
1ㅇ SÉRIE E.M. & 252 & 4,9444 & 4,9444 \\
3o SÉRIE E.M. & 349 & & 5,3840 \\
Sig. & &, 661 &, 103 \\
\hline
\end{tabular}

Means for groups in homogeneous subsets are displayed. 
Radical m-

Tukey HSD

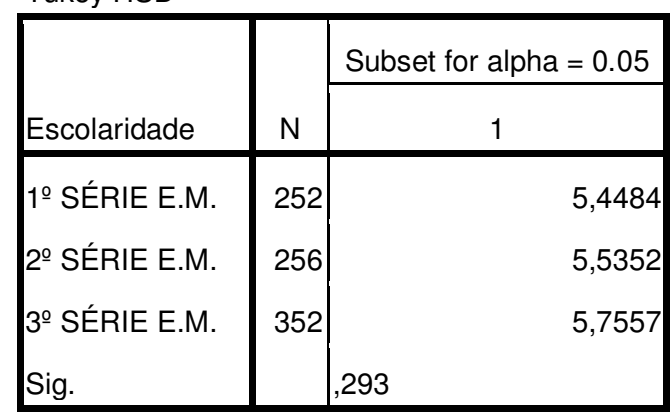

Means for groups in homogeneous subsets are displayed.

Radical 0-

Tukey HSD

\begin{tabular}{|c|c|c|c|}
\hline \multirow[b]{2}{*}{ Escolaridade } & \multirow[b]{2}{*}{$\mathrm{N}$} & \multicolumn{2}{|c|}{ Subset for alpha $=0.05$} \\
\hline & & & \\
\hline 1 SÉRIE E.M. & 252 & & 5,7579 \\
\hline 2º SÉRIE E.M. & 256 & & 5,7812 \\
\hline 3 SÉRIE E.M. & 349 & & 6,1232 \\
\hline Sig. & & ,223 & \\
\hline
\end{tabular}

Means for groups in homogeneous subsets are displayed. 
APÊNDICE F - Homogeneidade da Produtividade por série escolar masculina (n=720)

TOTAL Escolhas Positivas

Tukey HSD

\begin{tabular}{|c|c|c|c|}
\hline \multirow[b]{2}{*}{ Escolaridade } & \multirow[b]{2}{*}{ N } & \multicolumn{2}{|c|}{ Subset for alpha $=0.05$} \\
\hline & & 1 & 2 \\
\hline $2^{\mathrm{a}}$ SERIE E. M. & 181 & 25,0055 & \\
\hline $3^{\text {a }}$ SERIE E. M. & 277 & 28,2960 & 28,2960 \\
\hline 1ㄹ SERIE E. M. & 262 & & 28,6107 \\
\hline Sig. & & 057 & 974 \\
\hline
\end{tabular}

Means for groups in homogeneous subsets are displayed.

TOTAL Escolhas Negativas

Tukey HSD

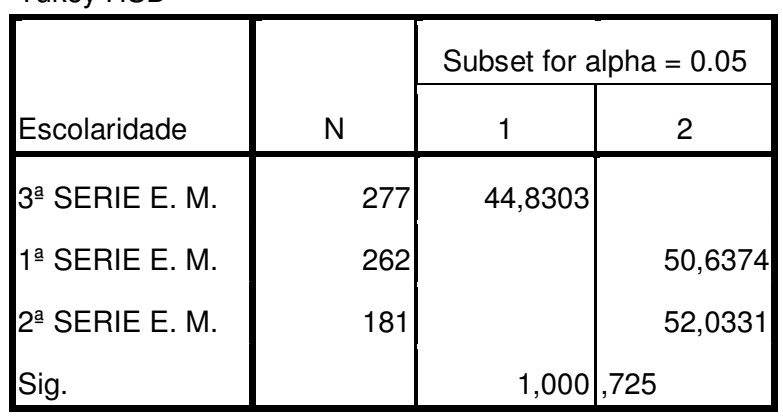

Means for groups in homogeneous subsets are displayed.

TOTAL Escolhas Neutras

Tukey HSD

\begin{tabular}{|c|c|c|c|}
\hline \multirow[b]{2}{*}{ Escolaridade } & \multirow[b]{2}{*}{$\mathrm{N}$} & \multicolumn{2}{|c|}{ Subset for alpha $=0.05$} \\
\hline & & 1 & 2 \\
\hline $1^{\text {a }}$ SERIE E. M. & 262 & 16,7519 & \\
\hline $2^{\mathrm{a}}$ SERIE E. M. & 181 & 18,9613 & \\
\hline $3^{\text {a }}$ SERIE E. M. & 277 & & 22,8736 \\
\hline Sig. & & ,131 & 1,000 \\
\hline
\end{tabular}

Means for groups in homogeneous subsets are displayed. 


\section{APÊNDICE G - Homogeneidade dos Radicais Primários Positivos por série escolar masculina $(n=720)$}

Radical W+

Tukey HSD

\begin{tabular}{|c|c|c|c|c|}
\hline \multirow[b]{2}{*}{ Escolaridade } & \multirow[b]{2}{*}{$\mathrm{N}$} & \multicolumn{3}{|c|}{ Subset for alpha $=0.05$} \\
\hline & & 1 & 2 & 3 \\
\hline 2 SÉRIE E.M. & 181 & .9779 & & \\
\hline 1 SÉRIE E.M. & 262 & & 1.3435 & \\
\hline 3 SÉRIE E.M. & 188 & & & 1.8511 \\
\hline Sig. & & 1.000 & 1.000 & 1.000 \\
\hline
\end{tabular}

Means for groups in homogeneous subsets are displayed.

Radical K+

Tukey HSD

\begin{tabular}{|l|c|c|c|}
\hline \multirow{2}{*}{ Escolaridade } & & \multicolumn{2}{|c|}{ Subset for alpha $=0.05$} \\
\cline { 3 - 4 } & $\mathrm{N}$ & 1 & 2 \\
\hline $2^{\circ}$ o SÉRIE E.M. & 181 & 1.7127 & \\
3o SÉRIE E.M. & 233 & & 2.2146 \\
1o SÉRIE E.M. & 262 & & 2.3359 \\
Sig. & & 1.000 & .761 \\
\hline
\end{tabular}

Means for groups in homogeneous subsets are displayed.

Radical S+

Tukey HSD

\begin{tabular}{|l|r|r|r|}
\hline \multirow{2}{*}{ Escolaridade } & & \multicolumn{2}{|c|}{ Subset for alpha $=0.05$} \\
\cline { 3 - 4 } & $\mathrm{N}$ & 1 & \multicolumn{1}{c|}{2} \\
\hline 20 SÉRIE E.M. & 181 & 2.5359 & \\
3o SÉRIE E.M. & 276 & 2.7699 & 2.7699 \\
1ㅇ SÉRIE E.M. & 262 & & 2.9866 \\
Sig. & & .248 & .302 \\
\hline
\end{tabular}

Means for groups in homogeneous subsets are displayed.
Radical Z+

Tukey HSD

\begin{tabular}{|l|r|r|r|}
\hline & & \multicolumn{2}{|c|}{ Subset for alpha $=0.05$} \\
\cline { 3 - 4 } Escolaridade & $\mathrm{N}$ & 1 & \multicolumn{1}{c|}{2} \\
\hline 2o SÉRIE E.M. & 181 & 1.8646 & \\
3o SÉRIE E.M. & 276 & 2.1105 & 2.1105 \\
1ㅇ SÉRIE E.M. & 262 & & 2.2328 \\
Sig. & & .235 & .697 \\
\hline
\end{tabular}

Means for groups in homogeneous subsets are displayed.

Radical V+

Tukey HSD

\begin{tabular}{|l|r|r|}
\hline & & \multicolumn{2}{|c|}{ Subset for alpha $=0.05$} \\
\cline { 3 - 3 } Escolaridade & $\mathrm{N}$ & 1 \\
\hline 1o SÉRIE E.M. & 262 & 2.4733 \\
2o SÉRIE E.M. & 181 & 2.6215 \\
3o SÉRIE E.M. & 276 & 2.6975 \\
Sig. & & .335 \\
\hline
\end{tabular}

Means for groups in homogeneous Subsets are displayed.

\section{Radical G+}

Tukey HSD

\begin{tabular}{|l|r|r|}
\hline & & \multicolumn{2}{|c|}{ Subset for alpha $=0.05$} \\
\cline { 3 - 3 } Escolaridade & $\mathrm{N}$ & 1 \\
\hline 2o SÉRIE E.M. & 181 & 2.5552 \\
1ㅇ SÉRIE E.M. & 262 & 2.8531 \\
3o SÉRIE E.M. & 276 & 2.9130 \\
Sig. & & .053 \\
\hline
\end{tabular}

Means for groups in homogeneous subsets are displayed. 
Radical M+

Tukey HSD

\begin{tabular}{|c|c|c|c|}
\hline \multirow[b]{2}{*}{ Escolaridade } & \multirow[b]{2}{*}{$\mathrm{N}$} & \multicolumn{2}{|c|}{ Subset for alpha $=0.05$} \\
\hline & & 1 & 2 \\
\hline 2o SÉRIE E.M. & 181 & 1.1326 & \\
\hline 1 SÉRIE E.M. & 262 & 1.3435 & \\
\hline 3ㅇ SÉRIE E.M. & 195 & & 2.0103 \\
\hline Sig. & & .361 & 1.000 \\
\hline
\end{tabular}

Means for groups in homogeneous subsets are displayed.

Radical O+

Tukey HSD

\begin{tabular}{|l|c|c|c|c|}
\hline \multirow{2}{*}{ Escolaridade } & & \multicolumn{3}{|c|}{ Subset for alpha $=0.05$} \\
\cline { 3 - 5 } & $\mathrm{N}$ & 1 & 2 & 3 \\
\hline 2ㅇ SÉRIE E.M. & 181 & 2.0276 & & \\
1ㅇ SÉRIE E.M. & 262 & & 2.4962 & \\
3ㅇ SÉRIE E.M. & 257 & & & 3.0700 \\
Sig. & & 1.000 & 1.000 & 1.000 \\
\hline
\end{tabular}

Means for groups in homogeneous subsets are displayed. 


\section{APÊNDICE H - Homogeneidade dos Radicais Secundários Positivos por série escolar masculina $(n=720)$}

Radical w+

Tukey HSD

\begin{tabular}{|c|c|c|c|}
\hline \multirow[b]{2}{*}{ Escolaridade } & \multirow[b]{2}{*}{$\mathrm{N}$} & \multicolumn{2}{|c|}{ Subset for alpha $=0.05$} \\
\hline & & 1 & 2 \\
\hline 2ํ SÉRIE E.M. & 181 & 2,7072 & \\
\hline 1ํ SÉRIE E.M. & 262 & & 3,2443 \\
\hline 3ㅇ SÉRIE E.M. & 257 & & 3,4125 \\
\hline Sig. & & 1,000 & 681 \\
\hline
\end{tabular}

Means for groups in homogeneous subsets are displayed.

Radical k+

Tukey HSD

\begin{tabular}{|l|l|r|r|}
\hline & & \multicolumn{2}{|c|}{ Subset for alpha $=0.05$} \\
\cline { 3 - 4 } Escolaridade & $\mathrm{N}$ & \multicolumn{1}{c|}{1} & \multicolumn{1}{c|}{2} \\
\hline 2o SÉRIE E.M. & 181 & 3,3149 & \\
3o SÉRIE E.M. & 271 & 3,5756 & \\
1ㅇ SÉRIE E.M. & 262 & & 4,1336 \\
Sig. & & & 1,000 \\
\hline
\end{tabular}

Means for groups in homogeneous subsets are displayed.

\section{Radical s+}

Tukey HSD

\begin{tabular}{|c|c|c|c|}
\hline \multirow[b]{2}{*}{ Escolaridade } & \multirow[b]{2}{*}{$\mathrm{N}$} & \multicolumn{2}{|c|}{ Subset for alpha $=0.05$} \\
\hline & & 1 & 2 \\
\hline 2º SÉRIE E.M. & 181 & 3,5470 & \\
\hline 1ㅇ SÉRIE E.M. & 262 & 3,8969 & 3,8969 \\
\hline 3오 SÉRIE E.M. & 266 & & 4,0940 \\
\hline Sig. & & 237 & 632 \\
\hline
\end{tabular}

Means for groups in homogeneous subsets are displayed.
Radical z+

Tukey HSD

\begin{tabular}{|l|l|r|}
\hline & & \multicolumn{2}{|c|}{ Subset for alpha $=0.05$} \\
\cline { 3 - 3 } Escolaridade & $\mathrm{N}$ & \multicolumn{2}{|c|}{1} \\
\hline 20 SÉRIE E.M. & 181 & 3,6464 \\
1o SÉRIE E.M. & 262 & 4,0458 \\
3o SÉRIE E.M. & 269 & 4,1041 \\
Sig. & &, 117 \\
\hline
\end{tabular}

Means for groups in homogeneous subsets are displayed.

Radical v+

Tukey HSD

\begin{tabular}{|c|c|c|c|}
\hline \multirow[b]{2}{*}{ Escolaridade } & \multirow[b]{2}{*}{$\mathrm{N}$} & \multicolumn{2}{|c|}{ Subset for alpha $=0.05$} \\
\hline & & 1 & 2 \\
\hline 2ํ SÉRIE E.M. & 181 & 3,0552 & \\
\hline 1ㅇ SÉRIE E.M. & 262 & 3,3473 & 3,3473 \\
\hline $3^{\circ}$ SÉRIE E.M. & 263 & & 3,7224 \\
\hline Sig. & & ,381 & ,205 \\
\hline
\end{tabular}

Means for groups in homogeneous subsets are displayed.

Radical g+

Tukey HSD

\begin{tabular}{|l|l|r|}
\hline & & \multicolumn{2}{|c|}{ Subset for alpha $=0.05$} \\
\cline { 3 - 3 } Escolaridade & $\mathrm{N}$ & \multicolumn{2}{|c|}{1} \\
\hline 2o SÉRIE E.M. & 181 & 3,2928 \\
1o SÉRIE E.M. & 262 & 3,6603 \\
3o SÉRIE E.M. & 263 & 3,7605 \\
Sig. & & \\
\hline
\end{tabular}

Means for groups in homogeneous subsets are displayed. 
Radical m+

Tukey HSD

\begin{tabular}{|c|c|c|c|c|}
\hline \multirow[b]{2}{*}{ Escolaridade } & \multirow[b]{2}{*}{$\mathrm{N}$} & \multicolumn{3}{|c|}{ Subset for alpha $=0.05$} \\
\hline & & 1 & & 2 \\
\hline 2ํ SÉRIE E.M. & 181 & 2,5249 & & \\
\hline 1ㅇ SÉRIE E.M. & 262 & & & 3,0611 \\
\hline 3ํ SÉRIE E.M. & 265 & & & 3,2491 \\
\hline Sig. & & 1,000 &, 657 & \\
\hline
\end{tabular}

Means for groups in homogeneous subsets are displayed.

Radical o+

Tukey HSD

\begin{tabular}{|l|r|r|r|}
\hline \multirow{2}{*}{ Escolaridade } & & \multicolumn{2}{|c|}{ Subset for alpha = 0.05 } \\
\cline { 3 - 4 } & $\mathrm{N}$ & \multicolumn{1}{c|}{1} & \multicolumn{1}{c|}{2} \\
\hline 2o SÉRIE E.M. & 181 & 2,9171 & \\
1ㅇ SÉRIE E.M. & 262 & 3,2214 & 3,2214 \\
3o SÉRIE E.M. & 262 & & 3,7023 \\
Sig. & &, 349 &, 073 \\
\hline
\end{tabular}

Means for groups in homogeneous subsets are displayed. 


\section{APÊNDICE I - Homogeneidade dos Radicais Primários Negativos por série escolar masculina $(n=720)$}

\section{Radical W-}

Tukey HSD

\begin{tabular}{|l|l|r|}
\hline & & \multicolumn{2}{|c|}{ Subset for alpha $=0.05$} \\
\cline { 3 - 3 } Escolaridade & $\mathrm{N}$ & \multicolumn{1}{|c|}{1} \\
\hline 3o SÉRIE E.M. & 270 & 5.2148 \\
1ㅇ SÉRIE E.M. & 262 & 5.3855 \\
2o SÉRIE E.M. & 181 & 5.6630 \\
Sig. & & .053 \\
\hline
\end{tabular}

Means for groups in homogeneous subsets are displayed.

Radical K-

Tukey HSD

\begin{tabular}{|l|l|r|}
\hline & & \multicolumn{2}{|c|}{ Subset for alpha $=0.05$} \\
\cline { 3 - 3 } Escolaridade & $\mathrm{N}$ & \multicolumn{2}{|c|}{1} \\
\hline 1ㅇ SÉRIE E.M. & 262 & 4.6489 \\
3o SÉRIE E.M. & 276 & 4.7681 \\
2o SÉRIE E.M. & 181 & 5.0387 \\
Sig. & & .119 \\
\hline
\end{tabular}

Means for groups in homogeneous subsets are displayed.

Radical S-

Tukey HSD

\begin{tabular}{|l|r|r|r|}
\hline & & \multicolumn{2}{|c|}{ Subset for alpha $=0.05$} \\
\cline { 3 - 4 } Escolaridade & $\mathrm{N}$ & \multicolumn{1}{c|}{1} & \multicolumn{1}{c|}{2} \\
\hline 3o SÉRIE E.M. & 276 & 3.3569 & \\
1ㅇ SÉRIE E.M. & 262 & 3.7252 & 3.7252 \\
2o SÉRIE E.M. & 181 & & 4.0635 \\
Sig. & & .064 & .098 \\
\hline
\end{tabular}

Means for groups in homogeneous subsets are displayed.
Radical Z-

Tukey HSD

\begin{tabular}{|l|c|c|r|}
\hline \multirow{2}{*}{ Escolaridade } & & \multicolumn{2}{|c|}{ Subset for alpha $=0.05$} \\
\cline { 3 - 4 } & $\mathrm{N}$ & \multicolumn{1}{|c|}{1} & \multicolumn{1}{c|}{2} \\
\hline 3o SÉRIE E.M. & 276 & 3.8949 & \\
1o SÉRIE E.M. & 262 & & 4.4103 \\
20 SÉRIE E.M. & 181 & & 4.4807 \\
Sig. & & 1.000 & .925 \\
\hline
\end{tabular}

Means for groups in homogeneous subsets are displayed.

Radical V-

Tukey HSD

\begin{tabular}{|c|c|c|c|}
\hline \multirow[b]{2}{*}{ Escolaridade } & \multirow[b]{2}{*}{$\mathrm{N}$} & \multicolumn{2}{|c|}{ Subset for alpha $=0.05$} \\
\hline & & 1 & 2 \\
\hline 3으 SÉRIE E.M. & 276 & 3.0543 & \\
\hline 2ํ SÉRIE E.M. & 181 & & 3.5331 \\
\hline 1을'RIE E.M. & 262 & & 3.7595 \\
\hline Sig. & & 1.000 & .449 \\
\hline
\end{tabular}

Means for groups in homogeneous subsets are displayed.

\section{Radical G-}

Tukey HSD

\begin{tabular}{|c|c|c|c|}
\hline \multirow[b]{2}{*}{ Escolaridade } & \multirow[b]{2}{*}{$\mathrm{N}$} & \multicolumn{2}{|c|}{ Subset for alpha $=0.05$} \\
\hline & & 1 & 2 \\
\hline 3ㅇ SÉRIE E.M. & 276 & 3.1848 & \\
\hline 2ํ SÉRIE E.M. & 181 & & 3.8149 \\
\hline 1ํ SÉRIE E.M. & 262 & & 3.8454 \\
\hline Sig. & & 1.000 & .984 \\
\hline
\end{tabular}

Means for groups in homogeneous subsets are displayed. 


\section{Radical M-}

\section{Tukey HSD}

\begin{tabular}{|l|r|r|r|}
\hline \multirow{2}{*}{ Escolaridade } & & \multicolumn{2}{|c|}{ Subset for alpha $=0.05$} \\
\cline { 3 - 4 } & $\mathrm{N}$ & \multicolumn{1}{c|}{1} & \multicolumn{1}{c|}{2} \\
\hline 3ํ SÉRIE E.M. & 270 & 4.8185 & \\
1ㅇ SÉRIE E.M. & 262 & 5.1641 & 5.1641 \\
2ㅇ SÉRIE E.M. & 181 & & 5.3370 \\
Sig. & & .207 & .673 \\
\hline
\end{tabular}

Means for groups in homogeneous subsets are displayed.

\section{Radical O-}

Tukey HSD

\begin{tabular}{|l|c|c|c|}
\hline \multirow{2}{*}{ Escolaridade } & & \multicolumn{2}{|c|}{ Subset for alpha $=0.05$} \\
\cline { 3 - 4 } & $\mathrm{N}$ & 1 & \multicolumn{1}{c|}{2} \\
\hline 3o SÉRIE E.M. & 259 & 3.4131 & \\
1ㅇ SÉRIE E.M. & 262 & & 3.9580 \\
2º SÉRIE E.M. & 181 & & 4.2099 \\
Sig. & & 1.000 & .432 \\
\hline
\end{tabular}

Means for groups in homogeneous subsets are displayed. 


\section{APÊNDICE J - Homogeneidade dos Radicais Secundários Negativos por série escolar masculina $(n=720)$}

Radical w-

Tukey HSD

\begin{tabular}{|l|l|r|r|}
\hline \multirow{2}{*}{ Escolaridade } & \multirow{2}{*}{$\mathrm{N}$} & \multicolumn{2}{|c|}{ Subset for alpha $=0.05$} \\
\cline { 3 - 4 } & \multicolumn{1}{|c|}{2} & \multicolumn{1}{c|}{2} \\
\hline 3o SÉRIE E.M. & 277 & 5,9928 & \\
1ㅇ SÉRIE E.M. & 262 & 6,2023 & \\
2o SÉRIE E.M. & 181 & & 6,8177 \\
Sig. & & & 1,000 \\
\hline
\end{tabular}

Means for groups in homogeneous subsets are displayed.

Radical k-

Tukey HSD

\begin{tabular}{|l|l|r|r|}
\hline & & \multicolumn{2}{|c|}{ Subset for alpha $=0.05$} \\
\cline { 3 - 4 } Escolaridade & $\mathrm{N}$ & \multicolumn{1}{c|}{1} & \multicolumn{1}{c|}{2} \\
\hline 3o SÉRIE E.M. & 276 & 5,6341 & \\
1ㅇ SÉRIE E.M. & 262 & 5,8092 & \\
2o SÉRIE E.M. & 181 & & 6,3978 \\
Sig. & &, 754 & 1,000 \\
\hline
\end{tabular}

Means for groups in homogeneous subsets are displayed.

Radical s-

Tukey HSD

\begin{tabular}{|c|c|c|c|}
\hline \multirow[b]{2}{*}{ Escolaridade } & \multirow[b]{2}{*}{$\mathrm{N}$} & \multicolumn{2}{|c|}{ Subset for alpha $=0.05$} \\
\hline & & 1 & 2 \\
\hline 3으 SÉRIE E.M. & 277 & 5,5126 & \\
\hline 1ㅇ SÉRIE E.M. & 262 & 6,0916 & 6,0916 \\
\hline 2o SÉRIE E.M. & 181 & & 6,3315 \\
\hline Sig. & & ,066 & ,623 \\
\hline
\end{tabular}

Means for groups in homogeneous subsets are displayed.
Radical z-

Tukey HSD

\begin{tabular}{|l|c|c|c|}
\hline \multirow{2}{*}{ Escolaridade } & & \multicolumn{2}{|c|}{ Subset for alpha $=0.05$} \\
\cline { 3 - 4 } & $\mathrm{N}$ & 1 & \multicolumn{1}{c|}{2} \\
\hline 3o SÉRIE E.M. & 270 & 5,2889 & \\
1ㅇ SÉRIE E.M. & 262 & & 5,9275 \\
20 SÉRIE E.M. & 181 & & \multicolumn{2}{|c|}{5,9669} \\
Sig. & & 1,000 &, 988 \\
\hline
\end{tabular}

Means for groups in homogeneous subsets are displayed.

Radical v-

Tukey HSD

\begin{tabular}{|l|c|c|c|}
\hline \multirow{2}{*}{ Escolaridade } & & \multicolumn{2}{|c|}{ Subset for alpha $=0.05$} \\
\cline { 3 - 4 } & $\mathrm{N}$ & 1 & 2 \\
\hline 3o SÉRIE E.M. & 267 & 5,4981 & \\
20 SÉRIE E.M. & 181 & & 6,2707 \\
1ㅇ SÉRIE E.M. & 262 & & 6,4351 \\
Sig. & & 1,000 &, 813 \\
\hline
\end{tabular}

Means for groups in homogeneous subsets are displayed.

\section{Radical g-}

Tukey HSD

\begin{tabular}{|c|c|c|c|}
\hline \multirow[b]{2}{*}{ Escolaridade } & \multirow[b]{2}{*}{$\mathrm{N}$} & \multicolumn{2}{|c|}{ Subset for alpha $=0.05$} \\
\hline & & 1 & 2 \\
\hline 3오 SÉRIE E.M. & 274 & 5,7080 & \\
\hline 1ํ SÉRIE E.M. & 262 & & 6,3588 \\
\hline 20 SÉRIE E.M. & 181 & & 6,3646 \\
\hline Sig. & & 1,000 & 1,000 \\
\hline
\end{tabular}

Means for groups in homogeneous subsets are displayed. 
Radical m-

Tukey HSD

\begin{tabular}{|l|c|c|c|}
\hline \multirow{2}{*}{ Escolaridade } & & \multicolumn{2}{|c|}{ Subset for alpha =0.05 } \\
\cline { 3 - 4 } & $\mathrm{N}$ & 1 & 2 \\
\hline 3ํ SÉRIE E.M. & 275 & 6,2218 & \\
1ㅇ SÉRIE E.M. & 262 & & 7,1527 \\
2ㅇ SÉRIE E.M. & 181 & & \multicolumn{2}{|c|}{7,3094} \\
Sig. & & 1,000 &, 839 \\
\hline
\end{tabular}

Means for groups in homogeneous subsets are displayed.

Radical o-

Tukey HSD

\begin{tabular}{|l|c|c|c|}
\hline \multirow{2}{*}{ Escolaridade } & & \multicolumn{2}{|c|}{ Subset for alpha $=0.05$} \\
\cline { 3 - 4 } & $\mathrm{N}$ & 1 & 2 \\
\hline 3o SÉRIE E.M. & 276 & 5,4529 & \\
2o SÉRIE E.M. & 181 & & 6,5746 \\
1ㅇ SÉRIE E.M. & 262 & & 6,6603 \\
Sig. & & 1,000 &, 948 \\
\hline
\end{tabular}

Means for groups in homogeneous subsets are displayed. 